\title{
"SÍNTESIS Y CARACTERIZACIÓN DE NUEVOS CATALIZADORES HETEROGÉNEOS BASADOS EN HETEROPOLIMOLIBDATOS PARA LA HIDROGENACIÓN SELECTIVA DE CINAMALDEHÍDO"
}

\section{GUILLERMO R. BERTOLINI}

Tesis presentada para la obtención del grado académico de Doctor en Ingeniería

Departamento de Ingeniería Química

Facultad de Ingeniería

Universidad Nacional de La Plata

La Plata, 27 de Noviembre de 2013 
Tesis presentada en la Universidad Nacional de La Plata para la obtención del Grado Académico de Doctor en Ingeniería

\section{"SÍNTESIS Y CARACTERIZACIÓN DE NUEVOS \\ CATALIZADORES HETEROGÉNEOS BASADOS EN HETEROPOLIMOLIBDATOS PARA LA HIDROGENACIÓN SELECTIVA DE CINAMALDEHÍDO"}

Por

\section{Guillermo R. Bertolini}

Centro de Investigación y Desarrollo en Ciencias Aplicadas "Dr. Jorge Ronco" (CINDECA), dependiente de la Universidad Nacional de La Plata (UNLP) y del Consejo Nacional de Investigaciones Científicas y Técnicas (CONICET)

Director de Tesis: Dra. Carmen I. Cabello

Co-director de Tesis: Dr. Marcelo R. Trivi

Miembros del jurado

Dra. María A. Volpe

Dr. Manuel Karim Sapag 


\section{AGRADECIMIENTOS}

En primer lugar deseo expresar mi agradecimiento a mis directores, Dra. Carmen I. Cabello y el Dr. Marcelo Trivi por su valioso estímulo, al haberme brindado sus conocimientos y dedicación que impulsaron la concreción de la presente tesis.

Al Consejo Nacional de Investigaciones Científicas y Técnicas (CONICET).

A la Universidad Nacional de La Plata, a la Facultad de Ingeniería y en especial al CINDECA, donde pude desarrollar las tareas de laboratorio necesarias para la realización de este trabajo.

A la Escuela de Postgrado y Educación Continua (EPEC) de la Facultad de Ingeniería por el apoyo recibido.

Al Director del CINDECA, Dr. Luis Gambaro por su apoyo y asesoramiento.

A la Dra. Mercedes Muñoz por su continua colaboración.

A mis compañeros de trabajo diario.

A las Dras. Mónica Casella y Virginia Vetere por su generoso y continuo asesoramiento.

A la valiosa y desinteresada ayuda de Ricardo Arizaga en las medidas realizadas en el Centro de Investigaciones Opticas, CIOP.

A la Prof. Delia Gazzoli y su grupo de trabajo del Dipartimento di Chimica, Universitá di Roma "La Sapienza", por poner a nuestra disposición la infraestructura y equipamiento para medidas fisicoquímicas especiales y su valioso aporte en la interpretación de los resultados.

Por último quiero dedicar esta Tesis a mi familia, especialmente a Lorena, a Facundo y Sofía, a mis amigos y a todos aquellos que de alguna u otra forma hicieron posible la realización de este trabajo. 


\section{ÍNDICE}

\section{PARTE I: GENERALIDADES Y OBJETIVOS}

Objetivos y resumen

i-iv

\section{Capítulo 1: MARCO TEORICO}

1.1. Introducción a la química de iso y heteropolioxoaniones

1.1.a. Formación de especies condensadas: Oxolación y Olación 3

1.2. Formación de isopolioxometalatos 5

1.2.a. Isopolioxoaniones con elevado número de centros metálicos 5

$\begin{array}{ll}\text { 1.3. Formación de polioxoaniones e isopolioxocationes } & 7\end{array}$

1.3.a. Heteropolioxoaniones de estructura Anderson $\left(\left[\mathrm{XM}_{6} \mathrm{O}_{24} \mathrm{H}_{6}\right]^{\mathrm{n}-}\right) \quad 8$

1.3.b. Isopolicationes con elevado número de centros metálicos. "Olación" 10

1.3.b.I. Estructura de polioxocationes: 13

1.4. Métodos de síntesis $\quad 15$

$\begin{array}{ll}\text { 1.4.a. Síntesis en solución acuosa } & 15\end{array}$

1.4.a.I. A partir de oxoaniones simples $\quad 15$

$\begin{array}{ll}\text { 1.4.a.II. A partir de otros polioxoaniones. } & 17\end{array}$

1.5. Aplicación de iso y heteropolioxoaniones 17

1.5.a. Antecedentes de la aplicación de HPOMs en procesos catalíticos. $\quad 19$

1.5.a.I. Utilización de heteropolicompuestos en reacciones de hidrotratamiento. 20

\subsection{Catálisis heterogénea y su aplicación en procesos de hidrogenación de} interés en química fina. $\quad 21$

1.6.a. Consideraciones generales.

1.6.b. Determinación de los sitios activos de un catalizador heterogéneo según el método de Boudart. 23

1.6.c. Procesos de hidrogenación en química fina. $\quad 24$

1.6.d. Hidrogenación selectiva de aldehídos $\alpha, \beta$-insaturados. 25

1.6.e. Efecto del soporte en catálisis heterogénea, consideraciones generales. 26 
1.6.e.I. Soportes a base de sílices.

$\begin{array}{ll}\text { 1.6.e.II. Soportes a base de alúmina. } & 28\end{array}$

1.7 Aluminosilicatos: Arcillas 29

1.7.a. Clasificación de los Silicatos Laminares 31

1.7 .a.I. Arcillas Pilareadas 33

1.7.a.II. Sistemas porosos heteroestructurados (porous clay

heterostructures: $(\mathrm{PCH})$.

1.8. Otras aplicaciones en catálisis heterogénea. 36

1.8.a. Oxidación selectiva de sulfuros arómáticos. 36

\section{PARTE II: EXPERIMENTAL}

\section{Capítulo 2: MÉTODOS DE SÍNTESIS Y CARACTERIZACIÓN}

2.1. Métodos de síntesis y caracterización 39

2.1.a. Síntesis de sales de heteropolioxoaniones con estructura tipo Anderson 39

2.1.a.I. Caracterización del Heteropolioxoanión tipo Anderson de Rh(III) 40

2.2. Preparación y caracterización de Soportes 40

2.2.a. Preparación de soportes a base de Sílice. 41

2.2.b. Preparación de soportes de Alúmina 42

2.2.c. Preparación de soportes a base de minerales de arcilla. 43

2.2.c.I. Etapa de "pilareado" (PILC) 43

2.2.c.II. Síntesis de materiales porosos heteroestructurados (porous clay heterostructures: $(\mathrm{PCH}) . \quad 44$

2.2.c.III. Funcionalización adicional de la superficie de arcillas modificadas químicamente (PILC y PCH) mediante el empleo de surfactantes. 45

2.2.c.IV. Caracterización de las Arcillas bentoniticas puras y modificadas. $\quad 47$

\subsection{Métodos de Preparación y caracterización de catalizadores 47}

2.3.a. Preparación de catalizadores a base del heteropolioxoanión Anderson $\mathrm{RhMo}_{6}$ soportados sobre sílice.

2.3.b. Preparación de catalizadores a base del heteropolioxoanión Anderson $\mathrm{RhMo}_{6}$ soportados sobre $\gamma-\mathrm{Al}_{2} \mathrm{O}_{3}$.

2.3.b.I. Preparación de catalizadores RhMo soportados sobre alúminas por 
métodos convencionales.

2.3.c. Preparación de catalizadores utilizando soportes a base de arcillas naturales modificadas químicamente PILC y PCH sin tratar y funcionalizados. 50

\subsection{Técnicas Instrumentales de Caracterización 50}

2.4.a. Análisis químico por ICP.AES 50

2.4.b. Análisis químico por absorción atómica (AAS) 51

2.4.b.I. Consideraciones generales 51

2.4.b.II. Equipamiento 52

2.5. Difracción de Polvos por Rayos X: DRX 54

2.5.a. Consideraciones generales $\quad 54$

2.5.a.I. Equipamiento. $\quad 54$

2.5.b. Microscopía Electrónica de barrido (SEM) y Microanálisis semicuantitativo por sonda de electrones (EDS). 55

2.5.b.I. Microscopía Electrónica de barrido: SEM 55

2.5.b.I. $1^{0}$. Microanálisis Semicuantitativo por Sonda de electrones

(EDS). $\quad 56$

2.5.b.II. Equipamiento.

2.5.b.II. $1^{\circ}$. Mapeo por microsonda electrónica (EDS). 57

2.6. Espectroscopia Fotoelectrónica por rayos X (XPS). 58

2.6.a. Consideraciones generales. 58

$\begin{array}{ll}\text { 2.6.b. Equipamiento } & 60\end{array}$

2.7. Espectroscopía Vibracional. 61

2.7.a. Espectroscopía vibracional Infrarroja con transformada de Fourier $\begin{array}{ll}\text { (FT-IR). } & 61\end{array}$

2.7.a.I Consideraciones generales. 61

2.7.a.II. Equipamiento. $\quad 65$

2.7.b. Espectroscopía Raman. $\quad 65$

2.7.b.I. Consideraciones generales. 65

$\begin{array}{ll}\text { 2.7.c. Raman Microprobe. } & 71\end{array}$

2.7.c. I. Consideraciones generales. 71

2.7.c.II. Equipamiento 72

2.8. Resonancia magnética nuclear: ${ }^{27}$ Al-MAS NMR 73

$\begin{array}{ll}\text { 2.8.a. Consideraciones Generales } & 73\end{array}$

$\begin{array}{ll}\text { 2.8.b. Equipamiento } & 75\end{array}$ 
2.9. Parámetros texturales y medidas de superficie mediante el método BET (Brunauer, Emmett, Teller).

2.9.a. Consideraciones Generales 75

2.9.b. Equipamiento 76

2.10. Análisis térmicos

2.10.a. Análisis termogravimétrico (TGA) y diferencial en atmósfera inerte $\begin{array}{ll}\text { (DTA) } & 77\end{array}$

2.10.a.I. Análisis termogravimétrico. 77

2.10.b. Análisis térmico diferencial. $\quad 78$

$\begin{array}{ll}\text { 2.10.b.I. Equipamiento } & 79\end{array}$

2.10.c. Reducción a temperatura programada (TPR) 79

$\begin{array}{ll}\text { 2.10.c.I. Consideraciones generales } & 79\end{array}$

$\begin{array}{ll}\text { 2.10.c.II. Equipamiento } & 81\end{array}$

2.11. Análisis de sitios ácidos por el método TPSR (Reacción Superficial a $\begin{array}{ll}\text { temperatura programada) } & 81\end{array}$

$\begin{array}{ll}\text { 2.11.a. Consideraciones generales } & 81\end{array}$

2.11.b. Procedimiento experimental y equipamiento 83

2.12. Técnicas de caracterización no convencionales. Técnica Laser Speckle Dinámico (DSL) 86

2.12.a. Puesta a punto y calibración de la Técnica 86

2.13. Evaluación de la Actividad catalítica

2.13.a. Tests de Hidrogenación Selectiva de Cinamaldehído 87

$\begin{array}{ll}\text { 2.13.b. Dispersión } & 88\end{array}$

2.13.b.I. Valoración $\mathrm{O}_{2} / \mathrm{H}_{2}$

2.13.c. Cálculo de actividad por centro activo: TOF (factor de turn-over) 92

2.13.d. Tests de oxidación selectiva de difenilsulfuro. 93

\section{Capítulo 3: ESTUDIO Y APLICACIÓN DEL MÉTODO LASER SPECKLE DINÁMICO (DSL)}

3.1. Antecedentes generales del Fenómeno "Speckle". 95

3.2. Propiedades Estadísticas. 98

$\begin{array}{lr}\text { 3.3. Speckle Dinámico } & 102\end{array}$

$\begin{array}{ll}\text { 3.4. Dispositivo experimental } & 104\end{array}$ 


\section{PARTE III: RESULTADOS Y DISCUSION}

\section{Capítulo 4: HETEROPOLIOXOANIONES DE ESTRUCTURA TIPO ANDERSON, SÍNTESIS Y CARACTERIZACIÓN}

4.1. Caracterización estructural

4.2. Análisis estructural por $\mathrm{XRD}$.

4.2.1. Fase de Anderson con X(III): $\left(\mathrm{NH}_{4}\right)_{3}\left[\mathrm{X}(\mathrm{III}) \mathrm{Mo}_{6} \mathrm{O}_{24} \mathrm{H}_{6}\right] .7 \mathrm{H}_{2} \mathrm{O}$,

4.3. Caracterización morfológica mediante microscopía electrónica SEM y Análisis químico semicuantitativo EDS.

4.4. Caracterización mediante espectroscopía vibracional.

4.4.a. Características espectroscópicas vibracionales FTIR

y Micro-Raman de heteropolimolibdatos de estructura Anderson

4.5. Estudio de la Estabilidad Térmica.

4.5.a. Análisis termogravimétrico (TGA) y diferencial en atmósfera inerte (DTA)

4.5.b. En Atmósfera reductora: TPR (Reducción térmica programada).

4.6. Conclusiones parciales

\section{Capítulo 5: CARACTERIZACIÓN FISICOQUIMICA DE SOPORTES}

5.1. Pretratamiento y caracterización de soportes a base de Sílice

5.1.c. Caracterización mediante difracción de polvos por Rayos X. 
Speckle dinámico.

$\begin{array}{ll}\text { 5.1.f. Conclusiones parciales } & 137\end{array}$

5.2. Preparación y caracterización de soportes a base de Alúminas. 137

5.2.a. Caracterización textural mediante el método BET 138

5.2.b. Caracterización por DRX 142

5.2.c. Análisis termogravimétrico (TGA) 144

5.2.d. Aplicación de la Técnica de Speckle dinámico en el proceso de $\begin{array}{ll}\text { hidroadsorción. } & 146\end{array}$

$\begin{array}{ll}\text { 5.2.e. Conclusiones parciales } & 149\end{array}$

5.3. Preparación y caracterización de soportes a base de Alúminosilicatos 150

$\begin{array}{ll}\text { 5.3.a. Introducción } & 150\end{array}$

5.3.b. Caracterización textural mediante el método BET 152

5.3.b.I. Bentonita purificada por el método de Stokes 152

5.3.c Caracterización por SEM-EDS. 156

5.3.d. Caracterización por DRX. 156

5.3.e. Análisis mediante espectroscopía FTIR 160

$\begin{array}{ll}\text { 5.3.f. Análisis termogravimétrico (TGA) } & 161\end{array}$

5.3.g. Caracterización del proceso de hidroadsorción de soportes a base de bentonita y otros aluminosilicatos mediante Laser Speckle dinámico. $\quad 164$

$\begin{array}{ll}\text { 5.3.h. Conclusiones parciales. } & 169\end{array}$

\section{Capítulo 6: CARACTERIZACIÓN FISICOQUÍMICA DE CATALIZADORES}

\subsection{Caracterización de Catalizadores a base de heteropolianiones}

$\begin{array}{ll}\text { tipo Anderson soportados sobre } \mathrm{SiO}_{2} & 171\end{array}$

$\begin{array}{ll}\text { 6.1.a. Caracterización por DRX } & 171\end{array}$

6.1.b. Caracterización mediante Reducción Térmica Programada (TPR). 173

6.1.c. Caracterización Espectroscopia Fotoelectrónica por rayos X (XPS) 174

\subsection{Caracterización de Catalizadores a base de heteropolianiones} $\begin{array}{ll}\text { tipo Anderson soportados sobre } \boldsymbol{\gamma}-\mathrm{Al}_{\mathbf{2}} \mathbf{O}_{3} & 175\end{array}$

$\begin{array}{ll}\text { 6.2.a. Caracterización por DRX } & 175\end{array}$

6.2.b. Estudio de la Isoterma de adsorción de $\mathrm{RhMo}_{6}$ en $\gamma-\mathrm{Al}_{2} \mathrm{O}_{3}(\mathrm{EI})$

6.2.c. Obtención de los parámetros de adsorción de las Fase de Anderson 
soportada en $\gamma-\mathrm{Al}_{2} \mathrm{O}_{3}$

6.2.d. Caracterización espectroscópica de los catalizadores a base

de fases de Anderson soportadas en $\gamma-\mathrm{Al}_{2} \mathrm{O}_{3}$ tipo EI.

6.2.d.I. Caracterización espectroscópica por DRS UV-visible

6.2.d.II. Caracterización mediante Microanálisis Raman.

6.2.e. Caracterización mediante reducción térmica programada (TPR).

6.2.f. Caracterización Espectroscopia Fotoelectrónica por rayos X (XPS)

6.3. Catalizadores a base de fase de Anderson de $\mathrm{Rh}$ soportados sobre bentonita modificada químicamente: PILC, PCH, PILC-F y PCH-F

6.3.a. Caracterización de la fase soportada por Espectroscopía de Reflectancia Difusa, DRS.

6.3.b. Análisis de acidez superficial de soportes y catalizadores por TPSR

6.3.c. Análisis por TPR de los soportes y catalizadores soportados.

6.3.d. Análisis termogravimétrico (TGA)

6.3.e. Caracterización estructural y espectroscópica comparativa de catalizadores a base de $\mathrm{CoMo}_{6}, \mathrm{RhMo}_{6} \mathrm{y} \mathrm{Co}_{2} \mathrm{Mo}_{10}$ soportados en bentonita modificada químicamente.

6.3.f. Conclusiones parciales.

PARTE IV: EVALUACION CATALITICA

\section{Capítulo 7: HIDROGENACIÓN SELECTIVA DE CINAMALDEHIDO Y OXIDACIÓN SELECTIVA DE DIFENILSULFURO}


7.2.a. Actividad del sistema $\mathrm{Rh}(\mathrm{III})$-hexamolibdato/ $\mathrm{SiO}_{2}$ en la hidrogenación selectiva de cinamaldehido.

7.2.b. Actividad del sitema $\mathrm{Rh}(\mathrm{III})$-hexamolibdato $/ \gamma-\mathrm{Al}_{2} \mathrm{O}_{3}$ en la hidrogenación selectiva de cinamaldehído.

7.2.b.I. Cálculo de actividad por centro activo: TOF (o factor de "turn-over")

7.2.b.I.I. Análisis de la influencia de las características texturales del soporte

7.2.c. Hidrogenación selectiva de cinamaldehido sobre catalizadores de

$\mathrm{Rh}$ (III)-hexamolibdato soportados en aluminosilicatos naturales funcionalizados.

7.3. Oxidación selectiva de difenilsulfuro. Introducción

7.3.a. Evaluación de fases anderson $\left[\mathrm{MMo}_{6} \mathrm{O}_{24} \mathrm{H}_{6}\right]^{3-}$ con $\mathrm{M}=\mathrm{Rh}(\mathrm{III})$

y $\mathrm{Co}(\mathrm{III})$ y un derivado estructural, $\left[\mathrm{Co}_{2} \mathrm{Mo}_{10} \mathrm{H}_{4} \mathrm{O}_{38}\right]^{6-}$ soportadas en arcillas porosas heteroestructuradas para la oxidación selectiva de difenilsulfuro.

7.3.b. Test Catalítico.

7.3.c . Conclusiones parciales. 


\section{Objetivos y Resumen}

Esta tesis se ha desarrollado en el marco de varios Proyectos de Investigación acreditados (UNLP, ANPCyT y CICPBA) y de tipo interdisciplinario, dirigidos al estudio de catalizadores a base de heteropolimetalatos de variada complejidad estructural como fases activas y soportes a base de óxidos inertes sintéticos así como aluminosilicatos naturales procedentes de depósitos nacionales, con el objeto de analizar su potencialidad tecnológica, particularmente en reacciones de interés en química fina y petroquímica.

Las investigaciones en el ámbito de la catálisis implican el estudio de procesos y mecanismos mediante diferentes catalizadores y condiciones operativas así como el diseño, preparación y caracterización de nuevos materiales para tal aplicación. En relación a los procesos de interés tanto en petroquímica como en química fina, actualmente la ciencia está realizando un gran esfuerzo para desarrollar sistemas catalíticos eficientes que conlleven el menor costo energético y ambiental.

En este sentido, algunos de los sistemas oxídicos mas estudiados como precursores catalíticos, en los últimos tiempos, son los llamados iso y heteropolioxoaniones ya que presentan varias ventajas comparativas respecto a los óxidos metálicos convencionales.

Recientes investigaciones en nuestros laboratorios, han mostrado que heteropolimetalatos de estructura Anderson de Co, Ni o Rh, se han revelado como interesantes precursores en catalizadores heterogéneos en procesos de hidrotratamiento, a través del estudio de la hidrogenación (HYD) de ciclohexeno en simultaneo con reacciones de hidrodesulfurización (HDS) de tiofeno (composición de la carga: 90\% de ciclohexano, 10\% de ciclohexeno y 15000 ppm de tiofeno) mediante fases de Anderson $\left[\mathrm{Co} / \mathrm{Rh} / \mathrm{Mo}_{6} \mathrm{O}_{24}\right]^{6-}$ y derivados estructurales como $\left[\mathrm{CoMo}_{10} \mathrm{O}_{38}\right]^{10-}$ soportadas en alúmina. Estos catalizadores mostraron mayor actividad hidrogenante que un catalizador CoMo convencional. Dichos estudios mostraron que la estructura planar del heteropolioxoanión, así como sus propiedades redox y de solubilidad, son factores relevantes en el 
proceso de interacción heteropolianión-soporte, produciendo una superficie activa con una distribución ordenada y deposición uniforme de los elementos metálicos, lo cual favorece el efecto sinérgico de los mismos.

Considerando la escasa producción de conocimientos existente acerca de la aplicación de heteropolicompuestos en hidrogenación catalítica en química fina y teniendo en cuenta los conceptos vertidos en los trabajos recién mencionados, esta tesis se propone como objetivo estudiar la preparación, caracterización y actividad en hidrogenación selectiva de cinamaldehído, de un catalizador bimetálico $\mathrm{RhMo}_{6}$, basado en el heteropolioxometalato de estructura tipo Anderson de fórmula: $\left(\mathrm{NH}_{4}\right)_{3}\left[\mathrm{RhMo}_{6} \mathrm{O}_{24} \mathrm{H}_{6}\right] \cdot 7 \mathrm{H}_{2} \mathrm{O}$ y soportado sobre distintos sistemas oxídicos relativamente inertes: Alúminas, sílices y aluminosilicatos naturales modificados a base de bentonita, un mineral de arcilla proveniente de depósitos nacionales y de bajo costo, empleado con el fin de evaluar la posibilidad de reemplazo de insumos importados. Asimismo y considerando las propiedades tanto ácidas como redox de los sistemas preparados, estos ultimos catalizadores son estudiados en reacciones "limpias" de oxidación selectiva de sulfuros aromáticos, en un test de interés en petroquímica y química fina. Paralelamente y como parte fundamental del objetivo se plantea la caracterización físico-química de todos los materiales y el estudio de la influencia del tipo de soporte en la actividad catalítica del heteropolianión. Para ello se utilizan técnicas físicoquímicas convencionales y de alta complejidad eficaces en el análisis de la interacción heteropolianión-soporte como la difracción de polvos por Rayos X (DRX), la Microscopía electrónica de barrido (ESEM-EDS), la espectroscopía vibracional (FTIR) y Raman Microprobe, análisis termogravimétricos (TGA), de reducción térmica (TPR) y de reacción en superficie a temperatura programada (TPSR), medidas texturales por el método BET, etc. Además en esta Tesis se introduce por primera vez, en un estudio catalítico, la aplicación de una nueva técnica no destructiva que, utilizando una radiación LASER de baja potencia, permite el análisis de la capacidad hidroadsorbente de cada soporte, logrando correlacionar de manera clara y eficaz las propiedades particulares de la superficie de cada catalizador con su actividad. 
El trabajo se inicia con el marco teórico enfocado hacia las propiedades generales de los heteropolicompuestos (aniónicos y catiónicos) así como de los materiales de soporte sintéticos y naturales. Posteriormente se hace referencia a las reacciones test seleccionadas para la evaluación de los catalizadores en estudio, continuando con la descripción de las técnicas empleadas experimentalmente tanto para la preparación como para la caracterización de fases puras, soportes sin tratar y catalizadores. Capítulos 1 y 2.

El capítulo 3 se encuentra íntegramente referido a la descripción de la técnica de "Laser Speckle Dinámico" (DSL) empleada para el estudio de la propiedad hidroadsorbente de los materiales utilizados como soportes en la presente tesis. Esta tarea se realizó en colaboración con el Centro de Investigaciones Ópticas (CICPBA-CONICET).

En la segunda parte del trabajo se presentan los principales resultados del diseño, la preparación y caracterización tanto de las fases precursoras como de los soportes originales y modificados químicamente, continuando con los catalizadores obtenidos. En todos los casos se analizan los datos de la aplicación de las diferentes técnicas de estudio antes mencionadas, haciendo referencia a las bases y alcances de cada una de ellas, permitiendo la selección de los catalizadores con los que se encaró el trabajo. Capítulos 4, 5 y 6.

La ultima parte del trabajo se centralizó en la aplicación de los catalizadores obtenidos, especialmente en el test de hidrogenación selectiva de cinamaldehido. Estos resultados de actividad permitieron establecer que los sistemas soportados en $\gamma-\mathrm{Al}_{2} \mathrm{O}_{3}$ fueron más activos respecto a aquellos soportados en sílice, así como analizar la influencia en la actividad catalítica de las propiedades del soporte. Asimismo, los catalizadores basados en soportes de arcilla modificada químicamente, mostraron efectividad en esta reacción, pudiendo determinar que aquellos soportados en arcillas heteroestructuradas y de superficie funcionalizada (PCH-F) presentaron buena perfomance dada la mayor concentración de $\mathrm{RhMo}_{6}$ adsorbido y la presencia de sitios ácidos Lewis y Brønsted observados por diferentes técnicas complementarias como DSL y TPSR. Teniendo en cuenta las propiedades ácidas y redox de estos últimos sistemas, se encaró su estudio como catalizadores en una reacción "limpia" de oxidación 
selectiva de un sulfuro aromático de interés tanto en química fina como en petroquímica. Capítulo 7.

Finalmente, en el capítulo 8 se presentan las principales conclusiones discutidas y planteadas a lo largo de esta tesis, asi como las nuevas perspectivas de investigación surgidas. 


\section{PARTE I:}

GENERALIDADES Y OBJETIVOS 
Capítulo 1:

MARCO TEÓRICO 


\subsection{Introducción a la química de iso y heteropolioxoaniones}

La química en solución acuosa de iones metálicos de transición del grupo 5 o 6 en su máximo estado de oxidación (como por ejemplo: $\mathrm{V}(\mathrm{V}), \mathrm{Nb}(\mathrm{V}), \mathrm{Ta}(\mathrm{V})$, Mo (VI) y $\mathrm{W}(\mathrm{VI})$ ) se caracteriza por presentar la formación de polioxometalatos [1] (abreviados comúnmente como POMs). Estas especies se forman por condensación de unidades oxídicas, de coordinación octaédrica, tetraédrica o piramidal de base cuadrada, adquiriendo estructuras de tamaño y forma definida. Las unidades se unen entre si por átomos de oxígenos para formar una estructura tridimensional, que puede llegar a contener entre 20 y 30 centros metálicos.

\section{1.a. Formación de especies condensadas: Oxolación y Olación.}

Los cationes metálicos con estado de oxidación superior a tres, en solución acuosa, sufren una secuencia de reacciones de hidrólisis, a medida que se va modificando el $\mathrm{pH}$, generando entidades condensadas. En estas últimas, los cationes involucrados, se unen entre si mediante diferentes tipos de enlaces por puente oxígeno $\left(\mathrm{OH}^{-}\right.$ó $\left.\mathrm{O}^{2-}\right)$, como se muestra en la tabla I-1.

La capacidad de un elemento para condensar o precipitar en solución, depende de su naturaleza y de las condiciones fisicoquímicas del medio [2]. De esta manera, los elementos más electropositivos, como los metales alcalinos y alcalino-térreos, con bajo potencial iónico forman iones hidratados, debido a que son demasiado grandes o poseen carga insuficiente para extraer electrones de las moléculas de agua de hidratación. Lo que significa que no forman óxidos hidratados como los elementos centrales de la tabla periódica.

Por otro lado, los elementos no metálicos (grupos V al VII) tampoco forman óxidos hidratados. Si estos son disueltos, en medio acuoso, con un elevado estado de oxidación (alto potencial iónico) presentan la propiedad de atraer electrones de los oxígenos del agua generando una especie oxídica individual de carácter covalente y características fuertemente ácidas (oxoaniones). 
Tabla I-1: Cationes metálicos hidratados, oxo-iones y óxidos poliméricos en función del $\mathrm{pH}[1]$.

\begin{tabular}{cc}
\hline Especie & Ejemplo \\
\hline Acuo-catión & {$\left[\mathrm{Fe}\left(\mathrm{H}_{2} \mathrm{O}\right)_{6}\right]^{3+},\left[\mathrm{Al}\left(\mathrm{H}_{2} \mathrm{O}\right)_{6}\right]^{3+}$} \\
$\mathrm{OH}^{-} \downarrow \uparrow \mathrm{H}^{+}$ & \\
(Poli) Oxo/Hidroxocationes & {$\left[\mathrm{VO}\left(\mathrm{H}_{2} \mathrm{O}\right)_{5}\right]^{2+},\left[\mathrm{Al}\left(\mathrm{H}_{2} \mathrm{O}\right)_{5}(\mathrm{OH})\right]^{2+}$} \\
$\mathrm{OH}^{-} \downarrow \uparrow \mathrm{H}^{+}$ & \\
Oxidos/Hidróxidos & $\mathrm{CrO}_{3}, \mathrm{MnO}(\mathrm{OH}), \mathrm{Al}(\mathrm{OH})_{3}$ \\
OH${ }^{-} \downarrow \uparrow \mathrm{H}^{+}$ & \\
Polioxo/Hidroxo-ión & {$\left[\mathrm{V}_{4} \mathrm{O}_{12}\right]^{4-},\left[\mathrm{Mo} \mathrm{O}_{26}(\mathrm{OH})_{2}\right]^{6-}$,} \\
OH $\downarrow \uparrow \uparrow \mathrm{H}^{+}$ & {$\left[\mathrm{AlO}_{4} \mathrm{Al}_{12}(\mathrm{OH})_{24}\left(\mathrm{H}_{2} \mathrm{O}\right)_{12}\right]^{7+}$} \\
Oxo/Hidroxoaniones & \\
\hline
\end{tabular}

El carácter altamente electronegativo del átomo central y la fuerza del enlace con el oxígeno impide la unión entre los oxoaniones generados y la consiguiente aglomeración para dar polioxoaniones. Un ejemplo de este comportamiento es el S(VI). De hecho, la carga positiva en especies de este tipo, formando un hidrato hipotético “ $\left[\mathrm{S}\left(\mathrm{H}_{2} \mathrm{O}\right)_{4}\right]^{6+}$ ", es removida inmediatamente por transferencia de protones, generándose una molécula neutra como el $\mathrm{SO}_{2}(\mathrm{OH})_{2} \mathrm{O}_{2} \mathrm{H}_{2} \mathrm{SO}_{4}$. En solución, éste fuerte ácido forma especies $\mathrm{HSO}_{4}{ }^{-} \mathrm{o} \mathrm{SO}_{4}{ }^{2}[3]$.

Si el elemento central es un metal de transición (grupos 5 ó 6), la adición de $\mathrm{H}_{3} \mathrm{O}^{+}$reduce la carga negativa en oxoaniones del tipo $\mathrm{MO}_{4}{ }^{\mathrm{n}-}$ o $\mathrm{MO}_{6}{ }^{\mathrm{n}-}$ mediante la eliminación de $\mathrm{H}_{2} \mathrm{O}$. Así, el oxoanión mantiene su número de coordinación de 4 o 6 mediante la formación de enlaces $\mathrm{M}-\mathrm{O}-\mathrm{M}$ con otro oxoanión. Un ejemplo típico es la formación del ión dicromato a partir del ion cromato en soluciones ácidas.

$$
2 \mathrm{CrO}_{4}{ }^{2-}+2 \mathrm{H}_{3} \mathrm{O}^{+} \longrightarrow \mathrm{Cr}_{2} \mathrm{O}_{7}{ }^{2-}+3 \mathrm{H}_{2} \mathrm{O}
$$


La reacción ocurre a través de la protonación del $\mathrm{CrO}_{4}{ }^{2-}$ a $\mathrm{CrO}_{3}(\mathrm{OH})^{-}$o $\mathrm{HCrO}_{4}{ }^{-}$. Dos de estas unidades se unen mediante enlaces por puente de hidrógeno, formándose, por eliminación de agua, un puente oxígeno entre dos átomos metálicos. La estructura resultante consiste de dos tetraedros $\mathrm{CrO}_{4}$ compartiendo un vértice. La condensación del $\mathrm{Cr}(\mathrm{VI})$, se detiene en el dímero.

Este proceso de condensación de unidades (oxoaniones sencillos), a través de la formación de puentes oxígeno, se denomina OXOLACION [4].

Contrariamente, el W(VI), con menor potencial iónico, no sólo puede formar iones condensados mucho mayores a un dímero, sino que también amplía la esfera de coordinación de las entidades individuales (pasando a coordinación octaédrica). Al acidificar una solución de $\mathrm{WO}_{4}{ }^{2-}$ a $\mathrm{pH}=4$ forma un isopolioxoanión de simetría dodecaédrica $\left[\mathrm{H}_{2} \mathrm{~W}_{12} \mathrm{O}_{40}\right]^{6-}$. Una acidificación aún mayor, lleva a la formación del óxido hidratado $\mathrm{WO}_{3} \cdot \mathrm{nH}_{2} \mathrm{O}$, el cual no tiene relación estructural con el polioxoanión [4].

\subsection{Formación de isopolioxometalatos}

Los elementos que, al igual que el $\mathrm{W}$, son capaces de formar polioxocompuestos o intervienen en la formación de heteropolioxocompuestos son los metales de transición: V, Cr, Nb, Mo, Ta y los elementos representativos como B, Al, Si, P, S, Ge, $\mathrm{As}, \mathrm{Se}$ y $\mathrm{Sb}$. En general, es posible observar que se encuentra cierta concordancia entre los elementos que forman óxidos anfotéricos con aquellos que forman oxoaniones condensados. Sin embargo, estas especies pueden no presentar el mismo estado de oxidación. Generalmente los polioxoaniones se forman a partir del estado de oxidación correspondiente al óxido ácido [2].

\section{2.a. Isopolioxoaniones con elevado número de centros metálicos.}

Usualmente se encuentra una compleja relación entre el grado de polimerización de un anión, la concentración y el pH de la solución, de acuerdo a la siguiente ecuación general: 


$$
\begin{gathered}
\mathbf{p H}^{+}+\mathbf{q M O}_{4}{ }^{\mathrm{n}-} \longrightarrow\left[\mathrm{H}_{\mathbf{x}} \mathrm{M}_{\mathbf{q}} \mathrm{O}_{\mathbf{y}}\right]^{\mathrm{n}-}+(\mathbf{4 q - y}) \mathrm{H}_{2} \mathrm{O} \\
\text { donde } \mathbf{p}=\mathbf{8 q - 2 y + x}[1] .
\end{gathered}
$$

Desde el punto de vista estructural, los polioxoaniones están constituidos por tetraedros $\mathrm{MO}_{4}$ compartiendo vértices o por octaedros $\mathrm{MO}_{6}$ compartiendo aristas o vértices, unidos por puentes oxígeno. De esta manera se conforman estructuras tridimensionales de isopolioxoaniones como la indicada en la Figura 1-1 correspondiente al heptamolibdato: $\left[\mathrm{Mo}_{7} \mathrm{O}_{24}\right]^{6-}$

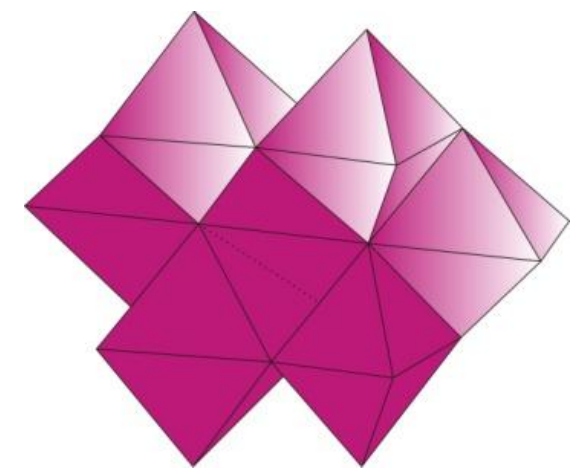

Figura 1-1: Representación del isopolianión, heptamolibdato $\left[\mathrm{Mo}_{7} \mathrm{O}_{24}\right]^{6-}$.

Otros ejemplos típicos es el octamolibdato $\left[\mathrm{Mo}_{8} \mathrm{O}_{26}\right]^{4-}$, dodecatungstato $\left[\mathrm{H}_{2} \mathrm{~W}_{12} \mathrm{O}_{40}\right]^{6-} \mathrm{y}$ decavanadato $\left[\mathrm{V}_{10} \mathrm{O}_{28}\right]^{6-}$, etc.

La mayoría de las sales de los polioxoaniones, al igual que los óxidos metálicos, son insolubles o poseen una limitada química en solución acuosa. Sin embargo, existen excepciones como los heteropolioxoaniones de los elementos de transición y algunos isopolianiones.

En general, estos complejos pueden ser representados por la fórmula general:

$$
\begin{array}{ll}
{\left[\mathbf{M}_{\mathbf{m}} \mathbf{O}_{\mathbf{y}}\right]^{\mathrm{n}-}} & \text { Isopolianiones } \\
{\left[\mathbf{X}_{\mathbf{x}} \mathbf{M}_{\mathbf{m}} \mathbf{O}_{\mathbf{y}}\right]^{\mathrm{n}-}} & \text { Heteropolianiones }
\end{array}
$$


donde M, llamado átomo addenda, es usualmente molibdeno o wolframio y menos frecuentemente vanadio, niobio o tantalio, en sus mayores estados de oxidación $\left(\mathrm{d}^{0}, \mathrm{~d}^{1}\right)$. En estos casos, cada anión polioxometálico se identifica estructuralmente, sobre la base de una coordinación cuasi-octaédrica del átomo metálico.

\subsection{Formación de polioxoaniones e isopolioxocationes}

Los elementos que tienen capacidad para formar heteropoli e isopolioxoaniones, son aquellos que poseen una combinación favorable de radio iónico, carga y capacidad para formar enlaces $\mathrm{d} \pi-\mathrm{p} \pi \mathrm{M}-\mathrm{O}$. En el caso de los heteropolioxoaniones, el heteroátomo $(\mathrm{X})$ no presenta dicha restricción, habiéndose encontrado más de sesenta y cinco elementos entre todos los grupos de la Tabla Periódica (exceptuando los gases nobles) que actúan como heteroátomos [1].

Si se tiene en cuenta aquellas especies con diferente relación $\mathrm{m} / \mathrm{x}(12,11,9$, $6, \ldots)$, con más de un tipo de heteroátomo y con mezcla de átomos addenda, el campo de los iso y heteropolioxoaniones resulta muy extenso [5].

En función de las características de enlace, los iso y heteropolioxoaniones forman una clase de compuestos única en su versatilidad topológica y electrónica, de suma importancia en muchas disciplinas. Estos compuestos han sido extensamente estudiados en un principio en la química del Mo (VI). Berzelius (1826) notó la formación de un compuesto amarillo cristalino, a partir de la reacción de molibdatos con fosfatos (o arseniatos), lo cual se conoce hoy en día como el heteropolioxoanión fosfomolibdato, de fórmula $\left[\mathrm{PMo}_{12} \mathrm{O}_{40}\right]^{3-}$, siendo el primer ejemplo de un heteropolioxoanión. Marignac (1862) descubrió los primeros heteropolitungstatos. Pauling fue el primero en proponer una estructura basada en unidades de octaedros $\mathrm{MO}_{6}$, donde los mismos compartían vértices. Keggin (1933) fue quien reportó, en primera instancia, la estructura del $\left[\mathrm{H}_{3} \mathrm{PW}_{12} \mathrm{O}_{40}\right] \cdot 6 \mathrm{H}_{2} \mathrm{O}$ mediante análisis de difracción de polvos por Rayos X. Evans (1948) presentó la estructura del $\left[\mathrm{TeMo}_{6} \mathrm{O}_{24}\right]^{6-}$ sugerida por Anderson, de quien toma su nombre [2]. 


\section{3.a. Heteropolioxoaniones de estructura Anderson $\left(\left[\mathrm{XM}_{6} \mathrm{O}_{24} \mathrm{H}_{6}\right]^{\mathrm{n}-}\right)$}

Dado que el sistema seleccionado en esta tesis para su aplicación catalítica contempla el empleo de un heteropolioxoanión tipo Anderson, en este punto se describirán con mayor detalle los aspectos estructurales del mismo. Básicamente, dichas fases están constituidas por seis octaedros $\mathrm{MO}_{6}$ donde $\mathrm{M}=\mathrm{Mo}$ o $\mathrm{W}$, los cuales se ubican en un mismo plano en torno a un átomo central, $\mathrm{X}$ que presenta también coordinación octaédrica. El átomo X puede presentar diferente estado de oxidación, por ej: Te(VI), $\mathrm{Co}(\mathrm{III}), \mathrm{Rh}(\mathrm{III}), \mathrm{Al}(\mathrm{III}), \mathrm{Ni}(\mathrm{II}), \mathrm{Cu}(\mathrm{II})$, etc. (Figura 1-2). Cada octaedro $\mathrm{MO}_{6}$ comparte una arista con alguno de sus dos vecinos $\mathrm{MO}_{6} \mathrm{y}$ un vértice con el octaedro $\mathrm{XO}_{6}$. Debido a esto, el octaedro $\mathrm{XO}_{6}$ presenta una simetría $\mathrm{D}_{3 \mathrm{~d}}$. Estos aniones poseen además protones no ácidos que forman parte de la estructura exceptuando al compuesto de $\mathrm{Te}(\mathrm{VI})$ dado que este elemento presenta un mayor valor de potencial iónico $(12,7)$ respecto a los demás heteroátomos (aprox. 6) [1, 2, 6, 7].

En esta estructura podemos distinguir tres tipos de átomos de oxígeno diferentes:

- átomos de oxígeno compartidos por tres poliedros (el octaedro central correspondiente al heteroátomo y dos octaedros del anillo de poliedros de molibdeno).

* átomos de oxígeno compartiendo vértices de octaedros $\mathrm{MO}_{6}$.

* pares de átomos de oxígeno relacionados a un solo átomo metálico M (denominados oxígenos terminales). 


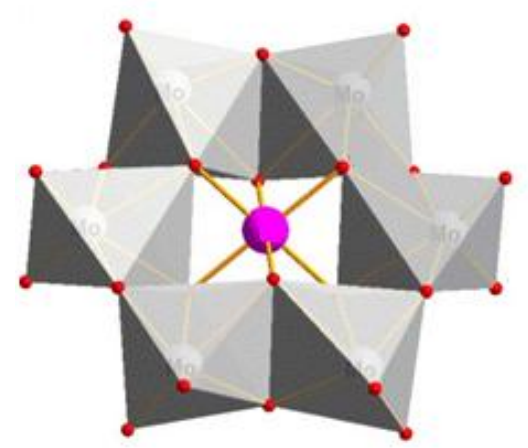

Figura 1-2: Representación poliédrica de la estructura del heteropolianión tipo Anderson de fórmula: $\mathrm{XMo}_{6} \mathrm{H}_{6} \mathrm{O}_{24}$, donde $\mathrm{X}$ corresponde al heteroátomo central $\mathrm{X}$ que puede ser: $\mathrm{Co}(\mathrm{III}), \mathrm{Rh}(\mathrm{III}), \mathrm{Ni}(\mathrm{II}), \mathrm{Cu}(\mathrm{II})$, etc. y está representado por la esfera fucsia.

En el caso del heteroátomo Co, existe además de la fase de Anderson, una estructura molibdo-cobáltica dímera derivada de la misma. Este anión, se origina por la condensación de dos entidades $\left[\mathrm{CoMo}_{6} \mathrm{O}_{24} \mathrm{H}_{6}\right]^{3-}$, como consecuencia de la pérdida de una fracción molecular $\mathrm{MoO}_{5}$ de cada una de ellas, generando una estructura donde los octaedros $\mathrm{CoO}_{6}$ comparten una arista. La estructura de la especie $\left[\mathrm{Co}_{2} \mathrm{Mo}_{10} \mathrm{O}_{38} \mathrm{H}_{4}\right]^{6-}$ $\left(\mathrm{Co}_{2} \mathrm{Mo}_{10}\right)$, se muestra en la Figura 1-3 [8].

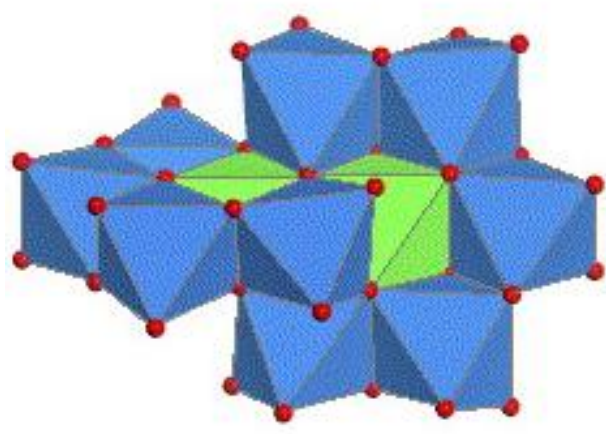

Figura 1-3: Estructura del heteropolioxoanión $\mathrm{Co}_{2} \mathrm{Mo}_{10}$. 


\section{3.b. Isopolioxocationes con elevado número de centros metálicos. "Olación"}

En la preparación de hidróxidos de cationes metálicos a partir de soluciones acuosas, se pueden obtener diferentes especies condensadas: clusters, especies de estructura laminar con enlaces covalentes direccionales, fases no estequiométricas, óxidos hidratados y eventualmente óxidos. Las moléculas de agua, unidas por puente-hidrógeno, pueden encontrarse formando parte de la estructura, como así también coordinadas con el catión, dependiendo del potencial iónico de la especie catiónica. Algunos metales tienen la capacidad de formar pequeños polímeros: (a)
$\left[\mathrm{Be}_{3}(\mathrm{OH})_{3}\left(\mathrm{H}_{2} \mathrm{O}\right)_{6}\right]^{3+}$,
(b) $\left[\mathrm{Al}_{2}(\mathrm{OH})_{2}\left(\mathrm{H}_{2} \mathrm{O}\right)_{8}\right]^{4+}$,
(c) $\left[\mathrm{Zr}_{4}(\mathrm{OH})_{8}\left(\mathrm{H}_{2} \mathrm{O}\right)_{16}\right]^{8+}$,

$\left[\mathrm{Sn}_{3}(\mathrm{OH})_{4}\left(\mathrm{H}_{2} \mathrm{O}\right)_{3}\right]^{2+}$, como se observa en la Figura 1-4. Cada estructura depende de la capacidad de los grupos $\mathrm{OH}^{-}$, considerando que éste posee tres pares electrónicos libres, capaces de actuar como bases de Lewis formando puentes con dos o tres iones metálicos [3].

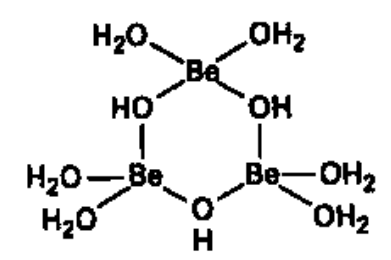

(a)

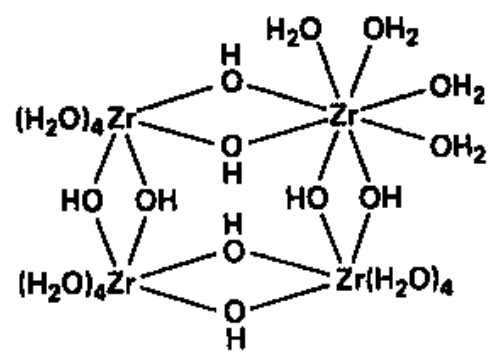

(c)
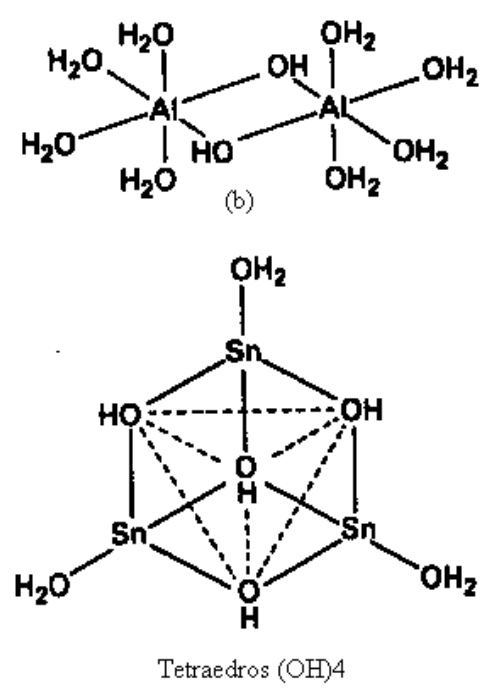

(d)

Figura 1-4: Hidroxocationes poliméricos: (a) $\left[\mathrm{Be}_{3}(\mathrm{OH})_{3}\left(\mathrm{H}_{2} \mathrm{O}\right)_{6}\right]^{3+}$, (b)

$$
\left[\mathrm{Al}_{2}(\mathrm{OH})_{2}\left(\mathrm{H}_{2} \mathrm{O}\right)_{8}\right]^{4+} \text {, (c) }\left[\mathrm{Zr}_{4}(\mathrm{OH})_{8}\left(\mathrm{H}_{2} \mathrm{O}\right)_{16}\right]^{8+},(\mathrm{d})\left[\mathrm{Sn}_{3}(\mathrm{OH})_{4}\left(\mathrm{H}_{2} \mathrm{O}\right)_{3}\right]^{2+} \text {. }
$$


Cabe analizar, en detalle, el comportamiento del catión altamente cargado $\mathrm{Al}^{3+}$, el cual en soluciones ácidas se encuentra hidratado por 6 moléculas de agua, como se muestra en la Figura 1-5 (a), $\left[\mathrm{Al}\left(\mathrm{H}_{2} \mathrm{O}\right)_{6}\right]^{3+}$. Cada molécula de agua de hidratación resulta unida por enlace puente-hidrógeno a otras moléculas.

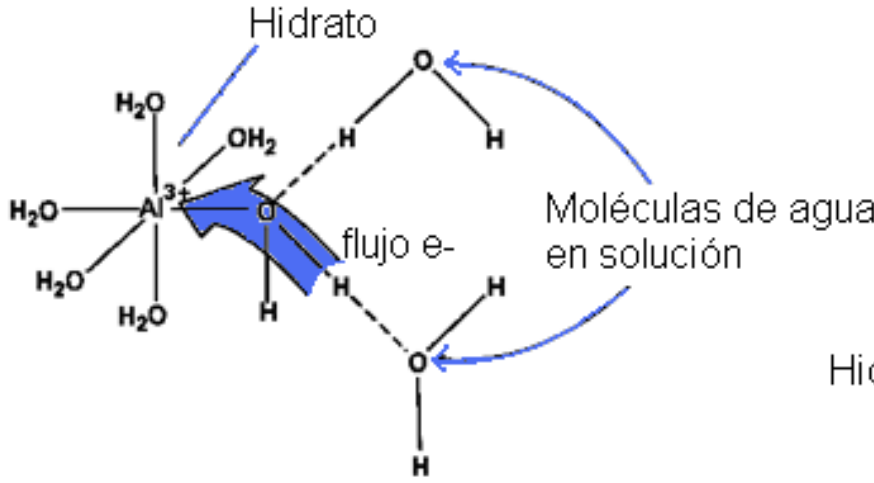

(a)

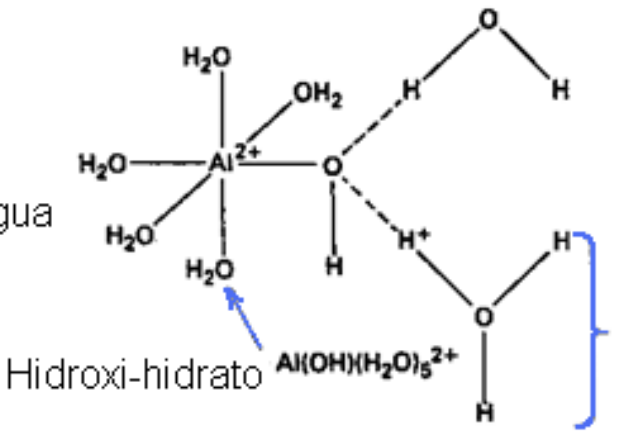

(b)

Figura 1-5: (a) Flujo de electrones y (b) flujo de protones para iones hidratados en solución acuosa.

Si se adiciona una base a la solución, los iones hidronio son removidos a través del equilibrio de $K w$. Los átomos de hidrógeno del ion hidronio (Figura 1-5) se unen a las moléculas de agua coordinadas al $\mathrm{Al}^{3+}$ favoreciendo la donación de electrones por parte del $\mathrm{O}$ (base de Lewis) hacia el $\mathrm{Al}^{3+}$ (ácido de Lewis), reforzándose el enlace Al$\mathrm{O}$ (ó Al--OH) y debilitándose las uniones por puente de hidrógeno. De este modo, el ion hidratado $\mathrm{Al}^{3+}$ actúa como un ácido débil que está siendo neutralizado. Así, cuando se eliminan tres protones del ion hidratado, la especie que se forma no posee carga neta. La ausencia de repulsión electrostática "monopolar" permite a la moléculas de $\mathrm{Al}(\mathrm{OH})_{3}\left(\mathrm{H}_{2} \mathrm{O}\right)_{3}$ aglomerarse a través de las unidades $\mathrm{OH}$ compartidas y enlaces de hidrógeno (las que pueden incluir moléculas de agua intermediarias), Figura 1-6. Esta estructura, no presenta la simetría correspondiente a la de un sólido cristalino, ya que los enlaces por puente de $\mathrm{H}$ son débiles. Esto da lugar a aglomeraciones o distribuciones extremadamente blandas (soft) y amorfas. Si la fase así formada se filtra y se seca de alguna manera, se obtendrá un óxido estructural y estequiométricamente poco definido, con un contenido de agua variable, característico de óxidos hidratados [3]. 


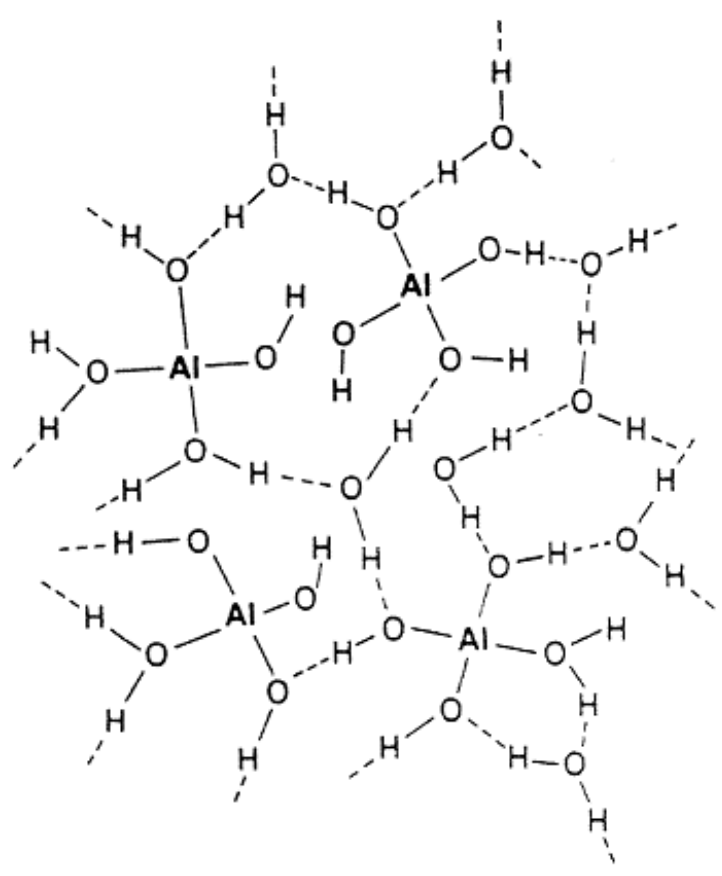

Figura 1-6: Enlaces de Hidrógeno en óxidos hidratados.

Este proceso de condensación de cationes para formar polioxocationes se denomina OLACION. La misma, procede mediante la formación de puentes hidroxo $(\mathrm{OH})$ por un mecanismo de sustitución nucleofílica. El ligando $\mathrm{OH}$, juega un rol importante como grupo entrante en la reacción de sustitución nucleofílica, sin experimentar cambio de coordinación en el paso de ligando terminal en el monómero, a ligando puente en la especie condensada. Este mecanismo, necesita la presencia de un grupo acuo $\left(\mathrm{H}_{2} \mathrm{O}\right)$ disponible, a fin de que la formación del ligando no implique la desprotonación del $\mathrm{OH}$. Esta reacción concierne a los complejos acuo-hidroxo $\left[\mathrm{M}(\mathrm{OH})_{\mathrm{h}}\left(\mathrm{H}_{2} \mathrm{O}\right)_{\mathrm{N}-\mathrm{h}}\right]^{(\mathrm{z}-\mathrm{h})+}(\mathrm{h} \leq \mathrm{z})$ formados por elementos de mediano potencial iónico que por lo general poseen estado de oxidación $\leq 4$ y se puede representar de acuerdo a la ecuación:

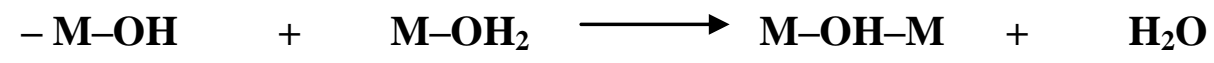




\section{3.b.I. Estructura de polioxocationes:}

La estructura de las especies condensadas está condicionada por ciertos factores tales como:

- El grado de hidrólisis, (h) definido como el avance del proceso por el cual se forman un número progresivo de enlaces-puente $\mathrm{OH}$.

- La geometría del poliedro de coordinación, limitando el modo de asociación de los poliedros según su capacidad de compartir vértices, aristas o caras.

- La ciclización. Estabiliza los puentes $\mathrm{OH}$ que unen vértices, los cuales se denominan $\mu_{1}, \mu_{2} \ldots \mu_{\mathrm{n}}$ de acuerdo al número de centros metálicos a los que están unidos.

La condensación de complejos catiónicos acuo-hidroxo $\left[\mathrm{M}(\mathrm{OH})_{\mathrm{h}}\left(\mathrm{H}_{2} \mathrm{O}\right)_{\mathrm{N}-\mathrm{h}}\right]^{(\mathrm{z}-\mathrm{h})+}$ $(\mathrm{h}<\mathrm{z})$ es limitada, finalizando espontáneamente según las características del ión central, por lo que se obtiene un grado de condensación finito. Las especies solubles permanecen en forma de policationes, que son por lo general entidades de tamaños moleculares [4].

Es importante remarcar, el efecto del $\mathrm{pH}$ sobre la estabilidad de la estructura del policatión dado que por un proceso de alcalinización progresivo de la solución, cuando las condiciones de formación del hidróxido son satisfechas, se produce una transformación estructural.

En lo que respecta a los elementos trivalentes, la química en solución de sus policationes es complicada. A pesar de la analogía estructural entre sus óxidos e hidróxidos, $\mathrm{M}_{2} \mathrm{O}_{3}$ y $\mathrm{M}(\mathrm{OH})_{3}$, el $\mathrm{Cr}(\mathrm{III}), \mathrm{Al}(\mathrm{III})$ y $\mathrm{Fe}(\mathrm{III})$ presentan un comportamiento en solución muy diferente, atribuido a las diferentes configuraciones electrónicas de los cationes (que determinan las variaciones que presentan los respectivos radios iónicos). En efecto el radio iónico del aluminio trivalente (tetraédrico 0.39 Å y octaédrico 0.53 $\AA ̊ ㇒)$ difiere de los correspondientes al Cr (III) y al Fe (III), especies gobernadas por la coordinación octaédrica ( 0.615 y $0.645 \AA$ respectivamente). El policatión de Al(III) $\left[\mathrm{AlO}_{4} \mathrm{Al}_{12}(\mathrm{OH})_{24}\left(\mathrm{H}_{2} \mathrm{O}\right)_{12}\right]^{7+}$ identificado como $\mathrm{Al}_{13}$ conserva su estructura durante el proceso de alcalinización y floculación formando un sólido no organizado por 
precipitación rápida (fase amorfa). Las diferencias de tamaño mencionadas son responsables de la formación de una estructura muy particular de tipo Keggin (Figura $1-7)$.

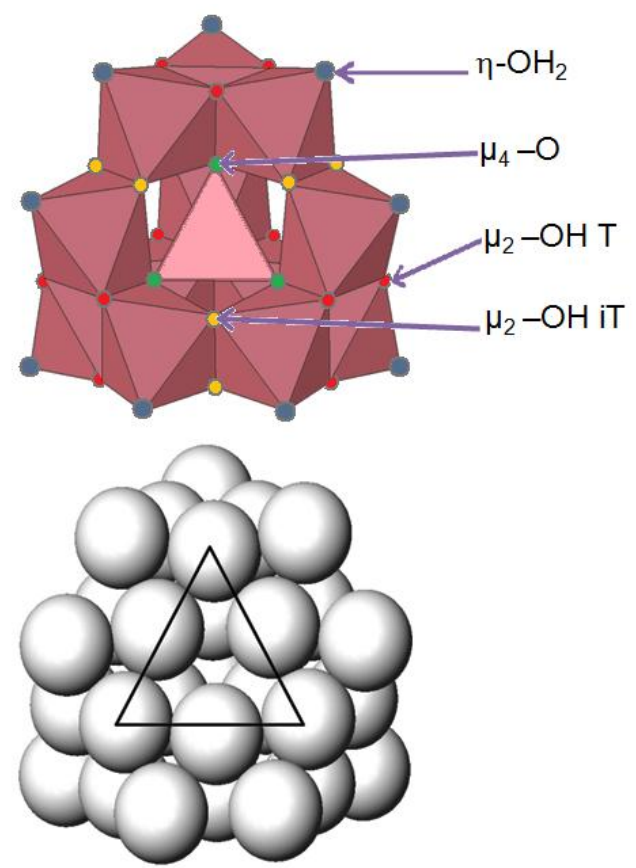

Figura 1-7: Representación del polioxocatión $\left[\mathrm{AlO}_{4} \mathrm{Al}_{12}(\mathrm{OH})_{24}\left(\mathrm{H}_{2} \mathrm{O}\right)_{12}\right]^{7+}$ donde se indica la ubicación de las moléculas de $\mathrm{H}_{2} \mathrm{O}$ y los puentes $\mathrm{O}$ y $\mathrm{OH}$ entre poliedros.

De acuerdo a la representación de la Figura 1-7 doce octaedros $\mathrm{AlO}_{6}$, distribuidos en cuatro trímeros, rodean a un tetraedro central, $\mathrm{AlO}_{4}$ [4].

En lo que respecta a las etapas que conducen a su formación, en primera instancia se forma un trímero de fórmula $\left[\mathrm{Al}_{3}(\mathrm{OH})_{4}\left(\mathrm{H}_{2} \mathrm{O}\right)_{9}\right]^{5+}$, el cual debido a su geometría es el más apto para minimizar las repulsiones electrostáticas entre los cationes. En esta entidad, existe un puente $\mu_{3}-\mathrm{OH}$ (Figura 1-8), que establece tres uniones con el catión y la cuarta con un átomo de $\mathrm{H}$. El $\mathrm{Al}(\mathrm{III})$, por su elevada relación carga/ radio $=6$, polariza fuertemente al átomo de oxígeno del $\mu_{3}-\mathrm{OH}$, generando una fuerte acidez que conduce a la pérdida del $\mathrm{H}^{+}$. De esta manera, el puente $\mu_{3}-\mathrm{O}$ del trímero puede ahora actuar como ligando nucleofílico de un monómero $\left[\mathrm{Al}\left(\mathrm{H}_{2} \mathrm{O}\right)_{6}\right]^{3+}$. 
Debido a razones estéricas, el $\mathrm{Al}(\mathrm{III})$ central no puede completar la configuración octaédrica con otros trímeros actuando finalmente como nucleófilo en la reacción con sólo cuatro trímeros y adoptando de esta manera una configuración tetraédrica. Finalmente, ocurre una condensación intramolecular por olación de los cuatro trímeros coordinados al Al central, eliminándose las moléculas de agua en posición cis.

\subsection{Métodos de síntesis}

Los hetero e isopolioxoaniones han sido preparados y aislados tanto en solución acuosa como no acuosa. En algunos casos, sales de polioxoaniones solubles en agua son preparadas a partir de mezclas fundidas, aunque generalmente dichos procesos generan un polioxoanión infinito o mezclas de óxidos estructurales que quedan excluidos de este análisis. No es posible tener un método sistemático de síntesis de todos los tipos de polioxoaniones existentes. A continuación se desarrolla una breve compilación sobre algunos métodos de síntesis de polioxoaniones [1].

\section{4.a. Síntesis en solución acuosa.}

\section{4.a.I. A partir de oxoaniones simples}

El método preparativo más utilizado es la simple acidificación de soluciones acuosas de los oxoaniones con los heteroátomos necesarios.

$$
\begin{aligned}
& 7 \mathrm{MoO}_{4}{ }^{2-}+8 \mathrm{H}^{+} \longrightarrow\left[\mathrm{Mo}_{7} \mathrm{O}_{24}\right]^{6-}+4 \mathrm{H}_{2} \mathrm{O} \\
& 6 \mathrm{MoO}_{4}{ }^{2-}+\mathrm{Cr}\left(\mathrm{H}_{2} \mathrm{O}\right)_{6}{ }^{3+}+6 \mathrm{H}^{+} \longrightarrow\left[\mathrm{Cr}(\mathrm{OH})_{6} \mathrm{Mo}_{6} \mathrm{O}_{18}\right]^{3-}+6 \mathrm{H}_{2} \mathrm{O} \\
& 12 \mathrm{WO}_{4}{ }^{2-}+\mathrm{HPO}_{4}{ }^{2-}+23 \mathrm{H}^{+} \longrightarrow\left[\mathrm{PW}_{12} \mathrm{O}_{40}\right]^{3-}+12 \mathrm{H}_{2} \mathrm{O}
\end{aligned}
$$

En estos casos, las constantes de equilibrio y las velocidades de formación son lo suficientemente grandes como para poder cristalizar las sales de los polianiones a partir de mezclas estequiométricas acidificadas de los componentes a temperatura ambiente. La estequiometría indicada en la ecuación de formación suele ser una buena guía para el 
diseño de una síntesis. Sin embargo, en muchos casos es necesario utilizar un exceso del heteroátomo y efectuar un cuidadoso control de la temperatura y/o del $\mathrm{pH}$, como ejemplo:

\section{$\mathrm{WO}_{4}{ }^{2-}, \mathrm{H}_{3} \mathrm{PO}_{4}$ (exceso), $\mathrm{H}^{+ \text {ebuttictót }}\left[\mathrm{P}_{2} \mathrm{~W}_{18} \mathrm{O}_{62}\right]^{6-}$ (isómeros) + otros tungtofosfatos}

También es importante la secuencia de adición de los reactivos. Asimismo, en ciertos casos se observan modificaciones en la formación de la especie final por el agregado de catalizadores. Ejemplo:

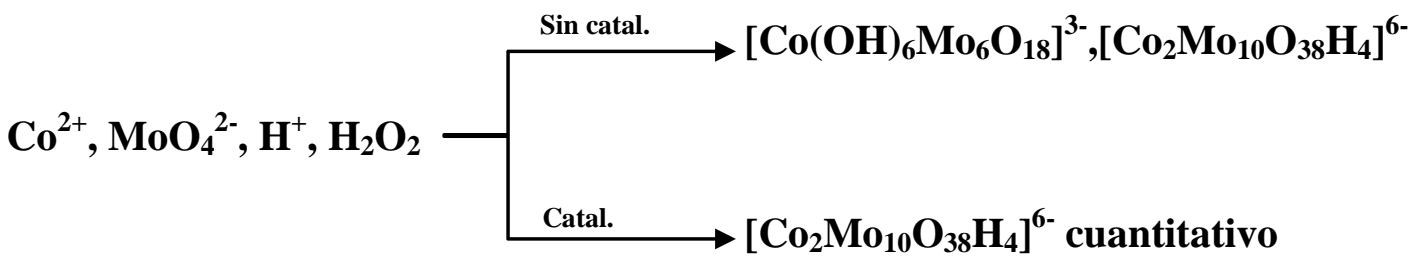

Generalmente la acidificación se realiza por adición de ácidos minerales comunes. En caso que deba evitarse la adición de otros aniones, se puede realizar una acidificación homogénea por oxidación electrolítica del solvente o por adición del anhídrido apropiado $\left(\mathrm{V}_{2} \mathrm{O}_{5}, \mathrm{MoO}_{3}, \mathrm{WO}_{3}\right)$.

El aislamiento del polioxoanión a partir de la solución se lleva a cabo, generalmente por adición de exceso del contraión correspondiente, para lo cual suele utilizarse un metal alcalino, amonio o tetra-alquilamonio. Las sales de sodio o litio tienden a ser más solubles en solución acuosa que las correspondientes a cationes mayores. Las sales de guanidinio frecuentemente poseen apreciable coeficiente de solubilidad que ayudan a la recristalización. Las sales de grandes cationes como el alquil-amonio, tetrabutilamonio, etc, usualmente son insolubles en agua, pero recristalizables con solventes como acetonitrilo, nitrometano, acetona, etc.

Los ácidos libres de muchos polioxoaniones son lo suficientemente estables como para ser cristalizados a partir de solución acuosa. En esos casos el anión puede ser aislado de la mezcla de reacción por el método llamado "etherate", descripto por primera vez en 1887. 
Los heteropoliácidos también han sido preparados por intercambio iónico y por precipitación con ácido sulfúrico [1].

\section{4.a.II. A partir de otros polioxoaniones.}

Un tipo importante de polioxoaniones son generados por adición de álcalis a los polioxoaniones ya preformados.

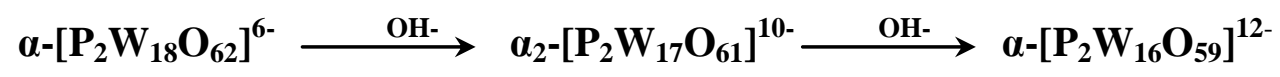

Estos iones se denominan "lacunares" debido al cambio en la relación O/metal por la pérdida de algunos poliedros de la estructura original. Los mismos pueden ser usados como material de partida en nuevos procesos de síntesis, para la obtención de heteropolioxoaniones de mayor complejidad, como por ej.,

$$
\alpha-\left[\mathrm{P}_{2} \mathrm{~W}_{16} \mathrm{O}_{59}\right]^{12-}+\mathrm{VO}^{2+} \stackrel{\mathrm{pH} 4-5}{\longrightarrow} \alpha-\left[\mathrm{P}_{2} \mathrm{~W}_{16} \mathrm{~V}_{2} \mathrm{O}_{62}\right]^{10-}
$$

En esta tesis se ha realizado la síntesis de la sal de amonio de la fase de Anderson de $\mathrm{Rh}(\mathrm{III})$ y $\mathrm{Mo}(\mathrm{VI})$ a partir de soluciones acuosas del heptamolibdato de amonio y $\mathrm{RhCl}_{3} \cdot \mathrm{XH}_{2} \mathrm{O}$, en cantidades estequiométricas con adición de $\left(\mathrm{NH}_{4}\right) \mathrm{Cl}$ manteniendo el pH entre 4 y 5 , de acuerdo a la siguiente ecuación:

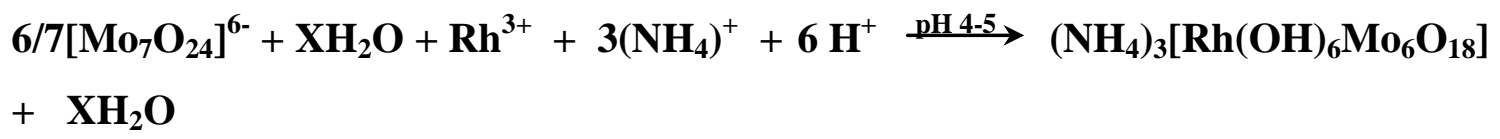

\subsection{Aplicación de iso y heteropolioxoaniones}

La aplicación de los heteropolioxometalatos se basa principalmente en algunas de sus propiedades, como tamaño, masa, capacidad de transferencia/ "almacenamiento" de electrones/ protones, estabilidad térmica, labilidad de los oxígenos estructurales, alta acidez Brónsted de los ácidos correspondientes, etc. Una ventaja adicional, la constituye la posibilidad de separación de los heteropoliácidos y purificación por extracción con solventes orgánicos [2]. 
Es bien conocida la aplicación de muchos de estos sistemas en los más variados campos de las Ciencias:

- La química Analítica y Clínica. Los polioxometalatos han sido ampliamente utilizados para la detección, separación y cuantificación de especies químicas, en base a propiedades de estos sistemas como el elevado peso molecular, capacidad redox con formación de especies coloreadas y capacidad de interacción química. En el área farmacéutica, estos sistemas han resultado de utilidad en la coagulación de ciertas proteínas y la precipitación de moléculas orgánicas. Resultan también de interés en la formación de intermediarios en la preparación de drogas, pesticidas, etc.

- En el campo de los conductores electrónicos y protónicos: el interés se centra en que sus propiedades se mantienen tanto en estado cristalino como en solución. Esto es atribuido a la débil atracción de las estructuras condensadas hacia los contraiones y moléculas solvatadas. En particular, la capacidad de transferir protones/ electrones es conservada en el estado cristalino, resultando así útiles como electrolitos sólidos en celdas de combustibles, por ej. el 12-molibdofosfato de amonio es utilizado en forma de pellets en la fabricación de poliestireno, etc.

- En Medicina han mostrado efectiva actividad antitumoral, antiviral y anti-retroviral. La bioactividad observada in-vitro e in-vivo se relaciona con la inhibición de algunas funciones enzimáticas y se atribuye básicamente al tamaño iónico, a la capacidad de transferencia - reserva electrónica y estabilidad al pH fisiológico [2].

- En el campo de la Catálisis y fotocatálisis han merecido especial atención y en tal sentido son utilizados exitosamente en una serie de procesos tecnológicos, básicamente de oxidación, hidrotratamiento y de catálisis ácida. Así, en el marco del objetivo propuesto en este trabajo de tesis doctoral, se ha focalizado la atención en la síntesis y caracterización de algunos heteropolioxoaniones de interés en procesos redox e hidrotratamiento de interés en petroquímica y química fina. 


\section{5.a. Antecedentes de la aplicación de HPOMs en procesos catalíticos}

Atendiendo la información reportada en la bibliografía, a continuación se realiza una reseña de las posibilidades de uso de los HPOMs en el campo de la catálisis.

Los Polianiones están construidos por poliedros M-On $(n=4-6)$ y se caracterizan por poseer preferentemente octaedros $\mathrm{MO}_{6}$ con enlaces terminales $\mathrm{M}=\mathrm{O}(\mathrm{d}-\mathrm{p} \pi \pi)$ que tienden a formar "estructuras discretas cerradas" con dichos enlaces dirigidos al exterior.

Las propiedades catalíticas de los POM se basan en sus funciones como ligandos inorgánicos (pueden contener metales de transición de los grupos 5 y 6) con una fuerte capacidad para aceptar electrones y estabilidad inherente hacia los donantes de oxígeno tales como el oxígeno molecular y peróxido de hidrógeno. Otras propiedades adicionales son su estabilidad en $\mathrm{H}_{2} \mathrm{O}$ y aire, constituyen centros redox reversibles, son ácidos de Arrhenius ( $\mathrm{pKa}<0$ ), tienen formas ácidas muy solubles en $\mathrm{H}_{2} \mathrm{O}$ y otras de transporte de oxígeno (disolventes éteres, alcoholes, cetonas), también solubles o transferibles a disolventes no polares. Dado que todos los polioxometalatos tienen átomos de valencia alta, tienen propiedades catalíticas en la activación de peróxido de hidrógeno, hidroperóxidos de alquilo-y otros perácidos comunes.

La presencia de centros redox reversibles hace que sean muy buenos sistemas catalíticos en oxidaciones, como por ej. la formación de ácidos carboxílicos a partir de los aldehídos correspondientes, la obtención de ácido metacrílico a partir de metacroleina en fase vapor y la oxidación de metano, entre otras [1, 2, 8].

En catálisis homogénea oxidativa los POMS han sido estudiados en procesos termo y fotoquímicos de deshidrogenación y evolución de $\mathrm{H}_{2}$ de especies del tipo $\mathrm{R}$ $\mathrm{COOH}, \mathrm{R}-\mathrm{CH}_{2} \mathrm{OH}$, etc. [1, 2]

Más allá de la amplia utilización en procesos catalíticos de oxidación, estos sistemas resultan excelentes para investigar algunos problemas fundamentales de la catálisis. Las superficies de los polioxometalatos pueden considerarse como modelos de óxidos metálicos. La actividad en la oxidación puede entenderse como la pérdida de átomos de oxígeno superficiales y la deslocalización de los electrones remanentes sobre 
los átomos metálicos, situación que es posible analizar en procesos de reacción en condiciones relativamente suaves $[2,8]$.

En catálisis ácida, la actividad de los heteropoliácidos puede relacionarse con el número de sitios ácidos presentes. Compuestos del tipo $\mathrm{H}_{\mathrm{x}}\left[\mathrm{XM}_{12} \mathrm{O}_{40}\right]$ (estructura tipo Keggin), actúan como ácidos fuertes "Strong polybasic acid”. Esa característica se basa en las propiedades estructurales inherentes a la presencia de protones deslocalizados los que pueden ser intercambiados rápidamente con los protones de las moléculas de agua de cristalización (de la llamada estructura secundaria), y con los protones localizados en los enlaces con oxígeno $\mu_{2}$-puentes de los polioxoaniones. En solución acuosa, estos ácidos fuertes se encuentran completamente disociados. Aunque, los heteropoliácidos son económicamente menos convenientes que los ácidos minerales, como el $\mathrm{H}_{2} \mathrm{SO}_{4} \mathrm{O}$ $\mathrm{HCl}$, poseen ventajas respecto a los segundos dado que son no-volátiles, inodoros y térmicamente estables, pudiendo utilizarse tanto en catálisis heterogénea como homogénea, como bulk o soportados en sistemas inertes como sílica-gel, carbón activado, etc. [2]. Actualmente, la principal aplicación catalítica de los heteropoliácidos, es la producción industrial de 2-propanol, 2-butanol y tert-butanol en fase líquida por hidratación de las correspondientes olefinas [2].

\section{$\mathrm{CH}_{2}=\mathrm{CHCH}_{3}+\mathrm{H}_{2} \mathrm{O} \longrightarrow \mathrm{CH}_{3} \mathrm{CH}(\mathrm{OH}) \mathrm{CH}_{3}$}

Dado que en estos sistemas los puentes oxo superficiales son considerados centros ácidos, el conocimiento de las estructuras electrónicas y de las densidades electrónicas es de suma importancia para comprender el comportamiento de los mismos en un proceso catalítico.

\section{5.a.I. Utilización de heteropolicompuestos en reacciones de hidrotratamiento.}

La utilización industrial de HPOMs más ampliamente difundida relacionada con hidrotratamientos se da en reacciones de Hidrodesulfurización (HDS), 
Hidrodenitrificación (HDN) e Hidrodemetalación (HDM) de combustibles fósiles. En nuestros laboratorios se ha estudiado la hidrogenación (HYD) de ciclohexeno en simultaneo con reacciones de HDS de tiofeno mediante fases de Anderson [Co/ $\left.\mathrm{Rh} / \mathrm{Mo}_{6} \mathrm{O}_{24}\right]^{6-}$ y derivados estructurales como $\left[\mathrm{CoMo}_{10} \mathrm{O}_{38}\right]^{10-}$ soportadas en alúmina. En la mayoría de los casos los catalizadores contienen, antes de la promoción, formas heptamolíbdicas soportadas sobre alúmina y las formas promovidas contienen en general "Polimolibdato de Cobalto". La actividad catalítica está relacionada al polimolibdato utilizado en la impregnación del soporte de alúmina $[2,9,10]$.

Por otro lado, la actividad y selectividad hidrogenante de los catalizadores heterogéneos convencionales puede ser afectada mediante la introducción de modificadores sobre el catalizador o en la mezcla de reacción. En el primer caso los modificadores están adsorbidos, ellos pueden ser sólidos ácidos, compuestos sulfurados, metales alcalinos u óxidos de metales de transición. Los promotores agregados a la mezcla de reacción son sales y bases inorgánicas que están disueltas en la fase líquida. Un tipo de modificador usado en hidrogenaciones selectivas son los heteropoliácidos. En la hidrogenación de furfural con catalizadores de Ni Raney se ha reportado un aumento en la actividad y selectividad a alcohol furfurílico cuando los sistemas fueron modificados con $\mathrm{Cu}_{1,5} \mathrm{PMo}_{12} \mathrm{O}_{40}$ [11]. Sin embargo, hasta el momento no está claro el mecanismo que conduce al aumento en la actividad y selectividad. Mayores selectividades fueron encontradas también en catalizadores de Co Raney, empleados para la hidrogenación de cinamaldehído, cuando fueron modificados con $\mathrm{Cu}_{1,5} \mathrm{PMo}_{12} \mathrm{O}_{40}$. Si bien en éste último caso la selectividad aumentó de $70 \%$, para el sistema sin modificar, a $83 \%$ para el modificado, una fuerte disminución en la conversión fue registrada para el catalizador modificado [12].

\subsection{Catálisis heterogénea y su aplicación en procesos de hidrogenación de interés en química fina.}

\section{6.a. Consideraciones generales.}

Los procesos de hidrogenación se aplican corrientemente en la industria química, petroquímica y de química fina. A diferencia de la industria petroquímica, que 
se caracteriza por producciones en grandes volúmenes, la química fina involucra la producción en pequeños volúmenes de sustancias conteniendo moléculas con funciones específicas a partir de productos naturales o sintéticos. Los productos obtenidos generalmente responden a especificaciones muy estrictas y son comercializados a precios altos.

Los denominados químicos finos y especialidades químicas encuentran su campo de aplicación en la energía nuclear, la electrónica, la industria agro-alimenticia, la industria farmacéutica, etc. Estas actividades industriales se caracterizan por un alto valor agregado en los productos que elaboran, haciendo que se justifiquen importantes inversiones en investigación y desarrollo, lo cual permite incorporar innovaciones tecnológicas en los procesos involucrados. La mayor parte de las veces se trata de procesos que implican la transformación de moléculas orgánicas complejas, las cuales pueden incluir heteroátomos como oxígeno, fósforo, nitrógeno, azufre y halógenos.

La química fina ha sido durante años un campo exclusivo de la síntesis orgánica y de la catálisis homogénea. Recientemente, debido al avance logrado en el conocimiento de los mecanismos fundamentales que rigen la catálisis heterogénea, se registra un notable incremento en las investigaciones básicas y aplicadas que utilizan catalizadores sólidos en reacciones de interés en el campo de la química fina. La mayor ventaja de la catálisis homogénea radica en la posibilidad de caracterizar intermediarios y a través de estos determinar mecanismos de reacción. Sin embargo su principal dificultad es la separación de los productos y la recuperación del catalizador. Este último aspecto resulta la principal ventaja que promueve el desarrollo de la catálisis heterogénea, la que resulta de menor costo, fácil manejo y una separación efectiva del catalizador.

En catálisis heterogénea el fenómeno catalítico está relacionado con las propiedades químicas de la superficie del sólido elegido como catalizador. Para que la catálisis tenga lugar es necesaria una interacción química entre el catalizador y el sistema de reactivos y productos que no modifique la naturaleza química del catalizador. La interacción entre el catalizador y el sistema reaccionante (fase fluida) se produce en la superficie (mediante el fenómeno de adsorción) del primero y no involucra el interior del sólido. 
En cualquier proceso catalítico heterogéneo, se pueden considerar varias etapas consecutivas, desde que el reactivo llega a la superficie del catalizador hasta que se obtiene el producto final. Estas etapas son:
a) difusión del reactivo (o reactivos) a través de los poros del catalizador,
b) adsorción del reactivo sobre la superficie del catalizador,
c) reacción química propiamente dicha con formación del producto adsorbido,
d) desorción del producto,
e) difusión del producto a través de los poros del catalizador.

\section{6.b. Determinación de los sitios activos de un catalizador heterogéneo según el método de Boudart.}

Michel Boudart, [13] ha definido dos clases de reacciones catalíticas heterogéneas: aquellas de estructura sensible, cuya actividad en función de los sitios activos expresados habitualmente como "TOF" (turnover frequencies), dependerá del tamaño de partícula, como la hidrogenolisis de enlaces C-C, y las de estructuras no sensibles, que no dependerán del tamaño de partícula, como por ejemplo la deshidrogenación de ciclohexano para dar benceno.

Dado que las poblaciones relativas de átomos expuestos en los vértices, aristas y planos de cristalitos de metal, pueden cambiar a medida que ocurren cambios de tamaño de partículas, se cree que en las reacciones de estructuras sensibles, las poblaciones de los sitios activos también cambian con el tamaño de las partículas.

Por otro lado, reacciones de estructuras no sensibles parecen ocurrir en todos los átomos expuestos (o más), y por lo tanto sus TOF (turnover frequencies) no están influenciados tanto por el tamaño de partícula. 
Debido a esta relación entre la actividad catalítica y tamaño de las partículas, es fácil comprender por qué la medida de la distribución de tamaño de partícula es un parámetro importante en la catálisis.

\section{6.c. Procesos de hidrogenación en química fina.}

En 1912 Paul Sabatier recibió el Premio Novel de Química por sus investigaciones en el uso de metales finamente divididos en reacciones de hidrogenación. Desde entonces la catálisis heterogénea en química orgánica se ha desarrollado enormemente. Se ha reconocido que el rol mas importante del catalizador metálico es generar hidrógeno atómico adsorbido, el que, en contraste con la molécula de hidrógeno relativamente inerte, puede adicionarse fácilmente a varias uniones insaturadas: $\mathrm{C}=\mathrm{C}, \mathrm{C}=\mathrm{O}, \mathrm{C} \equiv \mathrm{N}$, etc. Una alternativa a ese hidrógeno "heterogéneo" es el uso de hidruros inorgánicos $\left(\mathrm{LiAlH}_{4}, \mathrm{NaBH}_{4}\right.$, etc.) o la generación de hidrógeno naciente $(\mathrm{HCl} / \mathrm{Zn})$. Mientras que en las hidrogenaciones realizadas con hidruros inorgánicos, la arquitectura de un probable enlace de las moléculas insaturadas o de intermediarios parcialmente hidrogenados, puede ser difícil de establecer con exactitud, existe una extensa bibliografía acerca del intermediario adsorbido que se requiere en el transcurso de una hidrogenación heterogénea [14].

La hidrogenación de compuestos monofuncionales no es generalmente complicada. Tampoco hay grandes inconvenientes cuando hay dos grupos reducibles que tienen diferente reactividad; por ejemplo, el nitrobenceno es fácilmente reducido a anilina sin afectar al anillo aromático. Los diferentes grupos $-\mathrm{NO}_{2}$ (nitro), -NO (nitroso), $>\mathrm{C}=\mathrm{O}$ (ceto) y $-\mathrm{HC}=\mathrm{O}$ (aldehído), pueden reducirse para dar los respectivos grupo amino o alcohol secundario o alcohol primario, utilizando el catalizador adecuado en las condiciones convenientes. Aún en estos casos existe la posibilidad de una hidrogenólisis simultánea o secuencial de los enlaces -C-N- o -C-O para formar alcanos. Los anillos aromáticos homocíclicos o heterocíclicos también pueden hidrogenarse, pero se necesitan condiciones de reacción mas rigurosas que para la hidrogenación de los grupos antes mencionados. La presencia en la molécula de sustituyentes ricos en electrones tales como $-\mathrm{OH}$ o $-\mathrm{NH}_{2}$ parecen favorecer el anclaje de la molécula sobre la 
superficie del catalizador; así, por ejemplo, el fenol y la anilina son más fácilmente hidrogenables que el benceno. El grupo $-\mathrm{C} \equiv \mathrm{N}$ (nitrilo) y el grupo $-\mathrm{COOH}$ (ácido carboxílico) son muy difíciles de reducir. Sin embargo existen catalizadores adecuados para llevar a cabo este tipo de hidrogenaciones, con mayor o menor éxito. En general se trata de catalizadores metálicos, muchas veces promovidos por óxidos, como en el caso de aleaciones niquel-cobre y cromito de cobre.

El proceso de hidrogenación se hace más complejo cuando la molécula a hidrogenar posee dos o más grupos funcionales de reactividad comparable. Esta situación se da en moléculas que poseen grupos $\mathrm{C}=\mathrm{C}$ y $\mathrm{C}=\mathrm{O}$ conjugados, tales como aldehídos o cetonas $\alpha, \beta$-insaturados.

La hidrogenación del enlace $\mathrm{C}=\mathrm{C}$ es termodinámicamente más favorable que la del $\mathrm{C}=\mathrm{O}$, así la variación de energía libre en el primer caso es de aprox. $-17 \mathrm{Kcal} / \mathrm{mol} \mathrm{a}$ $300{ }^{\circ} \mathrm{K}$ y de aprox. $-12 \mathrm{Kcal} / \mathrm{mol}$ a $500{ }^{\circ} \mathrm{K}$ siendo por lo tanto la reacción irreversible. En el segundo caso, la variación de energía libre es de aprox. $-6 \mathrm{Kcal} / \mathrm{mol}$ y de aprox. $3 \mathrm{Kcal} / \mathrm{mol}$ a $300{ }^{\circ} \mathrm{K}$ y $500{ }^{\circ} \mathrm{K}$ respectivamente, existiendo por lo tanto un equilibrio, sobre todo a temperaturas elevadas.

\section{6.d. Hidrogenación selectiva de aldehídos $\alpha, \beta$-insaturados}

La hidrogenación selectiva de aldehídos $\alpha, \beta$-insaturados, asistida por catalizadores metálicos soportados, en su mayoría metales nobles soportados $(\mathrm{Pt}, \mathrm{Ru}$, $\mathrm{Rh}, \mathrm{Pd})$ [15] es una etapa clave en la obtención de productos farmacéuticos, sabores y fragancias [16-18]. La hidrogenación selectiva de cinamaldehído (CAL) es un buen ejemplo de este tipo de reacciones de importancia comercial, permitiendo la obtención de alcohol cinámico (COL), hidrocinamaldehído (HCAL) y alcohol hidrocinámico (HCOL). El alcohol cinámico es un producto valioso en la industria de la perfumería, tanto por su aroma como por sus propiedades fijadoras. También se emplea en la industria farmacéutica en la síntesis del antibiótico cloromicetina [19,20]. Más recientemente, se han encontrado también aplicaciones de importancia para el hidrocinamaldehído, por ejemplo su uso como intermediario en la síntesis de fármacos 
para el tratamiento del HIV [21-23]. A pesar de los numerosos trabajos publicados en la literatura relacionados con la obtención de catalizadores para la hidrogenación selectiva de cinamaldehído hacia alcohol cinámico o hidrocinamaldehído, el origen de la selectividad es aún materia de debate [24-26]. En particular, varios intentos se han desarrollado con vistas a lograr catalizadores a base de metales nobles selectivos a hidrocinamaldehído. Se ha encontrado que catalizadores bimetálicos exhiben un importante efecto sinérgico que promueve la selectividad a hidrocinamaldehído. Asimismo, catalizadores a base de $\mathrm{Rh}$ son algunos de los más efectivos en hidrogenación selectiva [27].

Reyes y colaboradores [27] estudiaron el efecto del Mo sobre las propiedades superficiales y catalíticas del sistema $\mathrm{Rh} / \mathrm{SiO}_{2}$ en la hidrogenación selectiva de cinamaldehído, donde determinaron que la actividad y selectividad de catalizadores de Rh soportados, podían ser modificadas por la presencia de óxidos de Mo. Las mejoras observadas pudieron ser atribuídas a un efecto promocional del Mo debido a la creación de sitios $\mathrm{Rh}^{\delta+}-\mathrm{MoO}_{\mathrm{x}}$ encontrando que el $\mathrm{Rh}$ es capáz de inducir la reducción de $\mathrm{MoO}_{3}$ hacia la especie $\mathrm{MoO}_{\mathrm{x}}$ y el óxido de molibdeno también puede producir una oxidación parcial de $\mathrm{Rh}$, generando especies $\mathrm{Rh}^{\delta+}$, responsables de la polarización del grupo carbonilo.

El presente trabajo se propone estudiar la actividad catalítica en la hidrogenación de cinamaldehido del heteropolianión tipo Anderson de Rh (III) y Mo(VI) soportado en diferentes materiales a base de alúmina, sílices y aluminosilicatos.

\section{6.e. Efecto del soporte en catálisis heterogénea, consideraciones generales.}

El objetivo principal del soporte, como bien indica su nombre, es su empleo como portador de la fase metálica permitiendo mejorar y optimizar su dispersión. Los soportes convencionales suelen ser óxidos metálicos con carácter acido o básico y algunos tipos de carbones. En términos de reactividad, los soportes pueden ser inertes (que no intervienen en la reacción) o activos (que intervienen directa o indirectamente en la reacción). Los soportes presentan propiedades muy distintas, desde áreas 
superficiales especificas muy diferentes que van desde los 10 hasta los $1200 \mathrm{~m}^{2} / \mathrm{g}$, diferente volumen de poro, acidez, distintas propiedades electrónicas y geométricas.

En el estudio de la hidrogenación selectiva de aldehídos $\alpha, \beta$-insaturados, la elección del soporte debe realizarse teniendo en cuenta tanto el tipo de reacción catalítica como las condiciones operativas en que se lleva a cabo la misma.

Los soportes mas idóneos para la preparación de catalizadores heterogéneos son los que poseen una elevada porosidad y por tanto, alta área superficial para que la relación de área activa por unidad de volumen sea elevada y la difusión de reactivos y productos a través de su estructura resulten favorecidos, facilitando la llegada de los mismos a los centros activos. Su interés industrial se fundamenta en la combinación de porosidad y resistencia mecánica.

Oxidos de Al, Sílice, aluminosilicatos (naturales o sintéticos), zeolitas, carbón activo, son los materiales mas comúnmente empleados como soportes sobre los que se dispersa el componente activo, por ser económicos además de estables química, térmica y mecánicamente. Por otro lado, es posible modificar determinadas características de los sólidos (acidez-basicidad, propiedades redox, tamaño de poros, etc.) mediante procesos sencillos, para adaptarlas a las necesidades de la reacción concreta en la que se empleen.

\section{6.e.I. Soportes a base de sílices.}

La Sílica-gel es un material químicamente inerte que se obtiene fácilmente como un adsorbente estable de alta porosidad cuyo método comercial de preparación a gran escala se realiza a partir de la deshidratación del hidrogel producido por tratamiento ácido del silicato de sodio. Estos materiales son ampliamente utilizados como adsorbentes y desecantes [28]. Asimismo tienen importancia como aislantes térmicos; soportes de catalizadores ó compuestos funcionales para aplicaciones químicas, electrónicas y ópticas [29]. Sin embargo, las aplicaciones prácticas resultan limitadas debido a dos propiedades: la fragilidad y la higroscopicidad por la cual adsorben la humedad del ambiente conduciendo al colapso de la estructura debido a las fuerzas capilares desarrolladas en los poros. 
Las características más destacadas de la $\mathrm{SiO}_{2}$ son: la alta adsorción y un comportamiento térmico estable siendo una sustancia de aspecto cristalino, porosa e inerte. Posee la capacidad de diferenciar la adsorción de diferentes moléculas actuando como un adsorbente selectivo. Otra de sus características es ser débilmente ácida y exhibe en su superficie grupos hidroxilo libres.

\section{6.e.II. Soportes a base de alúmina.}

Las alúminas u óxidos de aluminio son productos químicos inorgánicos con producción a gran escala. Anualmente unos 4,5 millones de toneladas son destinados a aplicaciones tecnológicas especialmente en catálisis. Las denominadas "alúminas activadas" son generalmente aplicadas como adsorbentes o soportes de catalizadores. Se preparan por tratamiento térmico de algunas formas de alúminas hidratadas como hidróxidos cristalinos, oxi-hidróxidos, o gel de hidro-alúmina. La propiedad adsorbente depende de las condiciones de calentamiento empleadas en las primeras etapas del mismo. Ciertos tipos de alúmina activada pueden ser usados como poderosos desecantes o para la retención de vapores. La propiedad adsorbente depende de las condiciones de calentamiento empleadas en las primeras etapas del mismo, como muestra el trabajo de Rouquerol (1999) [28].

En las primeras investigaciones sobre este fenómeno se observó una gran dificultad para correlacionar la evolución del área superficial registrada con la temperatura de calcinación. De hecho, esas diferencias no resultaron sorprendentes. Para obtener propiedades adsorbentes reproducibles es necesario el control de múltiples variables: (a) la naturaleza química y física del material de partida (es decir, su estructura, cristalinidad/tamaño de partículas, cantidad de muestra pura), (b) las condiciones de tratamiento térmico (tipo de horno, atmósfera, perfil tiempotemperatura, de preferencia mediante un análisis de velocidad térmica controlada, procedimiento de calentamiento) y (c) los métodos utilizados para interpretar los datos de adsorción (BET, BJH, etc.). Durante este tratamiento térmico en el intervalo de temperatura entre 200 y $1200{ }^{\circ} \mathrm{C}$, se puede obtener una serie de sólidos iónicos con la 
fórmula general $\mathrm{Al}_{2} \mathrm{O}_{3}\left(\mathrm{H}_{2} \mathrm{O}\right)_{\mathrm{n}}$, aunque ninguno en realidad contiene moléculas de agua. Estos materiales se denominan también alúminas de transición [28].

La $\gamma-\mathrm{Al}_{2} \mathrm{O}_{3}$ y la $\eta-\mathrm{Al}_{2} \mathrm{O}_{3}$ son sólidos de baja cristalinidad con iones $\mathrm{Al}^{3+}$ ocupando posiciones tetraédricas y octaédricas en la red cúbica densa de iones $\mathrm{O}^{2-}$. Salvo la acidez, presentan propiedades similares: altas superficies específicas (100-200 $\left.\mathrm{m}^{2} \mathrm{~g}^{-1}\right)$ y aceptables volúmenes porales $\left(0.5-1.0 \mathrm{~cm}^{3} \mathrm{~g}^{-1}\right)$. Estas alúminas no son estables térmicamente por encima de $900{ }^{\circ} \mathrm{K}$.

\subsection{Aluminosilicatos: Arcillas}

Desde el punto de vista mineralógico, la arcilla es una especie que abarca un grupo de minerales, filosilicatos en su mayor parte, cuyas propiedades físico-químicas dependen de su estructura y de su tamaño de grano (inferior a $2 \mu \mathrm{m}$ ). Desde el punto de vista petrológico la arcilla es una roca sedimentaria, en la mayor parte de los casos de origen detrítico, con características bien definidas. Para un sedimentólogo, arcilla es un término granulométrico, que abarca los sedimentos con un tamaño de grano inferior a 2 $\mu \mathrm{m}$. Desde el punto de vista económico las arcillas son un grupo de minerales industriales con diferentes características mineralógicas y distintas propiedades tecnológicas y aplicaciones.

Por consiguiente todos los filosilicatos pueden considerarse verdaderas arcillas si se encuentran con la granulometría adecuada, incluyendo minerales no pertenecientes al grupo de los filosilicatos (cuarzo, feldespatos, etc.) que pueden ser considerados partículas arcillosas cuando están incluidos en un sedimento arcilloso y sus tamaños no superan las $2 \mu \mathrm{m}[30]$.

En lo que respecta al tipo de silicatos laminares se pueden reconocer dos tipos básicos de bloques de construcción, uno correspondiente a capas de tetraedros $\mathrm{TO}_{4}$ (compartiendo tres vértices) y el otro a capas de octaedros unidos por aristas formados por átomos metálicos coordinados a átomos de $\mathrm{O}$ ó iones $\mathrm{OH}$, en los que no participa el elemento silicio. Las posibles modificaciones estructurales que permiten estas estructuras, están referidas casi exclusivamente a la forma en que cada capa básica 
participa en la estructura de la red cristalina. La Figura 1-9 muestra la combinación de capas tetra y octaédricas.

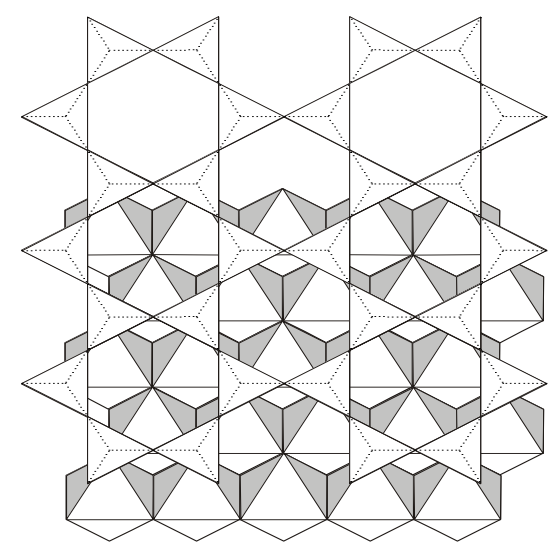

Figura 1-9: Vista superior de capas tetra y octaédricas adyacentes.

Considerando que la carga de la capa octaédrica debe ser positiva, el balance total de carga para la combinación capa tetraédrica-capa octaédrica es idealmente cero. Así se presenta cuando los sitios octaédricos se encuentran ocupados total o parcialmente, dependiendo de la carga de los iones en coordinación seis. Teniendo en cuenta la disposición como anillo hexagonal de tetraedros, típico de las arcillas, la carga neta del mismo, según las reglas de Pauling resulta ser -6 . Dado que es posible ubicar tres octaedros por cada anillo hexagonal de tetraedros, el balance se alcanza con la incorporación de tres cationes divalentes $(+2 \times 3)$. Esa disposición estructural se denomina "tri-octaédrica". Contrariamente, cuando el catión en posición octaédrica es trivalente, solamente dos tercios de las posiciones octaédricas se encuentran ocupados $(+3 \times 2)$, denominándose capa "di-octaédrica". Esta última distribución produce una mayor distorsión de la simetría local.

Las estructuras laminares también se ven afectadas por las diferentes formas que surgen del apilamiento de esas dos estructuras básicas. Sin embargo, deben mantenerse 
las restricciones impuestas por la regla de relación de radios para permitir la ocupación de un hueco octaédrico. Esto se ve favorecido por valores de $\rho$ ligeramente superiores a 0.40, de modo que el $\mathrm{Al}(\mathrm{III})$ es el catión que puede presentar una dualidad de coordinación. Así, los tamaños iónicos de las especies octaédricas deben encontrarse en el rango entre 0.53 y $0.70 \AA$ ̊: como el Fe(III) de bajo y alto espín es 0.550 y $0.645 \AA$, el Fe(II) 0.61 y $0.78 \AA$ (bajo y alto espín respectivamente), el Mg $0.72 \AA$.

De esta manera la posibilidad de sustitución ( $\mathrm{Si}-\mathrm{Al}$ en la capa tetraédrica y de cationes di y trivalentes en posición octaédrica) impone nuevas restricciones a la formación de estructuras laminares que usualmente se presentan en la naturaleza.

\section{7.a. Clasificación de los Silicatos Laminares}

La clasificación de silicatos laminares puede analizarse desde la forma de apilamiento de las capas tetra y octaédricas así como de sus ubicaciones relativas. La repetición de láminas define el plano basal (001) de la celda unitaria y es este espaciado el utilizado para identificar el tipo de especie laminar. Sobre la base del apilamiento es posible establecer la presencia de tres tipos de silicatos laminares:

- Silicatos Laminares 1:1

- Silicatos Laminares 2:1

- Silicatos Laminares 2:1:1

Silicatos Laminares 2:1: En el marco de esta tesis se estudiarán aluminosilicatos de este tipo para la preparación de catalizadores, razón por la que se detallan algunos aspectos de los mismos.

Surgen de la combinación entre dos capas tetraédricas y una octaédrica: T-O-T, Figura 1-10. La repetición de esta combinación, extendida en dos dimensiones, puede dar lugar a diferentes tipos de especies laminares, según se observe la ausencia de material interlaminar o se puedan albergar cationes grandes entre láminas, ya sean anhidros o hidratados. La incorporación de dichos cationes ocurre para mantener la neutralidad eléctrica cuando las sustituciones, tanto en la capa tetraédrica como en la 
octaédrica así lo requieran. Las características mencionadas permiten la siguiente subdivisión:

- Ausencia de material en espacio interlaminar.

- Capas cargadas interfoliadas con iones.

- Capas interfoliadas con iones hidratados.
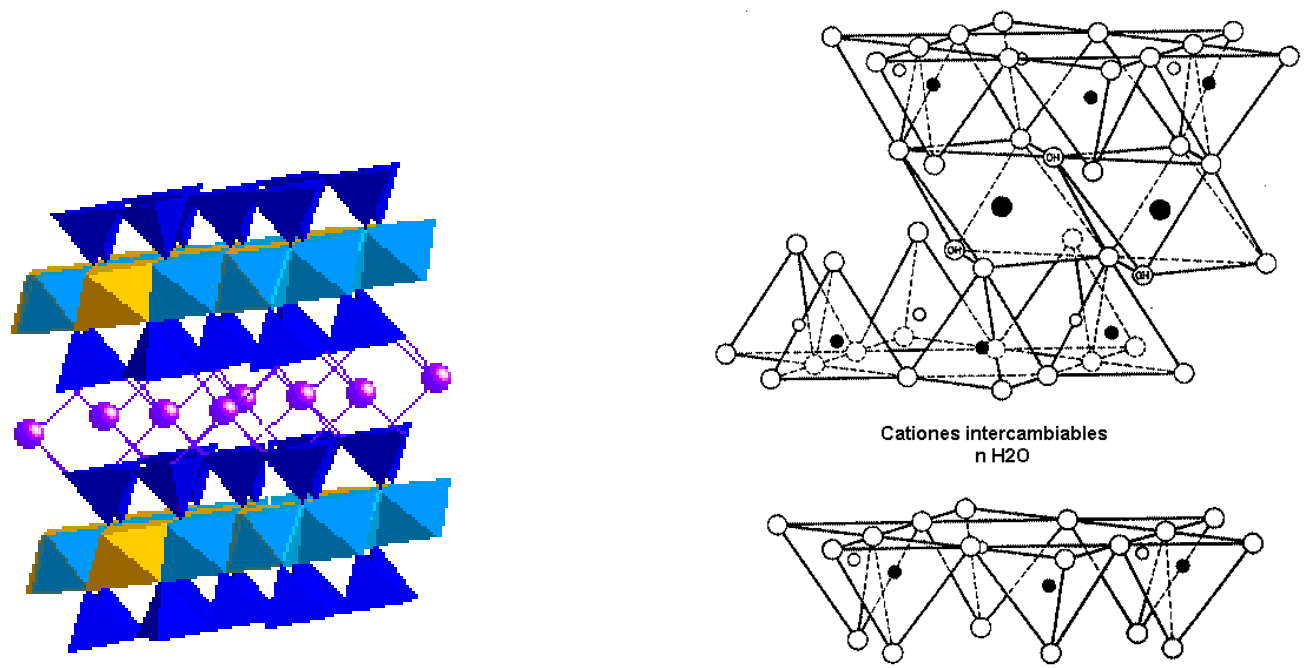

Cationes intercambiables

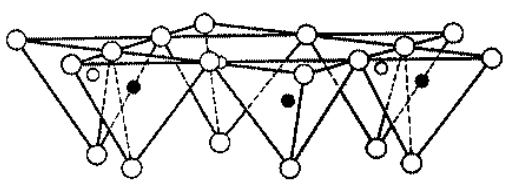

$\mathrm{O}$ 아요 $\mathrm{OH}, \mathrm{Fg}$

O Si Al

Figura 1-10: Dos representaciones de la estructura de una especie representativa de alúmino silicato 2:1, que corresponde a la montmorillonita.

El mineral de arcilla seleccionado para esta tesis es una "bentonita" cuya fórmula corresponde a la "montmorillonita" alúminosilicato que "nunca" presenta la fórmula ideal $\mathrm{Al}_{4}\left(\mathrm{Si}_{4} \mathrm{O}_{10}\right)_{2}(\mathrm{OH})_{4}$. La sustitución $\mathrm{Si}$ por $\mathrm{Al}$ y $\mathrm{Al}$ por $\mathrm{Mg}$ conduce a una deficiencia de carga positiva que usualmente se compensa por:

- reemplazo de $\mathrm{O}^{-}$por $\mathrm{OH}^{-}$

- exceso de cationes en capa octaédrica (dioctaédrica $\rightarrow$ trioctaédrica) 
- adsorción de cationes en la superficie de las capas (responsable de la elevada CIC o capacidad de intercambio catiónico)

De este modo, una posible fórmula es $[\mathrm{Al}, \mathbf{M g}, \mathbf{F e}(\mathbf{I I I})]_{4}(\mathrm{Si}, \mathrm{Al})_{8} \mathbf{O}_{20}(\mathbf{O H})_{4} \cdot \mathbf{n} \mathbf{H}_{2} \mathrm{O}$ ] ó en forma reducida $(\mathrm{Al}, \mathbf{M g}, \mathbf{F e}(\mathrm{III}))_{2}(\mathrm{Si}, \mathbf{A l})_{4} \mathbf{O}_{10}(\mathrm{OH})_{2} \cdot \mathbf{n H}_{2} \mathrm{O}$.

La deficiencia de carga positiva conduce usualmente a la unión de bloques ( $\mathrm{T}$ O-T) por iones $\mathrm{K}$, así el comportamiento de la especie se aparta del correspondiente a la montmorillonita y genera la illita, cuya estructura resulta transicional a la de la muscovita, cuyo contenido en $\mathrm{K}$ es aún mayor (presentando asimismo una relación $\mathrm{Si} / \mathrm{Al}$ constante).

\section{7 .a.I. Arcillas Pilareadas}

Las arcillas pilareadas o "PILCs" son obtenidas por intercambio de los cationes interlaminares del alúminosilicato por polioxocationes metálicos voluminosos ya sean simples o mixtos, proceso seguido por una etapa de calcinación. De esta manera, por ej. el policatión $\left[\mathrm{AlO}_{4}(\mathrm{OH})_{24}\left(\mathrm{H}_{2} \mathrm{O}\right)_{12}\right]^{7+}\left(\mathrm{Al}_{13}\right)$ mostrado en la Fig.1.7, expande el espaciado interlaminar de la arcilla de partida, convirtiéndose en óxido metálico por dehidratación y deshidroxilación, generando materiales de estructura microporosa rígida, esto se logra por una calcinación a moderada temperatura (400 a $\left.500^{\circ} \mathrm{C}\right)$, estabilizando el catión polimérico, previniendo el colapso del espacio interlaminar y generando una estructura porosa estable. Este proceso se muestra en la Figura 1-11,

Los primeros estudios acerca de la preparación de sistemas pilareados datan de 30 años atrás. El pilareado de bentonitas con el policatión $\mathrm{Al}_{13}$ fue reportado por varios autores entre los años 1977 - 1993, propiciando nuevos desarrollos en el marco de la industria del petróleo [31]. Debido a la estabilidad térmica, características texturales y propiedades fisicoquímicas, los sistemas pilareados están siendo estudiados en numerosas aplicaciones, entre ellas la catálisis, ya sea como bulk o soporte de especies catalíticamente activas [32]. 


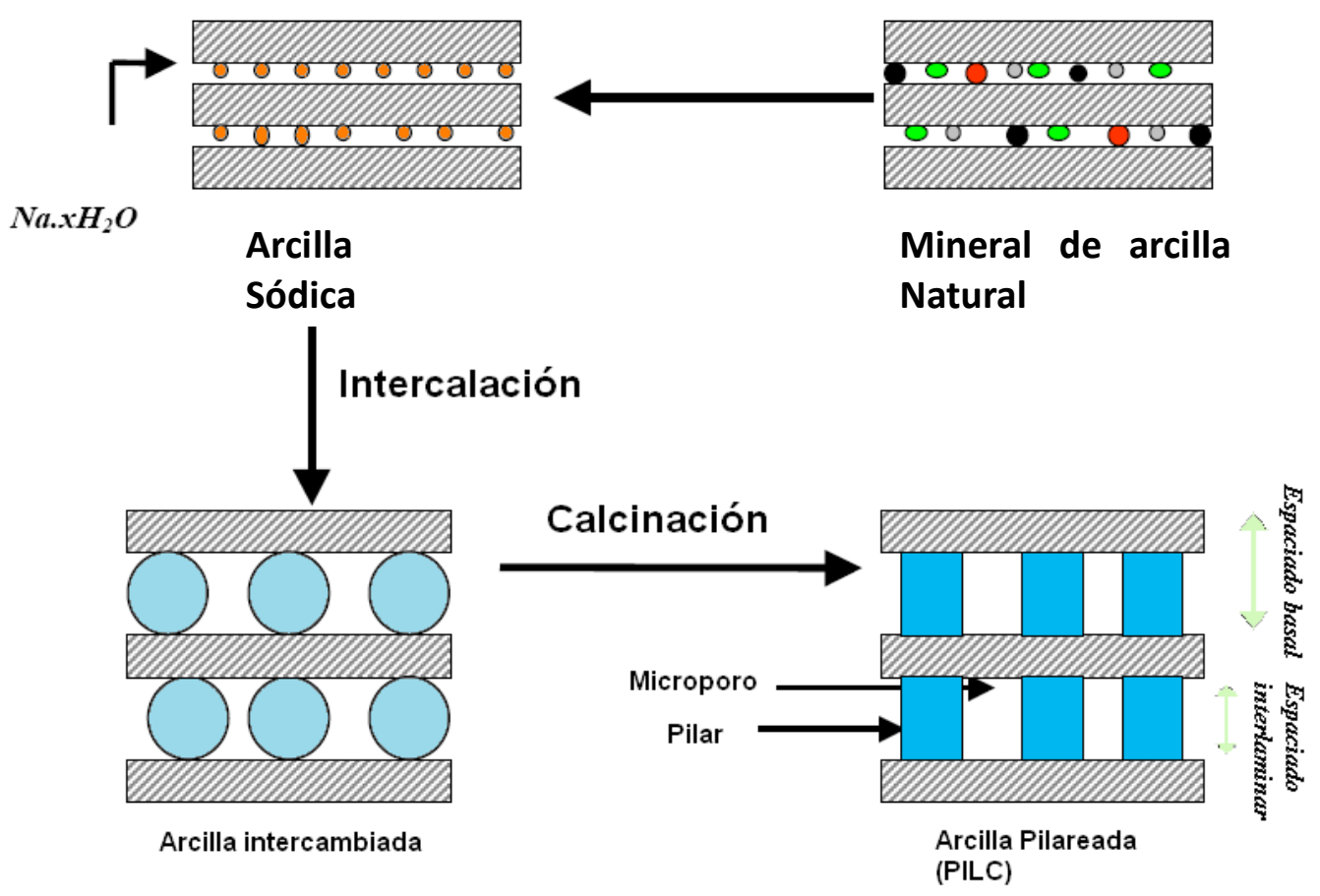

Figura 1-11: Representación esquemática del proceso de pilareado.

\section{7.a.II. Sistemas porosos heteroestructurados: PCH ("Porous clay heterostructured")}

La utilización de polímeros y surfactantes en el proceso de formación de especies porosas modifica las propiedades de las arcillas al intercalar moldes o "templates" removibles por tratamiento térmico [33]. Estas estrategias de síntesis conducen a una nueva ruta de obtención de estructuras porosas y de mayor área superficial que las arcillas naturales pilareadas.

Aprovechando la posibilidad de cambio del carácter hidrofílico que ofrece el espaciado interlaminar, se ha estudiado la utilización de numerosos surfactantes en la síntesis de sistemas PCH. El tratamiento de montmorillonitas con solución de bromuro de cetiltrimetilamonio (CTA-Br) genera un cambio del carácter hidrofílico a hidrofóbico. Khalaf y col. han encontrado que el espaciado interbasal de las muestras tratadas con CTA-Br y secadas, resultó de $21 \AA$ [34]. 
Dailey y Pinnavaia [35] fueron quienes estudiaron la intercalación de moléculas voluminosas orgánicas (amina) en arcillas y la posterior incorporación del tetraetilortosilicato (TEOS): $\mathrm{NH}_{2}-\left(\mathrm{CH}_{2}\right)_{3} \mathrm{Si}-\left(\mathrm{OCH}_{3}\right)_{3}$. De esta manera, la inserción de grupos Silanol "Si-OH" en silicatos laminares resulta un importante avance en la síntesis de derivados heteroestructurados.

La incorporación del catión voluminoso orgánico produce un incremento en el espaciado basal debido a la formación de una "bicapa" perpendicular a los planos del silicato. Al incorporar el TEOS, los grupos $\mathrm{Si}-\mathrm{OH}$ de la estructura de la arcilla reaccionan con el siloxano. La posterior calcinación genera un sistema pilareado con gran espaciado interbasal ( $25 \AA$ Á) y superficie específica $\left(\sim 800 \mathrm{~m}^{2} / \mathrm{g}\right)$. El proceso de formación de PCH se encuentra esquematizado en la Figura 1-12 [33].

Los sistemas $\mathrm{PCH}$ han resultado ser mesoestructuras que poseen la acidez intrínseca de una esmectita laminar. Por otra parte presentan un tamaño de poros comprendidos en la región entre supermicroporos y pequeños mesoporos, raramente observados. Esta condición conduce a un material de potencial aplicación en catálisis para reacciones selectivas en reemplazo de las zeolitas convencionales [36].

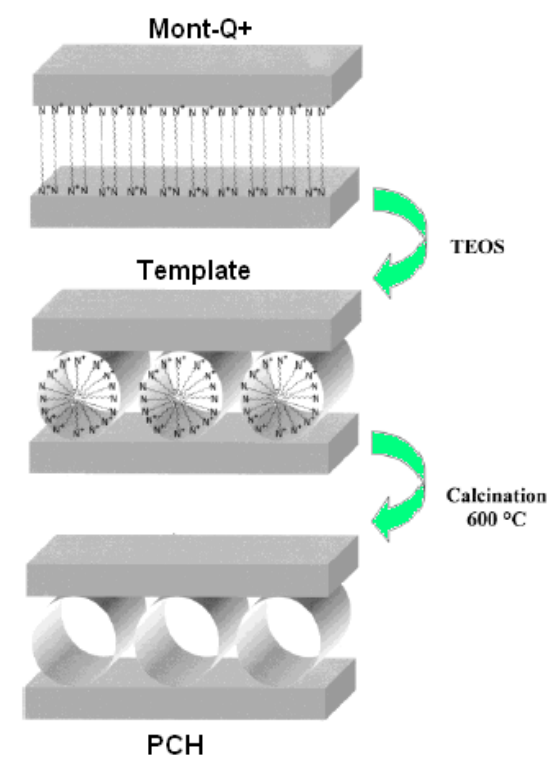

Figura 1-12: Representación esquemática del proceso de PCH. 


\subsection{Otras aplicaciones en catálisis heterogénea.}

\section{8.a. Oxidación selectiva de sulfuros arómáticos.}

Considerando la versatilidad de algunos catalizadores con propiedades ácidas y redox, propuestos para esta tesis, se decidió probar su efectividad en la reacción de oxidación selectiva de difenilsulfuro.

La oxidación de sulfuros aromáticos es interesante en la industria petroquímica particularmente en este siglo, debido a las estrictas regulaciones medioambientales que se legislan continuamente con el fin de limitar el contenido de azufre en los combustibles. Por otra parte, la oxidación selectiva de este tipo de compuestos también es interesante en el campo farmacéutico para producir sulfóxidos y/o sulfonas los que son intermediarios de medicinales básicos y que se aíslan fácilmente mediante operaciones de separación convencionales [37-40]. En el ámbito de la petroquímica, el proceso se denomina "desulfuración oxidativa" (ODS) y constituye una alternativa prometedora al de hidrodesulfurización (HDS) tradicional, ya que puede llevarse a cabo en fase líquida; a presión atmosférica; a bajas temperaturas; en ausencia de hidrógeno y usando peróxido de hidrógeno como agente oxidante, el que asegura una reacción no contaminante ya que el principal residuo de la reacción es agua; además es un proceso de alta selectividad y económico [37,41,42].

Entre los diversos catalizadores homogéneos y heterogéneos aplicados en procesos de ODS y activos en oxidaciones de sulfuros a sulfonas o sulfóxidos empleando peróxidos como oxidantes, los más usados son a base de oxo-especies de molibdeno (MoOx) soportados en varios óxidos, incluyendo alúmina, titania, sílice y sílice-alúmina [43-46]. En la literatura se ha reportado que la actividad hacia la eliminación de azufre depende de la presencia de especies de polimolibdatos, (hepta-y octamolibdatos); de la acidez del soporte y de la utilización de un disolvente aprótico polar [41-43].Teniendo en cuenta estos antecedentes, en esta tesis resultó interesante explorar la actividad ODS de algunos de los catalizadores preparados, especialmente aquellos a base de heteropolimolibdatos tipo Anderson soportados en arcillas modificadas, dada la escasa o nula información hallada en la literatura acerca de la aplicación en ODS de este particular y versátil sistema. 


\section{PARTE II:}

\section{EXPERIMENTAL}


Capítulo 2:

\section{MÉTODOS DE SÍNTESIS Y CARACTERIZACIÓN}


En el presente capítulo se hará referencia a los procesos de síntesis empleados, así como a las técnicas de análisis y caracterización empleadas. En relación a los materiales de origen natural (minerales de arcilla) se hizo uso de bentonita proporcionada por Empresa minera MINMARCO S.A. Esta especie mineral fue modificada químicamente. Asimismo se detallarán los ensayos catalíticos en los que fueron evaluados los materiales obtenidos.

\section{1 . Métodos de síntesis y caracterización}

\section{1.a. Síntesis de sales de heteropolioxoaniones con estructura tipo Anderson}

La síntesis general de la sal amoniacal de la fase de estructura tipo Anderson, $\left(\mathrm{NH}_{4}\right)_{\mathrm{n}}\left[\mathrm{XMo}_{6} \mathrm{O}_{24} \mathrm{H}_{6}\right] \cdot \mathrm{mH}_{2} \mathrm{O}$, con $\mathrm{X}(\mathrm{III})$, se lleva a cabo por precipitación a temperatura ambiente, a partir de las soluciones acuosas de las respectivas sales de los iones metálicos, siguiendo los métodos convencionales reportados [1-4]. Los mismos consisten básicamente en la mezcla, en proporciones estequiométricas y con agitación a temperatura ambiente, de soluciones acuosas de $\left(\mathrm{NH}_{4}\right)_{6}\left[\mathrm{Mo}_{7} \mathrm{O}_{24}\right] \cdot 4 \mathrm{H}_{2} \mathrm{O}$ (en adelante HMA) y soluciones de sales del heteroátomo metálico correspondiente. La precipitación se realiza en un medio ligeramente amoniacal, ajustando el $\mathrm{pH}$ en el rango 5-6, en el cual la especie es estable. Una vez obtenido el precipitado, se procede al filtrado y lavado con agua destilada.

Procedimiento: Para la obtención de la fase $\left(\mathrm{NH}_{4}\right)_{3}\left[\mathrm{RhMo}_{6} \mathrm{O}_{24} \mathrm{H}_{6}\right] \cdot 7 \mathrm{H}_{2} \mathrm{O}$ se procedió a la mezcla de $20 \mathrm{ml}$ de solución conteniendo $0.70 \mathrm{~g}$ de HMA (previamente calentada a $\mathrm{T}<80^{\circ} \mathrm{C}$ para favorecer la disolución) y $10 \mathrm{ml}$ de solución acuosa con la cantidad estequiométrica de $\mathrm{RhCl}_{3} \cdot \mathrm{H}_{2} \mathrm{O}$. El pH se reguló en 5-6 con solución de $\mathrm{NH}_{4} \mathrm{Cl}$. La solución resultante se mantuvo varios días a temperatura ambiente hasta observar la aparición del precipitado correspondiente, el mismo se filtró, lavó, se dejó secar al aire y luego en estufa a $80^{\circ} \mathrm{C}$. [5-6]. 


\section{1.a.I. Caracterización del Heteropolioxoanión tipo Anderson de Rh(III):}

Esta fase fue caracterizada mediante las siguientes técnicas:

- Difracción por Rayos X (método de polvo) (DRX).

- Microscopía electrónica de barrido (SEM) complementada con análisis químico semicuantitativo por energía dispersiva de RX (EDS).

- Espectroscopía infrarroja con transformada de Fourier (FTIR).

- Espectroscopía mediante Microanálisis Raman.

- Espectroscopía de reflectancia difusa UV-Visible (DRS).

- Espectroscopía fotoelectrónica de superficie por RX (XPS).

- Análisis térmicos en diferentes atmósferas:

Análisis termogravimétrico (TGA) y térmico diferencial (DTA).

Análisis térmico en atmósfera reductora (reducción a temp.programada TPR)

- Análisis químico por absorción atómica (AAS).

\subsection{Preparación y caracterización de Soportes}

La preparación de catalizadores por intercambio iónico, es un ejemplo típico de impregnación con interacción. Este método genera una fuerte interacción precursorsoporte, conduciendo a altos niveles de dispersión de la fase metálica activa. La técnica consiste en intercambiar un ión ligado al soporte por otro que contiene al precursor de la fase catalítica, presente en la solución de impregnación. Muchos sólidos se comportan como intercambiadores naturales (zeolitas, resinas de intercambio), otros presentan un carácter anfótero, como ocurre con algunos soportes cuya superficie es portadora de grupos $\mathrm{OH}$. La variación en la carga superficial puede describirse por la siguiente ecuación (1):

$$
\mathrm{Z}^{-} \mathrm{O}^{-}+\mathrm{H}^{+} \leftrightarrow \mathrm{Z}-\mathrm{OH} \leftrightarrow \mathrm{Z}^{+}+\mathrm{OH}^{-}
$$

Como se deduce de la ecuación, si se agrega un ácido en el medio, la reacción se desplaza hacia la derecha, dando como resultado un sólido cuya superficie está formada por especies $Z^{+}$, esto es un intercambiador aniónico. Por el contrario, si se agrega una base, la reacción se desplaza hacia la izquierda, la superficie del sólido se encuentra como Z-O', y en este caso actúa como intercambiador catiónico. Estos grupos 
superficiales cargados son los sitios de adsorción del ión activo en el intercambio y su concentración determina la cantidad de especies positivas o negativas que pueden ser quimisorbidas sobre la superficie del sólido. Existe un pH para el cual la resultante de cargas sobre la superficie es nula; esto es, la cantidad de grupos superficiales cargados positivamente, del tipo $\mathrm{Z}^{+}$, es igual a la cantidad de grupos cargados negativamente, $\mathrm{Z}$ $\mathrm{O}$. A este valor de $\mathrm{pH}$ se lo conoce como punto isoeléctrico (pI). En la tabla 2-I se dan los puntos isoeléctricos de sólidos de interés en catálisis. Así, a un valor de $\mathrm{pH}>\mathrm{pI}$, el soporte se comporta cómo intercambiador catiónico y a un $\mathrm{pH}<\mathrm{pI}$, como un intercambiador aniónico. Así, por ejemplo, el punto isoeléctrico de la $\mathrm{SiO}_{2}$ es 2, lo que significa que a $\mathrm{pH}>2$ su superficie tiene mayoritariamente cargas negativas, sin embargo esto llega a ser significativo a $\mathrm{pH}>5$.

Tabla 2-I. Punto isoeléctrico de sólidos de interés en catálisis.

\begin{tabular}{ccc}
\hline Sólido & p.I. & Tipo de intercambio \\
\hline $\mathrm{Sb}_{2} \mathrm{O}_{5}$ & $<0,4$ & catiónico \\
$\mathrm{WO}_{3}$ & $<0,5$ & catiónico \\
$\mathrm{SiO}_{2}$ & $1-2$ & catiónico \\
$\mathrm{MnO}_{2}$ & $3,9-4,5$ & aniónico o catiónico \\
$\mathrm{TiO}_{2}$ & 6 & aniónico o catiónico \\
$\mathrm{ZrO}_{2}$ & 6,7 & aniónico o catiónico \\
$\mathrm{CeO}_{2}$ & 6,8 & aniónico o catiónico \\
$\mathrm{Al}_{2} \mathrm{O}_{3}$ & $7-9$ & aniónico \\
$\mathrm{ZnO}$ & $8,7-9,7$ & aniónico \\
$\mathrm{MgO}$ & $12,1-12,7$ & aniónico \\
\hline
\end{tabular}

Por otro lado, a pH > 11 ocurre una disolución significativa de $\mathrm{SiO}_{2}$. De este modo, la $\mathrm{SiO}_{2}$ es un excelente intercambiador catiónico a pH entre 9 y 11 [7,8].

\section{2.a. Preparación de soportes a base de Sílice.}

Se seleccionaron dos tipos de sílica- gel comercial con diferentes características texturales: aerosil Degussa y Kieselgel - Merck. 
Con el objeto de acondicionar un soporte a base de sílica, se sometió el aerosil Degussa a un procedimiento publicado por Dalmon y Martín [9]. 20 g del material fueron tratados con $100 \mathrm{ml}$ de solución acuosa de $\mathrm{NH}_{4}(\mathrm{OH})$ alcanzando un $\mathrm{pH}=10.6$, para mejorar las propiedades hidrofílicas y texturales. Se mantuvo el sistema a $25^{\circ} \mathrm{C}$ en un baño termostatizado durante 30 minutos. La siguiente ecuación (2) representa la reacción que ocurre en esta etapa:

$$
\mathrm{Si}-\mathrm{OH}+\mathrm{NH}_{4}^{+} \leftrightarrow\left(\mathrm{NH}_{4}\right)^{+}(\equiv \mathrm{Si}-\mathrm{O})^{-}+\mathrm{H}^{+}
$$

El sólido se separó de la solución por filtración y se secó en estufa durante 24 h a $105^{\circ} \mathrm{C}$.

A partir del tratamiento a elevado $\mathrm{pH}$, la superficie de esta especie está compuesta básicamente por grupos "silanoles" $\mathrm{SiO}_{2} . \mathrm{OH}$ adquiriendo una gran concentración de grupos oxidrilos y aumentando la superficie específica, volumen y tamaño de poros.

Las características texturales se estudiaron por el método BET, empleando un equipo Micromeritics ASAP 2020. Asimismo estas muestras se caracterizaron por difracción de polvos por Rayos X con un difractómetro Philips PW 1714 (radiación Cu $\mathrm{K} \alpha$ y filtro de $\mathrm{Ni}$ ).

\section{2.b. Preparación de soportes de Alúmina}

Se procedió a la calcinación de un precursor de alúmina $[\mathrm{Al}(\mathrm{OH}) \mathrm{n}]$ a diferentes temperaturas para obtener un soporte de propiedades texturales adecuadas para su impregnación. Se seleccionaron dos muestras denominadas (A) y (AI) obtenidas por tratamiento del precursor de alúmina a $550^{\circ} \mathrm{C}$ y $480^{\circ} \mathrm{C}$ respectivamente de acuerdo a las mejores características texturales encontradas por el método BET, empleando un equipo Micromeritics ASAP 2020.

Para analizar el efecto del soporte se seleccionaron además otros dos óxidos de $\mathrm{Al}(\mathrm{III})$ de fase gamma, de origen comercial con diferentes propiedades texturales: $\gamma$ $\mathrm{Al}_{2} \mathrm{O}_{3}$ Esferalite denominadas $\mathrm{E}(\mathrm{I})$ y E(II). 
Todas las especies se caracterizaron por difracción de polvos por Rayos X con un difractómetro Philips PW 1714 (radiación $\mathrm{Cu} \mathrm{K} \alpha$ y filtro de Ni).

\section{2.c. Preparación de soportes a base de minerales de arcilla.}

\section{Etapa de purificación de la arcilla}

Se utilizó como material de partida un mineral de arcilla tipo "bentonita", de procedencia Argentina (proporcionada por Empresa minera MINMARCO S.A.). La misma fue caracterizada, tratada por el método de Stokes, a fin de separar las partículas por su tamaño en función de la velocidad de sedimentación de las mismas en un campo gravitacional. Esta técnica nos permite obtener solo la fracción granulométrica de partículas menores a $2 \mu \mathrm{m}$, que corresponde a la fracción arcilla eliminando impurezas de mayor tamaño (cuarzo, feldespatos, calcita, etc.) presentes en la muestra natural. Desde el punto de vista práctico el método de purificación consiste en suspender una cantidad de arcilla natural en cierto volumen de agua desmineralizada, luego se somete a una buena agitación hasta lograr una suspensión homogénea [10-12].

Para proceder a la separación granulométrica según el método mencionado, se suspendieron aproximadamente $40 \mathrm{~g}$ de arcilla en 2 litros de agua desmineralizada, trabajando en probeta de $50 \mathrm{~cm}$ de altura. Se agitó vigorosamente y después de un mínimo de 16 horas se recogieron los primeros $20 \mathrm{~cm}$ de suspensión, asegurando así la obtención de fracciones de mineral de tamaño menor de $2 \mu \mathrm{m}$. Se completó la probeta con agua desmineralizada y se repitió el proceso hasta que la fracción a recoger estuviera lo suficientemente clara. La fracción recogida fue separada por centrifugación y secada.

\section{2.c.I. Etapa de "pilareado" (PILC)}

La preparación de las arcillas pilareadas consta básicamente de cuatro etapas:

(i) Preparación de la solución "pilareante".

(ii) Tratamiento de la arcilla para su transformación en la forma sódica.

(iii) Tratamiento de la arcilla sódica con la solución pilareante.

(iv) Calcinación del material sólido obtenido. 
Para iniciar el proceso de pilareado, es necesario pre-tratar la arcilla purificada de manera de facilitar la incorporación del agente pilareante. Para ello se realizó un intercambio catiónico mediante suspensión de arcilla en solución salina en una relación de $2.00 \mathrm{~g}$ de arcilla en $250 \mathrm{ml}$ de solución de $\mathrm{NaCl}(1 \mathrm{M})$ durante 24 hs., bajo agitación constante a temperatura ambiente. La suspensión fue centrifugada y lavada sucesivamente hasta prueba negativa de $\mathrm{Cl}^{-}$con solución de $\mathrm{AgNO}_{3}$. Finalmente la arcilla- $\mathrm{Na}^{+}$fue secada al aire y posteriormente en estufa a $105^{\circ} \mathrm{C}[13,14]$.

La solución pilareante, conteniendo el oligómero $\mathrm{Al}_{13}$, se obtuvo a partir de la técnica de hidrólisis controlada del $\mathrm{AlCl}_{3}$. Realizada la hidrólisis, el oligómero se dejó madurar por 4 hs. a temperatura ambiente.

Para el proceso convencional de pilareado con policatión, se partió de una suspensión acuosa de $2.00 \mathrm{~g}$ de arcilla sódica que fue tratada lentamente y con agitación constante (a temperatura ambiente), con el hidrolizado de $\mathrm{Al}_{13}$ manteniendo en todos los casos una relación $[\mathrm{Al}(\mathrm{III})(\mathrm{mol}) /$ arcilla $(\mathrm{g})=4.16][12,15]$. Finalizado el agregado del policatión, se dejó madurar la suspensión durante 72 hs. Posteriormente, se separó la solución por centrifugación y se procedió a sucesivos lavados con agua desmineralizada hasta prueba negativa de $\mathrm{Cl}^{-}$con solución de $\mathrm{AgNO}_{3}$.

El material obtenido se dejó secar al aire, luego en estufa por 24 hs. y finalmente se procedió a la calcinación a $500^{\circ} \mathrm{C}$ por $5 \mathrm{hs}$. Luego del tratamiento térmico, el oligómero $\mathrm{Al}_{13}$ interlaminar, se transforma en una especie oxídica nanoscópica que expande la distancia entre los planos basales del alúmino-silicato generando el nuevo material "pilareado" que denominamos PILC [16,17,18].

\section{2.c.II. Síntesis de materiales porosos heteroestructurados (porous clay}

\section{heterostructures: (PCH).}

De la misma manera que en la síntesis de los sistemas pilareados, se utilizó la arcilla bentonítica proporcionada por la empresa minera MINMARCO S. A. purificada por el método de Stokes.

La preparación de los materiales PCH consta de 3 etapas: 
(i) Funcionalización de la especie bentonítica sódica: Generación de una especie bentonítica catiónica $\left(\mathrm{B}^{+}\right)$.

(ii) Funcionalización de la especie bentonítica catiónica $\left(\mathrm{B}^{+}\right)$: Generación de la especie porosa heteroestructurada.

(iii) Calcinación.

En la primera etapa se generó la especie bentonítica catiónica $\left(\mathrm{B}^{+}\right)$, mediante tratamiento de la arcilla sódica, con el surfactante bromuro de hexadeciltrimetilamonio [Sigma-Aldrich] (HDTMA-Br). Para ello, a una suspensión arcilla sódica (2.00g) se adicionó una solución $0.5 \mathrm{mM}$ de HDTMA-Br (relación Arcilla/HDTMA= 1.5). La suspensión se dejó en agitación 24 hs. a $50^{\circ} \mathrm{C}$, se separó por centrifugación y se lavó sucesivamente hasta alcanzar $\mathrm{pH}=7$.

En la segunda etapa se obtuvo la especie porosa heteroestructurada, haciendo reaccionar la arcilla- $\mathrm{B}^{+}$con una mezcla de dodecilamina (DDA) y tetraetoxiortosilicato (TEOS) [ambos Aldrich] en relación B ${ }^{+} / \mathrm{DDA} / \mathrm{TEOS}, 1 / 20 / 150$. La suspensión se agitó durante 4 hs. a temperatura ambiente. El sólido se separó por centrifugación y se dejó secar al aire. La intercalación del surfactante catiónico y una amina neutra entre las láminas de la arcilla, produce una micela estructural. La posterior adición del precursor silíceo (TEOS) provoca una polimerización "in situ” generando pilares de sílica alrededor de la micela estructural formada en la etapa anterior. Figura 1-12.

Finalmente se calcinó a $550^{\circ} \mathrm{C}$ durante 6 hs., conduciendo a la remoción de los "moldes" o "templates" orgánicos para dar lugar a materiales, prevalentemente microporosos, de alta superficie específica $[19,20]$.

\section{2.c.III. Funcionalización adicional de la superficie de arcillas modificadas químicamente (PILC y PCH) mediante el empleo de surfactantes.}

Con el objetivo de utilizar soportes a base de minerales de arcilla, tratados según la descripción del ítem 2.2.c (PILC y PCH), se realizó una funcionalización extra de los mismos para lograr la adsorción de iso y heteropolianiones en la superficie de estos materiales. Se utilizó como sistema funcionalizante un órgano-silano de amina: el 3-aminopropiltrietoxisilano (F). 
La funcionalización de los silanoles $(\mathrm{SiOH})$ superficiales, se produce usando $(\mathrm{F})$, según se muestra en la siguiente ecuación (3):

\section{$3 \mathrm{SiOH}+\mathrm{H}_{2} \mathrm{~N}\left(\mathrm{CH}_{2}\right)_{3} \mathrm{Si}(\mathrm{OEt})_{3} \rightarrow(\mathrm{Si}-\mathrm{O})_{3} \mathrm{Si}\left(\mathrm{CH}_{2}\right)_{3} \mathrm{NH}_{2}+3 \mathrm{EtOH}$}

El mecanismo implica la interacción de los grupos etoxi con tres grupos silanoles de la superficie de la arcilla modificada, generándose un grupo amino terminal en dicha superficie.

El método se inició con un pretratamiento de los materiales a los fines de favorecer la disponibilidad de los grupos silanoles. Para ello se suspendió el material de partida (PILC y PCH) en una mezcla agua/etanol (50:50) durante 24 hs. a temperatura ambiente. Posteriormente el material fue separado y secado en estufa por 24 hs. El proceso de funcionalización, llevado a cabo a continuación, consistió en la suspensión de $1 \mathrm{~g}$ de PCH ó PILC en tolueno y la adición del surfactante correspondiente, en función del peso molecular del funcionalizante y el área superficial del material utilizado $\left(\mathrm{S}_{\mathrm{BET}} \mathrm{PILC}=128 \mathrm{~m}^{2} / \mathrm{g}\right.$ y $\left.\mathrm{S}_{\mathrm{BET}} \mathrm{PCH}=579 \mathrm{~m}^{2} / \mathrm{g}\right)$. El funcionalizante utilizado fue el:

\section{(3-aminopropil)-trimetoxisilano (F)}

Se procedió a la agitación de la suspensión resultante, la que se llevó a cabo en un recipiente cerrado por 12 hs., a temperatura ambiente. Posteriormente se continuó la agitación a mayor temperatura $\left(70^{\circ} \mathrm{C}\right)$ manteniendo el sistema en esas condiciones por otras 12 hs. Finalmente la suspensión fue filtrada y lavada con tolueno y acetona. El sólido fue secado al vacío hasta peso constante [21,22]. 


\section{2.c.IV. Caracterización de las arcillas bentoniticas puras y modificadas.}

Básicamente la caracterización de estos sistemas se realizó mediante las técnicas ya mencionadas para los sistemas oxídicos descriptos. Asimismo se utilizaron otras técnicas complementarias.

- Difracción de polvos por Rayos X (DRX). Eventualmente realización de medidas "in situ" en atmósfera variable a temperatura programada.

- Microscopía electrónica de barrido, SEM y Análisis químico semicuantitativo EDS.

- Análisis químico cuantitativo por ICP.

- Parámetros texturales y medidas de superficie mediante BET.

- Espectroscopía vibracional.

- Espectroscopía infrarroja con transformada de Fourier (FT-IR).

- Espectroscopía por Microanálisis Raman.

- Análisis térmicos.

- Análisis termogravimétrico (TGA) y diferencial en atmósfera inerte (DTA).

- Análisis de reducción a temperatura programada (TPR).

- Análisis de sitios ácidos por el método TPSR (Reacción Superficial a temperatura programada)

- Análisis químico por absorción atómica (AAS).

- Estudio de la capacidad de intercambio catiónico.

- Adicionalmente se realizó el estudio de la capacidad de hidroadsorción de todos los soportes mediante la técnica denominada de "Laser Speckle Dinámico (DSL)" cuya descripción se encuentra en el capítulo 3.

\subsection{Métodos de preparación y caracterización de catalizadores}

En función a la descripción precedente referida a diferentes sistemas oxídicos sintéticos y/o naturales de diferente complejidad, y considerando la potencialidad de los mismos en el campo de la catálisis, se procederá a la descripción de los métodos de 
preparación y caracterización de los catalizadores obtenidos utilizando las especies anteriores como precursores catalíticos y/o soportes.

\section{3.a. Preparación de catalizadores a base del heteropolioxoanión Anderson} RhMo6 soportados sobre sílice.

Se prepararon diferentes catalizadores conteniendo la fase de Anderson $\left(\mathrm{NH}_{4}\right)_{3}\left[\mathrm{RhMo}_{6} \mathrm{O}_{24} \mathrm{H}_{6}\right] \cdot 7 \mathrm{H}_{2} \mathrm{O}$ en adelante $\left(\mathrm{RhMo}_{6}\right)$, los que se denominaron de la siguiente manera:

- $\boldsymbol{R h M \boldsymbol { h } _ { 6 }}(\boldsymbol{D})$ (en $\mathrm{SiO}_{2}$ preparada según Dalmon y Martín [7] de área superficial: $180 \mathrm{~m}^{2} / \mathrm{g}$, volúmen de poros: $0.76 \mathrm{~cm}^{3} / \mathrm{g}$ y tamaño de partícula: $200 \mu \mathrm{m}$.)

- $\boldsymbol{R} \boldsymbol{h M o} \boldsymbol{o}_{\boldsymbol{\sigma}}(\boldsymbol{K})$ (en $\mathrm{SiO}_{2}$ comercial Kieselgel -Merck (K) de área superficial: 225 $\mathrm{m}^{2} / \mathrm{g}$, volúmen de poros: $0.61 \mathrm{~cm}^{3} / \mathrm{g}$ y tamaño de partícula: $200 \mu \mathrm{m}$.)

La preparación de los catalizadores en base al heteropolianión tipo Anderson fue llevada a cabo por impregnación en equilibrio de $\mathrm{SiO}_{2}$. Se utilizaron soluciones acuosas de las respectivas sales de amonio. La impregnación fue llevada a cabo utilizando un volumen total de $6 \mathrm{~cm}^{3}$ de solución impregnante por cada $0.5 \mathrm{~g}$ de Sílice. La concentración de la solución fue de $10 \mathrm{mg} \mathrm{Mo} / \mathrm{cm}^{3}$.

Luego del proceso de impregnación, el residuo sólido fue separado por centrifugación y secado en estufa a $80^{\circ} \mathrm{C}$. La etapa de calcinación fue evitada para prevenir el colapso de la estructura y formación de otras fases oxídicas.

\section{3.b. Preparación de los catalizadores a base de heteropolioxoaniones tipo} Anderson soportados sobre $\gamma-\mathrm{Al}_{2} \mathrm{O}_{3}$.

Se prepararon diferentes catalizadores conteniendo $\left(\mathrm{RhMo}_{6}\right)$, los que se denominaron de la siguiente manera: 
- $\boldsymbol{R h M \boldsymbol { h } _ { 6 }}(\boldsymbol{A})\left(\mathrm{en} \gamma-\mathrm{Al}_{2} \mathrm{O}_{3}\right.$ preparada por calc. a $500{ }^{\circ} \mathrm{C}$ de área superficial: 150 $\mathrm{m}^{2} / \mathrm{g}$, volúmen de poros: $0.23 \mathrm{~cm}^{3} / \mathrm{g}$ y tamaño de partícula: $200 \mu \mathrm{m}$ ).

- $\boldsymbol{R h M o}_{\boldsymbol{\sigma}}(\boldsymbol{E I})\left(\right.$ en $\gamma-\mathrm{Al}_{2} \mathrm{O}_{3}$ comercial esferalite (I) de área superficial: $236 \mathrm{~m}^{2} / \mathrm{g}$, volúmen de poros: $0.65 \mathrm{~cm}^{3} / \mathrm{g}$ y tamaño de partícula: $\left.200 \mu \mathrm{m}\right)$.

- $\boldsymbol{R h M o}_{\boldsymbol{6}}(\boldsymbol{E I I})$ (en $\gamma-\mathrm{Al}_{2} \mathrm{O}_{3}$ comercial esferalite (II) de área superficial: $328 \mathrm{~m}^{2} / \mathrm{g}$, volúmen de poros: $0.36 \mathrm{~cm}^{3} / \mathrm{g}$ y tamaño de partícula: $\left.200 \mu \mathrm{m}\right)$.

La preparación de los catalizadores en base al heteropolianión tipo Anderson fue llevada a cabo por co-impregnación en equilibrio de $\gamma-\mathrm{Al}_{2} \mathrm{O}_{3}$. Se utilizaron soluciones acuosas de las respectivas sales de amonio. La impregnación fue llevada a cabo utilizando un volumen total de $6 \mathrm{~cm}^{3}$ de solución impregnante por cada $0.5 \mathrm{~g}$ de

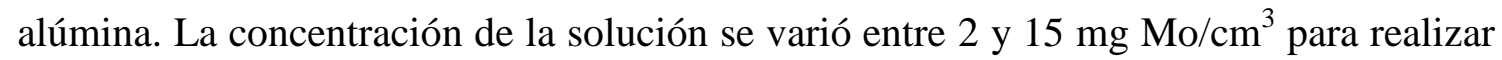
una isoterma de adsorción.

Luego del proceso de impregnación, el residuo sólido fue separado por centrifugación y secado en estufa a $80^{\circ} \mathrm{C}$. La etapa de calcinación fue evitada para prevenir el colapso de la estructura y formación de otras fases oxídicas.

\section{3.b.I. Preparación de catalizadores RhMo soportados sobre alúminas por métodos convencionales.}

Con fines comparativos se prepararon dos soluciones acuosas conteniendo (a) heptamolibdato de amonio: $\left(\mathrm{NH}_{4}\right)_{6}\left[\mathrm{Mo}_{7} \mathrm{O}_{24}\right] .4 \mathrm{H}_{2} \mathrm{O}$ y (b) $\mathrm{RhCl}_{3} \cdot 6 \mathrm{H}_{2} \mathrm{O}$ para obtener un catalizador de $1 \%$ de Rh y $6 \%$ de Mo, en adelante (RhMo), preparado por impregnación sucesiva a exceso de volumen de poros en las diferentes alúminas. El soporte fue impregnado con la solución de cloruro de $\mathrm{Rh}$, secado en estufa. Posteriormente el sólido fue impregnado con la solución del heptamolibdato de amonio y secado en estufa [23], los que se denominaron de la siguiente manera:

- $\boldsymbol{R} \boldsymbol{h M o} / \boldsymbol{A}$ (en $\gamma-\mathrm{Al}_{2} \mathrm{O}_{3}$ preparada por calc. a $500{ }^{\circ} \mathrm{C}$ de área superficial: $150 \mathrm{~m}^{2} / \mathrm{g}$, volúmen de poros: $0.23 \mathrm{~cm}^{3} / \mathrm{g}$ y tamaño de partícula: $200 \mu \mathrm{m}$.) 
- $\boldsymbol{R h M o / E I ~ ( e n ~} \gamma-\mathrm{Al}_{2} \mathrm{O}_{3}$ comercial esferalite (I) de área superficial: $226 \mathrm{~m}^{2} / \mathrm{g}$, volúmen de poros: $0.65 \mathrm{~cm}^{3} / \mathrm{g}$ y tamaño de partícula: $200 \mu \mathrm{m}$.)

- $\boldsymbol{R h M o / E I I ~ ( e n ~} \gamma-\mathrm{Al}_{2} \mathrm{O}_{3}$ comercial esferalite (II) de área superficial: $328 \mathrm{~m}^{2} / \mathrm{g}$, volúmen de poros: $0.36 \mathrm{~cm}^{3} / \mathrm{g}$ y tamaño de partícula: $200 \mu \mathrm{m}$.)

\section{3.c. Preparación de catalizadores utilizando soportes a base de arcillas naturales modificadas químicamente PILC y PCH sin tratar y funcionalizados para su estudio comparativo.}

Se prepararon los siguientes catalizadores soportados en bentonita modificada y posteriormente funcionalizada: $\mathrm{RhMo}_{6} / \mathrm{PCH}, \mathrm{RhMo}_{6} / \mathrm{PCH}-\mathrm{F} ; \mathrm{RhMo}_{6} / \mathrm{PILC}$ y $\mathrm{RhMo}_{6}$ /PILC-F, siguiendo el método de impregnación en equilibrio a exceso de volumen de poros sobre los distintos soportes. Para ello se utilizaron soluciones acuosas de $\left(\mathrm{NH}_{4}\right)_{3}\left[\mathrm{RhMo}_{6} \mathrm{O}_{24} \mathrm{H}_{6}\right] \cdot 7 \mathrm{H}_{2} \mathrm{O}$ conteniendo $10 \mathrm{mg} \mathrm{Mo} / \mathrm{cm}^{3}$. En todos los casos se utilizaron $250 \mathrm{mg}$ de soporte y $3 \mathrm{~cm}^{3}$ de solución impregnante. El contenido de Mo adsorbido fue calculado por balance de masas a partir de la medida del contenido de Mo en soluciones iniciales y finales por Absorción Atómica.

Con fines comparativos se prepararon catalizadores a base de fase de Anderson disponibles en nuestro laboratorio de $\mathrm{Co}(\mathrm{III}) \mathrm{Mo}_{6} / \mathrm{PCH}-\mathrm{F}$ y $\mathrm{Co}(\mathrm{III})_{2} \mathrm{Mo}_{10} / \mathrm{PCH}-\mathrm{F}$ [4].

Se empleó el método de impregnación en equilibrio en exceso de volumen de poros de los materiales PCH funcionalizados. Para ello se utilizaron soluciones acuosas de $15 \mathrm{mgMo} / \mathrm{ml}$ a partir de $\left(\mathrm{NH}_{4}\right)_{3}\left[\mathrm{MMo}_{6} \mathrm{O}_{24} \mathrm{H}_{6}\right], \mathrm{M}=\mathrm{Co}$ (III) (en adelante: $\mathrm{CoMo}_{6}$ ) y $\left(\mathrm{NH}_{4}\right)_{6}\left[\mathrm{Co}_{2} \mathrm{Mo}_{10} \mathrm{H}_{4} \mathrm{O}_{38}\right]$ en adelante $\left(\mathrm{Co}_{2} \mathrm{Mo}_{10}\right)$. En todos los casos se utilizaron $250 \mathrm{mg}$ de soporte y $3 \mathrm{~cm}^{3}$ de solución impregnante.

\subsection{Técnicas Instrumentales de Caracterización}

\section{4.a. Análisis químico por ICP.AES}

La técnica ICP.AES (Inductively Coupled Plasma- Atomic Emission Spectroscopy) es una de las técnicas cuantitativas disponibles en espectroscopia atómica analítica. Es una forma especial de la espectrometría por emisión. 
El plasma consiste en un gas altamente ionizado eléctricamente neutro, formado por iones, electrones y átomos. En la naturaleza se puede encontrar plasma en el sol, en los rayos y en las auroras boreales. La energía que genera un plasma de análisis químico se deriva de un campo eléctrico o magnético, que no "quema". Este es generado por inducción de energía perteneciente a ondas de radio. La mayoría de los plasmas analíticos operan con argón o helio puro, lo que hace que no se genere combustión.

Los plasmas se caracterizan por sus altas temperaturas de análisis, así como por presentar densidades iónicas y electrónicas elevadas. Aquellos utilizados en análisis cuantitativo normalmente operan a temperaturas entre 600 y $8000^{\circ} \mathrm{K}$ [24].

La ventaja del análisis ICP es su límite muy bajo de detección. El método ICP es especialmente apropiado para la determinación de concentraciones pequeñas (traza) y de elementos difíciles a atomizar como los elementos de las tierras raras (REE), los elementos alcalinotérreos, B, Si, U y Ta. Estos elementos, caracterizados por una afinidad alta respecto a oxígeno, introducidos en una llama de absorción atómica tienden a formar radicales de óxido o de hidróxido, que no se disocian más. A las altas temperaturas de ionización establecidas en el plasma no ocurre esto y se logra la atomización o la ionización de los elementos. Otras ventajas del método ICP son la determinación simultánea de varios elementos y su susceptibilidad baja con respecto a interferencias químicas.

El Análisis por ICP-ES se realizó mediante $\mathrm{LiBO}_{2} / \mathrm{Li}_{2} \mathrm{~B}_{4} \mathrm{O}_{7}$ Fusión (ACME).

\section{4.b. Análisis químico por absorción atómica (AAS)}

\section{4.b.I. Consideraciones generales}

La espectroscopía Atómica es un método instrumental que se basa en la absorción, emisión y fluorescencia de radiación electromagnética por partículas atómicas. Se emplean principalmente radiaciones del espectro ultravioleta (UV) y visible, y rayos $\mathrm{X}$. 
Para obtener un espectro de radiaciones de longitudes de ondas específicas, o rangos pequeños en lugar de bandas, es necesario que las partículas de la muestra se descompongan en partículas elementales gaseosas, proceso conocido como atomización. La técnica de atomización más usada es la de absorción atómica con llama, que nebuliza la muestra y luego la disemina en forma de aerosol dentro de una llama de aire-acetileno u óxido nitroso-acetileno [25].

Entre las ventajas de este método se cuentan: gran especificidad, amplio campo de aplicación en la química analítica, excelente sensibilidad a pequeñas concentraciones del orden de las ppm, rapidez en la determinación y gran selectividad.

Dentro de este método instrumental pueden emplearse tipos de espectroscopía como emisión atómica (la muestra es atomizada en la llama y actúa como fuente de radiación) y absorción atómica (donde la muestra se atomiza en la llama pero existe una radiación externa que produce la excitación de los electrones al estado excitado).

Aplicación: La Espectroscopía de Absorción Atómica constituye un método sensible para la cuantificación de más de 60 elementos. Pueden analizarse elementos metálicos como aluminio, calcio, cadmio, cromo, litio, hierro, magnesio, potasio y sodio, en un orden de detección entre las $3 \times 10^{-4} \mathrm{ppm}$ a las 20 ppm.

\section{4.b.II. Equipamiento}

El análisis químico de los compuestos disueltos en las soluciones de impregnación se llevó a cabo con un equipo Varian AA 240.

La concentración de Mo en los catalizadores soportados fue analizada en las soluciones iniciales $\left(\mathrm{C}_{\mathrm{i}}\right)$ y finales $\left(\mathrm{C}_{\mathrm{f}}\right)$ mediante espectrometría de absorción atómica. La concentración de Mo adsorbida $\left(\mathrm{C}_{\mathrm{ad}}\right)$, fue calculada mediante un balance de masas, a partir de las concentraciones iniciales y finales, teniendo en cuenta el volumen de la solución impregnada y la masa de soporte de acuerdo la siguiente expresión (4): 


$$
C_{a d}=\left\{\frac{\left(C_{i}-C_{f}\right) \times V}{m}\right\} \times 100
$$

Donde,

$\mathrm{C}_{\mathrm{ad}}=$ Concentración de Mo adsorbido ( $\mathrm{g} \mathrm{Mo} / \mathrm{g}$ de soporte).

$\mathrm{C}_{\mathrm{i}}=$ Concentración de Mo inicial $\left(\mathrm{g} \mathrm{Mo} / \mathrm{cm}^{3}\right)$.

$\mathrm{C}_{\mathrm{f}}=$ Concentración de Mo final.

$\mathrm{V}=$ volumen inicial de solución impregnante $\left(\mathrm{cm}^{3}\right)$.

$\mathrm{m}=$ masa de soporte $\left(\mathrm{g}\right.$ de $\left.\gamma-\mathrm{Al}_{2} \mathrm{O}_{3}\right)$.

La concentración de Mo adsorbido ( $\left.\mathrm{C}_{\mathrm{ad}} \mathrm{Mo}\right)$, [expresado como (\%) de monocapa o bien como g Mo/ $100 \mathrm{~g} \gamma-\mathrm{Al}_{2} \mathrm{O}_{3}$ ] fue graficado en función de la concentración de Mo en la solución en equilibrio $\left(\mathrm{C}_{\mathrm{f}}\right)$. La forma de las curvas responde al modelo de Langmuir [4], cuya forma linealizada corresponde a la siguiente ecuación: $\left[C_{f} / C_{a d}=(1 /\right.$ $\left.\left.\mathrm{K}_{\mathrm{ad}} \mathrm{S}\right)+\left(\mathrm{C}_{\mathrm{f}} / \mathrm{S}\right)\right]$ y por extrapolación de la línea recta obtenida, fue posible calcular el número total de sitios activos (S), expresado en $\mathrm{g} \mathrm{Mo} / \mathrm{g} \gamma-\mathrm{Al}_{2} \mathrm{O}_{3}$. La constante de equilibrio de adsorción $\left(\mathrm{K}_{\mathrm{ad}}\right)$ expresada en $\mathrm{ml} / \mathrm{g}$ Mo también pudo ser obtenida a partir de la pendiente de la recta. Para todos los catalizadores se procedió de esta manera, permitiendo el cálculo de la concentración tanto de Mo como del heteroátomo presente [Rh(III) y $\operatorname{Co}(\mathrm{III})]$.

Se hicieron medidas complementarias utilizando varias técnicas espectroscópicas de superficie: Espectroscopía fotoelectrónica de Rayos X (XPS); Microscopía electrónica de Barrido SEM y análisis semicuantitativo EDS (Microscopio con sistema de energía dispersiva para microanálisis por Rayos X, EDS), así como Raman Microprobe para corroborar la composición y la preservación de la estructura Anderson soportada en alúmina. 


\section{5 . Difracción de Polvos por Rayos X: DRX}

\section{5.a. Consideraciones generales}

La difracción por rayos $\mathrm{X}$ es el método usualmente empleado para la caracterización de estructuras cristalinas. Se fundamenta en la dispersión de los rayos X producida por la distribución ordenada de los átomos en la red cristalina. Entre la radiación $\mathrm{X}$ dispersa es posible hallar interferencia de tipo constructivo y destructivo, dado que las distancias entre los centros de dispersión son del mismo orden de magnitud que la longitud de onda de la radiación. El resultado neto conocido como fenómeno de difracción de Bragg establece que la interferencia constructiva se producirá cuando:

$$
\mathbf{n} \lambda=2 \mathbf{d} \operatorname{sen} \theta
$$

Esta ecuación (5) conocida como Ley de Bragg relaciona el espacio interplanar (d) en un cristal con la longitud de onda $(\lambda)$ de los rayos $\mathrm{X}$ incidentes (depende del tubo catódico que se utilice), donde $\mathbf{n}$ es el orden de la reflexión. La relación anterior indica que la medición de la intensidad del haz difractado en función del ángulo incidente $(\boldsymbol{\theta})$, conducirá a un patrón de difracción que es característico de la estructura cristalográfica de la muestra irradiada.

La técnica permite:

- Caracterizar especies químicas sintetizadas y minerales presentes en los sistemas originales analizados.

- Seguir el curso de la transformación estructural que ocurre por efecto de la interacción de las especies en diferentes medios de reacción.

- Eventualmente refinar los parámetros de la celda unitaria.

\section{5.a.I. Equipamiento.}

Los diagramas de polvo por difracción de Rayos $\mathrm{X}$ se obtuvieron con un difractómetro Philips PW 1714 utilizando la radiación $\mathrm{CuK} \alpha$ y filtro de $\mathrm{Ni}$, en un rango de medida de $2 \theta$ entre $2^{\circ}$ ó $5^{\circ}$ y $70^{\circ}$. 
Asimismo se realizaron medidas de DRX "in situ” en un equipo Philips PW1729 usando cámara de alta temperatura y flujo gaseoso de aire (Antón PAAR (HTK10) con programador de temperatura, tubo de $\mathrm{Cu}$, filtro de $\mathrm{Ni}$. Velocidad de barrido empleada fue de $1^{\circ}$ de $2 \theta$ /minuto. El mismo se encuentra en el "Istituto per lo studio dei materiali nanostrutturati" (I.S.M.N.) del "Dipartimento di Chimica" Università di Roma "La Sapienza”, Roma, Italia.

\section{5.b. Microscopía Electrónica de barrido (SEM) y Microanálisis semicuantitativo por sonda de electrones (EDS).}

\section{5.b.I.Microscopía Electrónica de barrido: SEM}

El microscopio electrónico de barrido (SEM, Scanning Electron Microscope) es un instrumento de gran utilidad para examinar y analizar características morfológicas y estructurales de muestras sólidas.

El principio de funcionamiento se basa en el empleo de una fuente de emisión de electrones o cátodo. El mismo es un filamento de tungsteno de $\sim 100 \mu \mathrm{m}$ de diámetro, en forma de $\mathrm{V}$, que calentado por una corriente eléctrica produce un haz de electrones mediante un proceso llamado emisión termoiónica. El haz de electrones así generado se acelera a través de un potencial de hasta $30 \mathrm{Kv}$ entre el cátodo y el ánodo. Simultáneamente, una grilla o cilindro de Wehnelt, polarizado negativamente respecto al cátodo, obliga al haz a converger en una sección eficaz mínima de $\sim 10-5 \mu \mathrm{m}$ de diámetro.

Las lentes condensadoras (que determinan la corriente del haz que incide sobre la muestra) y las finales o lentes objetivo (que determinan el tamaño final del haz) demagnifican esta sección eficaz para obtener una sonda final de electrones cuyo diámetro puede variarse entre 10 y $500 \mathrm{~nm}$.

La señal más frecuentemente elegida para imágenes micrográficas es la producida por los electrones secundarios, debido a su sensibilidad topográfica y alta resolución espacial. El detector de los electrones secundarios que salen de la muestra más ampliamente utilizado en microscopia electrónica de barrido es el centelladorfotomultiplicador. El componente principal de este detector es un material centellador que emite luz al ser alcanzado por electrones de alta energía. A través de una guía de 
luz, estos fotones son llevados hasta la ventana de un fotomultiplicador, produciendo una cascada de electrones en el mismo. Estos electrones producirán luego una señal eléctrica en el sistema de video que posibilitará la formación de la imagen.

El sistema de visualización de imágenes del microscopio cuenta con dos tubos de rayos catódicos, uno utilizado para la observación directa y optimización de la imagen y otro destinado al registro de la misma en forma fotográfica y/o digital. A fin de interpretar correctamente las imágenes observadas debe pensarse que existe una correspondencia uno a uno entre los puntos barridos sobre la muestra y los de la pantalla del tubo de rayos catódicos del sistema de visualización. Esta correspondencia obedece al sistema de bobinas deflectoras que barren la muestra en sincronismo con el barrido en la pantalla de video. Las distintas señales resultantes de la interacción del haz de electrones con la superficie de la muestra se utilizan para modular el brillo uniforme, pero en la mayoría de las muestras esto no ocurre así debido a que dicha interacción es variable de una zona a otra. La interacción puede ser afectada por la topografía, composición, cristalinidad, propiedades eléctricas y magnéticas u otras características de la muestra.

La magnificación resulta del cociente entre el área barrida en el tubo de rayos catódicos y el área barrida en la muestra. Como el tamaño de la pantalla es fijo, el reducir el área barrida sobre la muestra se traduce en una mayor magnificación. El rango de magnificación del microscopio va desde $\sim 10$ a 200.000 aumentos.

\section{5.b.I.1 ${ }^{0}$.Microanálisis Semicuantitativo por Sonda de Electrones (EDS).}

El microanálisis por sonda de electrones consiste en analizar los rayos $\mathrm{X}$ generados por una muestra que ha sido bombardeada con un haz de electrones. Los valores de longitud de onda e intensidad de las líneas del espectro característico emitido, permiten realizar análisis químico en áreas muy pequeñas. El análisis cualitativo consiste en la identificación de los elementos presentes a partir de su correspondiente longitud de onda, mientras que en el análisis semi-cuantitativo las intensidades son comparadas, en general, con las muestras patrones de composición conocida. Las intensidades medidas deben ser corregidas por efecto del instrumento utilizado, como así también por el fondo, cuya fuente principal es el espectro continuo de rayos X. 
El análisis de los rayos $\mathrm{X}$ implica medir muy precisamente sus longitudes de onda o energías y las correspondientes intensidades. Existen dos formas para llevar a cabo estas mediciones: en el sistema denominado dispersivo en longitudes de onda, los rayos $\mathrm{X}$ son dispersados por un cristal analizador, vía la difracción de Braga, estos rayos $\mathrm{X}$ difractados son registrados en un contador proporcional de gas. En el otro sistema, denominado dispersivo en energías, el detector de rayos $\mathrm{X}$ se coloca antes del sistema dispersante a fin de colectar la mayor cantidad de radiación posible; y la señal de rayos X proveniente del detector es analizada por un sistema de análisis de altura de pulsos, donde esta altura está relacionada con la energía del fotón incidente. El método en éste último caso requiere, no solo un detector proporcional de energía incidente, sino también con una buena resolución en energías y es por eso que en lugar de un detector de gas se utiliza un detector de estado sólido de $\mathrm{Si}$ ( $\mathrm{Li}$ ) que tiene una resolución muy superior. Los datos obtenidos fueron los promedios estadísticos de al menos 10 determinaciones.

\section{5.b.II. Equipamiento.}

Las medidas fueron realizadas en un microscopio electrónico de barrido marca PHILIPS, modelo SEM 505, con un sistema de microanálisis de energía dispersiva de RX (EDS), EDAX 9100. Las condiciones en que fueron tomadas las micrografías se especifican en cada una de ellas.

\section{5.b.II.1 ${ }^{\circ}$. Mapeo por Microsonda Electrónica (EDS).}

Dado que el microscopio SEM utilizado, está provisto de una microsonda de electrones, constituyendo un método importante para la determinación de la composición elemental de las superficies y la sonda del analizador EDS-EDAX puede detectar hasta una profundidad de $1 \mu \mathrm{m}$, es posible realizar un mapeo de elementos proporcionando información gráfica sobre su distribución.

El sistema de microanálisis usa un detector de ventana ultrafina (UTW), y para la realización de un mapeo del o de los elementos las imágenes son digitalizadas por un programa computacional (Soft Imaging Sistem ADDA II) que permite obtener 
imágenes donde se observa la distribución de puntos para cada elemento (conforme a su concentración).

\subsection{Espectroscopia Fotoelectrónica por rayos X (XPS)}

\section{6.a. Consideraciones generales}

La principal característica de la espectroscopía de fotoelectrones (XPS o ESCA) es su sensibilidad en la superficie de los materiales estudiados. El método se basa fundamentalmente en el efecto fotoeléctrico, donde un sólido es irradiado con rayos $\mathrm{X}$ de energía conocida y se mide la energía cinética del electrón característico producido por la interacción de los fotones con el material estudiado. Como el camino libre medio de los electrones que dejan la muestra es pequeño, solamente aquellos generados en las últimas capas son detectados, en una región de entre 5 hasta $50 \AA$ A dependiendo de las características del material y de las condiciones de análisis. Cada elemento posee un espectro particular cuyos picos, con sus intensidades y energía características, están directamente asociados a la distribución y la densidad de electrones en sus orbitales. La intensidad de los picos está asociada con la distribución y dispersión de los elementos, de su energía de unión y de la forma de las líneas del estado químico de las fases presentes en la superficie. Por medio de la espectroscopía XPS es posible determinar y cuantificar la presencia de cualquier elemento, excepto $\mathrm{H}$ o $\mathrm{He}$, y también el estado o el ambiente químico en el que se encuentran cada uno de los elementos presentes en la superficie en estudio. Es decir que la espectroscopía de fotoelectrones permite determinar la composición elemental y química de las últimas capas atómicas de la superficie de cualquier material.

Efecto fotoeléctrico: consiste en irradiar con Rayos $\mathrm{X}$ un cátodo de un tubo al vacío y medir la corriente generada en la fotocélula, proporcional a la distribución de las energías cinéticas de los electrones generados por la interacción del fotón con la materia. Solamente la radiación con longitud de onda lo suficientemente corta/baja es capaz de generar fotoemisión de electrones, y esta, cuando ocurre, es proporcional a la intensidad de la radiación. La energía cinética, $\boldsymbol{E}_{\boldsymbol{K}}$, de los electrones generados se determina por medio de la medida del potencial $V$ necesario para interrumpir la corriente eléctrica entre el cátodo y el ánodo de la célula de vacío. Cuando la corriente 
del circuito es cero, la energía potencial (eU), fortalecida por la fuente externa $(\boldsymbol{V})$, es igual a la energía cinética máxima de los fotoelectrones generados. Estas experiencias se realizan en función de la frecuencia de radiación $v$ y son una forma directa de determinar la relación entre la constante de Planck y la carga electrónica, y también la función trabajo $\boldsymbol{\Phi}_{f}$ del metal (cátodo) estudiado.

La ecuación básica que rige la espectroscopía de fotoelectrones establece una relación entre la energía conocida del fotón incidente (hv) y la energía cinética medida de los electrones que dejan la muestra $\left(\mathrm{E}_{\kappa}\right)$, dada en primera aproximación por:

$$
E_{\mathrm{K}}=h v-E_{B}-\Phi_{S}
$$

De acuerdo con el modelo atómico de Bohr, los electrones de un átomo existen en orbitales bien definidos en energía, característicos de cada elemento. Los electrones oriundos de esos niveles excitados por los fotones de rayos $\mathrm{X}$ constituyen el espectro XPS. Estos dejan el átomo si la energía del fotón (hv) es suficiente para removerlos de su orbital, o sea, es suficiente para vencer la energía de unión $\left(E_{B}\right)$. Para dejar una muestra sólida, estos electrones deben tener energía para vencer el potencial cristalino de la muestra, que es igual a la función trabajo del espectrómetro $\left(\Phi_{\mathrm{S}}\right)$. Los electrones que dejan la muestra, generados en el proceso fotoeléctrico sin sufrir pérdidas de energía, son llamados fotoelectrones.

Cada uno de los picos que aparece en el espectro fotoelectrónico tiene su energía de enlace determinada por la ecuación anterior, y se puede asociar a uno de los orbitales ionizados de uno de los elementos presentes en la superficie. La energía de enlace de los orbitales internos varía en función de la distribución de los electrones de valencia, o sea, el entorno químico en el cual se encuentra el átomo.

Todos los orbitales atómicos con energía de enlace menor que la del fotón de excitación pueden ser ionizados. Como existe una probabilidad de ionización distinta para cada uno de los orbitales de cada uno de los elementos, dada por su ecuación de choque, los espectros XPS presentan un conjunto de picos con energía e intensidad característicos, que reflejan los niveles de energía de enlace discretos y la densidad de electrones de los elementos presentes en el sólido. Los fotoelectrones que constituyen los picos discretos de los espectros XPS se superponen a un fondo que tiene como 
origen, los electrones generados en el proceso fotoeléctrico, que sufren pérdidas de energía antes de salir de la muestra.

Los principales componentes de un espectrómetro de fotoelectrones son la fuente de radiación, el analizador de energía de los electrones, el detector de electrones, el sistema de vacío y las unidades de control y adquisición de datos.

Se puede analizar cualquier tipo de muestra sólida. El cuidado básico a tener en cuenta es la limpieza de la muestra y de las herramientas utilizadas dentro de la cámara de vacío. Las muestras contaminadas con compuestos de baja presión de vapor gasificarán el sistema de vacío, perjudicando el sistema de bombeo, además de contaminar las otras muestras y la propia cámara de análisis.

Las muestras se fijan al portamuestras por medio de una cinta adhesiva de doble faz, prensadas en forma de pastillas o en un receptáculo propio del portamuestras.

El método se lleva a cabo en condiciones de alto vacío $\left(10^{-8}-10^{-11}\right.$ mbar $)$ para evitar que los fotoelectrones, que poseen energía característica, sufran pérdidas de energía por colisiones con la atmósfera residual de la cámara de análisis y para evitar la contaminación de la superficie que se desea estudiar.

La fuente de rayos $\mathrm{X}$ más utilizada en los espectrómetros de fotoelectrones es la constituida por un ánodo doble de $\mathrm{Mg}$ y $\mathrm{Al}$, con o sin monocromador.

La información adquirida permite conocer aspectos tales como la composición química de la sustancia analizada, el estado de oxidación de los elementos, el tipo de enlace y entorno de los mismos (coordinación).

\section{6.b. Equipamiento}

Las medidas realizadas para esta tesis se efectuaron en el "Dipartimento di Chimica” La Sapienza Università di Roma.

El análisis XPS de las muestras se llevó a cabo en un espectrómetro LeyboldHeraeus LHS-10 usando radiación $\mathrm{K} \alpha$ de Al $(1486.6 \mathrm{eV})$ en modo FAT y paso de energía $50 \mathrm{eV}$. Para los valores de energía de enlace BE ("binding energy") se utilizó como referencia el pico a $285.0 \mathrm{eV}$ correspondiente al C1s. La composición superficial 
se obtuvo a partir de la razón de las áreas de los picos, usando los factores de sensibilidad propuestos por Wagner y col. [26].

\subsection{Espectroscopía Vibracional.}

\section{7.a. Espectroscopía vibracional Infrarroja con transformada de Fourier (FT-} IR).

\section{7.a.I. Consideraciones generales}

La radiación infrarroja ocurre en la región del espectro electromagnético comprendida entre el visible y las microondas (10000 a $\left.30 \mathrm{~cm}^{-1}\right)$. Las unidades más utilizadas para la longitud de onda $(\lambda)$ son los $\mu \mathrm{m}$ y para el número de onda $(v) \mathrm{cm}^{-1}$. La expresión $v=10000 / \lambda(\mu \mathrm{m})$ convierte una unidad en otra.

Esta región del espectro electromagnético se divide en IR próximo (entre 10000 y $4000 \mathrm{~cm}^{-1}$ ); IR propiamente dicho (entre 5000 y $660 \mathrm{~cm}^{-1}$ ) y lejano (entre 660 y 30 $\left.\mathrm{cm}^{-1}\right)$.

Por otra parte, es posible considerar la energía total de una molécula como el resultado de la contribución de tres componentes: la energía correspondiente a su rotación, aquella asignada a la vibración de los átomos que la constituyen y la asociada al movimiento o salto de los electrones en la molécula (transición electrónica).

Los espectros vibracionales puros son observados en el rango que va desde 100 hasta $1 \mu \mathrm{m}$ de longitud de onda. El valor de la energía queda expresado por la relación (7):

$$
\mathrm{E}=\mathrm{hv}=\mathrm{hc} / \lambda=\mathrm{hc} v
$$

Donde $\mathrm{h}=$ constante de Planck $=6,626 \times 10^{-34}$ Joul.seg, $\mathrm{c}=$ velocidad de la luz= $2.9979 \times 10^{10} \mathrm{~cm} \mathrm{seg}^{-1}, \mathbf{v}=$ frecuencia de la radiación expresada en $\mathrm{Hz}\left(\mathrm{seg}^{-1}\right), \boldsymbol{\lambda}$ es la longitud de onda de la misma, expresada en $\mathrm{cm}$ y $v$ el número de onda expresado en $\mathrm{cm}^{-}$ ${ }^{1}$. De aquí que la energía de: $1 \mathrm{~cm}^{-1}=1,98610^{-23}$ Joule. 
La radiación infrarroja posee la suficiente energía como para causar transiciones traslacionales, rotacionales y vibracionales de la molécula.

En una molécula, los niveles energéticos se encuentran cuantizados. En un oscilador armónico sólo son permitidas aquellas transiciones entre dos niveles adyacentes, de modo que $E=(u+1 / 2) h v$, donde $u$ es el número cuántico vibracional $(0,1,2,3 \ldots)$. En el caso más simple de una molécula diatómica, de masas $m_{1}$ y $m_{2}$, la energía absorbida cuando la molécula pasa de un estado cuantizado a otro queda expresada de la siguiente forma:

$E=h / 2 \pi \sqrt{ }(K / \mu),\left(1 / \mu=1 / m_{1}+1 / m_{2}\right)$

$\boldsymbol{K}$ : es la constante de fuerza entre dos átomos en el enlace químico [27].

$\boldsymbol{\mu}=\left(\boldsymbol{m}_{1}+\boldsymbol{m}_{2}\right) / \boldsymbol{m}_{1} \boldsymbol{m}_{2}$ : es la masa reducida en un enlace diatómico.

Existe la siguiente relación empírica

\section{$\left.K=1,8610^{5} /\left(r-d_{i j}\right)\right)^{3} \quad$ en dina $/ \mathrm{cm}$}

r: es la distancia interiónica,

$\boldsymbol{d}_{i j}$ : es una constante característica de la posición de los átomos en el sistema periódico.

Una expresión de gran utilidad que relaciona $\mathrm{K}$ y distancia interatómica es la siguiente:

$$
K=1,67 N\left(x_{A} x_{B} / r^{2}\right)^{3 / 4}+0,3010^{-5} \quad \text { en dina/cm }
$$

$x$ : representa la electronegatividad de los átomos que forman parte del enlace y

$N$ : es el orden de enlace [28].

Independientemente de la expresión que se utilice, puede establecerse que a mayor masa reducida menor será la energía (o frecuencia) de la vibración y que a una mayor fuerza del enlace le corresponde una menor longitud del mismo. Esto significa que es posible observar zonas de vibración características para los enlaces entre diferentes átomos o diferentes órdenes de enlace. Por ej. : $\mathrm{C}-\mathrm{C} \sim 1000 \mathrm{~cm}^{-1}, \mathrm{C}=\mathrm{C} \sim 1650$ $\mathrm{cm}^{-1}, \mathrm{C} \equiv \mathrm{C} \sim 2200 \mathrm{~cm}^{-1}, \mathrm{C} \equiv \mathrm{O} \sim 2138 \mathrm{~cm}^{-1}, \mathrm{C}-\mathrm{H} \sim 2861 \mathrm{~cm}^{-1}$ [29]. 
Los modos de vibración activos en IR quedan determinados por las características de simetría de la especie, de tal forma que una disminución de la misma va acompañada por la activación y el desdoblamiento de algunos modos. En particular, existen reglas de selección que determinan el número de bandas o desdoblamiento de los modos según la simetría del sitio puntual la que debe ser subgrupo del grupo espacial cristalino y del grupo puntual molecular (tetraédrico ideal o $\mathrm{T}_{\mathrm{d}}$ ).

Al absorber una molécula frecuencias de entre 10000 y $100 \mathrm{~cm}^{-1}$, la misma se convierte en energía vibracional de la molécula. El espectro vibracional aparece como una serie de bandas en vez de líneas, debido a que cada variación de energía vibracional coincide con una serie de variaciones de energías rotacionales, las líneas se superponen dando lugar a las bandas observadas. El espectro infrarrojo se origina de transiciones entre los niveles de energía rotacional y vibracional con la correspondiente absorción o emisión de energía a frecuencias discretas, correspondiendo a ciertos modos normales de vibración de las moléculas o grupos superficiales. El número de modos vibracionales aumenta con la complejidad de la molécula; existen 3n-6 modos normales para una molécula no linear y 3n-5 para una molécula linear, compuestas por n átomos. Si el movimiento (grado de libertad) es acompañado por una variación del momento dipolar de la molécula (variación de las posiciones de los centros de carga positiva y negativa) la radiación infrarroja puede ser absorbida o emitida a esta frecuencia y por lo tanto esta vibración es activa al infrarrojo. El movimiento de traslación no altera el momento dipolar de la molécula y, por eso no genera bandas en la región del infrarrojo.

Los modos vibracionales pueden ser:

Estiramiento: aquellos donde ocurren variaciones en las distancias entre los átomos a lo largo de las uniones químicas que los conectan. Pueden ser simétricas si las variaciones de longitud de las uniones ocurren en la misma dirección, o asimétricas, si ocurren en direcciones opuestas. Corresponden a n-1 de los modos vibracionales posibles.

Deformación: aquellas que dan lugar a la curvatura periódica de la molécula (modificación de los ángulos de unión). Son de más baja energía que las de estiramiento debido a que las fuerzas involucradas son menores. Hay varios tipos de deformaciones: balanceo, torsión, aleteo, etc. Corresponden a 2n-5 modos vibracionales posibles. 
En general todos los átomos de una molécula están involucrados en un modo vibracional, es más, la mayoría de los movimientos están frecuentemente concentrados en una unión o un grupo de átomos. En este caso, las masas de los átomos en este grupo es una constante de las fuerzas asociadas a las uniones entre las que gobierna la frecuencia de vibración. Por esta razón a una misma frecuencia, aproximadamente, se observa para un grupo dado de distintos compuestos. Estas frecuencias de grupo permiten identificar estructuras que en general absorben en un región espectral entre

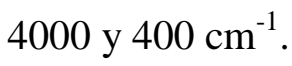

Grupos de superficie y moléculas adsorbidas son normalmente identificadas por comparación de sus frecuencias de absorción con frecuencias de grupos de espectros de compuestos conocidas. El espectro de las moléculas adsorbidas tienden a asemejarse con los espectros de estas moléculas en estado líquido, además las interacciones con una superficie pueden desplazar la frecuencias a valores mayores o menores, lo mismo que conducir a la aparición de nuevas bandas por variaciones del momento dipolar en vibraciones que normalmente no se exhibían.

El objetivo de la técnica es determinar grupos funcionales contenidos en un material. Cada grupo funcional absorbe a una frecuencia característica en el infrarrojo. Por lo tanto un gráfico de intensidad de radiación versus frecuencia (espectro infrarrojo) constituye una impresión digital de los grupos identificables de la muestra desconocida. No se conoce, un detector infrarrojo que pueda detectar al mismo tiempo frecuencia e intensidad de radiación con buena resolución. Los detectores normalmente usados en infrarrojo, termocupla, son detectores de integración. Informan una media de todas las frecuencias que llegan al detector en una única lectura de intensidad. Para resolver este problema se utiliza una combinación de dos técnicas: una dispersiva, donde cada elemento de frecuencia es observado por un tiempo y una de transformada de Fourier, que convierte la información de frecuencia en audio frecuencia, donde el detector y los sistemas electrónicos son capaces de sensar ambos, frecuencia e intensidad. Los instrumentos dispersivos fueron usados por varias décadas, a lo largo de las cuales se fueron introduciendo varias mejoras con los avances tecnológicos, como sustitución de prismas por redes para mejorar la resolución y dispersión, etc. [29]. [30]:

Algunas ventajas de la espectroscopía Infrarroja con Transformada de Fourier son 
- las radiaciones penetran el sólido másico.

- permite determinar la naturaleza de especies químicas superficiales

- sensibilidad de monocapa

- permite distinguir según tipo, concentración y fuerza de los enlaces químicos

- permite trabajar in situ (alta T, baja presión)

Entre las limitaciones pueden enunciarse las siguientes:

- los óxidos usualmente usados como soportes absorben señales debajo de $1000 \mathrm{~cm}^{-1}$ interfiriendo con las señales superficiales

- no puede penetrar a través del agua, ya que ésta absorbe la radiación.

\section{7.a.II. Equipamiento.}

Los espectros fueron registrados en un espectrofotómetro de infrarrojo (FT-IR) modelo Brucker IFS-66v por transformada de Fourier, registrando la región comprendida entre 4000 y $400 \mathrm{~cm}^{-1}$ con una resolución de $4 \mathrm{~cm}^{-1}$. Pequeñas cantidades de sólido (inferior a $2 \mathrm{mg}$ ) fueron dispersadas en $\mathrm{KBr}$ utilizando el método de pastillado de forma de obtener una lámina translúcida.

\section{7.b. Espectroscopía Raman}

\section{7.b.I. Consideraciones generales.}

La espectroscopía Raman es una técnica fotónica de alta resolución, que proporciona en pocos segundos información química y estructural de casi cualquier material o sustancia, permitiendo así su identificación.

La espectroscopía Raman se ha convertido en una técnica fundamental de la espectroscopía molecular. Junto a la técnica de FTIR (espectroscopia infrarroja), es utilizada para obtener información acerca de la estructura y propiedades de las moléculas a partir de sus transiciones vibracionales. La teoría de la "dispersión Raman" es más compleja que la teoría de la "absorción de IR", sin embargo existen muchos conceptos paralelos en ambas teorías. 
Como es bien conocido, la absorción de infrarrojo proviene del efecto de resonancia directa entre la frecuencia de la radiación IR incidente y la frecuencia vibracional de un modo particular de vibración. La propiedad molecular involucrada en la interacción resonante es el "cambio en el momento dipolar" de la molécula como consecuencia de su modo vibracional.

La espectroscopía de IR es un evento que implica la absorción de un fotón. Este fotón de frecuencia IR incide en la molécula y es absorbido por la misma adquiriendo así un nivel vibracional superior mediante la transferencia de energía del fotón a la frecuencia de vibración resonante.

En contraste, la dispersión Raman es un proceso que involucra dos fotones. El fotón incidente interactúa con la molécula y luego se emite un fotón de frecuencia diferente. En este caso la propiedad molecular afectada es el cambio en la "polarizabilidad" de la molécula asociada a un modo vibracional. El momento dipolar inducido $\mu$ es proporcional a la energía del campo incidente E según: $\vec{\mu}_{\text {ind }}=\alpha \vec{E}$ donde $\alpha$ es la polarizabilidad.

La interacción de la "polarizabilidad" con la radiación (fotón) incidente promedio crea un momento dipolar inducido en la molécula y la radiación (fotón) emitida por este efecto es lo que se conoce como la dispersión o "scattering" Raman. Para que un modo vibracional sea activo en Raman se debe cumplir que la relación entre la variación de la polarizabilidad $\alpha$ y la distorsión molecular $\mathrm{Q}$, sea distinta de cero: $\frac{d \alpha}{d Q} \neq 0$ Además la intensidad del Scattering Raman es proporcional a: $\left(\frac{d \alpha}{d Q}\right)^{2}$

Debido a esta dependencia, las moléculas homonucleares como heteronucleares presentan actividad Raman ya que en ambos casos ocurre una variación de la polarizabilidad con la vibración. El análisis Raman se basa en hacer incidir un haz monocromático de frecuencia $v 0$ con energía hv0 (donde h es la constante de Planck), sobre una muestra cuyas características moleculares se desean determinar y examinar la luz dispersada por dicha muestra. La mayor parte de radiación dispersada presenta la misma frecuencia que la luz incidente pero una fracción muy pequeña presenta un cambio en la misma, resultado de la interacción de la luz con la materia. La luz que 
mantiene la misma frecuencia que la incidente se conoce como dispersión Rayleigh y no aporta ninguna información vibracional sobre la composición de la muestra analizada. La luz dispersada que presenta frecuencias distintas a la incidente es la que proporciona información vibracional de la molécula y se la denomina “dispersión Raman” en honor al indio Sir C. V. Raman quien junto a K. S. Krishnan descubrió el efecto en 1928.

Las nuevas frecuencias, $v 0+v m$ y $v 0-v m$ son las frecuencias Raman, características de la naturaleza química y el estado físico de la muestra e independientes de la radiación incidente.

En la Figura 2-1 se ilustran los tipos de radiación dispersada a causa del momento dipolar inducido por una radiación monocromática incidente: las dispersiones Rayleigh y Raman.

La primera es "elástica" ya que se emite a la misma frecuencia de la luz incidente, mientras que la radiación Raman es "inelástica" por ser emitida a diferente frecuencia y por ende diferente energía que la incidente a causa de la energía vibracional que adquiere o pierde la molécula. Si la radiación emitida es de menor frecuencia que la incidente se denomina "Stokes" y si es mayor se denomina "AntiStokes".

La polarizabilidad es un tensor con dos componentes cartesianas, una está asociada con el fotón incidente y la otra con el fotón dispersado. Ambos fotones están conectados mediante un simple proceso mecánico cuántico, que hace a la dispersión Rayleigh y Raman diferentes a partir de dos eventos fotónicos, uno de absorción seguido por otro de emisión.

En la Figura 2-2 se muestra un diagrama que ilustra la absorción de IR (proceso mono-fotónico) y la dispersión Raman (proceso bi-fotónico de absorción y emisión). 


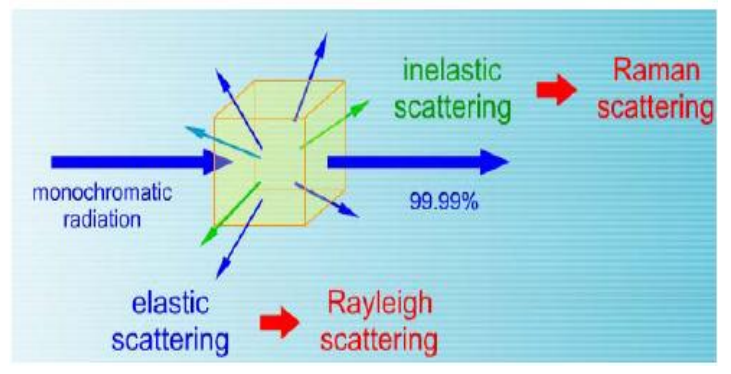

Figura 2-1: Representación de la interacción de una radiación monocromática con la materia y los distintos tipos de dispersión producida.

En ambos casos el estado inicial es un nivel vibracional cero de energía $\mathrm{E}_{0} \mathrm{y}$ el estado final es el primer estado vibracional correspondiente a un nivel de energía $\mathrm{E}_{0}+$ $\mathrm{h} v_{\mathrm{m}}$.

La absorción de radiación en IR, alcanza este estado en una etapa, mientras que la dispersión Raman requiere dos etapas que involucran fotones de energía superior a la correspondiente a la transición vibracional de IR. Así la molécula puede ganar (radiación Stokes) o perder energía vibracional (Antistokes), partiendo desde un nivel vibracional elevado.

La dispersión Raman puede ser sensitiva a todos los niveles excitados electrónicos de la molécula.

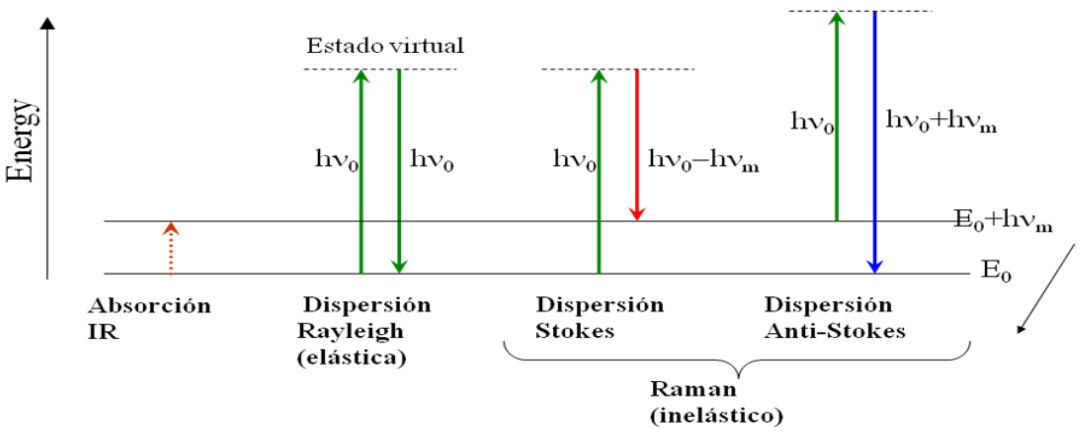

Figura 2-2: Diagrama de niveles de energía para la absorción de IR y la dispersión Raman Stokes y Anti-stokes para una transición vibracional E0 $\rightarrow \mathrm{E} 0+$ hvm. La energía del fotón dispersado hv0 +/- hvm, es la energía de la radiación del laser incidente modificada por la energía vibracional hvm de la molécula en un modo vibracional. 
Cuando los fotones incidentes, con energía $h v_{0}$ mucho mayor a la diferencia de energía entre dos niveles vibracionales (o rotacionales) de la molécula, impactan en ella, la mayor parte la atraviesan pero una pequeña fracción es dispersada $(\sim 1$ fotón dispersado cada $10^{11}$ incidentes). Esta dispersión puede ser interpretada como el proceso siguiente: el fotón incidente lleva a la molécula transitoriamente a un nivel de energía vibracional (o rotacional) superior no permitido, el cual abandona rápidamente para pasar a uno de los niveles de energía permitidos emitiendo un fotón; la frecuencia a la cual es liberado este fotón dependerá del salto energético realizado por la molécula.

Si el resultado de la interacción fotón-molécula es un fotón dispersado a una frecuencia distinta del incidente, se dice que el choque es inelástico (existe transferencia de energía entre la molécula y el fotón); en este caso pueden darse dos fenómenos:

- Si el fotón dispersado tiene una frecuencia menor a la del incidente, se produce una transferencia de energía del fotón a la molécula que, después de saltar al estado de energía no permitido, vuelve a uno permitido mayor al que tenía inicialmente; el fotón es dispersado con frecuencia $v 0-v m$ y se produce la dispersión Raman Stokes.

- Si el fotón dispersado tiene una frecuencia mayor a la del incidente, se produce una transferencia de energía de la molécula al fotón; esto significa que la molécula, inicialmente antes del choque no se encontraba en su estado vibracional fundamental sino en uno de mayor energía y después del choque pasa a este estado; el fotón es dispersado con frecuencia $v_{0}+v_{m}$ y se produce la dispersión Raman anti-Stokes.

Cada material tendrá un conjunto de valores vm característicos de su estructura poliatómica y de la naturaleza de los enlaces químicos que la forman.

El espectro Raman registra estos fenómenos representando la intensidad óptica dispersada en función del número de onda normalizado $v$ al que se produce. El número de onda normalizado es una magnitud proporcional a la frecuencia e inversamente proporcional a la longitud de onda, que se expresa en $\mathrm{cm}^{-1}: \mathrm{v}=\mathrm{v} / \mathrm{c}=1 / \lambda\left[\mathrm{cm}^{-1}\right]$, donde c es la velocidad de la luz. 
Un ejemplo se observa en la Figura 2-3 El espectro Raman del $\mathrm{Cs}_{2} \mathrm{NaBiCl}_{6}$ está formado por una banda principal o Rayleigh y dos series de bandas secundarias correspondientes a las bandas Raman Stokes y anti-Stokes, situadas simétricamente a ambos lados de la banda Rayleigh.

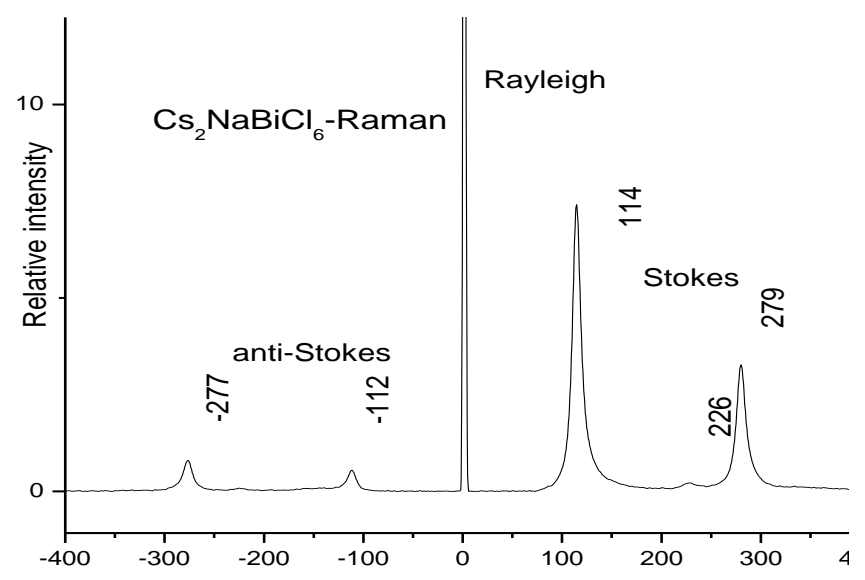

Figura 2-3: Espectro Raman del $\mathrm{Cs}_{2} \mathrm{NaBiCl}_{6}^{n}$ chift $\left(\mathrm{rm}^{-1}\right)$

Es importante resaltar que el desplazamiento de las frecuencias Raman respecto a la frecuencia incidente $v_{0}$ es independiente de esta última. Por ello el centro de la banda Rayleigh suele tomarse como origen del eje de las abscisas para representar los espectros Raman. Así, en el eje $x$ aparecerá la diferencia entre la frecuencia Raman y la $v_{0}$ del laser de excitación, normalizada respecto a la velocidad de la luz: $v=\left(v-v_{0}\right) / c$ $\left[\mathrm{cm}^{-1}\right]$.

A temperatura ambiente, según la ley de distribución de energías de MaxwellBoltzman, el $99 \%$ de las moléculas se encuentra en el estado vibracional de menor energía, y por tanto, la probabilidad de que ocurran transferencias de energía que den lugar a la dispersión Stokes es mucho mayor que para anti-Stokes. Esto se traduce en que la intensidad de la dispersión Stokes es del orden de 100 veces superior a la de antiStokes. La diferencia entre la intensidad del efecto Stokes y el anti-Stokes hace que 
habitualmente se trabaje midiendo sólo el efecto Stokes y por comodidad se sitúa el resultado en la parte positiva del eje $x$ de la Figura 2-3.

En ocasiones, debido a la naturaleza química del material que se analiza, unido al efecto Raman se produce un efecto de fluorescencia (fenómeno de emsión de luz para saltos electrónicos) que puede llegar a enmascarar las bandas Raman.

En el campo de la catálisis, la espectroscopía Raman ha recibido recientemente una considerable atención, por ofrecer una serie de ventajas potenciales en relación a otras técnicas espectroscópicas vibracionales. De esta forma, por ejemplo, la espectroscopía Raman ofrece información tanto sobre las especies adsorbidas en la superficie como de la estructura del catalizador en condiciones reales de trabajo (In situ).

\section{7.c. Raman Microprobe}

\section{7.c. I. Consideraciones generales.}

A continuación se hace referencia a la técnica Raman Microprobe o "Microanálisis Raman" cuyo instrumento está acoplado a un Microscopio Confocal: El mismo consiste en un microscopio óptico acoplado al laser y al espectrómetro. De esta manera, se genera un sistema capaz de obtener imágenes convencionales de la muestra y obtener espectros Raman en el límite de difracción (del orden $\sim 1 \mu \mathrm{m}$ ).

Dado que las lentes del objetivo del microscopio enfocan el láser en un rango de varios micrómetros de diámetro, la intensidad luminosa es mucho mayor que la que se logra con Raman convencionales. Esto tiene el beneficio añadido de una mayor desactivación de la fluorescencia. Sin embargo, la alta concentración de fotones también puede causar la degradación de la muestra, y por esta razón en algunos casos se requiere de un sustrato que conduzca térmicamente (lo que actúa como un disipador de calor) a fin de evitar que eso suceda.

Un microscopio Raman consta de un microscopio óptico estándar con un láser de excitación, un monocromador y un detector sensible (como un dispositivo de carga 
acoplada "CCD", o un tubo fotomultiplicador "PMT"). En la Figura 2-4 se representa esquemáticamente el espectrómetro Micro-Raman Confocal.

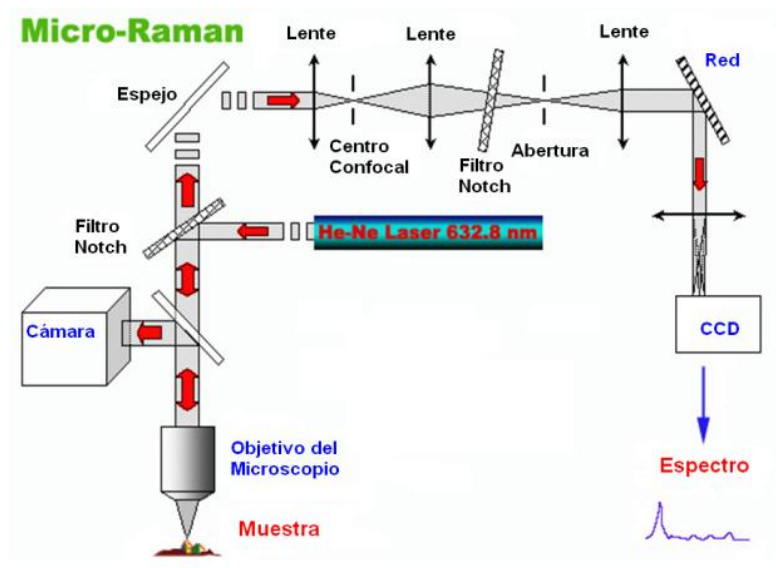

Figura 2-4: Diagrama de un instrumento Raman microprobe.

De todas las técnicas de caracterización utilizadas en sistemas catalíticos, FTIR y Raman son ideales para el estudio molecular "in situ" ya que sus reglas de selección dependen de las características moleculares y pueden proveer análisis en tiempo real.

Sin embargo, en comparación con FTIR, la técnica Raman es más apropiada para la caracterización "in situ" simultánea de catalizadores y especies adsorbidas a causa de su capacidad para la discriminación entre varias unidades moleculares en un sistema de múltiples componentes.

\section{7.c.II. Equipamiento}

Los espectros Raman se registraron en el "Istituto per lo studio dei materiali nanostrutturati” - CNR-Univ. de Roma, Italia, mediante un equipo Renishaw spectrometer equipado con un detector CCD refrigerado por aire y un filtro superNotch. La línea de emisión a $514.5 \mathrm{~nm}$ a partir de un laser de iones Ar+ se centro en la 
muestra bajo un microscopio Leica DLM utilizando un objetivo de $20 \mathrm{x}$. Cinco acumulaciones se alcanzaron para cada muestra con una potencia de haz incidente de aproximadamente $5 \mathrm{~mW}$.

La resolución espectral fue de $2 \mathrm{~cm}^{-1}$ y los espectros se calibraron usando la línea de $520,5 \mathrm{~cm}^{-1}$ de una buffer de silicona.

\subsection{Resonancia magnética nuclear: ${ }^{27} \mathrm{Al}-\mathrm{MAS}$ NMR}

\section{8.a. Consideraciones Generales}

La resonancia magnética nuclear es un método espectrométrico de análisis, que se basa en la absorción de energía en la zona de la radiofrecuencia por parte de los núcleos de algunos átomos, cuando éstos se colocan en un campo magnético externo intenso y de alta homogeneidad. Como la frecuencia exacta de esta absorción depende del entorno de estos núcleos, se puede emplear para determinar la estructura molecular. En principio es aplicable a todos los núcleos con espín nuclear distinto de cero, los que poseerán un momento magnético y uno angular. Esta condición no la cumplen los núcleos con número másico y número atómico par (como el $\left.{ }^{12} \mathrm{C},{ }^{16 o},{ }^{32} \mathrm{~S}\right)$. Los núcleos más importantes en química orgánica son: ${ }^{1} \mathrm{H},{ }^{13} \mathrm{C},{ }^{31} \mathrm{P},{ }^{19} \mathrm{~F}$ y ${ }^{15} \mathrm{~N}$. Otros núcleos importantes: ${ }^{7} \mathrm{Li},{ }^{11} \mathrm{~B},{ }^{27} \mathrm{Al},{ }^{29} \mathrm{Si}$, etc. Se prefieren los núcleos de número cuántico de espín nuclear igual a 1/2, ya que carecen de un momento cuadrupolar eléctrico que produce un ensanchamiento de las señales de RMN.

Una dificultad del método reside en la abundancia natural del núcleo en estudio. En efecto, la mayor parte de los núcleos estables no poseen momento magnético y los isótopos observables están a menudo en cantidades muy bajas y la intensidad de la señal depende de la concentración de los núcleos activos.

El momento magnético de espín nuclear $\left(\mu_{I}\right)$ está asociado a I (número cuántico de espín) siguiendo la relación (8):

$$
\mu_{I}=\gamma I \mathbf{h}, \mathbf{h}=\mathbf{h} / 2 \pi
$$


h: es la constante de Planck, $\gamma$ : es la relación giromagnética nuclear que está especificada para cada isótopo.

En presencia de un campo magnético externo, $\mu_{I}$ puede orientarse con referencia dicho campo en las direcciones $2 \mathrm{I}+1$ correspondientes cada una a los valores de diferencia de energía, creándose así 2I+1 valores de energía distintos, niveles de energía Zeeman. La resonancia magnética nuclear consiste en inducir una transición entre estos niveles de energía tal que $\Delta \mathrm{m}=+/-1$ de manera de modificar su población ("m" número cuántico magnético) [31].

Los datos son reportados en base al parámetro $\delta$, desplazamiento químico, el cual relaciona la resonancia observada para la muestra problema con aquélla del compuesto de referencia. El desplazamiento químico está asociado con la protección del campo magnético externo producida por los electrones que rodean al núcleo en cuestión. Este puede tener diferentes valores en diferentes partes de la molécula y también depender de la orientación de la molécula respecto del campo externo.

En solución, los movimientos de las moléculas hacen que la mayoría de las interacciones magnéticas sean promediadas, de esta manera sólo la parte isotrópica de estas interacciones puede observarse. Por otra parte, en estado sólido las diferentes interacciones sufridas por los espines nucleares aparecen con una anisotropía de orientación que se traduce en un alargamiento importante de las líneas y la aparición de diferentes resonancias sobre la dirección de observación.

La anisotropía del desplazamiento químico puede proveer información valiosa sobre el entorno de moléculas adsorbidas o núcleos pesados en la estructura del sólido.

Los espectros de NMR de estado sólido difieren según el tipo de núcleo en estudio. En nuestro caso, el isótopo en estudio es ${ }^{27} \mathrm{Al}$, con una abundancia natural de $100 \%$, siendo un núcleo de espín nuclear 5/2. A diferencia de la solución, los núcleos presentan en NMR de sólidos líneas bastantes anchas debida a dos fenómenos físicos: la interacción dipolar y la anisotropía del desplazamiento químico. La interacción dipolar originada en el campo magnético crea un nivel de cada átomo por los momentos magnéticos nucleares de átomos vecinos. Resulta en una modificación de los niveles de energía y en consecuencia un ensanchamiento de la línea. La rotación rápida de la 
muestra alrededor de un eje (con ángulo $54.7^{\circ}$ ), en referencia a un campo magnético, permite anular un término que interviene en la expresión de la interacción bipolar, y entonces la señal de NMR se vuelve más fina. Esta técnica llamada "Rotación de Angulo Mágico", conocida por las siglas MAS-NMR, es la que se utilizó para caracterizar los heteropoliácidos preparados. El segundo fenómeno que origina el ensanchamiento de la línea es la anisotropía del desplazamiento químico, que puede ser a su vez promediada por la aplicación de dicha técnica. La rotación de la muestra engendra, sistemáticamente, la aparición de bandas de rotación espaciadas de la frecuencia de rotación y centradas sobre el pico anisotrópico.

\section{8.b. Equipamiento}

El análisis de ${ }^{27} \mathrm{Al} \mathrm{RMN}$ se realizó con un espectrómetro cedido por el Centro "Unité de catalyse et chimie du solide" (UCCS), UMR-CNRS, Universite' des Sciences et technologies de Lille, Francia, mediante un equipo Bruker ASX400 (9.4 T) operando a la frecuencia Larmor ${ }^{27} \mathrm{Al}$ de $104.3 \mathrm{MHz}$ usando "probeheads" de $4 \mathrm{~mm}$. Los espectros ${ }^{27} \mathrm{Al}$ - MAS NMR se registraron mediante un pulso de adquisición simple con pequeño ángulo (П/12) para asegurar una excitación de transición central y ciclos de $5 \mathrm{seg}$. La referencia usada fue a 0 ppm relativa a $\mathrm{Al}\left(\mathrm{NO}_{3}\right)_{3} 1 \mathrm{M}$ en solución acuosa.

\subsection{Parámetros texturales y medidas de superficie mediante el método BET (Brunauer, Emmett, Teller ).}

\section{9.a. Consideraciones Generales}

El área superficial de un material es una propiedad de importancia fundamental para el control de velocidad de interacción química entre sólidos y gases o líquidos.

El método básico de medición de área superficial (Método BET) implica la determinación de la cantidad de un gas inerte, normalmente nitrógeno $\left(\mathrm{N}_{2}\right.$ como absorbato), requerido para formar una capa con un espesor mono molecular sobre la superficie de una muestra a una temperatura criogénica. El área de la muestra se calcula luego utilizando el área conocida (a partir de otras consideraciones) a ser ocupada por cada molécula de nitrógeno en esas condiciones. Clásicamente, las mediciones 
necesarias son llevadas a cabo utilizando una muestra evacuada encerrada en una cámara y enfriada en un baño de nitrógeno líquido al cual se admite la entrada de cantidades conocidas de nitrógeno gaseoso. La medición de la presión de gas y de los cambios de presión permite determinar el punto en el cual se forma la monocapa. Estos datos establecen también el volumen de gas que compone la monocapa, y en consecuencia el número de moléculas. Un cálculo directo da luego el área superficial de la muestra. Un aspecto deseable de esta técnica es que solo incluye mediciones fundamentales de fuerza y longitud (volumen).

Usando $\mathrm{N}_{2}$, el área superficial se obtiene mediante la ecuación (9):

$$
\mathrm{SA}\left(\mathrm{m}^{2} / \mathrm{g}\right)=4.35 \mathrm{Vm}\left(\mathrm{cm}^{3}(\mathrm{CNTP}) / \mathrm{g}\right)
$$

Donde 4.35 es una constante que involucra el área cubierta por una molécula de $\mathrm{N}_{2}$.

Pese a que el modelo de BET ha sufrido varias críticas debido a que las superficies reales de los sólidos no siguen todas las aproximaciones del modelo [32], es el método más ampliamente usado para determinar área superficial de sólidos. En el rango de presiones relativas $0.05-0.35$ es capaz de interpolar los datos experimentales para la mayoría de los sólidos. En el caso de sólidos microporosos, el Vm computado por la ecuación de BET corresponde al volumen de microporos más el volumen de la monocapa sobre la superficie externa de los microporos [33]. En este caso es recomendable utilizar el término "área aparente".

\section{9.b. Equipamiento}

El análisis textural se hizo mediante isoterma de adsorción de $\mathrm{N}_{2}$ a $77^{\circ} \mathrm{K}$ en un equipo automático Micromeritics ASAP 2020 determinando la superficie específica aparente $(\mathrm{Sg})$, el volumen total de poros $(\mathrm{Vp})$ y de microporos (Vo). La desgasificación se realizó a $100^{\circ} \mathrm{C}$ por debajo de $30 \mu \mathrm{m} \mathrm{Hg}$. 


\subsection{Análisis térmicos}

Los métodos de análisis térmicos se basan en la medida de la relación entre la temperatura y alguna propiedad de un sistema, como la masa o el calor de reacción. Los métodos térmicos más utilizados son tres,

- Análisis termogravimétrico, TGA

- Análisis térmico diferencial, DTA

- Reducción por temperatura programada, TPR.

2.10.a. Análisis termogravimétrico (TGA) y diferencial en atmósfera inerte (DTA)

\subsection{0.a.I. Análisis termogravimétrico}

En el análisis termogravimétrico se registra de forma continua, en atmósfera controlada, la masa de una muestra a medida que aumenta su temperatura en forma lineal desde la temperatura ambiente hasta temperaturas del orden de $1200^{\circ} \mathrm{C}$. La gráfica de la masa en función de la temperatura se denomina termograma y proporciona información cualitativa y cuantitativa de las muestras. También se puede representar la derivada de la masa en función del temperatura (o tiempo, dependiendo si la experiencia es estática o dinámica), generándose un termograma diferencial.

El aparato para realizar un análisis termogravimétrico, se denomina termobalanza, que incluye: Una balanza analítica, horno, mecanismo de control y programación de la temperatura del horno, un registrador y equipo opcional para trabajar en vacío o en atmósfera controlada a presión controlada.

Un cambio de masa origina un desequilibrio en el brazo y un cambio en la trayectoria del haz luminoso que se detecta con fotocélulas. La corriente resultante se amplifica y se registra, además de alimentar la bobina del galvanómetro, haciendo que el haz regrese a su posición inicial. La carga máxima de la balanza suele ser de $2.5 \mathrm{~g}$, detectándose cambios del orden del mg con una precisión relativa de $\pm 0.1 \%$. El incremento de temperatura puede realizarse desde 0.5 hasta $25\left({ }^{\circ} \mathrm{C} / \mathrm{min}\right)$. 
Las temperaturas se miden por medio de termocuplas. Estos suelen ser de $\mathrm{Pt}-\mathrm{Rh}$, Fe-constantan (constantan es una aleación de 60 \% Cu y $40 \%$ Ni), Cr-alumel (alumel es una aleación de 94 \% Ni y pequeñas cantidades de Si, Al, Mn), dependiendo de las temperaturas máximas que se desee alcanzar.

Los métodos termogravimétricos están limitados por las reacciones de descomposición y de oxidación y por procesos tales como la vaporización, la sublimación y la desorción.

En el presente estudio, se pesaron $30 \mathrm{mg}$ de cada muestra, luego fueron humedecidas con $10 \mu \mathrm{l}$ del agua destilada, pesadas y secadas en estufa $1 \mathrm{~h}$ a $80^{\circ} \mathrm{C}$ y pesadas nuevamente.

El análisis TGA se realizó con 10 mg de cada material así tratado.

\subsection{0.b. Análisis térmico diferencial}

Mide la diferencia de temperatura entre la muestra y un material inerte de referencia mientras son sometidos al mismo programa de temperaturas. La muestra de referencia inerte suele ser alúmina o carburo de silicio, sometiéndose ambas a un incremento de temperatura a velocidad constante.

Las características fundamentales que debe cumplir el material de referencia son:

- no experimentar procesos térmicos en el intervalo de temperatura a estudiar,

- no reaccionar con el crisol que lo contiene o con los termopares,

- presentar una conductividad térmica similar a la de la muestra.

Las gráficas presentan picos positivos o negativos, correspondientes a procesos exotérmicos o endotérmicos.

Los cambios térmicos están asociados a fenómenos físicos o químicos. En los procesos físicos endotérmicos están incluidos la fusión, vaporización, sublimación y desorción. La absorción y adsorción suelen ser procesos endotérmicos y las transiciones 
cristalinas pueden ser tanto exotérmicos como endotérmicos. Las reacciones químicas pueden ser igualmente endotérmicas y exotérmicas.

Las aplicaciones más comunes del análisis térmico diferencial son: Determinación de cambios de fase (fusión, cristalización, sublimación, cristal A - cristal B), estudios de reacciones químicas, estudios de procesos de desorción, etc.

Las cantidades pesadas de la muestra y la sustancia de referencia se colocan en dos platillos indicados correctamente. Cualquier diferencia de temperaturas entre el termopar de la muestra y el de referencia, conectados en serie, se traduce en una corriente que se amplifica y se registra. Al igual que en la termogravimetría se puede trabajar a vacío y en atmósferas controladas.

\subsection{0.b.I. Equipamiento}

El análisis térmico TG-DTA se realizó con un equipo Shimadzu Thermolanalyzer en atmósfera de aire entre temperatura ambiente y $1000{ }^{\circ} \mathrm{C}$.

\subsection{0.c Reducción a temperatura programada (TPR)}

\subsection{0.c.I. Consideraciones generales}

Para analizar la interacción precursor-soporte se realizaron medidas de Reducción Térmica Programada TPR. Se utilizó un equipo Quantachrome, modelo Quantasorb Jr. En el presente estudio, los diagramas de TPR se obtuvieron con una mezcla de $10 \%$ de $\mathrm{H}_{2}$ y $90 \%$ de $\mathrm{N}_{2}$ con un caudal de $20 \mathrm{~cm}^{3} / \mathrm{min}$, utilizando un programa de calentamiento a partir de temperatura ambiente hasta $850{ }^{\circ} \mathrm{C}$.

La reducción térmica a temperatura programada es una técnica relativamente nueva que se usa para la caracterización de materiales oxídicos. Esta técnica, sencilla en su concepto y aplicación, se basa en la reducibilidad de los mismos, permitiendo obtener información no solo de naturaleza puramente analítica, sino también y más importante, de la condición de las especies presentes. 
Al comenzar la experiencia de reducción a temperatura programada, el gas reductor (usualmente mezclas de $\mathrm{H}_{2} / \mathrm{N}_{2}$ ) se hace fluir sobre una cantidad fija del sólido a bajas temperaturas, hasta entrar en régimen. La temperatura se aumenta gradualmente a una velocidad lineal.

El consumo de $\mathrm{H}_{2}$ se detecta por medio de una celda de conductividad térmica. Como es ampliamente conocido, el perfil típico de TPR $\left(\mathrm{H}_{2}\right.$ consumido vs. Temperatura) muestra una o más señales en el proceso de reducción para componentes metálicos, de acuerdo a la reacción general (10):

$$
\mathrm{MO}_{\mathrm{x}}+\mathrm{xH}_{2} \rightarrow \mathrm{M}^{\mathbf{o}}+\mathrm{xH}_{2} \mathrm{O}
$$

Asimismo en el proceso de reducción pueden estabilizarse óxidos metálicos con estados de oxidación menores, dependiendo de las características redox de los elementos.

Resulta conveniente medir el consumo de hidrógeno por las diferencias en la conductividad térmica del gas antes y después de la reducción. Esto se logra fácilmente usando bajas concentraciones del mismo en nitrógeno o argón (ej. 5-10 \% $\mathrm{H}_{2} / \mathrm{N}_{2}$ ).

Para realizar una medida se parte de una determinada cantidad de muestra ( 50-200 mg) la que se coloca en el reactor y se la somete a una corriente gaseosa que pasa a través del sistema a una velocidad de flujo de aproximadamente $50-60 \mathrm{~cm}^{3} / \mathrm{min}$. El gas reductor pasa a través de un catalizador de desoxigenación, una trampa de frío y un brazo de la celda de conductividad térmica para luego entrar en el reactor en donde se calienta a una velocidad lineal programada $\left(1-20^{\circ} \mathrm{C} / \mathrm{min}\right)$.

Al salir del reactor pasa por otra trampa de enfriamiento que contiene un tamiz molecular u otro absorbente (para remover el agua que es producto de la reacción) y entra al otro brazo de la celda de conductividad térmica en la cual se detecta por comparación entre las dos ramas el cambio en la concentración de hidrógeno. El cambio en la concentración de hidrógeno versus el tiempo es graficado por un registrador. Dado que el flujo de gas es constante, el cambio en dicha concentración es proporcional a la velocidad de reducción. Los distintos procesos de reducción de la muestra aparecen como picos en el perfil del diagrama de reducción a temperatura programada. 


\subsection{0.c.II. Equipamiento}

El gas utilizado en todas las experiencias consistió en una mezcla de $10 \%$ de $\mathrm{H}_{2}$ $90 \%$ de $\mathrm{N}_{2}$, el caudal del mismo se mantuvo entre 60 y $100 \mathrm{~cm}^{3} / \mathrm{min}$ y la velocidad de calentamiento en $10^{\circ} \mathrm{C} / \mathrm{min}$, la temperatura máxima alcanzada fue de $1000^{\circ} \mathrm{C}$. En todos los casos el peso de la muestra fue de $\sim 50 \mathrm{mg}$. El $\mathrm{H}_{2}$ consumido se detectó mediante una celda conductimétrica.

\subsection{Análisis de sitios ácidos por el método TPSR (Reacción Superficial a temperatura programada)}

\subsection{1.a. Consideraciones generales}

La Reacción Superficial a Temperatura Programada (TPSR) es una técnica termo-analítica, frecuentemente usada para caracterizar las propiedades químicas superficiales de catalizadores. Está basada en la adsorción química de un gas sobre un sólido y la posterior desorción mediante un aumento progresivo de la temperatura.

Puesto que se está hablando de quimisorción, la energía de interacción adsorbato-superficie está en el intervalo de 40-800 kJ/mol, es decir, una energía del orden requerido para la formación de enlaces. Por tanto, el gas adsorbato debe ser capaz de interaccionar químicamente con la superficie.

En la superficie de los sólidos, generalmente los centros sobre los que tiene lugar la quimisorción y posterior reacción, no son todos iguales, de forma que cada uno de ellos interacciona con el adsorbato con fuerza desigual. De esta manera, la desorción de los productos desde los distintos centros se producirá a diferentes temperaturas.

La TPSR permite determinar el tipo de centros activos que posee un determinado sólido, así como la cantidad relativa de ellos.

La reacción test de descomposición de 2-propanol (isopropanol) es una determinación indirecta para la caracterización de sitios ácidos y básicos presentes sobre 
la superficie de un sólido. La descomposición de este alcohol involucra reacciones de eliminación (deshidratación y deshidrogenación) que se llevan a cabo a través de tres mecanismos distintos: mecanismo $\mathrm{E}_{1}$, mecanismo $\mathrm{E}_{1 \mathrm{CB}}$ у mecanismo $\mathrm{E}_{2}$. En la Figura 25 se presenta el esquema de reacción y los mecanismos que explican la formación de los diferentes productos.

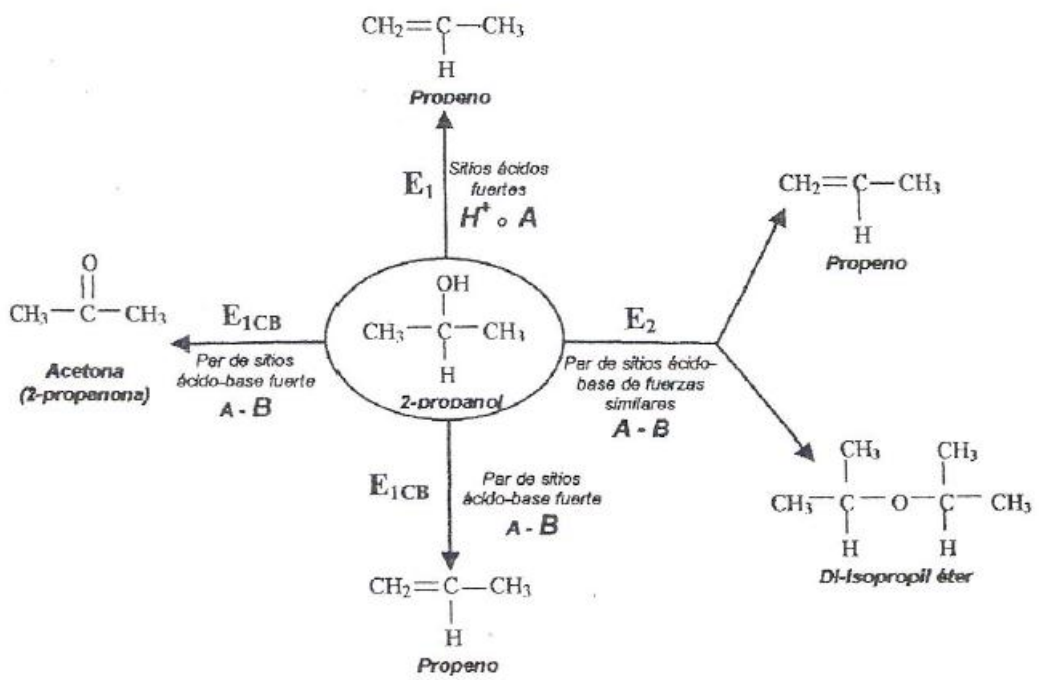

Figura 2-5: Esquema de reacción de descomposición de 2-propanol. (A: Sitio ácido fuerte de Lewis; $\mathbf{H}^{+}$: sitio ácido fuerte de Bronsted; $\mathbf{B}$ : sitio básico de Bronsted; y A: sitio ácido débil de Lewis).

Si se modifican las propiedades ácido-base superficiales, también se modifica la selectividad, lo que constituye el motivo principal por el que se utiliza esta reacción para evaluar los centros activos ácidos y básicos. La formación de propeno y de diisopropil éter se produce por deshidratación, mientras que la de acetona por deshidrogenación. El propeno puede ser generado a través de cualquiera de los tres mecanismos que permite obtener olefinas. El mecanismo $\mathrm{E}_{1}$ involucra sitios ácidos fuertes de Bronsted $\left(\mathrm{H}^{+}\right)$o de Lewis (A), para dar propeno como producto de reacción. Por otro lado, el mecanismo $\mathrm{E}_{1 \mathrm{CB}}$ requiere sitios básicos y sitios ácidos débiles de Lewis, los que actúan concertadamente produciendo igualmente propeno. Por último, el mecanismo de deshidratación $\mathrm{E}_{2}$ involucra pares de sitios ácido-base de fuerzas similares. Por este mecanismo también se produce di-isopropil éter por condensación seguida de deshidratación. 
La deshidrogenación de isopropanol a acetona, se produce a través de un mecanismo $\mathrm{E}_{1 \mathrm{CB}}$ que involucra sitios básicos moderados y fuertes y sitios ácidos débiles. A partir de estas consideraciones, la obtención mayoritaria de propeno (o propeno mas di-isopropiléter) es indicativa de un soporte de naturaleza preponderantemente ácida, mientras que la presencia de acetona indica claramente la existencia de sitios básicos.

\subsection{1.b. Procedimiento experimental y equipamiento.}

Los ensayos de quimisorción y TPSR, para los estudios realizados en esta tesis, se efectuaron con el equipo que se presenta en la Figura 2-6.

Se usaron dos detectores: una celda catarométrica (shimadzu GC-8A) la cuál fue utilizada como detector en tiempo real y un Espectrómetro de Masas Quadrupolar Balzers QMG 112A, que monitoreó la composición de las sustancias desorbidas.

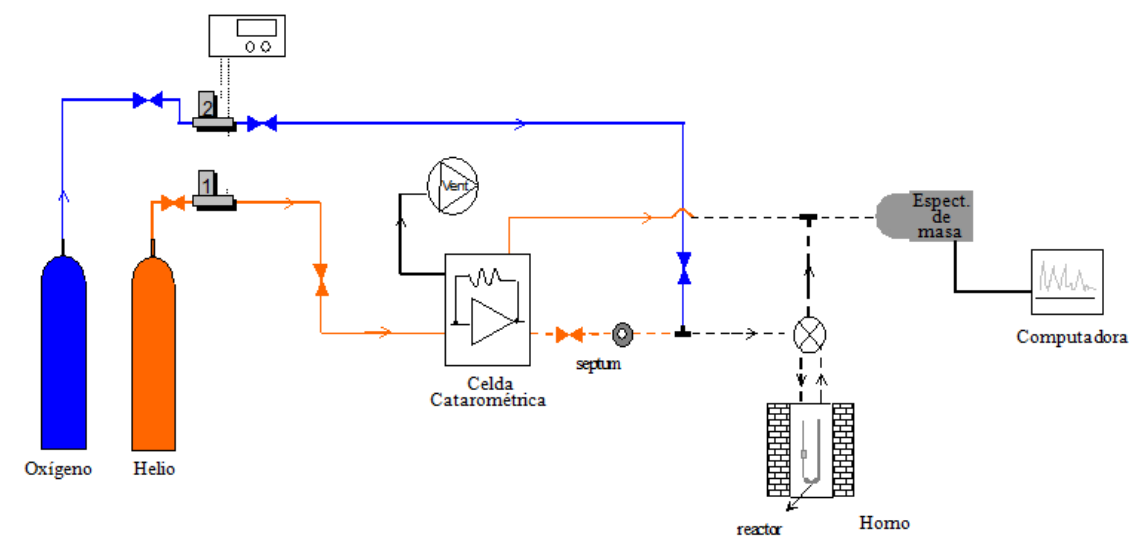

Figura 2-6: Diagrama de flujo del equipo usado para TPSR. (---) líneas de calentamiento.

El sistema posee un flujo controlado de oxígeno de alta pureza para el pretratamiento y helio de 99,9990 \% de pureza, como gas carrier para los estudios de adsorción-desorción. 
La muestra a ensayar se coloca en el reactor en forma de U, ubicado dentro del horno eléctrico, cuya velocidad de calentamiento se controla y registra en una computadora. Las líneas que conectan el septum y el espectrómetro de masas se calientan a $120^{\circ} \mathrm{C}$ para mantener el reactivo (alcohol que puede ser: etanol, isopropanol y n-propanol) y los productos en fase gaseosa.

Para la adsorción química se realiza una serie de inyecciones de una cantidad conocida del reactivo en la corriente de gas inerte $(\mathrm{He})$ que pasa a través del lecho del catalizador en fase gaseosa, hasta saturación de la superficie, se sabe que se llegó a saturar la superficie cuando el detector (celda catarométrica) indica que la cantidad total de inyecciones subsiguientes pasan a través de la muestra sin ninguna pérdida de reactivo. La temperatura a la que se realiza la adsorción es aquella a la que sólo ocurre quimisorción. La misma es monitoreada in situ a través del espectrómetro de masas y de la celda de conductividad, que detecta el alcohol no adsorbido y/o las posibles especies desorbidas desde la muestra (transientes).

Una vez que el reactivo es quimisorbido sobre la superficie de los sitios activos se realiza el TPSR, aplicando temperaturas crecientes sobre la muestra. A una cierta temperatura la energía de calentamiento excede a la energía de unión y las especies quimisorbidas o sus productos de reacción superficial se liberan. Si los sitios activos tienen más de una energía de activación, las especies se desorberán a diferentes temperaturas.

Las moléculas desorbidas entran al flujo del carrier inerte y son llevadas al detector (espectrómetro de masas) que mide la concentración del gas. Mediante un monitor se observa una gráfica con las diferentes cantidades de adsorbato en función de la temperatura.

La identidad y cantidad de las sustancias desorbidas a cada temperatura se puede determinar por el espectrómetro de masas.

Un espectrómetro de masas se fundamenta en la separación de partículas moleculares o atómicas por su diferente masa [34]. Posee tres componentes fundamentales: 
- Fuente de ionización, donde se generan los iones a partir de las sustancias químicas a analizar. La ionización de la muestra se consigue por bombardeo mediante electrones (e-) según el proceso (11):

$$
\mathrm{M}+\mathrm{e}^{-} \rightarrow \mathrm{M}^{+}+2 \mathrm{e}^{-}
$$

- Analizador de masa, diferencia los iones generados en función de su relación masa/carga (m/e).

- Detector, produce una señal eléctrica amplificada para cada uno de los iones generados.

Así, es necesario ionizar las moléculas a través de la ionización electrónica, que se basa en el bombardeo de las mismas con electrones [34].

Una vez generados los iones pasan al analizador, siendo el más usado el denominado cuadrupolo. Este analizador (Figura 2-7) se compone de 4 barras alargadas conectadas eléctricamente entre sí en pares opuestos a los que se le aplica un voltaje variable y, para un voltaje dado, sólo los iones con una relación $\mathrm{m} / \mathrm{e}$ determinada presentarán una trayectoria estable y podrán ser detectados (iones resonantes) mientras que el resto son neutralizados por las barras y expulsados del cuadrupolo por la bomba de vacío.

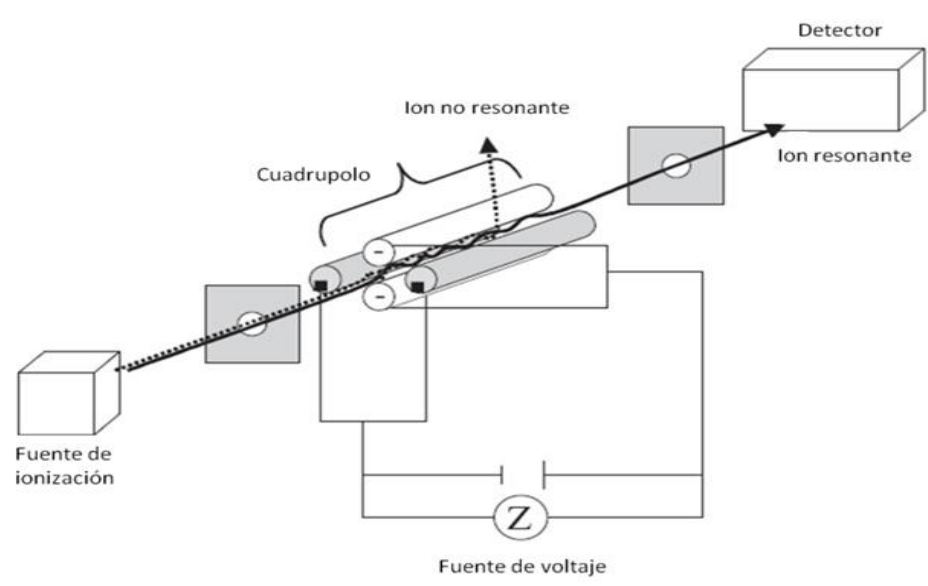

Figura 2-7: esquema del funcionamiento de un cuadrupolo. 
En el presente estudio, como tratamiento previo "in situ" se calentaron los soportes y catalizadores a $350^{\circ} \mathrm{C}$ en $\mathrm{He} 99,999 \%$ de pureza durante $30 \mathrm{~min}$, se enfriaron a $40^{\circ} \mathrm{C}$ y se inyectaron 5 pulsos de isopropanol, posteriormente se calentaron los sólidos hasta $350^{\circ} \mathrm{C}$ con una rampa de calentamiento de $10^{\circ} \mathrm{C} / \mathrm{min}$.

\subsection{Técnicas de caracterización no convencionales. Técnica Laser Speckle Dinámico (DSL)}

Las técnicas ópticas han sido ampliamente usadas para la caracterización de superficies [35]. En particular en esta Tesis se utiliza una técnica conocida como “Speckle Laser Dinámico”.

La misma se basa en un fenómeno de interferencia aleatorio que ocurre cuando un haz de luz coherente proveniente de un láser ilumina una superficie ópticamente rugosa, para longitudes de onda del orden $\lambda=10^{-7} \mathrm{~m}$. En este caso la superficie aparece cubierta de pequeñas regiones brillantes y oscuras llamadas "diagramas de speckle"

Si las superficies no son rígidas, sino que presentan movimientos locales, los diagramas de speckle evolucionan en el tiempo. Por lo tanto, es posible correlacionar los diagramas de speckle dinámicos con el comportamiento de la superficie, permitiendo identificar algunas características de interés.

\subsection{2.a Puesta a punto y calibración de la Técnica}

En esta etapa se realizaron los primeros ensayos para el estudio de la actividad de Speckle dinámico en el proceso de hidroadsorción de distintos materiales de soporte, estableciendo algunas condiciones, de manera de optimizar la técnica de trabajo.

En un laboratorio con ambiente climatizado se realizaron diversas pruebas a los efectos de seleccionar las condiciones óptimas para la implementación de la técnica en este tipo de muestras. Los parámetros seleccionados fueron: temperatura ambiente de $19^{\circ} \mathrm{C}$ y humedad de $60 \%$; en el portamuestra realizado especialmente, se colocó una masa de $30 \mathrm{mg}$ de cada material (previamente molido 60-100 mesh), el que 
inmediatamente después de ser iluminado por el haz del Laser, fue humedecido mediante una microjeringa con $10 \mu 1$ de agua destilada. A partir de ese momento se dió inicio a la adquisición de datos y la experiencia fue controlada cada 12,5 segundos; así la evolución del speckle se registró durante $180 \mathrm{seg}$. Estos parámetros fueron validados comprobándose su reproducibilidad, obteniendo 10 curvas de actividad de Speckle en función del tiempo para cada muestra.

La teoría y método de la técnica de Speckle Laser Dinámico se describe en el Capítulo III.

\subsection{Evaluación de la Actividad catalítica}

Los catalizadores preparados fueron evaluados en dos tipos de reacciones: Hidrogenación Selectiva de Cinamaldehido hacia Hidrocinamaldehído y Test de Oxidación selectiva de Difenilsulfuro.

\subsection{3.a. Tests de Hidrogenación Selectiva de Cinamaldehído}

Se evaluaron los catalizadores preparados por impregnación en equilibrio, indicada en sección 2.2 de las fases Anderson conteniendo Rh. Los catalizadores fueron activados por reducción in situ, sin ser calcinados previamente. La eliminación de la etapa de calcinación, simplifica notoriamente la preparación del catalizador como se ha visto en trabajos previos realizados en hidrotratamiento.

El objetivo es verificar el efecto promotor del heteroátomo (Co, $\mathrm{Rh}$, etc.) en la reacción de hidrogenación selectiva de cinamaldehido hacia hidrocinamaldehido.

La hidrogenación de cinamaldehído en fase líquida fue realizada en un reactor tipo autoclave (Autoclave Engineers) Figura 2-8, a 10 atm de presión de $\mathrm{H}_{2}$ y $85^{\circ} \mathrm{C}$ de temperatura. En cada ensayo se utilizó $0,20 \mathrm{~g}$ de catalizador, previamente reducido en flujo de $\mathrm{H}_{2}$ durante 2 horas a $350^{\circ} \mathrm{C}$. En cada ensayo se utilizaron $0,8 \mathrm{~mL}$ de cinamaldehído y $60 \mathrm{~mL}$ de tolueno como solvente. 


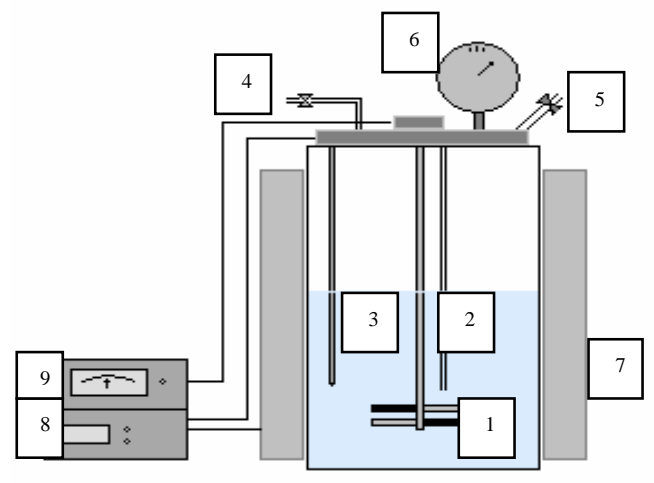

Figura 2-8. Esquema del reactor utilizado para las reacciones de hidrogenación.

(1) agitador; (2) tubo toma-muestra; (3) termocupla; (4) entrada de $\mathrm{H}_{2}$; (5) ingreso de sustrato; (6) manómetro; (7) horno; (8) controlador de temperatura; (9) controlador de velocidad de agitación.

La evolución de la reacción fue seguida por cromatografía gaseosa en un cromatógrafo Varian CP-3800 provisto de una columna capilar CP wax $52 \mathrm{CB}$ (30 m x $0.53 \mathrm{~mm}$ ) y un detector FID. Los productos de reacción fueron identificados utilizando un equipo GC/MS Shimadzu QP5050 con una columna capilar SUPELCO SPBTM-5 (30m, 0.25mm d.i.).

La conversión (\%) de CAL se calculó en base a la diferencia entre moles iniciales de CAL y moles de CAL no consumidos en un tiempo $t$ / moles iniciales de CAL.

La selectividad (\%) se calculó en base a la relación de mol de producto / moles totales de productos obtenidos.

\subsection{3.b. Dispersión}

La dispersión de un catalizador es un término que se refiere a la relación entre el número de átomos de metal expuesto frente al total de los átomos soportados en el precursor. Determinada por una valoración con $\mathrm{H}_{2} \mathrm{O}_{2}$. 
Este dato es de gran importancia ya que determina la cantidad de metal que puede actuar como catalizador en las reacciones en las que intervenga. Los valores de dispersión de la fase metálica de un catalizador depende de diversos factores, como puede ser el precursor metálico utilizado, su interacción con el soporte, el método de preparación, la presión parcial del agua sobre el sólido, el proceso de reacción y la temperatura de reducción.

Durante el proceso de reducción se forman inicialmente pequeños cristalitos de metal que actúan como centros de nucleación y sobre ellos el reductor. En nuestro caso el $\mathrm{H}_{2}$, se adsorbe disociativamente, resultando la formación de átomos de hidrógeno quimisorbidos. El complejo metálico está adsorbido sobre el soporte y sus partículas son de alguna manera móviles.

Cuando éstas alcanzan los centros de nucleación cubiertos de hidrógeno, se reducen a metal provocando un aumento de su superficie y como consecuencia un aumento de la velocidad de reducción y un crecimiento más rápido del cristal. Se puede decir, por lo tanto, que los cristalitos catalizan su propio crecimiento [36].

Dado que el aumento de la velocidad de reducción se produce en forma abrupta, éste debe producirse cuando los cristalitos alcanzan un tamaño mínimo, crítico. Por otro lado, puesto que pueden obtenerse catalizadores dispersos, debe de haber un gran número de cristalitos que alcancen el tamaño crítico al mismo tiempo y por lo tanto, la nucleación de los cristalitos debe ocurrir también al mismo tiempo una vez comenzado el proceso de reducción.

Esto implica que, o bien los núcleos ya están presentes en ese instante, o que una fracción del metal está en forma reactiva, formándose núcleos tan pronto como empieza la reducción.

La dispersión de los catalizadores dependerá para un determinado soporte, por lo tanto, de tres factores:

1.- El número de cristalitos que alcancen el tamaño crítico al mismo tiempo, es decir, del número de núcleos iniciales. 
2.- La velocidad de transporte de los complejos metálicos hacia los cristalitos en crecimiento.

3.- La velocidad de reducción de los complejos sobre la superficie metálica.

Cuando la reducción del complejo sobre la superficie es la etapa controlante (lenta) de la velocidad de reducción, la velocidad de crecimiento de los cristalitos será proporcional a su área superficial, con lo que, los cristalitos más grandes crecerán rápidamente, dando como resultado un número pequeño de cristales de gran tamaño y, por lo tanto, una dispersión baja. Cuando la difusión del complejo metálico hacia la superficie de los cristalitos es la etapa controlante (lenta), todos los cristalitos crecerán con la misma velocidad al ser rápida la reducción del metal en su superficie y se conseguirá una dispersión alta [37].

Teniendo esto en cuenta se conseguirá una dispersión óptima cuando:

- Haya un número alto de núcleos iniciales.

- La reducción del complejo metálico sobre la superficie de los cristalitos sea rápida.

- La difusión del complejo metálico sea lenta.

\subsection{3.b.I. Valoración $\mathrm{O}_{2} / \mathrm{H}_{2}$}

La determinación de la dispersión metálica mediante la valoración $\mathrm{O}_{2} / \mathrm{H}_{2}$ fue desarrollada por Benson y Boudart [38]. La determinación de la estequiometría entre $\mathrm{O}_{2} / \mathrm{H}_{2}$ es uno de los principales temas de controversia en la aplicación de esta valoración. La bibliografía consultada establece para el rodio una relación $\mathrm{H} / \mathrm{O}$ en torno a tres, de acuerdo a la reacción (12):

$$
\mathrm{Rh}-\mathrm{O}+3 / 2 \mathrm{H}_{2} \rightarrow \mathrm{Rh}-\mathrm{H}+\mathrm{H}_{2} \mathrm{O}
$$

En la reacción (3-2) la estequiometría $\mathrm{Rh} / \mathrm{H}_{2}$ es 1:3 [39]. El método consiste en comparar las diferencias en las valoraciones volumétricas que experimenta el gas que entra en contacto con la muestra. 
El método de trabajo consistió en la reducción "in situ" de $0.5 \mathrm{~g}$ (en forma de pastillas) de cada precursor catalítico, los que fueron pretratados en corriente de $\mathrm{N}_{2}$ durante media hora a $150^{\circ} \mathrm{C}$, luego reducidos en $\mathrm{H}_{2}\left(10 \%\right.$ en $\left.\mathrm{N}_{2}\right)$ a $350^{\circ} \mathrm{C}$ durante $1 \mathrm{~h}$ y purgados con $\mathrm{N}_{2}$ a $350^{\circ} \mathrm{C}$ por $1 \mathrm{~h}$ antes de enfriar a temperatura ambiente, en $\mathrm{N}_{2}$. Las muestras fueron expuestas a un flujo de $\mathrm{O}_{2}\left(10 \%\right.$ en $\left.\mathrm{N}_{2}\right)$ a temperatura ambiente durante 30 min. y se purgó con un flujo de $\mathrm{N}_{2}$ durante $30 \mathrm{~min}$. Después de una cuidadosa evacuación a temperatura ambiente se redujo la presión a $1 \mathrm{~Pa}$, y se determinó el $\mathrm{H}_{2}$ irreversible " $\mathrm{H}_{\text {irr" }}$ " a temperatura ambiente. En particular, el $\mathrm{H}_{2}$ total adsorbido se determinó a presión cero mediante la extrapolación de las isotermas de adsorción, (usando la presión del hidrógeno en un rango de 6,6 a 26,6 kP). Las muestras fueron posteriormente purgadas a temperatura ambiente por $30 \mathrm{~min}$. y se determinó una segunda isoterma correspondiente a la parte reversible de la adsorción. La diferencia entre el valor consumido total (primer isoterma) y el valor consumido de la isoterma reversible (segunda isoterma) de la parte lineal y en paralelo de las isotermas, dió el valor consumido irreversible de la adsorción (Isoterma doble método). La átomos de $\mathrm{Rh}$ expuestos, luego, fueron calculados a partir de $\mathrm{H}_{\text {irr }}$, suponiendo una relación $\mathrm{H}_{\mathrm{irr}} / \mathrm{Rh}=$ 1.

El porcentaje de metal disperso en la superficie del soporte se calculó teniendo en cuenta la cantidad de rodio anclado en cada soporte.

A partir de los datos obtenidos por quimisorción se puede calcular la superficie metálica expuesta y el tamaño de las partículas metálicas. La superficie metálica, S, se calcula a partir de la expresión (13):

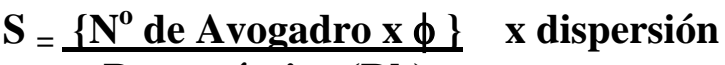 Peso atómico $(\mathbf{R h})$}

Siendo $\phi$ la sección transversal del átomo metálico (en el $\mathrm{Rh} \phi=7.6 \AA^{2}$ ) y $\mathrm{S}$ la superficie metálica expresada en $\mathrm{m}^{2} / \mathrm{g}$ metal.

Una vez conocida la superficie metálica es posible calcular el tamaño de partícula metálica, suponiendo que posee una determinada forma geométrica. 
La determinación de la forma de las partículas es complicada en un catalizador bien disperso, suponiéndose una forma esférica, cúbica o formas más complejas como icosaédricas o cubooctaédricas.

En nuestro caso, el tamaño del cristal se calcula considerando la forma esférica de la partícula a partir de la expresión (14) donde la densidad, $\rho$, para $\mathrm{Rh}$ es $12.4 \mathrm{~g} / \mathrm{cm}^{3}$.

$$
\mathrm{d}=\frac{6}{\mathrm{~S} \times \mathrm{\rho}}
$$

\subsection{3.c. Cálculo de actividad por centro activo: TOF (factor de turn-over)}

Para que el efecto de la carga metálica incorporada al soporte no enmascare los valores de conversión se ha procedido a estudiar la actividad por centro activo de los catalizadores, calculando los valores TOF (factor de turn-over, expresado en nuestro caso como moles del producto mayoritario, hidrocinamaldehido, obtenido por mol de $\mathrm{Rh}$ por minuto, de acuerdo con los valores de dispersión de Rh calculados mediante la valoración $\mathrm{H}_{2} / \mathrm{O}_{2}$ por el método Boudart [38]. Estos valores se calculan según la fórmula (15):

$$
\text { TOF }=\frac{\left(C \cdot S_{\text {HCAL }}\right) \cdot n_{\text {CAL }}}{m \cdot D \cdot \sigma}
$$

Siendo: $\mathrm{C} \rightarrow$ Conversión (\%) de cinamaldehido

$\mathrm{S}_{\mathrm{HCAL}} \rightarrow$ Selectividad hacia el Hidrocinamaldehido (\%)

$\mathrm{n}_{\mathrm{CAL}} \rightarrow \mathrm{n}^{\circ}$ de moles de cinamaldehido a $20^{\circ} \mathrm{C}$

$\mathrm{m} \rightarrow$ masa de precursor $(0.200 \mathrm{~g})$

$\mathrm{D} \rightarrow$ Dispersión (\%)

$\sigma \rightarrow$ Carga metálica $(\% \mathrm{Rh} / \mathrm{Pat})$

$\mathrm{Pat} \rightarrow$ Peso atómico del Rh = $103 \mathrm{~g} / \mathrm{mol}$. 


\subsection{3.d. Tests de oxidación selectiva de difenilsulfuro.}

Dentro de un amplio proyecto dirigido a la síntesis y aplicación de nuevos materiales oxídicos sintéticos y naturales para HDS y/o ODS, los sistemas preparados fueron evaluados como catalizadores en un test típico tipo batch para oxidación selectiva de difenisulfuro (DFS), utilizando $\mathrm{H}_{2} \mathrm{O}_{2}$ como oxidante y acetonitrilo como solvente. Por tal motivo, en el presente trabajo se realizó la funcionalización de materiales PCH (previamente obtenidos en nuestro laboratorio por los métodos antes descriptos) a los fines de obtener soportes adecuados para la adsorción de iso y/ó heteropolimolibdatos del tipo: Anderson $\left[\mathrm{MMo}_{6} \mathrm{O}_{24} \mathrm{H}_{6}\right]^{3-}$ con $\mathrm{M}=\mathrm{Co}(\mathrm{III})$ y $\mathrm{Rh}$ (III) y un derivado estructural, $\left[\mathrm{Co}_{2} \mathrm{Mo}_{10} \mathrm{H}_{4} \mathrm{O}_{38}\right]^{6-}$, para ser utilizados como sistemas catalíticos en oxidesulfuración (ODS) [40-42].

Se llevó a cabo en un reactor batch, a $80^{\circ} \mathrm{C}$, durante períodos determinados a partir de resultados preliminares obtenidos por cromatografía en capa delgada (CCD). Se disolvió $1 \mathrm{mmol}$ de difenilsulfuro (DFS) en $5 \mathrm{ml}$ de $\mathrm{CH}_{3} \mathrm{CN}$. Se agregaron $50 \mathrm{mg}$ de catalizador y $1 \mathrm{ml}$ de $\mathrm{H}_{2} \mathrm{O}_{2} 35 \% \mathrm{p} / \mathrm{V}$. La cuantificación de reactivos/productos se realizó por cromatografía gaseosa (CG). CG: Se utilizó un Cromatógrafo VARIAN Start 3400cx, equipado con una columna Crhompack CP-sil 5 CB (30 m) y Detector FID. 
Capítulo 3:

\section{LASER SPECKLE DINÁMICO (DSL)}

Teoría y método 
En el presente capítulo se hará referencia a la teoría y metodología de la técnica Laser denominada Speckle Dinámico (DSL) orientado al estudio de procesos que evolucionan temporalmente. En este trabajo se aplicará a la caracterización del proceso de adsorción de agua en soportes comerciales y pretratados los que serán luego utilizados para la preparación de los catalizadores de interés en esta Tesis, habida cuenta que la impregnación de los soportes se realiza con soluciones acuosas de la fase activa.

\subsection{Antecedentes generales del Fenómeno "Speckle"}

Cuando un objeto es iluminado por un haz de luz coherente proveniente de un laser, éste adquiere una apariencia granular, constituida por pequeñas regiones brillantes y oscuras a la cual se denomina Diagrama o Patrón de Speckle [1]. Este es un fenómeno de interferencia que aparece cuando una superficie ópticamente rugosa, para longitudes de onda del orden $\lambda=10^{-7} \mathrm{~m}$, se ilumina con un haz de luz coherente. Este es el caso de la mayoría de las superficies salvo aquellas muy pulidas como los vidrios, lentes y espejos. La fuente de luz coherente que se utiliza en los estudios que se presentan en esta Tesis es un láser de He-Ne cuya $\lambda$ es $632,8 \mathrm{~nm}$. Las ondas luminosas observadas en un punto situado a una cierta distancia de la superficie son la superposición de varios paquetes de onda coherentes surgidos cada uno de ellos de diferentes elementos de la superficie difusora. Estas ondas originadas en la superficie tienen una fase y una amplitud aleatoria en el punto de observación y la diferencia de camino óptico entre ellas pueden diferir en varias longitudes de onda. La interferencia entre estas ondas esféricas desfasadas pero coherentes, da como resultado el diagrama granular conocido en Óptica como "Speckle Laser".

No obstante, la historia del speckle comienza desde hace más de dos siglos, mucho antes que la del laser. Nombres como los de Newton [2] y Lord Rayleigh [3] aparecen relacionados con él. Pero sin embargo, se comenzó a estudiar en forma rigurosa con el desarrollo de una fuente luminosa coherente, el laser, donde se ha profundizado su análisis y se han encontrado numerosas aplicaciones [4,5].

Un registro de diagrama de speckle se muestra en la Figura 3-1. Un haz luminoso proveniente de un laser ilumina una superficie ópticamente rugosa. A una cierta distancia se forma el patrón de speckle compuesto por pequeñas regiones brillantes y 
oscuras. El mismo puede observarse a simple vista o proyectado sobre una pantalla o sensor como por ejemplo una cámara CCD.

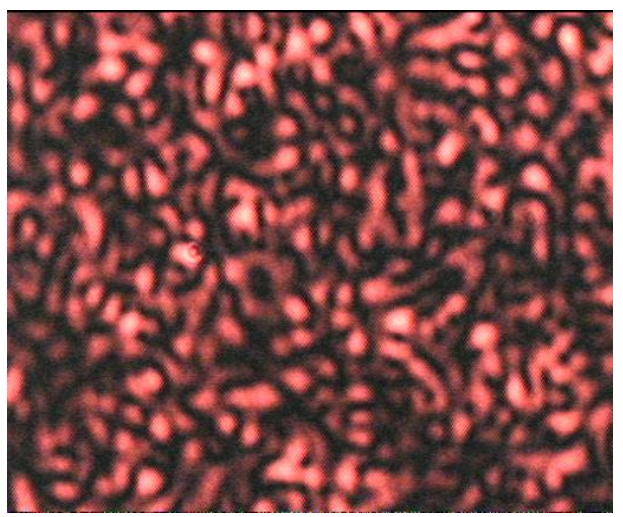

Figura 3-1: Formación de speckle por reflexión.

También un patrón de speckle puede observarse por transmisión como se muestra en la Figura 3-2. En este caso el laser ilumina una superficie transparente rugosa, típicamente un vidrio despulido. A una cierta distancia del mismo, se observa un patrón de características similares al caso del speckle por reflexión

\section{Physical Origin of Speckle}

(Transmission)

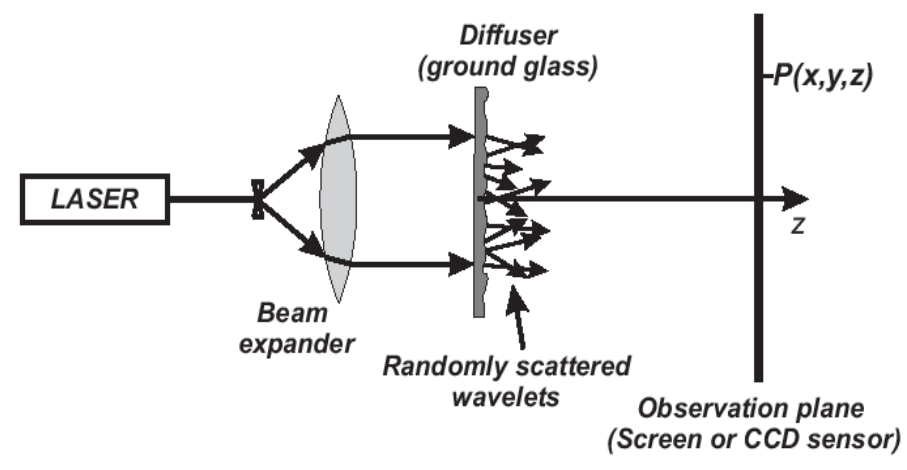

Figura 3-2: Formación de speckle por transmisión. 
La estructura detallada de la granularidad óptica o "speckle" no tiene una relación directa con las características macroscópicas del objeto, sino que aparece caótica y desordenada.

Por lo tanto, la naturaleza aleatoria de los diagramas de speckle hace que este fenómeno sea estudiado convenientemente utilizando un punto de vista estadístico [6]. Las propiedades estadísticas dependen de la coherencia del haz incidente, de las características de la superficie difusora y del medio de registro empleado como detector.

En los primeros años del laser y debido al aspecto granular que presentan los objetos cuando son iluminados de esta forma, el speckle se constituyo en un inconveniente para la holografía [7], ya que degradaba la calidad de la imagen. Es por ello que varios investigadores desarrollaron métodos para reducir el ruido de speckle en imágenes holográficas [8].

Sin embargo, debido a las propiedades particulares del haz de radiación luminosa, el láser es una herramienta ideal en muchas aplicaciones donde es necesaria una fuente controlada y localizada de energía. Si a este factor diferenciador inicial se le suma la facilidad para su control automático y regulación, se observa cómo se amplía el campo de utilización a otros usos en los que la precisión, la minimización de daños colaterales y la menor modificación de la características del material circundante y de sus dimensiones son importantes. De ahí el amplísimo rango de aplicaciones [4,5,9].

Es por ello que, paralelamente, a medida que se lograban avances para disminuir la presencia del speckle como factor de ruido en los sistemas ópticos, las técnicas speckles han sido utilizadas con éxito por ejemplo en Ingeniería, como técnicas de ensayos mecánicos no destructivos para estudiar desplazamientos, deformaciones, fisuras, rugosidad, etc. $[10,4,11,12,13]$.

Los métodos aplicados son conocidos como interferometría speckle y fotografía speckle [14]. La ventaja de los métodos es que el tamaño del grano puede ser ajustado de acuerdo a la resolución de los detectores preservando la información sobre el desplazamiento a escala interferométrica, es decir pocos micrones para las longitudes de onda usualmente empleadas. Algunas de estas técnicas pueden ser extendidas de modo que proporcionen información a tiempo real utilizando cámaras de video combinadas 
con un procesamiento analógico y digital de las imágenes obtenidas. A estos métodos se los denomina genéricamente ESPI (interferometría electrónica de diagramas de speckle) o DSPI (Digital Speckle pattern interferometry) [15].

\subsection{Propiedades Estadísticas [5,7]}

Como se ha mencionado en la Sección 3.1, en general cualquier objeto iluminado por un laser presenta una estructura granular muy fina siempre que su superficie sea ópticamente rugosa, es decir estos objetos son difusores, tales como el vidrio, papel, metal, etc. Dicho aspecto granular determina la estructura característica de los diagramas de interferencia producida por la distribución aleatoria de fase del objeto. Si reemplazamos el ojo de un observador por un sistema óptico formador de imágenes, por ejemplo una cámara digital $\mathrm{CCD}$, el registro muestra un diagrama de granos de speckle cuyo tamaño y forma dependen de la apertura del objetivo y de la geometría del sistema óptico. La estructura del speckle será mas fina cuanto mayor sea la apertura, ya que decrece el diámetro de la figura de difracción. Este diagrama granular es denominado "Speckle subjetivo o de Fraunhofer". La Figura 3-3 (b) muestra la configuración experimental para obtener speckle de Fraunhofer.

Si el diagrama de speckle no es obtenido por una imagen, sino por una CCD sin lente colocada a una cierta distancia finita del objeto, se produce una superposición de frentes de ondas denominado "speckle objetivo o de Fresnel" que se muestra en la Figura 3-3 (a). En este caso el tamaño del grano de speckle depende del área iluminada y de la distancia de observación. 


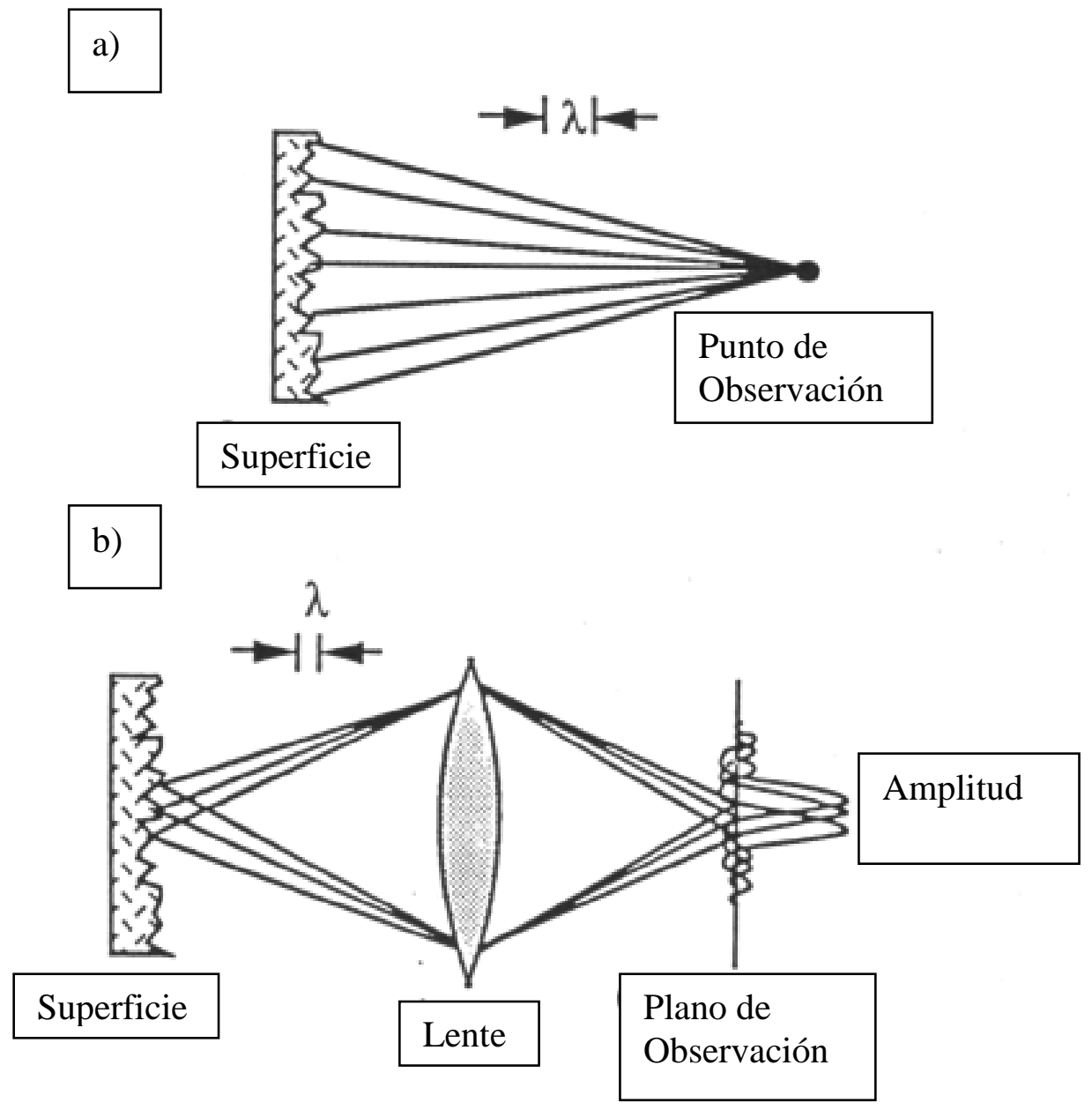

Figura 3-3: (a) Speckle Fresnel, (b) Speckle de Fraunhofer

Estas características del tamaño del grano de speckle surgen del análisis estadístico de los patrones de speckle.

En esta Sección mencionaremos solo algunas propiedades estadísticas elementales necesarias para una mejor comprensión de las técnicas que utilizaremos en esta Tesis.

De acuerdo a Goodman [6], para luz coherente y considerando que el medio no despolariza la luz, que introduce diferencias de fases mayores que $2 \pi$ y que un gran número de centros difusores contribuye a la intensidad en un punto de observación, es posible demostrar que la intensidad en un punto del diagrama de speckle obedece a una función de densidad de probabilidad exponencial negativa. Se utiliza aquí el teorema 
central del límite en una estadística Gaussiana. También se demuestra que el contraste es igual a uno y que la intensidad mas probable es igual a cero. La fase está uniformemente distribuida entre $-\pi$ y $\pi$.

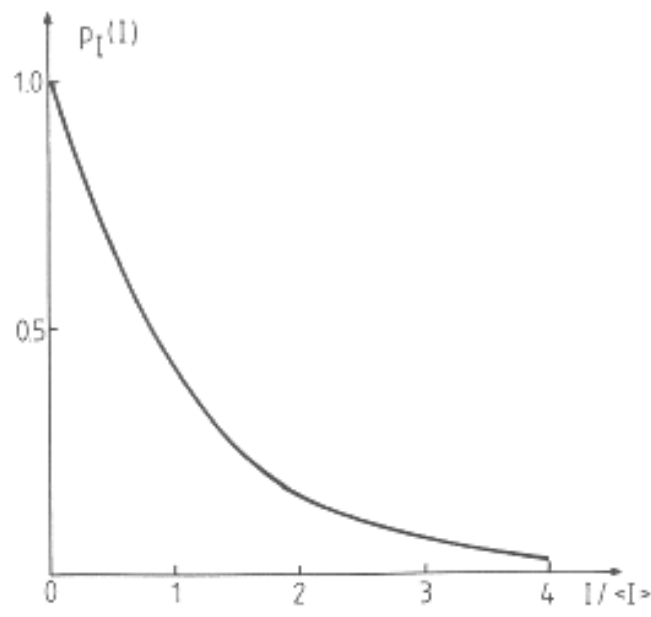

(a)

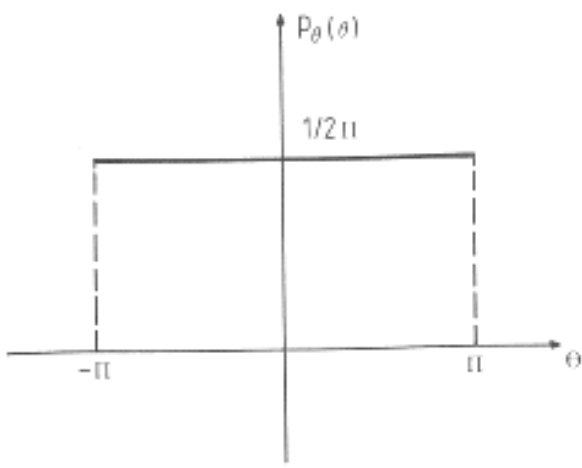

(b)

Figura 3-4: Estadísticas de a) Intensidad y b) Fase de un diagrama de speckle.

En la Figura 3-4, se muestran gráficos para las estadísticas de intensidad y fase de un diagrama de speckle típico.

La estructura de los diagramas de speckle se puede definir en términos de la función de autocorrelación de la pupila que limita al sistema óptico involucrado.

Se define función de autocorrelación: 
En el procesamiento de señales, dada una señal $\mathrm{f}(\mathrm{t})$, la autocorrelación $\operatorname{Af}(\tau)$ es la correlación cruzada de $\mathrm{f}(\mathrm{t})$ con sí mismo, con el retardo $\tau$, y se define como:

$$
A f(t)=f^{\prime}(-\tau) \otimes f(\tau)=\int_{-\infty}^{\infty} f(t+\tau) f^{\prime}(t) d t=\int_{-\infty}^{\infty} f(t) f^{\prime}(t-\tau) d t
$$

Las propiedades estadísticas dependen de la posición en el plano de observación y la función de autocorrelación debe calcularse en términos de los ángulos de difusión radiales y azimutales. La coherencia espacial parcial afecta a los diagramas de speckle, bajando el contraste y causando un incremento en el tamaño de los granos.

El tamaño típico de cada grano está determinado por la pupila del sistema, siendo su dimensión inversamente proporcional al tamaño de la misma [16].

Considerando una pupila circular de diámetro $\mathrm{D}$ y la distancia imagen $\mathrm{d}_{\mathrm{i}}$, el radio aproximado de los granos de speckle será del orden del disco de Airy.

$$
\mathbf{R}=\mathbf{0 . 6 1} \lambda / \alpha
$$

siendo $\alpha=\mathrm{D} / 2 \mathrm{~d}_{\mathrm{i}}$ la apertura numérica de sistema.

Típicamente, para un objetivo de apertura numérica $\alpha=1 / 4, \lambda=600 \mathrm{~nm}$, la figura de difracción tiene un diámetro de $3 \mu$.

La estructura granular se altera si se realiza un desplazamiento en la dirección del plano difusor, de modo tal que no es posible correlacionarla con la que existía antes del movimiento.

La traslación $\Delta \mathrm{Z}$ compatible con diagramas de speckle correlacionados está acotada por la dimensión lineal del volumen localizado que presenta la distribución tridimensional de energía en el punto imagen:

$$
\Delta \mathrm{Z} \leq 4 \lambda / \alpha^{2}
$$

De las expresiones (1) y (2) se deduce que en el caso de una pupila circular el grano de speckle tiene una estructura volumétrica con una forma aproximada a la de un "cigarro" cuya dimensión longitudinal es : $\Delta Z \leq 4 \lambda / \alpha^{2}$ y su dimensión transversal está dada por 
la figura de difracción y vale $0.61 \lambda / \alpha$. Por lo tanto tiene mayor tolerancia en el eje $\mathrm{Z}$ que en el eje $\mathrm{X}$, con respecto a la correlación. Estas propiedades surgen del estudio estadístico del speckle [6]. Ver Figura 3-5

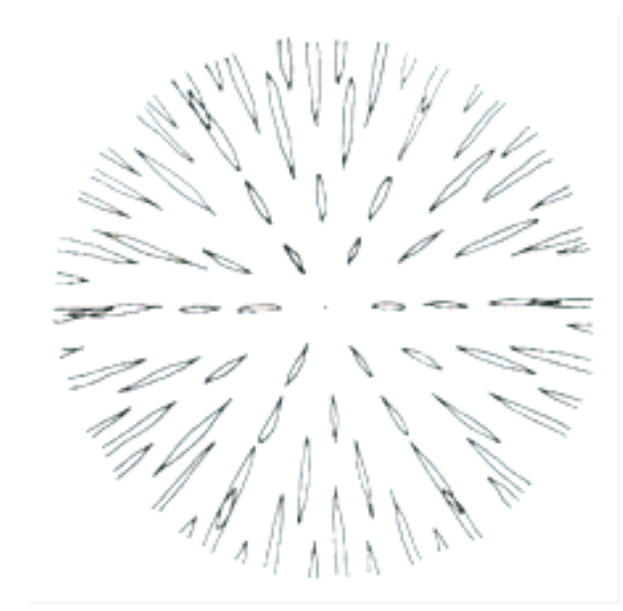

Figura 3-5: Estructura de un patrón de speckle.

A partir de estas consideraciones, el fenómeno speckle no debe ser visto solo como un elemento de ruido, sino como portador de información, ya que su tamaño y forma se regulan con diferentes pupilas que determinan el espectro de frecuencia del registro de speckle. Dicha información es utilizada como herramienta útil en diferentes aplicaciones ya mencionadas y deben ser tenidas en cuenta para diseñar el dispositivo experimental para implementar las técnicas de speckle para nuestras aplicaciones.

\subsection{Speckle Dinámico}

Si la superficie de los objetos iluminados por un láser no permanece rígida, sino que presenta algún tipo de movimiento local, entonces el diagrama de speckle observado evolucionará en el tiempo. Este fenómeno es característico de muestras biológicas. En este caso el diagrama de speckle dinámico adquiere una apariencia similar a un líquido hirviendo y por ese motivo es denominado también como "boiling speckle" o "biospeckle" $[9,17]$.

La observación de patrones de biospeckle muestran que los mismos fluctúan de manera espacio-temporal debido a la complicada estructura y actividad de los objetos 
vivos. Por ese motivo el análisis debe ser también analizado desde un punto de vista estadístico ya que una adecuada descripción matemática es muy dificultosa. Un estudio riguroso debe incluir teorías de scattering múltiple, pero sin embargo se han podido establecer algunas descripciones estadísticas mas simplificadas que aproximan muy bien el comportamiento de los biospeckles [18].

La evolución temporal o "actividad" del diagrama speckle puede ser producida por movimientos de partículas (efecto Doppler), cambios del índice de refracción, movimientos convectivos, explosiones de burbujas, etc. que causan variación aleatoria de la intensidad luminosa local [19].

Como las fluctuaciones de los patrones de biospeckle son producidas por movimientos locales en los objetos, es esperable que haya una correlación entre ambos. Por ejemplo cuando la actividad biológica disminuye con el tiempo, las variaciones en los diagramas de speckle también disminuyen.

La actividad de speckle en muchos casos no es uniforme a lo largo de la superficie, sino que puede variar en distintas regiones de la misma, presentando zonas de alta actividad en contraste con otras de baja actividad. Un ejemplo de ello son los tejidos biológicos que presentan zonas necrosadas con muy escasa actividad de speckle, mientras que zonas biológicamente activas presentan patrones de speckle que evolucionan rápidamente.

Por ese motivo, el estudio de la evolución temporal de diagramas de speckle provee una herramienta interesante para analizar los parámetros biológicos y fisiológicos involucrados en estos procesos y muchos esfuerzos se han desarrollado para realizar medidas que caractericen esta actividad [9]. Con el uso extendido de la tecnología laser en medicina y biología, en los últimos años se han incrementado las aplicaciones de técnicas de biospeckle para el estudio, por ejemplo, de flujo sanguíneo, movilidad de parásitos, placas ateroescleróticas, actividad cerebral en ratas, tejidos tumorales, especímenes botánicos, etc. [9]

A pesar que el fenómeno de biospeckle se presenta en tejidos biológicos, también se puede observar en algunos procesos industriales dinámicos. Tal es el caso del proceso de secado de pinturas, corrosión, evolución de espumas, eflorescencia de sal 
en piedras, etc. [9]. En esta Tesis se presenta un aporte original, al aplicar la técnica del speckle dinámico, al estudio de la hidroadsorción de diversos materiales utilizados como soportes de interés en catalizadores, tales como sílices, alúminas, arcillas, etc.

\subsection{Dispositivo experimental}

En las técnicas de speckle dinámico que presentaremos utilizaremos el esquema experimental que se muestra en la Figura 3-6.

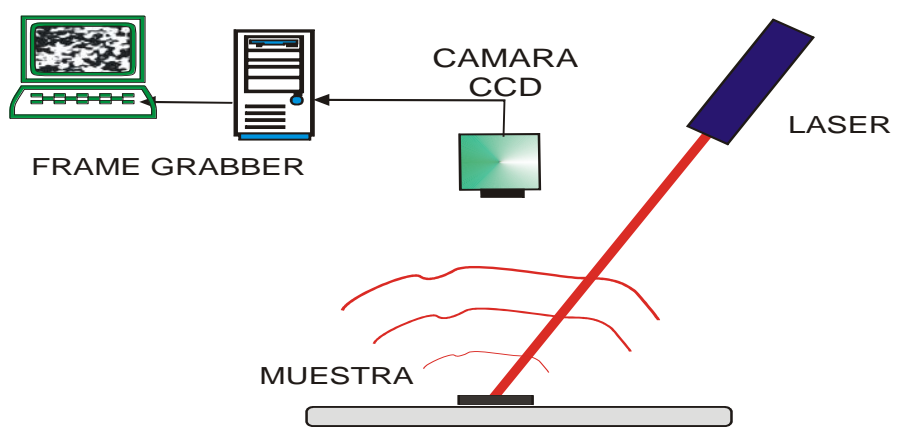

Figura 3-6: Dispositivo experimental para la medición del Speckle dinámico.

Las experiencias se realizan iluminando la muestra con un laser Melles Griot de He-Ne de (longitud onda $\lambda=632,8 \mathrm{~nm}$, potencia $=5 \mathrm{~mW}$ ). Se utiliza como medio de registro una cámara CCD PULNIX conectada a una computadora personal provista de un "Frame Grabber" IT 151 IMAGE TECNHNOLOGY para digitalizar la imagen, teniendo la precaución que el diagrama de speckle sea bien resuelto por el sensor. Es decir, el dispositivo experimental se calibra para que el tamaño del grano de speckle sea mayor que el tamaño del pixel del sensor, (en nuestro caso $8 \times 13 \mu \mathrm{m}^{2}$ ). Es por ello que es necesario el análisis estadístico para determinar el tamaño del grano de speckle, de forma que garantice que la celda de resolución (pixel) sea menor que dicho tamaño.

El nivel de promedio de gris se adecua con un filtro neutro variable con el fin de atenuar el haz incidente para evitar efectos de saturación o de insuficiente iluminación. El nivel de gris, varía desde 0 a 256, siendo 80 el nivel de gris promedio usado en nuestras mediciones. 
Se coloca la muestra y se obtienen múltiples diagramas de speckle correspondientes a su evolución temporal. Luego es necesario el análisis de los datos experimentales. Un modo conveniente es la propuesta de Oulamara et al. [20]. Para cada estado del fenómeno en estudio, se registran 512 imágenes sucesivas del diagrama de speckle dinámico, capturadas cada 0.08 segundos, y se selecciona una columna de cada una de ellas. Con estas columnas se construye una nueva imagen de 512 x 512 pixeles, que denominamos Historia Temporal de los Diagramas de Speckle (HTDS), cuyas filas representan distintos puntos del objeto y las columnas representan su intensidad luminosa. Ver Figura 3-7.

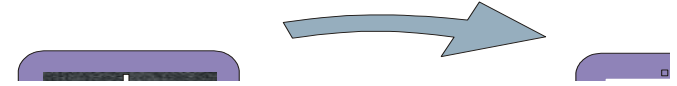 \\ Imagen tiempo real speckle Historia temporal del diagrama speckle (HTDS)}

Figura 3-7. Sistema de adquisición de datos

La actividad de la muestra produce cambios de intensidad (niveles de gris) en la dirección horizontal. Así, cuando el fenómeno muestra baja actividad, la HTDS muestra formas elongadas y cuando es muy activo, la HTDS se parece a un diagrama de speckle ordinario como se muestra en la Figura 3-8.

Existen varios métodos para establecer una estimación cuantitativa de la actividad de los diagramas de speckle basados en el estudio de la textura de la HTDS. [21]. 


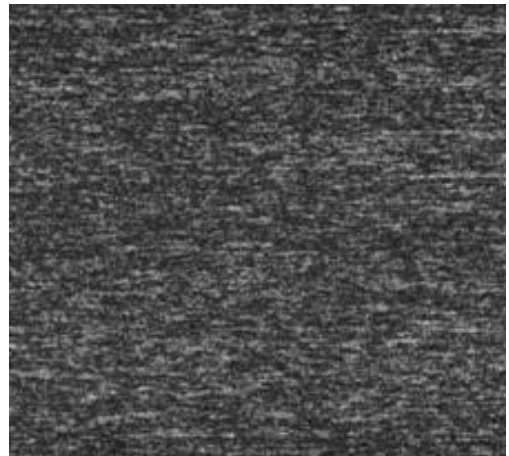

HTDS. Muestra muy activa

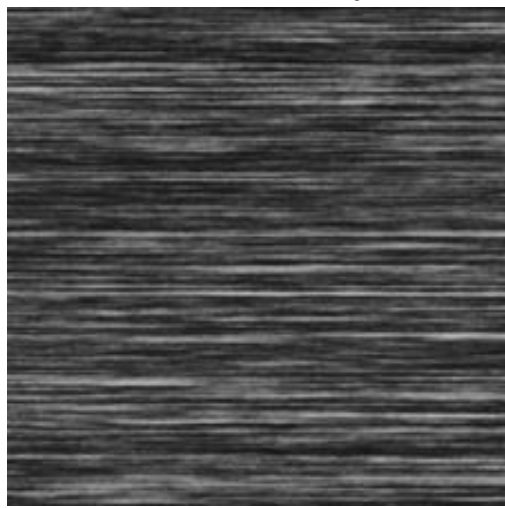

Estado intermedio 2

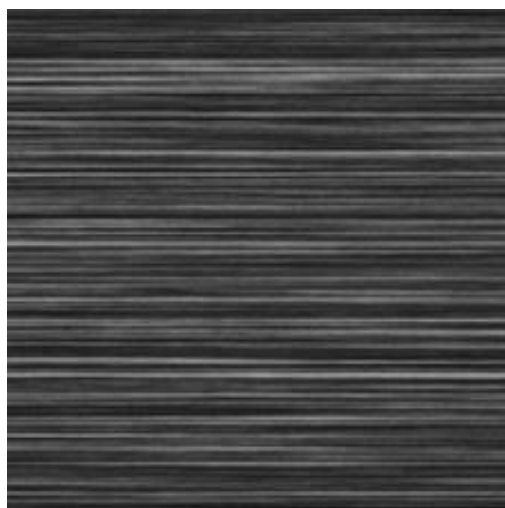

Muestra poco activa

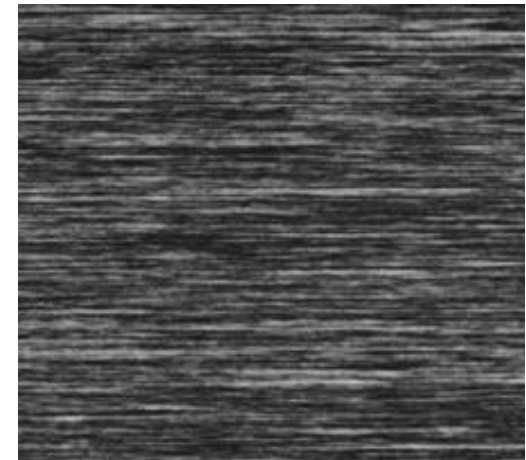

Estado intermedio 1

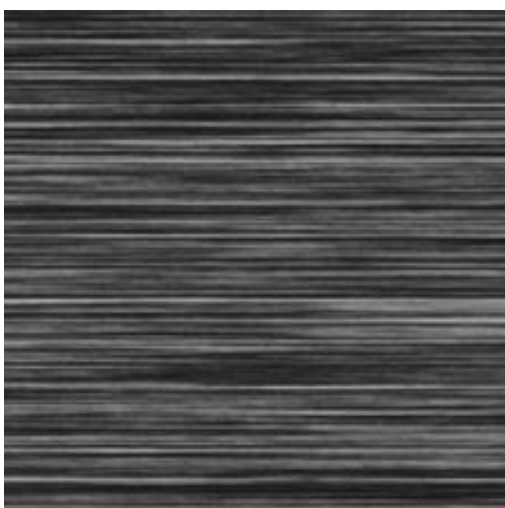

Estado intermedio 3

Figura 3-8: Imágenes mostrando Historias temporales de diagramas de Speckle (HTDS) a diferentes tiempos del proceso

\subsection{Momento de Segundo orden de la matriz de coocurrencia}

Una medida para caracterizar los diagramas de speckle dinámico basado es el estudio de los momentos de segundo orden de la matriz de co-ocurrencia de la Historia Temporal del Diagrama de speckle (HTDS) [18].

La matriz de co-ocurrencia $\left(M C O_{i, j}\right)$ es un histograma bidimensional que describe la distribución de probabilidad de la ocurrencia de dos eventos simultáneos. En 
nuestro caso, $M C O_{i, j}$ es el número de veces que el Nivel Gris $i$ está "acompañado" por el Nivel Gris $\boldsymbol{j}$. Como en el HTDS interesa la dirección temporal, representada en el eje x de la Figura 3.8, entonces. "Acompañado" = pixel $\boldsymbol{x}$ y pixel $\boldsymbol{x}+\boldsymbol{I}$

Se define la matriz de co-ocurrencia $\left(M C O_{i, j}\right)$ :

$$
\mathrm{MCO}_{i, j}=[\mathrm{Nij}]
$$

Donde Nij es el número de ocurrencias de un cierto valor de intensidad i seguido inmediatamente por un valor intensidad $\mathrm{j}$.

Se divide cada fila por el número de veces que aparece el primer nivel de gris, con el fin de normalizar la matriz.

$$
\mathbf{M}_{\mathrm{ij}}=\mathbf{N i j} / \sum_{\mathrm{ij}} \mathbf{N}_{\mathrm{ij}}
$$

Como la variable de interés en el tiempo, los valores de $\mathrm{N}$ muestran la ocurrencia de un cierto valor de gris $\mathrm{i}$, seguido en el instante siguiente por un valor de j, en la HTDS. Si la muestra no tiene actividad, la matriz de co-ocurrencia es una matriz diagonal. En cambio si la muestra presenta actividad, su intensidad local presenta fluctuaciones temporales, la matriz de co-ocurrencia tendrá valores fuera de la diagonal principal.

Por lo tanto la medida de dispersión de los valores alrededor de los valores $\mathrm{M}$ alrededor de la diagonal principal es una posible caracterización de la actividad.

El momento de segundo orden (MSO) o momento de inercia (MI) se define como:

$$
M I=\sum_{i j} M_{i j}(\mathbf{i}-\mathbf{j})^{2}
$$

Los valores de $\mathrm{M}$ mas alejado y mas pesados contribuyen mayormente con el MSO, mientras que las ocurrencias en la diagonal no contribuyen.

Matrices de co-ocurrencia de situaciones extremas de alta y escasas actividades se muestran en la Figura 3-9 que presenta las HTDS. Se observa que cuando el fenómeno es muy activo Figura 3-9 (b) la matriz asociada está dispersa respecto de la 
diagonal principal, mientras que si está concentrada en su diagonal principal, la Figura 3-9 (a) corresponde a una muestra de baja actividad.

Matriz Co-ocurrencia

HTDS

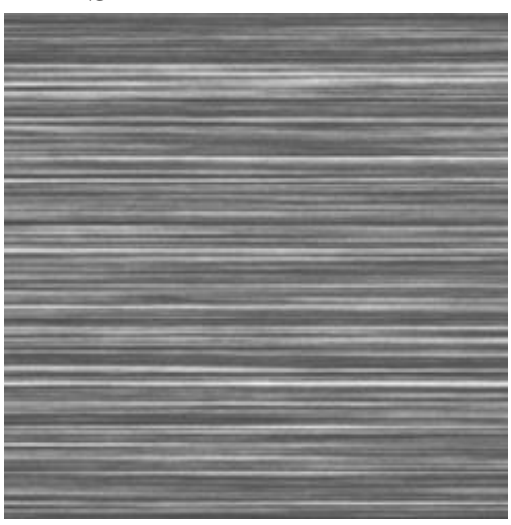

\section{Baja actividad}

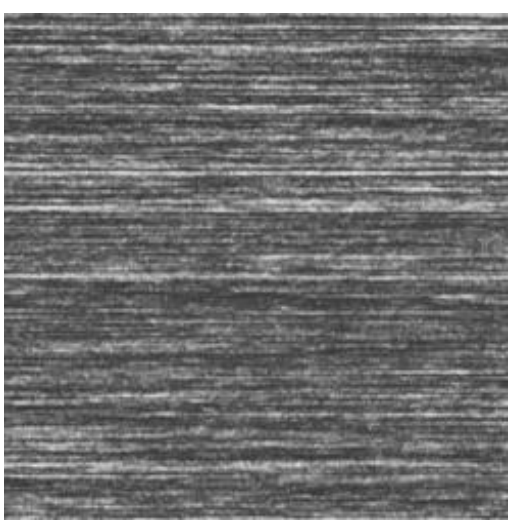

Alta actividad
Matriz Co-ocurrencia
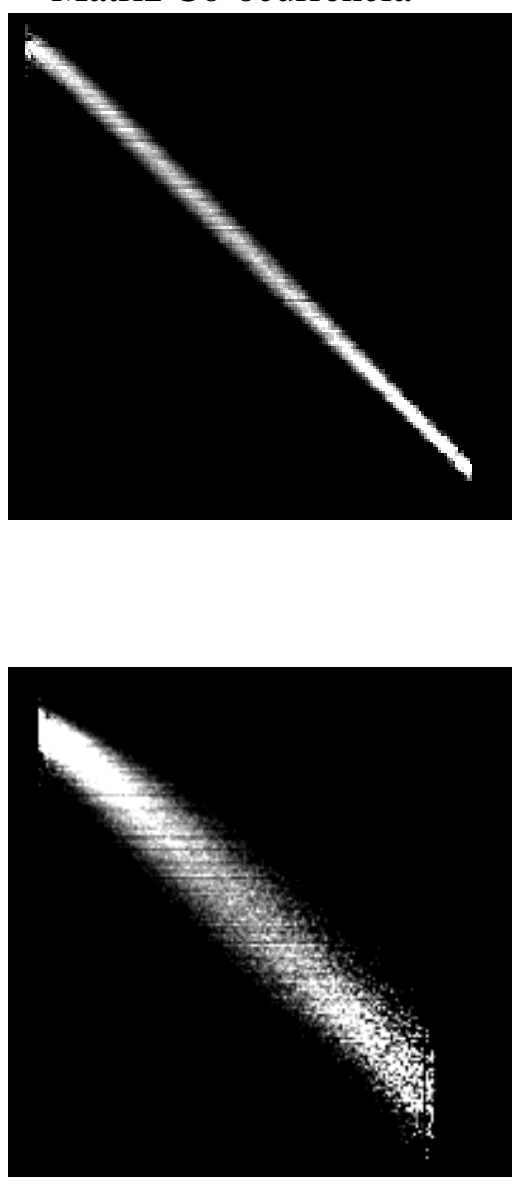

Figuras 3-9: HTDS y sus matrices de co-ocurrencia para a) baja actividad, b) alta actividad

La HTDS de una muestra dinámica real involucra diversas variables. Por lo tanto para estudiar el MSO se deben realizar aproximaciones en condiciones controladas.

\subsection{Conclusiones parciales}

En conclusión, las técnicas de speckle dinámico han demostrado ser herramientas útiles para el análisis de la evolución temporal de muestras biológicos e inorgánicas, por lo cual se consideró la factibilidad de su aplicación en el estudio de 
procesos de hidroadsorción. En consecuencia, la metodología de speckle dinámico se utilizará para caracterizar la actividad de este tipo de procesos en los materiales que servirán de soporte para los catalizadores a ser estudiados en esta Tesis. Los resultados obtenidos serán discutidos en el Capítulo 5. 


\section{PARTE III:}

\section{RESULTADOS Y DISCUSIÓN}




\section{Capítulo 4:}

\section{HETEROPOLIOXOANIONES DE} ESTRUCTURA TIPO ANDERSON, SÍNTESIS Y CARACTERIZACIÓN 


\section{1 . Caracterización estructural}

En el marco de esta Tesis se sintetizó y estudió la fase de Anderson conteniendo $\mathrm{Rh}(\mathrm{III})$.

\section{$\left(\mathrm{NH}_{4}\right)_{3}\left[\mathrm{RhMo}_{6} \mathrm{O}_{24} \mathrm{H}_{6}\right] \cdot 7 \mathrm{H}_{2} \mathrm{O}$}

Estructuralmente, el grupo $\left[\mathrm{XMo}_{6} \mathrm{O}_{24} \mathrm{H}_{6}\right]$ (en adelante $\left.\mathrm{XMo}_{6}\right)$, como mencionamos, se conforma de un empaquetamiento de seis octaedros $\mathrm{MoO}_{6}$ alrededor de un poliedro $\mathrm{XO}_{6}$ en configuración planar de simetría $\mathrm{D}_{3 \mathrm{~d}}$ [1] como se muestra en la figura 1-2 (Capítulo 1). En general, el octaedro central puede ubicar heteroátomos de radio iónico entre 0.5 y 0.7 Á, por ello es posible la preparación de una amplia variedad de fases, con $\mathrm{X}(\mathrm{III})(\mathrm{X}=\mathrm{Al}, \mathrm{Co}, \mathrm{Cr}, \mathrm{Rh}, \mathrm{Fe}), \mathrm{X}(\mathrm{II})(\mathrm{X}=\mathrm{Cu}, \mathrm{Ni})$ y $\mathrm{X}(\mathrm{VI})(\mathrm{X}=\mathrm{Te})$. En las fases que contienen heteroátomos en los menores estados de oxidación (+2 ó +3), el anión contiene seis protones no ácidos unidos a los oxígenos del octaedro central, $\mathrm{XO}_{6}$.

Las dimensiones promedio para las fases Anderson más conocidas calculadas para la simetría $\mathrm{D}_{3 \mathrm{~d}}$ están expresadas en la tabla 4-I. Los datos muestran la flexibilidad de la estructura donde el heteroátomo central se ubica manteniendo la estructura octaédrica [2].

Tabla 4-I: Distancias de enlaces para los heteropolioxoaniones Anderson $(\hat{A})$ [2].

\begin{tabular}{cccccc}
\hline Heteropolioxoanión & $\mathrm{M}-\mathrm{O}_{\mathrm{a}}$ & $\mathrm{M}-\mathrm{O}_{\mathrm{b}}$ & $\mathrm{M}-\mathrm{O}_{\mathrm{c}}$ & $\mathrm{X}-\mathrm{O}$ & $\mathrm{M} \ldots \mathrm{M}$ \\
\hline$\left[\mathrm{TeMo}_{6} \mathrm{O}_{24}\right]^{6-}$ & 1.71 & 1.94 & 2.29 & 1.93 & 3.29 \\
{$\left[\mathrm{CrMo}_{6} \mathrm{O}_{24} \mathrm{H}_{6}\right]^{3-}$} & 1.71 & 1.94 & 2.29 & 1.97 & 3.33 \\
\hline
\end{tabular}

En la Figura 4-1 (a) se muestra la estructura poliédrica de una fase típica $\left(\mathrm{NH}_{4}\right)_{3}\left[\mathrm{Rh}(\mathrm{III}) \mathrm{Mo6}_{24} \mathrm{H}_{6}\right] .7 \mathrm{H}_{2} \mathrm{O}$. Su configuración es planar de simetría $\mathrm{D}_{3 \mathrm{~d}}$, está constituido por $\mathrm{Rh}(\mathrm{III})$ como heteroátomo en el centro de un octaedro cuyos vértices son grupos $(\mathrm{OH})$ que se comparten con seis octaedros $\mathrm{Mo}(\mathrm{VI}) \mathrm{O}_{6}$. En la Figura 4-1 (b) se muestra a efectos comparativos la estructura del isopolianión heptamolibdato formado por 7 octaedros $\mathrm{Mo}(\mathrm{VI}) \mathrm{O}_{6}$ en una configuración no planar. 


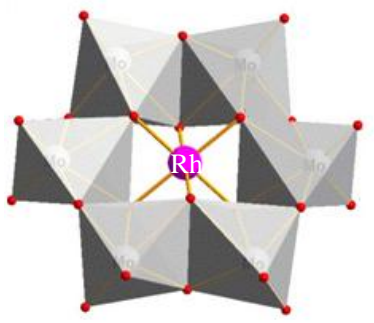

(a)

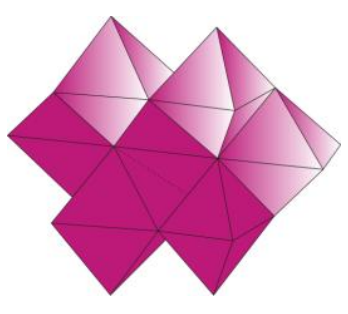

(b)

Figura 4-1: Representación de las estructuras (a) tipo Anderson correspondiente al heteropolianión planar $\mathrm{Rh}(\mathrm{III})$ hexamolibdato $\left[\mathrm{RhMo}_{6} \mathrm{O}_{24} \mathrm{H}_{6}\right]^{3-}$ y (b) al isopolianión heptamolibdato $\left[\mathrm{Mo}_{7} \mathrm{O}_{24}\right]^{6-}$

\subsection{Análisis estructural por DRX.}

4.2.1. Fases de Anderson con $\mathrm{X}(\mathrm{III})$ : $\left(\mathrm{NH}_{4}\right)_{3}\left[\mathrm{X}(\mathrm{III}) \mathrm{Mo}_{6} \mathrm{O}_{24} \mathrm{H}_{6}\right] .7 \mathrm{H}_{2} \mathrm{O}, \mathrm{X}=$ $\mathrm{Al}(\mathrm{III}), \mathrm{Co}(\mathrm{III})$ y $\mathrm{Rh}(\mathrm{III})\left(\mathrm{XMo}_{6}\right)$.

Desde el punto de vista cristalográfico, las fases conteniendo $\mathrm{X}(\mathrm{III})$ son isomorfas. Cristalizan en el sistema triclínico y contienen parámetros de celda del órden

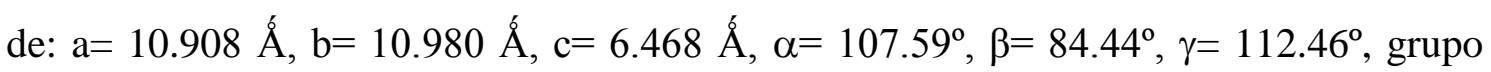
espacial $\mathrm{P} \overline{1}, \mathrm{Z}=1$, tal como se reportó para la fase de Cr(III) PDF: 74-0596.

Los sistemas Anderson conteniendo X(III), presentan un diagrama DRX característico. De esta manera encontramos que el diagrama de DRX para la fase de $\mathrm{Rh}$ (III) es similar a aquellos correspondientes a las fases conteniendo $\mathrm{Al}$ (III) y $\mathrm{Co}$ (III), como se muestra en la Figura 4-2. 


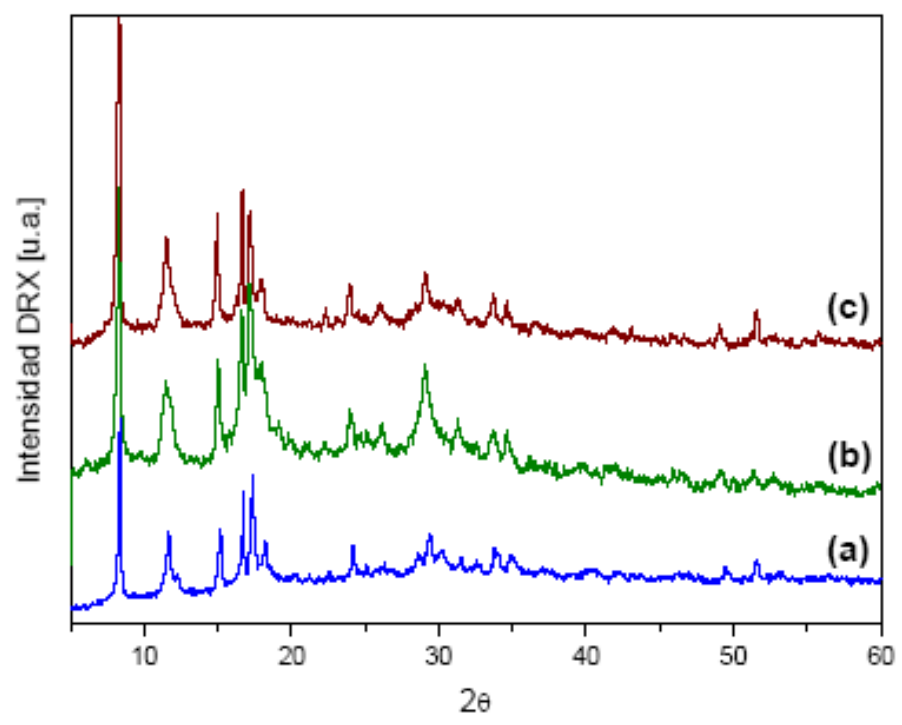

Figura 4-2: Diagrama DRX comparativo de las fases tipo Anderson $\mathrm{XMo}_{6}(\mathrm{X}=$ (a) $\mathrm{Co}$, (b) $\mathrm{Al}$, (c) $\mathrm{Rh}$ ).

\subsection{Caracterización morfológica mediante microscopía electrónica SEM y Análisis químico semicuantitativo EDS.}

Se obtuvieron cristales color naranja pálido cuyo estudio por Microscopía SEMEDS mostró la similitud con otras fases Anderson estudiadas ampliamente en nuestro laboratorio como $\mathrm{CoMo}_{6}, \mathrm{CrMo}_{6}, \mathrm{AlMo}_{6}$ etc. [3]. El análisis por SEM - EDS resulta también un buen método para la caracterización de estas fases.

En la Figura 4-3(a) se presenta la microfotografía correspondiente a la fase preparada de $\mathrm{RhMo}_{6}$. La morfología consiste en "placas cuadradas", generalmente macladas cuyo tamaño oscila entre 20 y $100 \mu \mathrm{m}$. En la Figura 4-3 (b) se muestra la microfotografía de la fase de $\mathrm{CoMo}_{6}$. 

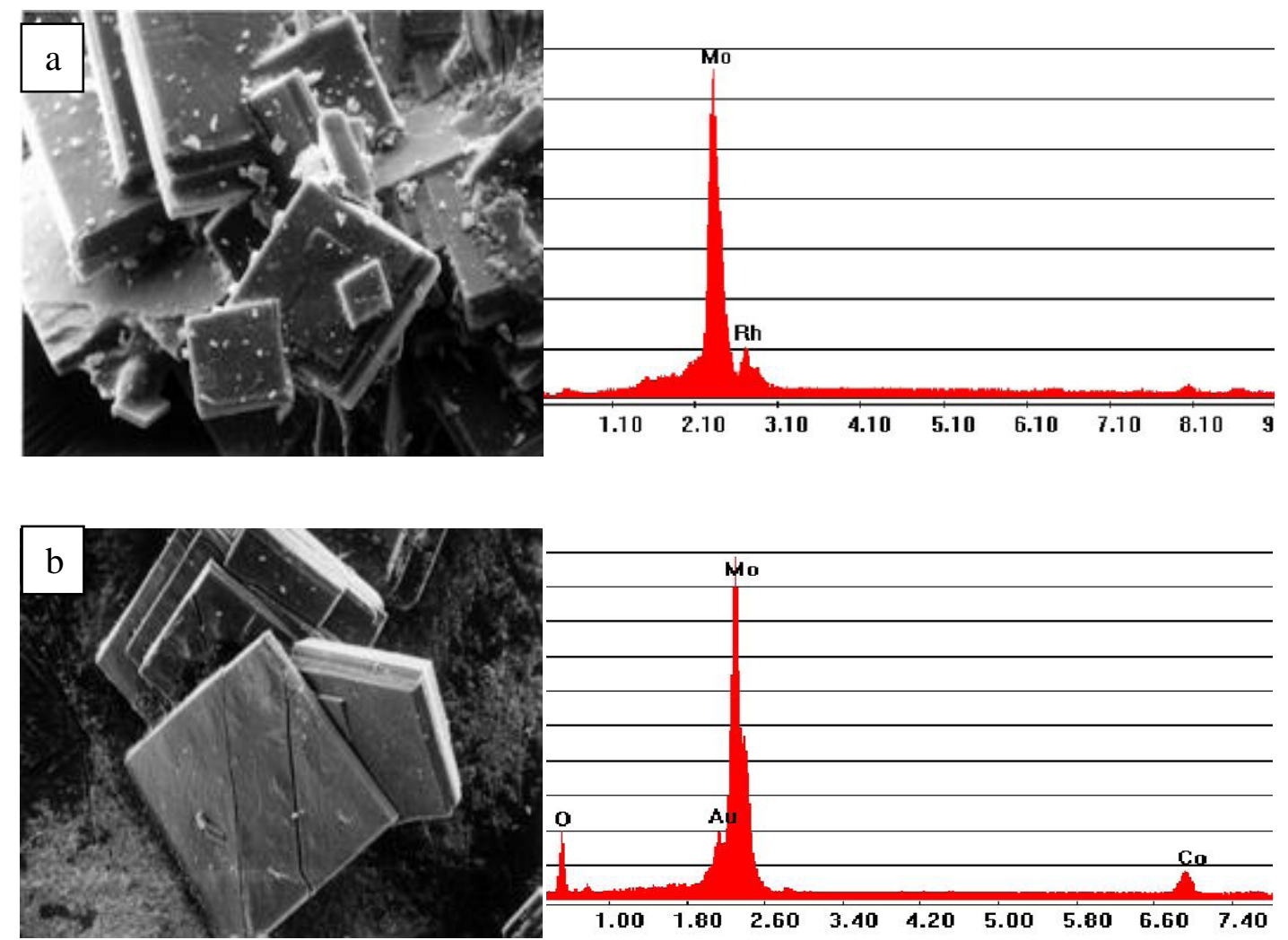

Figura 4-3: Microfotografía SEM y espectro EDS de las fases Anderson (a) $\mathrm{RhMo}_{6}\left(\right.$ magnificación x 500, escala =50 $\mu \mathrm{m}$ ), y (b) $\mathrm{CoMo}_{6}$ (magnificación x 200 , escala. $=50 \mu \mathrm{m})$

Por otra parte, mediante el análisis químico semicuantitativo por EDS de la fase estudiada, se observa buena concordancia entre el contenido de heteroátomo X y Mo obtenidos experimentalmente $(15.91 \%$ y $84.09 \%$ respectivamente para $\mathrm{X}=\mathrm{Rh}(\mathrm{III})$, por ej.), comparados con los valores calculados de manera teórica: $15.16 \%$ para el $\mathrm{Rh}(\mathrm{III})$ y $84.83 \%$ para el Mo(VI).

\subsection{Caracterización mediante espectroscopía vibracional.}

4.4.a. Características espectroscópicas vibracionales FTIR y Micro-Raman de heteropolimolibdatos de estructura Anderson 
La espectroscopía vibracional, FTIR y Raman, proporciona información muy útil acerca de la estructura y dinámica de los sistemas. El análisis del espectro vibracional de heteropolioxoaniones se lleva a cabo en base a las características de los enlaces involucrados en la formación de cada grupo de átomos en la fase [6-9].

Básicamente, los heteropolioxomolibdatos se caracterizan por la presencia de enlaces puente $\mathrm{Mo}-\mathrm{O}$ y enlaces terminales $\mathrm{Mo}-\mathrm{O}_{2 \mathrm{t}}[2,8,10]$.

Estructuralmente en el grupo $\left[\mathrm{XMo}_{6} \mathrm{O}_{24} \mathrm{H}_{6}\right]$ podemos encontrar tres tipos de enlaces diferentes $\mathrm{Mo}-\mathrm{O}$ : enlace $\mathrm{Mo}-\mathrm{O}_{2 \mathrm{t}}$ dioxo terminal y enlaces puente $\mathrm{Mo}-\mathrm{O}_{\mathrm{b}}(\mathrm{Mo}-$ $\mathrm{O}-\mathrm{Mo})$ у Mo-- $\mathrm{O}_{\mathrm{c}}(\mathrm{Mo}-\mathrm{O}(\mathrm{H})-\mathrm{X})[11]$.

Además el contra-catión monovalente $\left(\mathrm{NH}_{4}{ }^{+}\right.$en nuestro estudio), se encuentra coordinado por átomos de oxígeno del heteropolioxoanión y moléculas de agua, encontrándose en el cristal un extenso arreglo de enlaces de hidrógeno.

El espectro vibracional típico de estas fases puede dividirse en regiones típicas:

- $3600-2800 \mathrm{~cm}^{-1}$ : estiramientos $\mathrm{O}-\mathrm{H}$ y N-H.

- $1650-1400 \mathrm{~cm}^{-1}$ : deformaciones angulares $\mathrm{O}-\mathrm{H}$ y $\mathrm{N}-\mathrm{H}$.

- $950-800 \mathrm{~cm}^{-1}$ : estiramientos simétricos y antisimétricos Mo-Ot.

$750-550 \mathrm{~cm}^{-1}$ : modos fundamentales Mo-Ob.

- Por debajo de $450 \mathrm{~cm}^{-1}$ : vibraciones Mo-Oc y algunos otros modos vibracionales de red.

La región espectral a menores frecuencias resulta más difícil de asignar. Entre 550 y $500 \mathrm{~cm}^{-1}$ es posible observar algunas bandas atribuidas a los modos de la red del agua.

A frecuencias menores de $450 \mathrm{~cm}^{-1}$ encontramos los modos correspondientes a las de formaciones angulares

En las fases Anderson, las deformaciones $\mathrm{X}-\mathrm{O}(\mathrm{H})$ son observadas alrededor de $900 \mathrm{~cm}^{-1}$. Pero estas bandas IR aparecen solapadas con los modos Mo-O. Además, asociado también con el catión trivalente, es altamente probable observar los estiramientos $\mathrm{XO}_{6}$ entre 600 y $400 \mathrm{~cm}^{-1}$. 
En la Figura 4-4 se presenta el diagrama FTIR de la fase en estudio.

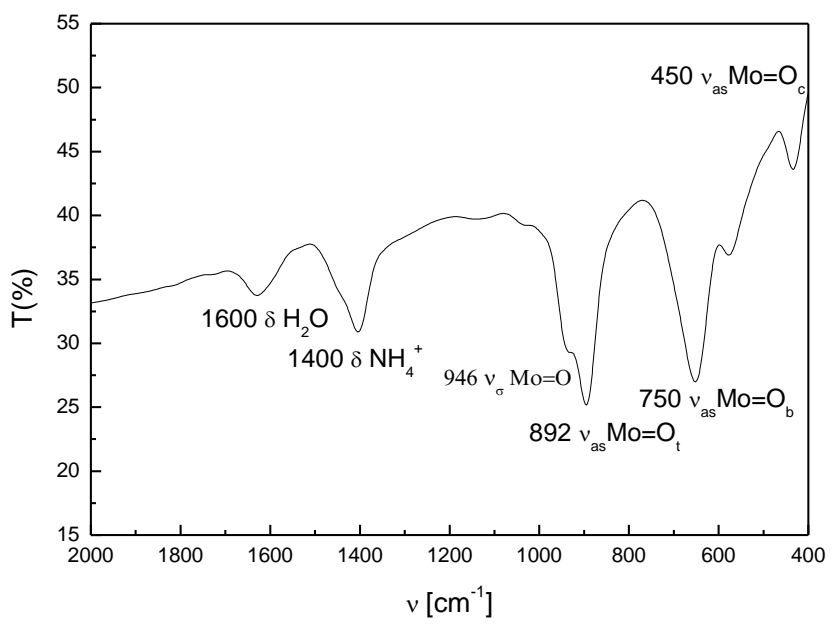

Figura 4-4: Espectro FTIR entre 2000 y $400 \mathrm{~cm}^{-1}$

Por otra parte, es posible observar a partir de estudios cristalográficos que el tamaño del heteropolioxoanión no depende apreciablemente del radio iónico del heteroátomo [12]. El entorno molíbdico de este tipo de fases presenta alta capacidad de reordenamiento cuando ocurren algunos reemplazos del heteroátomo central, con pequeños cambios en los ángulos Mo-O-Mo. Este efecto también se presenta en algunas fases Keggin. Si se observan las bandas Raman localizadas entre 950 y $200 \mathrm{~cm}^{-}$ ${ }^{1}$ comparando una serie de heteropolioxoaniones Anderson, las líneas que resultan más afectadas al cambio de heteroátomo son las correspondientes a los enlaces Mo-Ot. Para una serie isomorfa se observa un desplazamiento a mayores frecuencias cuando se incrementa el tamaño del hetroátomo X.

La espectroscopía Raman, presenta líneas agudas, haciendo más marcados los desplazamientos de este tipo. Generalmente, el espectro Raman de elementos que presentan coordinación octaédrica presenta las líneas principales a altas frecuencias $\left(800-1000 \mathrm{~cm}^{-1}\right)$ [7].

En la Figura 4-5 se muestra el espectro Raman Microprobe de la fase en estudio. Esta técnica resulta aun más interesante ya que permite caracterizar las fases de 
Anderson soportadas en alúmina (más claramente que otras técnicas), mostrando la preservación de la estructura.

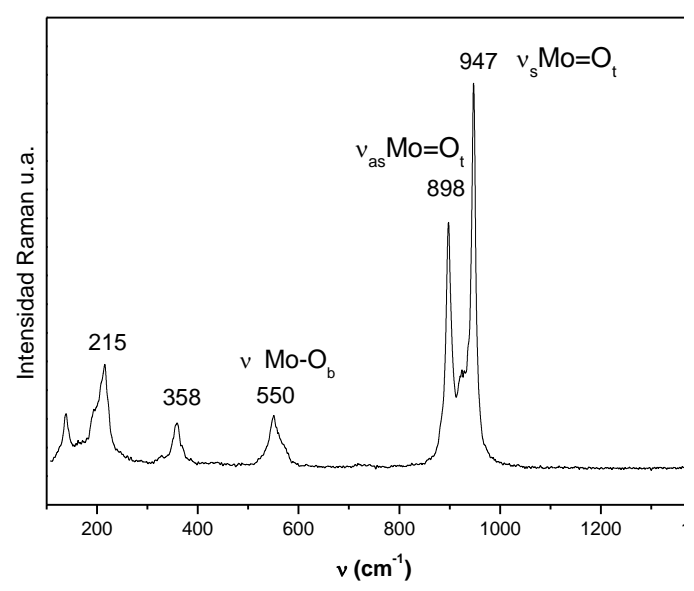

Figura 4-5: Espectro Raman Microprobe de $\left[\mathrm{RhMo}_{6} \mathrm{O}_{24} \mathrm{H}_{6}\right]$.

\subsection{Estudio de la Estabilidad Térmica.}

Los diagramas TG-DTA en aire de la fase $\mathrm{RhMo}_{6}$ tratada a temperaturas hasta $1000{ }^{\circ} \mathrm{C}$ presentan el típico comportamiento de las fases Anderson, Figura 4-6, con tres pérdidas de peso 126,255 y $404^{\circ} \mathrm{C}$ correspondientes a la pérdida de agua de hidratación (proceso reversible), hasta $126^{\circ} \mathrm{C}$ y $\mathrm{NH}_{3}$ a $255^{\circ} \mathrm{C}[9,12]$, con la ruptura total del polianión a partir de $300^{\circ} \mathrm{C}$. La resolución de la segunda pérdida, menos definida, es asignada a la eliminación de $\mathrm{NH}_{3}$ y $\mathrm{H}_{2} \mathrm{O}$ (del contracatión y de agua proveniente de los puentes $\mathrm{H}$ intramoleculares). La tercera pérdida de masa ocurre alrededor de los $400^{\circ} \mathrm{C}$, se asocia al colapso de la estructura del anión. Los análisis por XRD y EDS de muestras de la fase original tratadas en horno eléctrico en atmosfera de aire, a las distintas temperaturas de los picos mostraron que si bien a $420^{\circ} \mathrm{C}$, el producto de descomposición resulta amorfo, según los diagramas $\mathrm{XRD}$, al continuar el tratamiento térmico se observa la incipiente formación de la fase $\mathrm{MoRh}_{2} \mathrm{O}_{6}$ (trirutilo), con la simultánea eliminación del $\mathrm{MoO}_{3}$, proceso que se incrementa notoriamente a partir de los $600^{\circ} \mathrm{C}$. Los datos se muestran en la Tabla 4-II junto a los correspondientes al HMA a efectos comparativos. 


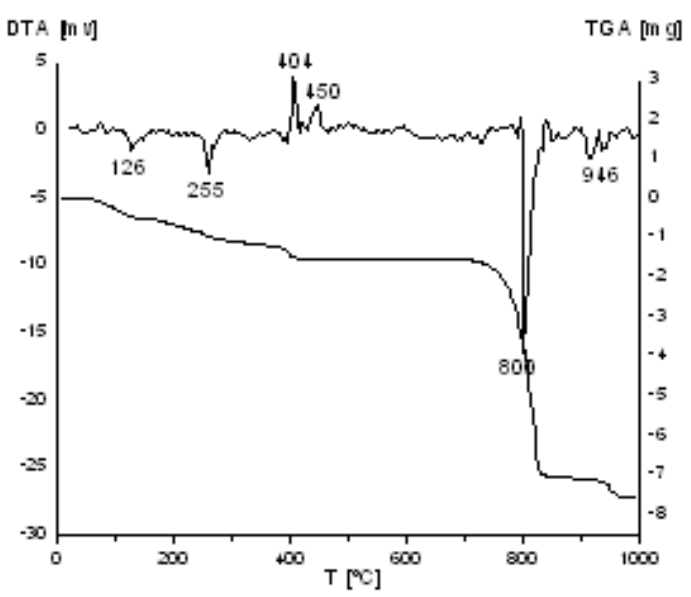

Figura 4-6: Diagramas TG-DTA de la fase $\mathrm{RhMo}_{6}$ tratada en aire entre $\mathrm{T}$. amb y $1000{ }^{\circ} \mathrm{C}$

Tabla 4-II Datos comparativos correspondientes a los picos principales de pérdidas de peso de los diagramas TG-DTA de la fase $\mathrm{RhMo}_{6} \mathrm{y} \mathrm{HMA}\left(\left[\mathrm{Mo}_{7} \mathrm{O}_{24}\right]^{6-}\right)$ entre T ambiente y $400^{\circ} \mathrm{C}$.

\begin{tabular}{ccccc}
\hline Fase & $\mathbf{T}^{\mathbf{0}} \mathbf{C}$ & $\mathbf{T}^{\mathbf{0}} \mathbf{C}$ & $\mathbf{T}^{\mathbf{0}} \mathbf{C}$ & $\begin{array}{c}\text { Residuo sólido } \\
\mathbf{4 0 0}^{\mathbf{0}} \mathbf{C}\end{array}$ \\
\hline $\mathrm{RhMo}_{6}$ & 126 & 255 & 400 & $\mathrm{MoRh}_{2} \mathrm{O}_{6}, \mathrm{MoO}_{3}$ \\
HMA & 112 & 232 & 344 & $\mathrm{MoO}_{3}$ \\
\hline
\end{tabular}

La fase de rutilo resulta cristalina y puede ser detectada mediante análisis de DRX (más las líneas del $\mathrm{MoO}_{3}$ ). Finalmente, a T $1000{ }^{\circ} \mathrm{C}$, la fase relacionada al rutilo descompone en $\mathrm{MoO}_{3}$ y $\mathrm{Rh}_{2} \mathrm{O}_{3}$. El estudio por EDS revela las transformaciones comentadas en base a las variaciones en los contenidos X/Mo. En la Figura 4-7 y tabla 4-II (b), se presentan las microfotografías SEM y el análisis EDS de las muestras tratadas a diferentes temperaturas, en las que podemos observar los cambios en la morfología cristalina y en la composición de la siguiente secuencia de calentamiento:

$$
\begin{aligned}
& 2 \mathrm{RhMo}_{6} \rightarrow 7_{00}^{\circ} \mathrm{C} \rightarrow \text { (A) } \mathrm{MoRh}_{2} \mathrm{O}_{6}+(\mathrm{B}) \mathrm{11MoO}_{3} \uparrow \rightarrow{ }_{800^{\circ}} \mathrm{C} \rightarrow \text { (C) } \mathrm{MoRh}_{2} \mathrm{O}_{6} \rightarrow{ }_{1000^{\circ}} \\
& \text { (D) } \mathrm{Rh}_{2} \mathrm{O}_{3}+\mathrm{MoO}_{3} \uparrow
\end{aligned}
$$




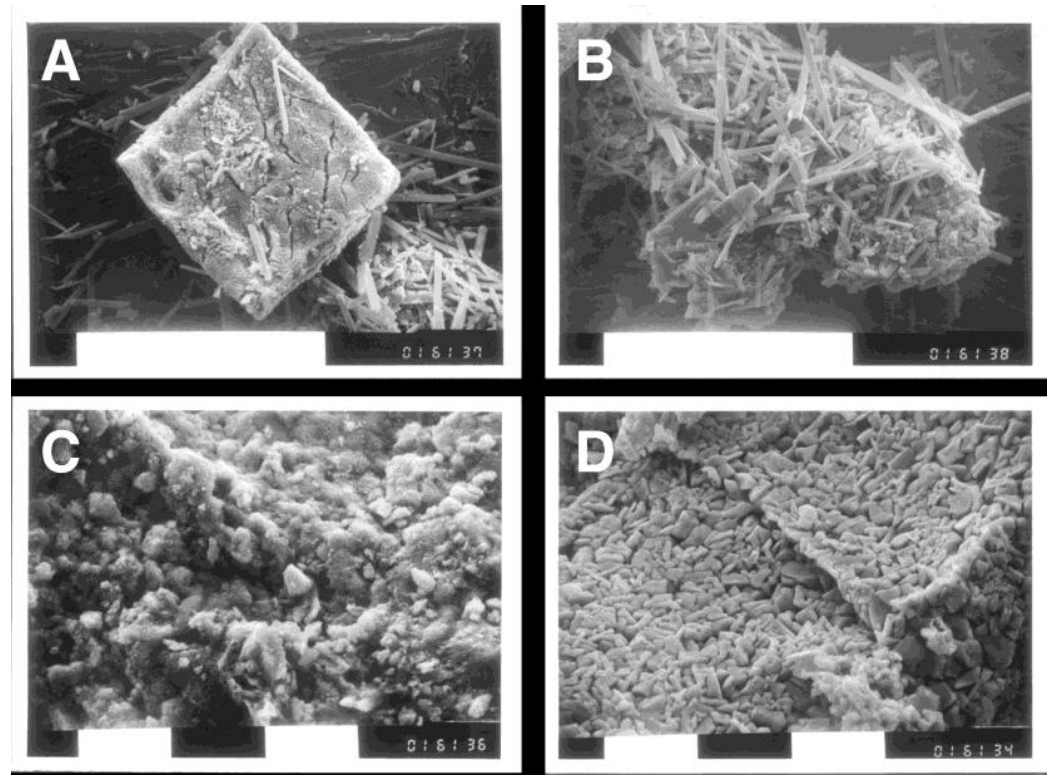

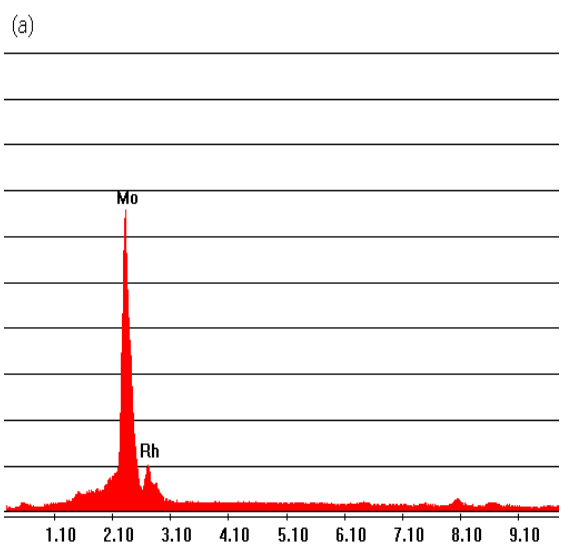

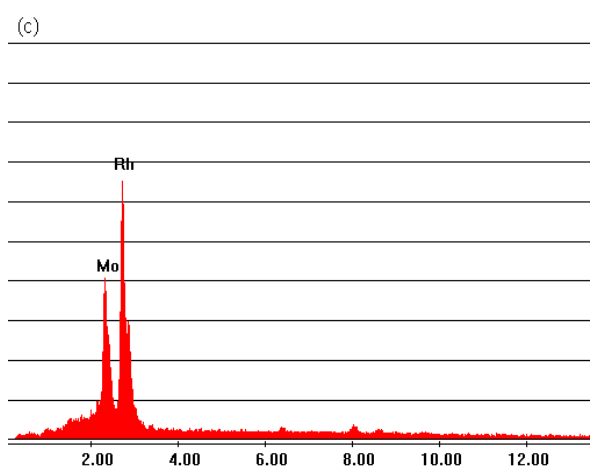

(b)

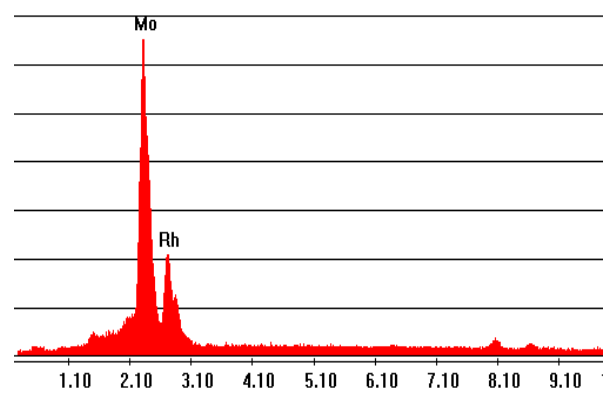

(d)

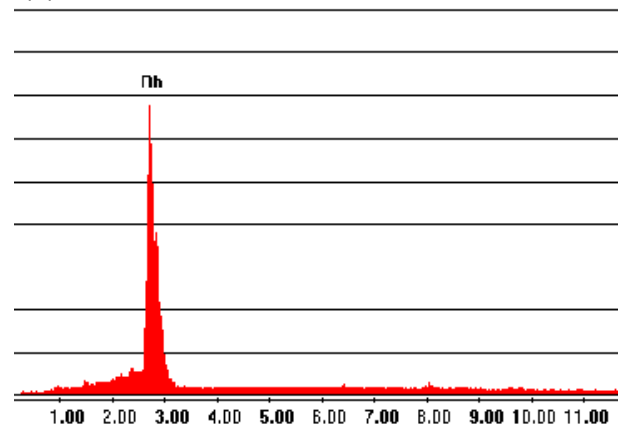

Figura 4-7: Microfotografías SEM y EDS de la fase $\mathrm{RhMo}_{6}$ correspondientes a

diferentes etapas del tratamiento térmico (en aire). (a) fase a temperatura ambiente magnificación x 680 , escala $=100 \mu \mathrm{m}$ ), (b) muestra tratada a $700^{\circ} \mathrm{C}$ (magnificación x 650, escala $=100 \mu \mathrm{m}$ ), (c) muestra tratada a $800^{\circ} \mathrm{C}$ (magnificación x 2500 , escala $=10 \mu \mathrm{m}$ ) y $(\mathrm{d})$ muestra tratada a $1000^{\circ} \mathrm{C}$ (magnificación x 2500, escala $=10 \mu \mathrm{m}$ ). 
Tabla 4-II (b): Datos de composición química semicuantitativa EDS comparativos correspondientes a los picos principales de pérdidas de pesos de los diagramas TG-DTA de las fases $\mathrm{AlMo}_{6}, \mathrm{CoMo}_{6}, \mathrm{RhMo}_{6} \mathrm{y} \mathrm{Mo}_{7} \mathrm{O}_{24}$ entre $\mathrm{T}$ ambiente y $1000{ }^{\circ} \mathrm{C}$.

\begin{tabular}{ccccc}
\hline Elemento & Original & $\mathbf{7 0 0}^{\circ} \mathbf{C}$ & $\mathbf{8 0 0}^{\mathbf{}} \mathbf{C}$ & $\mathbf{1 0 0 0}^{\mathbf{}} \mathbf{C}$ \\
\hline $\mathrm{Rh}$ & 15.90 & $36.40-0$ & 68.80 & 100 \\
Mo & 84.10 & $63.60-100$ & 31.20 & - \\
\hline
\end{tabular}

El diagrama TG de la fase $\mathrm{RhMo}_{6}$ alrededor de $750{ }^{\circ} \mathrm{C}$ presenta una pérdida de peso correspondiente a la eliminación de $\mathrm{MoO}_{3}$, obteniéndose una única fase oxídica de $\mathrm{MoRh}_{2} \mathrm{O}_{6}$ que se mantiene estable hasta los $950^{\circ} \mathrm{C}$ la que se evidencia en el difractograma XRD de la fase tratada hasta $800^{\circ} \mathrm{C}$ y se muestra en la figura $4-8$. A partir de estos datos se calcularon los parámetros de celda para una estructura tetragonal, resultando $\mathrm{a}=4.61 \AA \mathrm{y} \mathrm{c}=3.03 \AA$, los cuales coinciden con los datos publicados en PDFWIN para el óxido de Mo-Rh de estructura de rutilo (83-1963), que se muestra en la Tabla 4-III. Este óxido mixto descompone a $950{ }^{\circ} \mathrm{C}$ en $\mathrm{MoO}_{3}$ que volatiliza y en $\mathrm{Rh}_{2} \mathrm{O}_{3}$.

Los datos comparativos de EDS, mostrados en la Tabla 4-II (b), también contribuyen al análisis los efectos térmicos oxidativos. Se encuentra que la relación $\mathrm{Rh} / \mathrm{Mo}(0.18)$ se incrementa a $2.20(68.80 \% \mathrm{Rh}$ y $31.20 \% \mathrm{Mo})$ para la muestra tratada a $850^{\circ} \mathrm{C}$, lo cual concuerda para la relación teórica correspondiente a la fase $\mathrm{MoRh}_{2} \mathrm{O}_{6}$ $(\mathrm{Rh} / \mathrm{Mo}=2.15 \mathrm{Rh}=68.20 \%$ y $\mathrm{Mo}=31.80 \%)$.

En lo que respecta a la formación de la fase de tri-rutilo, cabe señalar que el Rh y Mo, originariamente en un entorno octaédrico en el heteropolioxoanión Anderson, son estructuralmente desplazados y reordenados para formar $\mathrm{MoO}_{3}$ y el óxido mixto, ambos con los metales en coordinación octaédrica. La relación EDS Rh/Mo variable alrededor de $750^{\circ} \mathrm{C}$ puede atribuirse a una deficiencia en el contenido de $\mathrm{Rh}$ en la formación del tri-rutilo provocando la segregación del $\mathrm{MoO}_{3}$. Este hecho, junto con la diferente estabilidad térmica de ambos óxidos, permite la formación de una mezcla oxídica como única fase entre los 800 y $950^{\circ} \mathrm{C}$. 


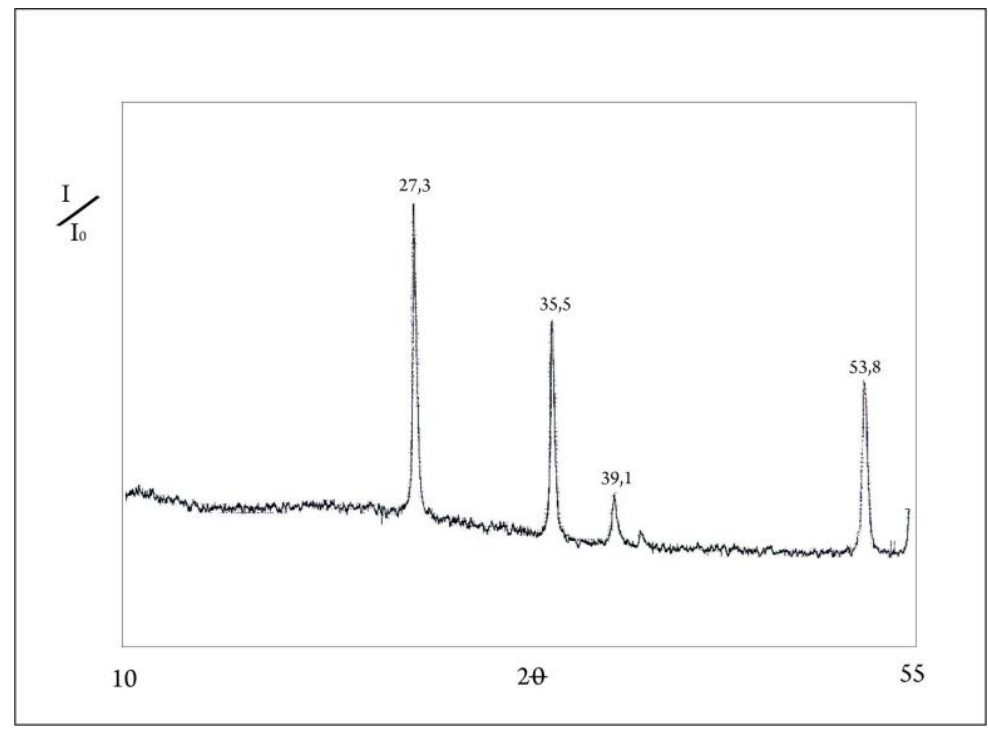

Figura 4-8: Diagrama XRD correspondiente a la fase $\mathrm{MoRh}_{2} \mathrm{O}_{6}$ obtenida por calentamiento de la fase de Anderson $\mathrm{RhMo}_{6}$ hasta $800^{\circ} \mathrm{C}$, en atmósfera inerte.

Tabla 4-III: Parámetros cristalográficos correspondientes a la fase $\mathrm{MoRh}_{2} \mathrm{O}_{6}$ reportados en la base de datos "International Centre for Diffraction Data" PCPDFWIN.

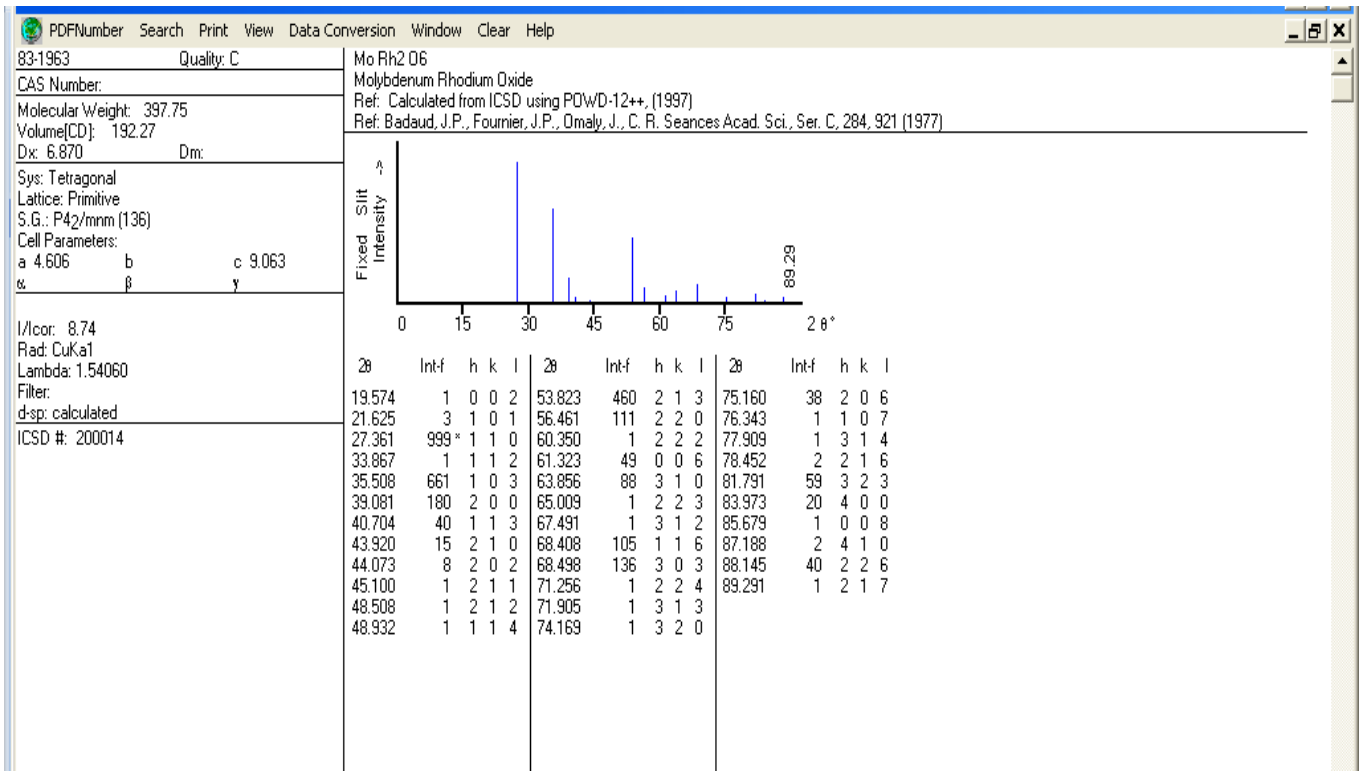

En una atmósfera medianamente reductora de $\mathrm{H}_{2}$ a elevadas temperaturas ocurre un complejo proceso de reducción del Mo(VI): $\mathbf{M o}(\mathbf{V I}) \rightarrow \mathbf{M o}(\mathbf{I V}) \rightarrow \mathbf{M o}^{\mathbf{o}}$, el mismo está influenciado por el entorno metálico, por la estructura cristalina de la fase original, 
las fases parcialmente reducidas y por la presencia de un metal adicional en la estructura $[9,12,16]$.

Las fases de Anderson son más fácilmente reducibles hacia los óxidos intermediarios $\mathrm{Mo}_{\mathrm{x}} \mathrm{O}_{\mathrm{y}}$ que el heptamolibdato $\left(\left[\mathrm{Mo}_{7} \mathrm{O}_{24}\right]^{6-}\right)$, mostrando una señal de TPR que comienza a temperaturas por debajo de $400^{\circ} \mathrm{C}$ [13]. El estudio de TPR permite predecir cómo será el comportamiento catalítico de estos sistemas [12].

\section{5.b. Fase de Anderson $\left(\mathrm{NH}_{4}\right)_{3}\left[\mathrm{X}(\mathrm{III}) \mathrm{Mo}_{6} \mathrm{O}_{24} \mathrm{H}_{6}\right] .7 \mathrm{H}_{2} \mathrm{O}, \mathrm{X}=\mathrm{Rh}(\mathrm{III})\left(\mathrm{XMo}_{6}\right)$.}

En la Figura 4-9 se presentan los diagramas de TPR comparativos entre la fase de Anderson en estudio RhMo 6 y el HMA.

El diagrama TPR de la fase $\mathrm{RhMo}_{6}$ presenta una señal muy intensa a $285^{\circ} \mathrm{C}$, varias señales de baja intensidad entre 390 y $500^{\circ} \mathrm{C}$ y otra a $732^{\circ} \mathrm{C}$. El HMA, presenta dos señales atribuidas a las reducciones del Mo antes mencionadas, las mismas son observadas entre 580 y $730^{\circ} \mathrm{C}$ (débil) y entre 850 y $990^{\circ} \mathrm{C}$ (fuerte) respectivamente. [8, 12].

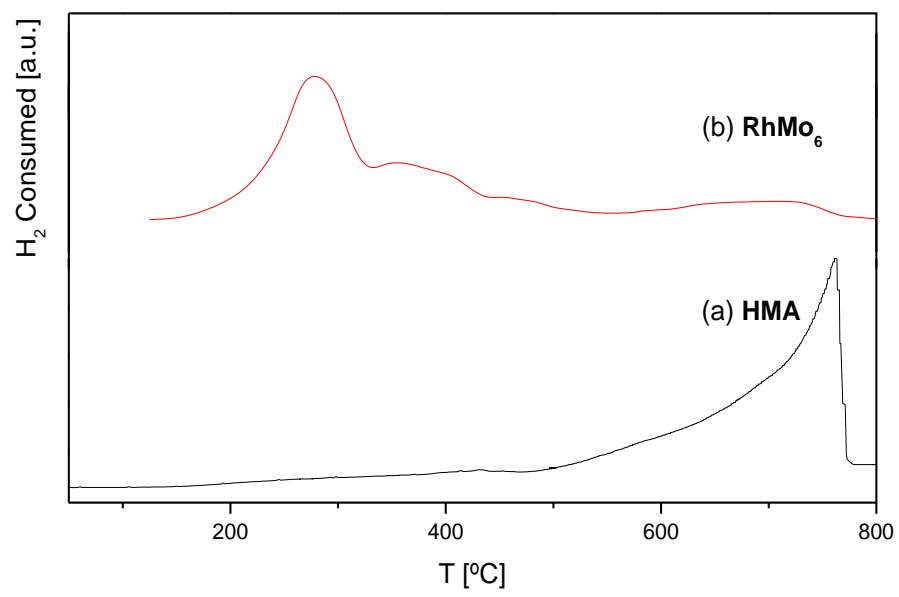

Figura 4-9: Diagramas de TPR del (a) HMA y de la fase (b) $\mathrm{RhMo}_{6}$.

En lo que respecta a la fase $\mathrm{RhMo}_{6}$, si tenemos en cuenta que la reducción $\mathrm{Rh}(\mathrm{III})-\mathrm{Rh}^{\mathrm{o}}$ del $\mathrm{Rh}_{2} \mathrm{O}_{3}$ ocurre a $135^{\circ} \mathrm{C}$ [15], esta resulta una temperatura menor que la 
observada para la fase $\mathrm{RhMo}_{6}\left(286^{\circ} \mathrm{C}\right)$. Este efecto puede estar relacionado con la mayor estabilidad del metal en la estructura condensada. A modo comparativo los datos TPR de las fases Anderson $\mathrm{CoMo}_{6}, \mathrm{AlMo}_{6} \mathrm{y} \mathrm{RhMo}_{6}$ se presentan en la tabla 4-III donde se incluyen los datos correspondientes al HMA.

La elevada reducibilidad de la fase $\mathrm{RhMo}_{6}$ se puede relacionar con el carácter oxidante del heteroátomo $\left(\mathrm{E}^{\mathrm{o}} \mathrm{Rh}(\mathrm{III}) \rightarrow \mathrm{Rh}^{\mathrm{o}}=0.44 \mathrm{v}\right)$ que afecta la estabilidad del Mo(VI). En el diagrama de TPR de la fase $\mathrm{RhMo}_{6}$, se observa que el área del segundo pico es mucho menor que la del primero, lo cual muestra el efecto promotor del $\mathrm{Rh}^{\mathrm{o}}$, siendo baja la temperatura de reducción para ambas señales, (T 300 y $732^{\circ} \mathrm{C}$ ). Este efecto se puede explicar mediante el modelo de reducción en capas "shrinking core" [17] el cual predice que durante la reacción en un sistema gas - sólido, la relación de reducción se incrementa por acción del heteroátomo reducible, generándose probablemente un sistema conteniendo una fase metálica bien dispersa con un íntimo contacto entre partículas. Así, a mayor reducibilidad del heteroátomo, mayor reducibilidad el Mo, observándose menores temperaturas de reducción para este elemento. Este efecto sinérgico, induce dos reacciones de reducción solapadas, en el caso de la reducción del $\mathrm{RhMo}_{6}$ a bajas temperaturas ocurre la siguiente reacción: $\mathrm{Mo}(\mathrm{VI}) \rightarrow \mathrm{MoO}_{2} \rightarrow \mathrm{Mo}^{\circ}$. De esta manera, el área del segundo proceso de reducción disminuye notablemente. La característica de este tipo de reducciones (elevada velocidad y bajas temperaturas) inhibe el adecuado reordenamiento de los átomos, afectando no solo el tamaño y distribución de las partículas, sino también la nucleación y crecimiento de los productos intermediarios oxídicos. Consecuentemente el $\mathrm{MoO}_{2}$ obtenido presenta baja cristalinidad y no se pudo detectar por XRD.

Tabla 4-III: Resultados TPR comparativos para las fases (a) $\mathrm{AlMo}_{6}$, (b) $\mathrm{CoMo}_{6} \mathrm{y}$ (c) $\mathrm{RhMo}_{6}$ (efecto de la reducibilidad del heteroátomo en la reducción del Mo). 


\begin{tabular}{|c|c|c|c|c|c|}
\hline Fase & $\begin{array}{l}\text { Potencial de } \\
\text { reducción del } \\
\text { heteroatomo }\end{array}$ & $\begin{array}{c}\text { Temperatura } \\
\text { del proceso } \\
\text { Mo(VI)-Mo(IV) }\end{array}$ & Productos & $\begin{array}{l}\text { Temperatura } \\
\text { del proceso } \\
\text { Mo(IV)-Mo }\end{array}$ & Productos \\
\hline $\mathrm{RhMo}_{6}$ & $0.78 \mathrm{v}$ & $285^{\circ} \mathrm{C}$ & $\begin{array}{c}\mathrm{Rh}^{\circ}, \mathrm{MoO}_{2} \\
\mathrm{Mo}^{\circ}\end{array}$ & $732^{\circ} \mathrm{C}$ & $\mathrm{Rh}^{\mathrm{o}}, \mathrm{Mo}^{\mathrm{o}}$ \\
\hline $\mathrm{CoMo}_{6}$ & $1.80^{\mathrm{a}}-0.28^{\mathrm{b}} \mathrm{v}$ & $610^{\circ} \mathrm{C}$ & $\begin{array}{c}\mathrm{CoMoO}_{4}, \mathrm{M} \\
\mathrm{oO}_{2}\end{array}$ & $884^{\circ} \mathrm{C}$ & $\mathrm{Co}^{\circ}, \mathrm{Mo}^{\circ}$ \\
\hline \multirow[t]{2}{*}{$\mathrm{AlMo}_{6}$} & $-1.66 \mathrm{v}$ & $586^{\circ} \mathrm{C}$ & $\mathrm{MoO}_{2}^{\mathrm{c}}$ & $990^{\circ} \mathrm{C}$ & $\mathrm{Mo}^{\circ}$ \\
\hline & & & & & $\mathrm{Al}_{2} \mathrm{O}_{3}$ \\
\hline HMA & & $730^{\circ} \mathrm{C}$ & $\mathrm{MoO}_{2}$ & $850^{\circ} \mathrm{C}$ & $\mathrm{Mo}^{\mathrm{o}}$ \\
\hline
\end{tabular}

\subsection{Conclusiones parciales.}

Se sintetizó y caracterizó una fase tipo Anderson $\mathrm{XMo}_{6}$, donde el heteroátomo es $\mathrm{Rh}$ (III). La misma resultó isomorfa a las correspondientes fases de $\mathrm{Al}(\mathrm{III})$ y $\mathrm{Co}(\mathrm{III})$. Al comparar los respectivos diagramas de polvo por Rayos $\mathrm{X}$ y espectros vibracionales (FTIR y Raman) no se observan diferencias.

El tratamiento térmico en condiciones oxidantes, presentó para la fase de $\mathrm{Rh}(\mathrm{III})$ un comportamiento diferente al de las fases mencionadas.

Para el $\mathrm{RhMo}_{6}$, se observó la formación de una fase de tri-rutilo $\mathrm{RhMo}_{2} \mathrm{O}_{6}$, estable entre 700 y $900^{\circ} \mathrm{C}$, donde el $\mathrm{Rh}$ en condiciones reductoras actúa como promotor de la reducción de Mo.

El comportamiento observado para la fase RhMo6 en condiciones reductoras es diferente al que presentan otras fases Anderson de heteroátomo trivalentes, $\mathrm{XMo}_{6}, \mathrm{X}=$ $\mathrm{Co}, \mathrm{Al}$, etc. La presencia del $\mathrm{Rh}$ metálico induce la reducción completa $\mathrm{Mo}(\mathrm{VI})$ $\mathrm{Mo}(\mathrm{IV})-\mathrm{Mo}^{\circ}$ a bajas temperaturas (alrededor de $250^{\circ} \mathrm{C}$ ). Sin embargo, la reducción $\mathrm{Rh}(\mathrm{III})$ - $\mathrm{Rh}^{\mathrm{o}}$ ocurre a temperaturas mayores que la observada para otros sistemas binarios $\mathrm{Rh}-\mathrm{O}$, debido a la estabilidad de la estructura del heteropolianión. 
Capítulo 5:

CARACTERIZACIÓN FISICOQUIMICA DE SOPORTES 
En el presente capítulo se hará referencia a los resultados obtenidos en las experiencias relativas a la preparación, pretratamiento y caracterización de los materiales seleccionados para su empleo como soportes de los catalizadores estudiados en esta tesis.

\section{1 . Pretratamiento y caracterización de soportes a base de Sílice}

\section{1.a. Introducción}

La Sílica-gel es un material químicamente inerte que se obtiene fácilmente como un adsorbente estable de alta porosidad cuyo método comercial de preparación a gran escala se realiza a partir de la deshidratación del hidrogel producido por tratamiento ácido del silicato de sodio. Estos materiales son ampliamente utilizados como adsorbentes y desecantes [1]. Asimismo tienen importancia como aislantes térmicos; soportes de catalizadores ó compuestos funcionales para aplicaciones químicas, electrónicas y ópticas [2]. Sin embargo, las aplicaciones prácticas resultan limitadas debido a dos propiedades: la fragilidad y la higroscopicidad por la cual adsorben la humedad del ambiente conduciendo al colapso de la estructura debido a las fuerzas capilares desarrolladas en los poros.

\section{1.b. Caracterización textural mediante el método BET}

Se seleccionaron dos tipos de silica- gel comercial con diferentes características texturales: aerosil Degussa y Kieselgel-Merck. Tal como se expuso en la sección experimental, ítem 2.2.a, el aerosil Degussa fue tratado con solución acuosa de $\mathrm{NH}_{4}(\mathrm{OH})$ para mejorar las propiedades texturales por la técnica usada corrientemente en catálisis [3]. En la Tabla 5-I se muestran dichas propiedades encontradas para las sílices utilizadas en este estudio. Los datos de superficie según el método BET fueron obtenidos por adsorción-desorción de $\mathrm{N}_{2}$ a $77{ }^{\circ} \mathrm{K}$. La isoterma completa se realizó en un rango de presión relativa entre 0.05 y 0.30 (P/Po). Además se muestran los valores de volumen de poro y el diámetro de poro promedio. Este último parámetro se determinó por el método BJH (Barrett, Joyner y Halenda) [4,5]. 


\section{1.b.1. Aerosil Degussa}

En la Figura 5-1 se muestra la isoterma de adsorción/desorción de $\mathrm{N}_{2}$ para el Aerosil Degussa. La isoterma obtenida según la nomenclatura IUPAC es característica de materiales mesoporosos. Esta propiedad del soporte se correlaciona con los datos obtenidos de la caracterización superficial de la Tabla 5-I, en donde el área superficial es baja y el tamaño de poro promedio $(12.8 \mathrm{~nm})$ está dentro del rango para materiales mesoporosos $(2-50 \mathrm{~nm})$.

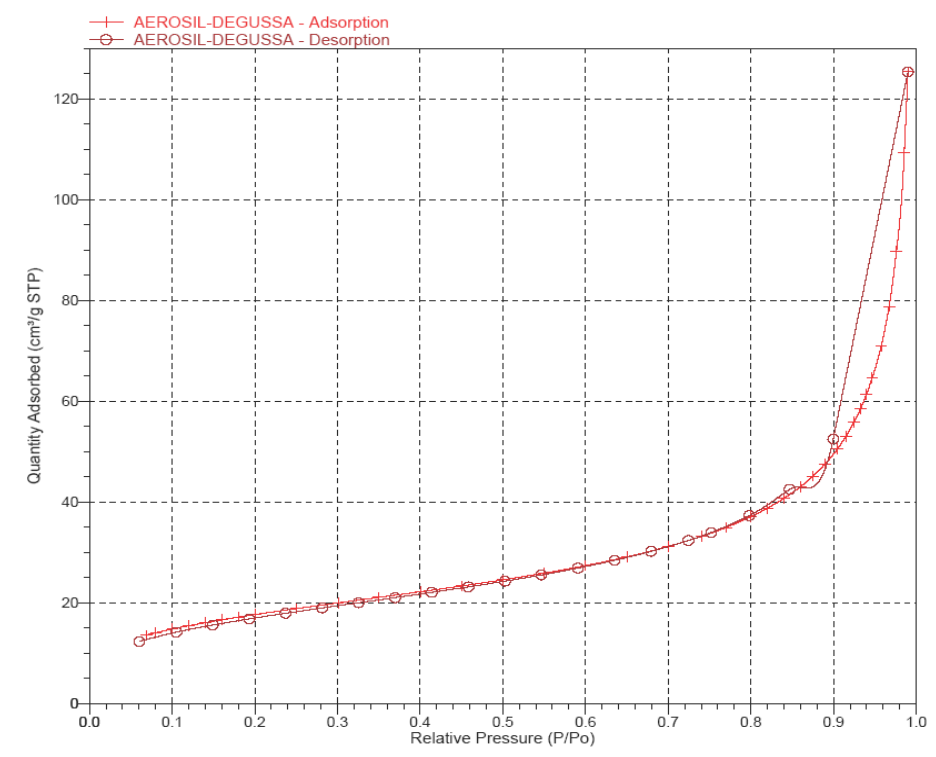

Figura 5-1: Isoterma $\mathrm{N}_{2}$ adsorción/desorción de la aerosil Degussa.

\section{1.b.2. Sílice Degussa tratada}

En la Figura 5-2 se muestra la isoterma de adsorción/desorción de $\mathrm{N}_{2}$ para el aerosil Degussa tratado según item 2.2.a. La isoterma obtenida luego del tratamiento para mejorar las propiedades texturales es de tipo IV, que corresponde a un material mesoporoso. Como consecuencia del tratamiento, se observó un aumento del $\mathrm{S}_{\mathrm{BET}}$ respecto al aerosil original (Tabla 5-I). 


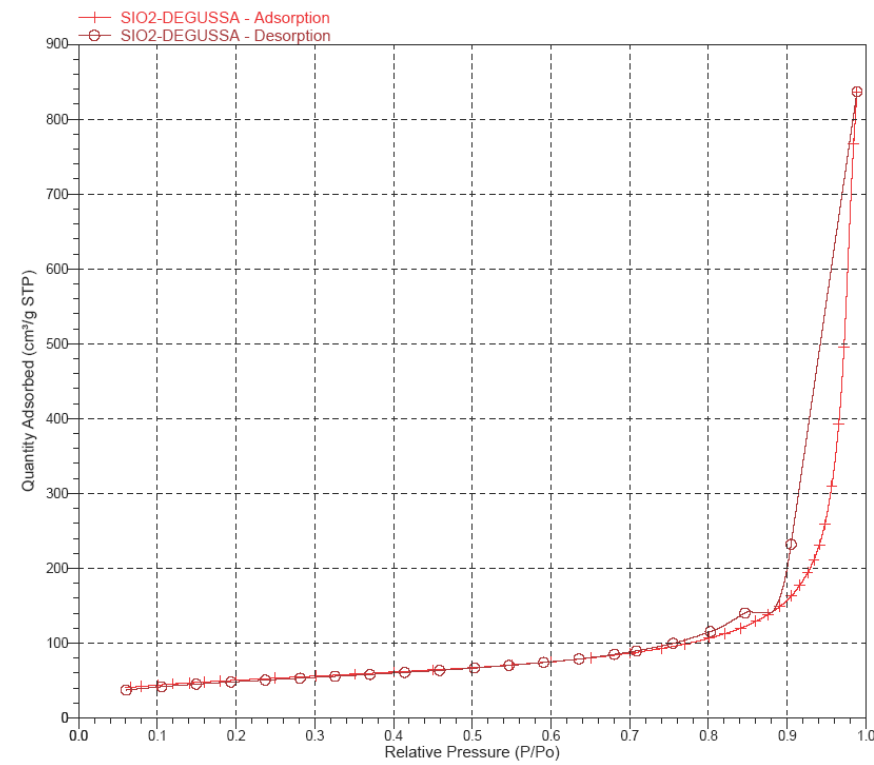

Figura 5-2: Isoterma $\mathrm{N}_{2}$ adsorción/desorción de sílice Degussa (tratada)

\section{1.b.3 Sílice Kieselgel}

La isoterma obtenida (Figura 5-3), es característica de materiales mesoporosos. Las curvas de adsorción y la desorción muestran un incremento gradual y bien definido en el rango de presiones parciales $0<\mathrm{P} / \mathrm{P}_{0}<0.6$, lo cual demuestra que la adsorción y la desorción siguen mecanismos distintos. Esta última observación se relaciona con la forma de los poros y con el fenómeno de condensación capilar en los poros del material. El material muestra mesoporosidad y mayor $S_{\mathrm{BET}}$ que los materiales a base de sílice Degussa, tal como se observa en la Tabla 5-I. 


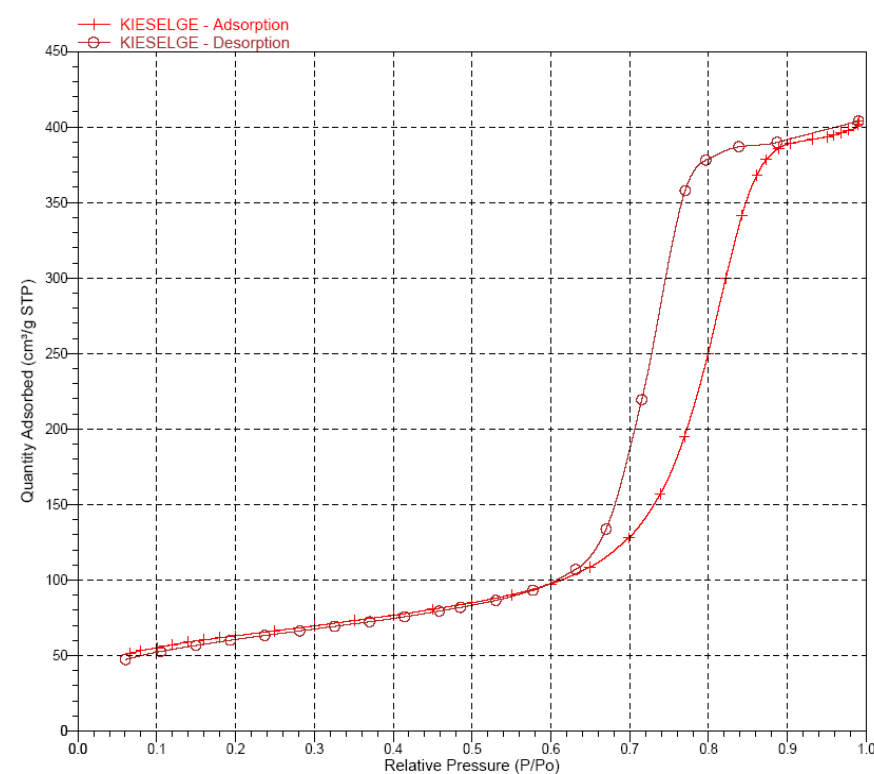

Figura 5-3: Isoterma $\mathrm{N}_{2}$ adsorción/desorción de sílice Kieselgel

Tabla 5-I: Parámetros texturales de las Sílices Degussa (tratada y sin tratar) y Kieselgel.

\begin{tabular}{cccc}
\hline Silica-gel & $\begin{array}{c}\mathbf{S}_{\text {BET }} \\
\left(\mathbf{m}^{\mathbf{2}} / \mathbf{g}\right)\end{array}$ & $\begin{array}{c}\text { Volumen de } \\
\text { Poros }\left(\mathbf{c m}^{\mathbf{3}} / \mathbf{g}\right)\end{array}$ & $\begin{array}{c}\text { DP-BJH } \\
(\mathbf{n m})\end{array}$ \\
\hline Aerosil Degussa & 65 & 0.138 & 12.8 \\
Degussa (tratada) & 180 & 0.766 & 31.4 \\
Merck Kieselgel & 224 & 0.615 & 9.8 \\
\hline
\end{tabular}

\section{1.c. Caracterización mediante difracción de polvos por Rayos X.}

En las Figuras 5-4 (a y b) se muestran los diagramas DRX obtenidos para las sílices (K) Kieselgel y (D) Degussa tratada. Ambos diagramas muestran una banda ancha correspondiente a una sílice amorfa coincidente con la reportada en la base de datos internacional (PDFWIN: 38-0448), sin embargo el diagrama de (K) muestra picos que podrían deberse a sustancias o agregados generalmente utilizados en sílices de calidad cromatográfica. Por otra parte cabe mencionar que la sílice (D) tratada mostró un diagrama DRX similar al de sílice (D) sin tratar. 


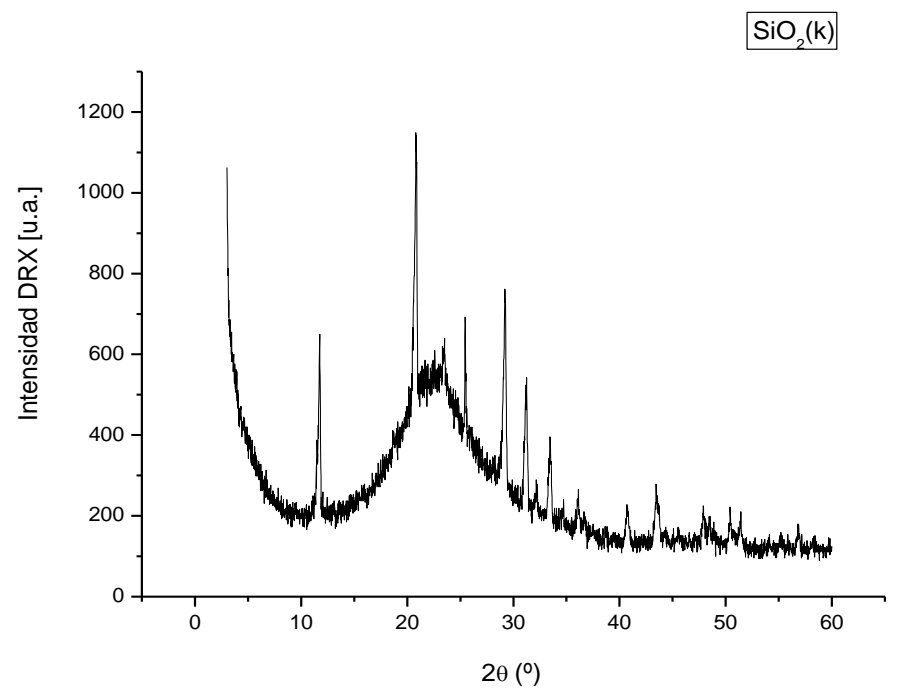

Figura 5-4 (a): DRX Sílice Kieselgel (K).

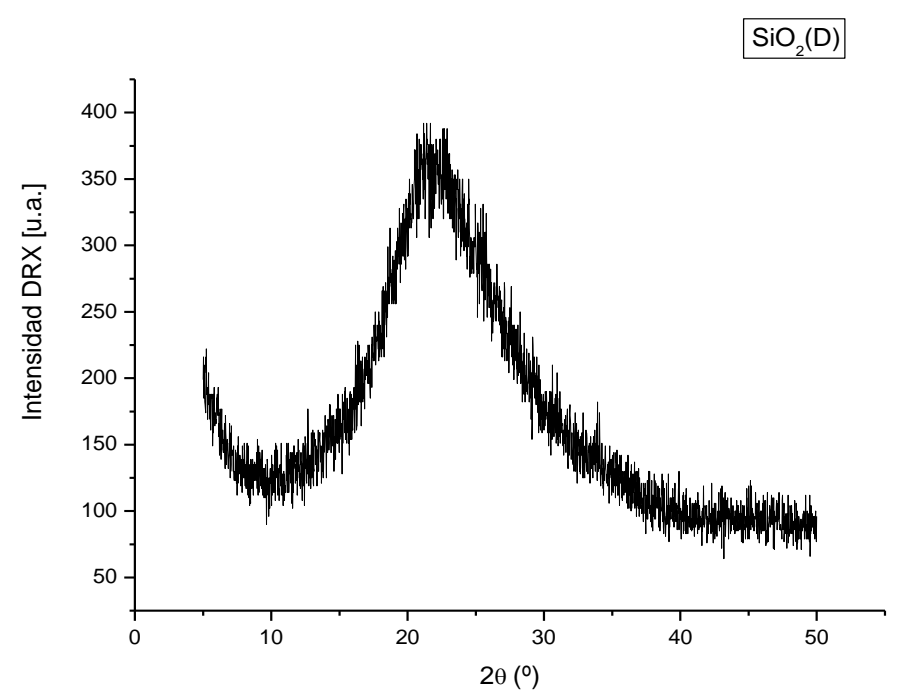

Figura 5-4 (b): DRX correspondiente a la Sílice Degussa (D) tratada.

\section{1.d. Análisis termogravimétrico (TGA)}

A partir del tratamiento a elevado $\mathrm{pH}$ con $\mathrm{NH}_{4}(\mathrm{OH})$, el Aerosil Degussa presentó mayor $\mathrm{S}_{\mathrm{BET}} \mathrm{y}$ porosidad que la muestra de origen sin tratar por lo que la superficie de esta especie está compuesta básicamente por grupos "silanoles" $\mathrm{SiO}_{2} . \mathrm{OH}$ adquiriendo 
una gran concentración de grupos oxidrilos y aumentando la superficie específica, volumen y tamaño de poros [3].

Cabe señalar que la importancia de la formación de grupos silanoles en la superficie, está asociada al control de las interacciones de fisisorción específicas ya que la elevada concentración superficial de dichos grupos incrementa las interacciones con otras moléculas, siendo significativas cuando las moléculas adsorbidas son cuadrupolares (ej. $\mathrm{N}_{2}$ y $\mathrm{CO}_{2}$ ) y mas aún en presencia de puentes hidrogeno provenientes de moléculas de $\mathrm{H}_{2} \mathrm{O}$. Luego de este tratamiento la superficie se torna hidrofílica dando lugar a la formación de grupos $\left[\mathrm{SiO}_{2}(\mathrm{OH}) \cdot \mathrm{nH}_{2} \mathrm{O}\right]$ en contacto con el agua. En esta superficie hidrofílica el agua se adsorbe a través de dos puentes hidrógenos unidos a dos silanoles.

Las moléculas de agua superficiales ocupan los macro, meso y micro-poros. La posterior remoción de los grupos silanoles por tratamiento térmico, dará lugar a una drástica liberación del agua adsorbida. El proceso de deshidratación de grupos $\left[\mathrm{SiO}_{2}(\mathrm{OH}) \cdot \mathrm{nH}_{2} \mathrm{O}\right]$ ocurre alrededor de $70^{\circ} \mathrm{C}$. En el rango de temperatura entre $20 \mathrm{y}$ $180^{\circ} \mathrm{C}$, la sílica generalmente pierde las moléculas de agua las que desorben completamente a partir de los macro, meso y micro-poros. Luego de este proceso sólo los grupos $\mathrm{SiO}_{2} . \mathrm{OH}$ estarán presentes y el proceso de “des-oxidrilación” continúa hasta $500^{\circ} \mathrm{C}[2]$.

A los fines de analizar la capacidad hidroadsorbente, se pesaron y humedecieron las muestras y se obtuvieron los diagramas de TGA (ver Capítulo 2) que se muestran en la Figura 5-5. En estos se observa la pérdida de peso alrededor de $100^{\circ} \mathrm{C}$ de acuerdo con la evaporación del agua adsorbida. El efecto se observa con mayor intensidad en la silica Kieselgel-Merck de mayor $\mathrm{S}_{\mathrm{BET}}$.

Inversamente, los diagramas TGA para el aerosil Degussa original y tratado, muestran un comportamiento similar que no permite observar una diferencia significativa de acuerdo a las características hidrofílicas y texturales respectivas. 


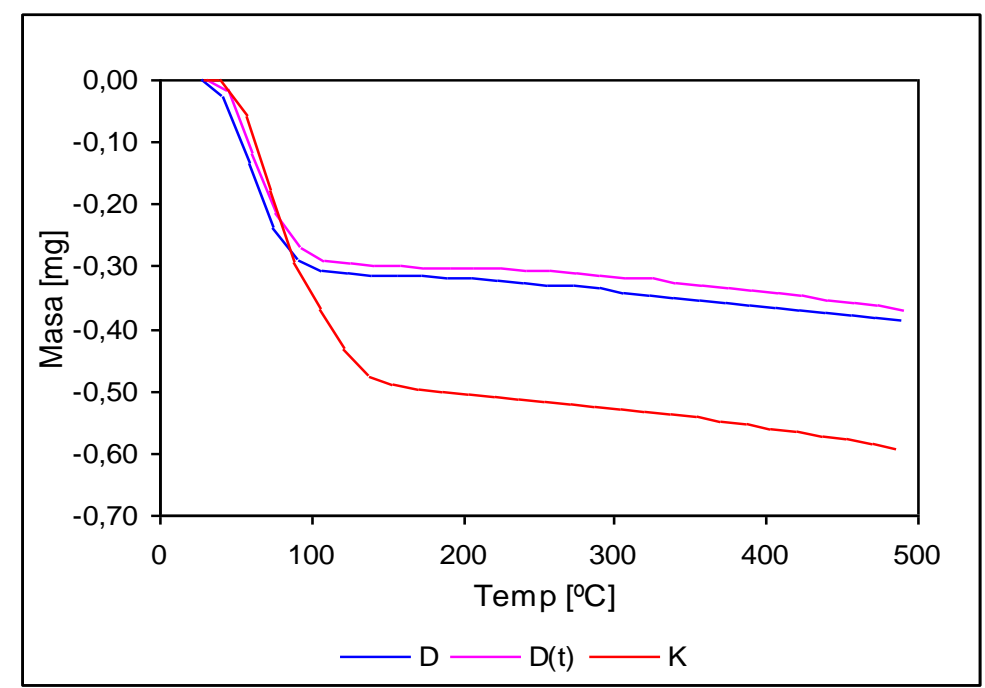

Figura 5-5: Diagramas TGA para las diferentes muestras de sílica previamente humedecidas y secadas a $80{ }^{\circ} \mathrm{C}$. D (t): Degussa tratada, D: Degussa sin tratar y K:

Kiesegel.

Para determinar las moléculas de agua adsorbida por $\mathrm{nm}^{2}$, por cada sílice se empleó el método reportado por Rinaldi, et al., (2006) [6], mediante la ecuación (1), a partir de los parámetros del TGA y $\mathrm{S}_{\mathrm{BET}}$ :

$$
W=\frac{\Delta m}{M_{H_{2} O}} \frac{1}{S_{\text {BET }} m_{i}} \text { NA }
$$

Donde W es el número de moléculas de $\mathrm{H}_{2} \mathrm{O} / \mathrm{nm}^{2}$ de sílice a temperatura ambiente. $\Delta \mathrm{m}$ la pérdida de peso a una temperatura dada por TGA, $\mathrm{m}_{\mathrm{i}}$ es el peso inicial de la muestra (gr) usado en el experimento, $\mathrm{M}_{\mathrm{H} 2 \mathrm{O}}$ masa molecular del agua ( $18.053 \mathrm{gr}$ mol $\left.{ }^{-1}\right)$, NA la cte. de Avogadro $\left(6,023 \times 10^{23} \mathrm{~mol}^{-1}\right)$ y $\mathrm{S}_{\mathrm{BET}}$ es el área superficial determinada por el Método BET $\left(\mathrm{nm}^{2} \mathrm{gr}^{-1}\right)$.

Asimismo se analizó el volumen a humedad incipiente de las tres muestras. Este es un método estimativo y standard utilizado corrientemente en catálisis para la selección de soportes en la preparación de catalizadores. Se midió el volumen de agua 
adsorbido por una cantidad conocida $(100 \mathrm{mg})$ de cada material hasta alcanzar la humedad incipiente.

Los valores de cantidad de agua adsorbida a humedad incipiente y los datos de W de las sílices liberadas en el intervalo de $25-200^{\circ} \mathrm{C}$, se muestran en la Tabla 5-II.

Tabla 5-II: Valores de volumen de agua adsorbida a humedad incipiente y $\mathrm{W}$ de las muestras en estudio

\begin{tabular}{ccc}
\hline Tipo de Sílice & $\mathbf{H}_{\mathbf{2}} \mathbf{O}(\mathbf{m l})$ / Sílice $(\mathbf{1 0 0 m g})$ & W $\left(\mathbf{m o l e c}\right.$. agua $\left./ \mathbf{n m}^{\mathbf{2}}\right)$ \\
\hline Aerosil Degussa & 6.0 & 12 \\
Degussa (tratada) & 2.5 & 5 \\
Merck Kieselgel & 2.0 & 7 \\
\hline
\end{tabular}

Se puede observar que los valores obtenidos tanto para el volumen como para las moléculas de $\mathrm{H}_{2} \mathrm{O}$ liberadas de la superficie y antes "adsorbidas" resultan admisibles, teniendo en cuenta los diferentes valores de área superficial y porosimetría de cada especie. Si comparamos la sílice (D) sin tratar, de pequeña área superficial y mesoporos de mayor diámetro respecto de la sílice $(\mathrm{K})$ con mayor área y mesoporos mas pequeños, es natural que esta última adsorba menor cantidad de agua por $\mathrm{nm}^{2}$ suponiendo que la atracción de agua depende básicamente de la mayor o menor disponibilidad de grupos silanoles que existen en la superficie de la sílice.

\section{1.e. Evaluación de la capacidad hidroadsorbente por la Técnica Laser Speckle dinámico.}

En este sentido, resultó interesante utilizar la técnica Láser denominada "speckle dinámico" como método alternativo para evaluar la capacidad de adsorción de agua y que permita una correlación con las propiedades texturales del material.

La evolución temporal de los diagramas de Speckle se relaciona con la "actividad" de la superficie de un dado material y puede proporcionar una herramienta interesante para caracterizar los parámetros implicados en los cambios físicos de un 
material durante procesos de secado, adsorción o desorción. En el presente trabajo de tesis se muestran los primeros resultados de la aplicación del "Speckle dinámico" al estudio de hidroadsorción de soportes de catalizadores con diversas características texturales, tales como área superficial y volumen de poros.

Los resultados experimentales obtenidos para las tres muestras de sílice en estudio se muestran en la Figura 5-6. Las actividades cuantitativas del Speckle expresadas como momento de inercia (MI) se graficaron en función del tiempo transcurrido durante el proceso de adsorción de agua, como se indicó en la sección experimental. La actividad inicial se normalizó para las tres muestras. Se evidencia el diverso comportamiento de las sílices $(D)$ original, $\left(D_{t}\right)$ tratada y el de $(K)$.

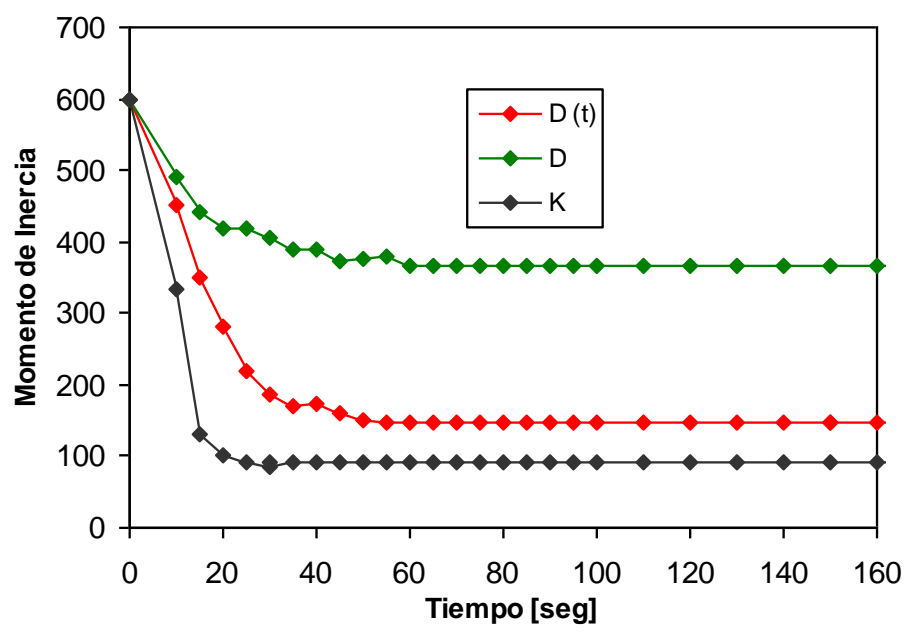

Figura 5-6: Actividad de Speckle en función del tiempo para el proceso de hidroadsorción de diferentes muestras de sílice.

El material aerosil original (D) mostró alta actividad inicial y una leve caída de la misma, manteniéndose alta en el tiempo, comportamiento que coincide con el proceso de atracción de moléculas de agua y que continúa con una interacción dinámica sin lograr un estado de relajación o de baja actividad. Contrariamente el material $(\mathrm{K})$ de mayor $\mathrm{S}_{\mathrm{BET}}$ y mayor volumen de poros más pequeños genera una rápida adsorción de moléculas de $\mathrm{H}_{2} \mathrm{O}$ por lo que la actividad de Speckle decae rápidamente y se mantiene baja o prácticamente nula indicando que el sistema llega 
en 20 seg. a un estado de relajación. Este comportamiento sugiere que el proceso de adsorción resultó más eficiente para la muestra con mayor área superficial.

La muestra (Dt) muestra un comportamiento intermedio acorde con sus propiedades texturales intermedias. Los materiales de mayor área y volumen de poros que el aerosil original adsorben menor cantidad de $\mathrm{H}_{2} \mathrm{O}$ por $\mathrm{nm}^{2}$ por lo que el proceso llega al equilibrio más rápidamente (menor tiempo de relajación) como se observa en la Figura 5-6. En una primera aproximación, estos resultados sugieren una correlación de la actividad de Speckle con el proceso de interacción agua-superficie dependiente de la hidrofilicidad y textura de las muestras.

En el gráfico mostrado en la Figura 5-7 se ha representado el tiempo de relajación de cada sílice, tomando el tiempo necesario para llegar al "plateau" de las respectivas curvas MI vs. Tiempo. En el mismo se ha representado además el valor de área superficial y de W para cada muestra. En esta gráfica se observa una mejor correlación entre el tiempo de relajación de los sistemas adsorbentes respecto a su valor de $\mathrm{S}_{\mathrm{BET}}$, que respecto al parámetro $\mathrm{W}$ calculado teóricamente a partir de las señales del TGA, corroborando que el proceso de adsorción es complejo y dependiente de varios factores tanto químicos como físicos intervinientes en la superficie.

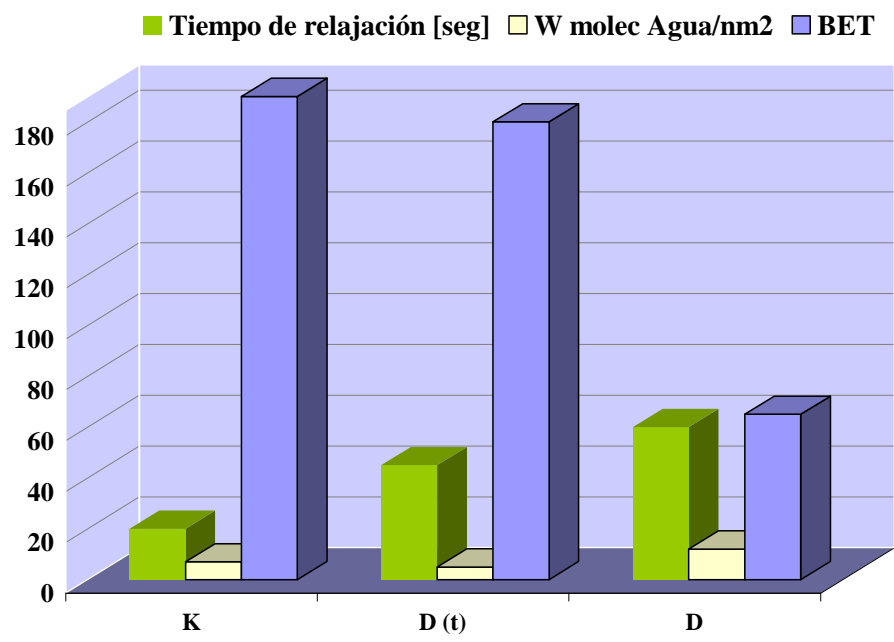

Figura 5-7: Tiempos de estabilización de HTDS vs W moléculas de Agua /nm² y el $S_{\text {BET }}$ para Sílices. 


\section{1.f. Conclusiones parciales:}

Se seleccionaron dos tipos de sílices, una de las cuales fue pretratada con $\mathrm{NH}_{4}(\mathrm{OH})$ con el fin de modificar sus propiedades texturales y ser utilizada posteriormente como soporte catalítico. Estos materiales se caracterizaron por técnicas estructurales como DRX y texturales por el método BET.

También se estudiaron sus propiedades de hidroadsorción utilizando los diagramas termogravimétricos (TGA) y el método de Speckle Dinámico. Los resultados preliminares sugieren que este último método podría ser una buena herramienta para comparar sílices de diferentes propiedades texturales. En estas experiencias, el método de Speckle dinámico mostró mayor sensibilidad que el método TGA para diferenciar el comportamiento hidroadsorbente entre la sílice Dt y D. El método Laser es además una técnica de caracterización sencilla, económica y no destructiva, aspectos que conllevan una gran ventaja respecto al gasto energético y de insumos que generan otros métodos de caracterización.

\subsection{Preparación y caracterización de soportes a base de Alúminas.}

Preparación y tratamiento de $\boldsymbol{\gamma}$-alúmina: se procedió a la calcinación de un precursor de alúmina $\mathrm{Al}(\mathrm{OH})_{3}$ "gibbsite" a diferentes temperaturas para obtener óxidos de diferentes propiedades texturales tal como se muestra en la Tabla 5-III. Se seleccionaron dos muestras denominadas (A) y (AI) obtenidas por tratamiento del precursor de alúmina a $550^{\circ} \mathrm{C}$ y $480^{\circ} \mathrm{C}$ respectivamente. 
Tabla 5-III: Parámetros BET de muestras de alúmina a diferentes temperaturas de

\begin{tabular}{ccc}
\multicolumn{3}{c}{ calcinación } \\
\hline $\begin{array}{c}\text { Temp. } \\
{ }_{\mathbf{0}} \mathbf{C}\end{array}$ & $\begin{array}{c}\mathbf{S}_{\text {BET }} \\
\left(\mathbf{m}^{\mathbf{2}} / \mathbf{g}\right)\end{array}$ & $\begin{array}{c}\text { Vol.Poros } \\
\left(\mathbf{c m}^{\mathbf{3}} / \mathbf{g}\right)\end{array}$ \\
\hline 900 & 97 & 0.236 \\
750 & 114 & 0.234 \\
720 & 109 & 0.225 \\
700 & 123 & 0.230 \\
680 & 131 & 0.232 \\
$550^{1}$ & 159 & 0.227 \\
$480^{2}$ & 150 & 0.239 \\
Precursor sin calcinar & 5 & 0.0036 \\
\hline
\end{tabular}

Ref.: ${ }^{1}$ Alúmina denominada A y ${ }^{2}$ Alúmina denominada AI

Para realizar un estudio comparativo se seleccionaron además otras de origen comercial con diferentes propiedades texturales: $\gamma-\mathrm{Al}_{2} \mathrm{O}_{3}$ denominadas "Esferalite" (EI), (EII) y Ketjen (K).

\section{2.a. Caracterización textural mediante el método BET}

Las características texturales de los materiales elegidos para su estudio como soportes, fueron analizadas por el método BET, tal como se expuso en la sección experimental, ítem $\mathbf{2 . 8}$.

En las Figuras 5-8 a 12 se muestran las isotermas de adsorción de $\mathrm{N}_{2}$. Para todas las muestras se observa que, a una presión relativa mayor a 0.4 , se inicia la formación de un lazo de histéresis y de acuerdo a la clasificación de la IUPAC, estas pueden ser consideradas de tipo H3 [7], asociadas a materiales conteniendo poros en forma de rendijas. En las figuras 5-11 y 12 se muestran las isotermas de A y A1 las que resultan prácticamente idénticas. 


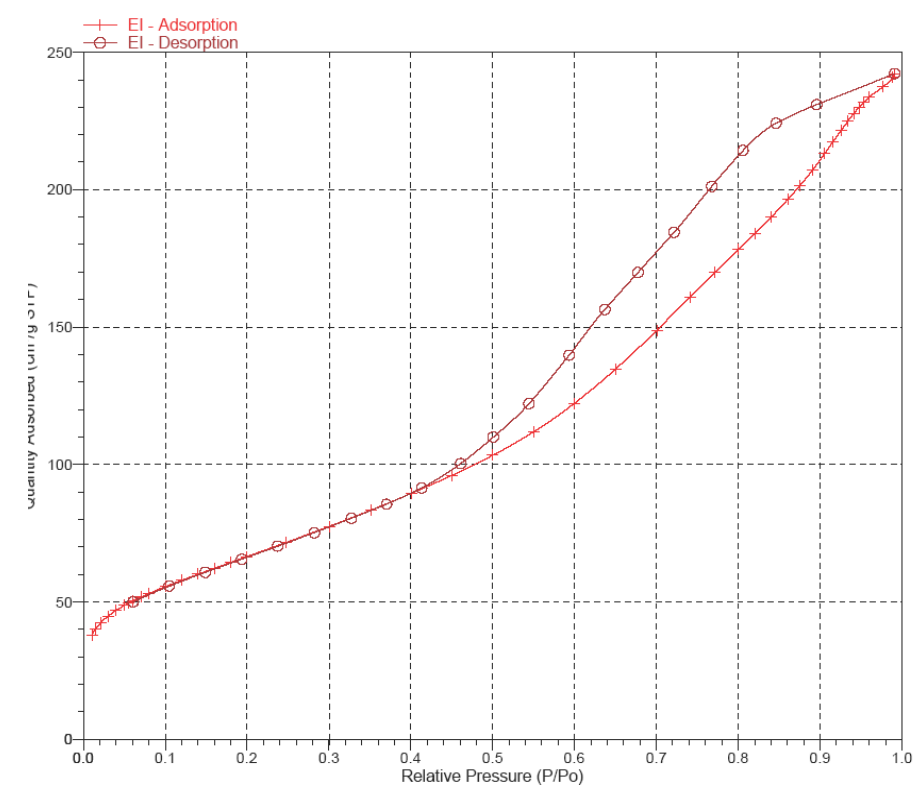

Figura 5-8: Isoterma $\mathrm{N}_{2}$ adsorción/desorción de $\gamma-\mathrm{Al}_{2} \mathrm{O}_{3}$ Esferalite (EI)

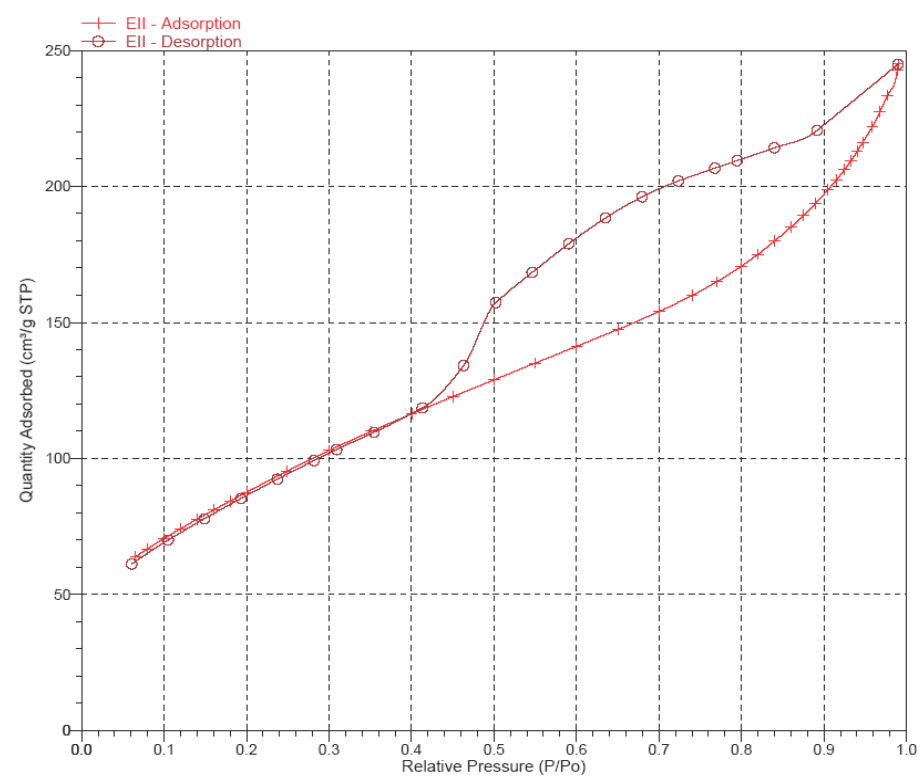

Figura 5-9: Isoterma $\mathrm{N}_{2}$ adsorción/desorción de $\gamma-\mathrm{Al}_{2} \mathrm{O}_{3}$ Esferalite (EII) 


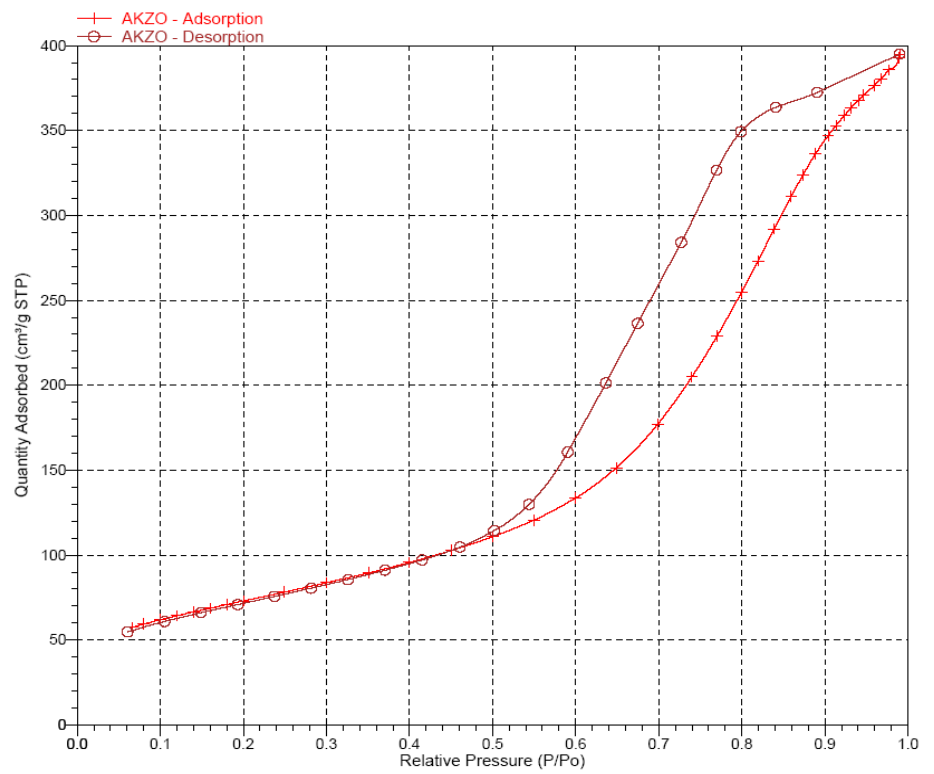

Figura 5-10: Isoterma $\mathrm{N}_{2}$ adsorción/desorción de $\gamma-\mathrm{Al}_{2} \mathrm{O}_{3}$ Ketjen $(\mathrm{K})$

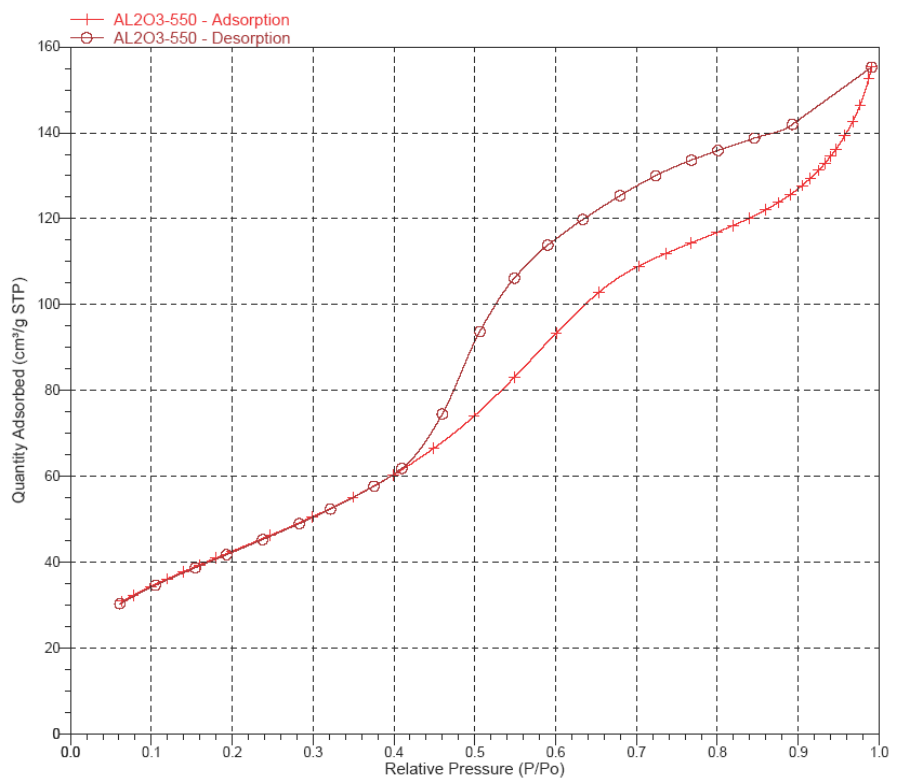

Figura 5-11: Isoterma $\mathrm{N}_{2}$ adsorción/desorción de $\gamma-\mathrm{Al}_{2} \mathrm{O}_{3}(\mathrm{~A})$ 


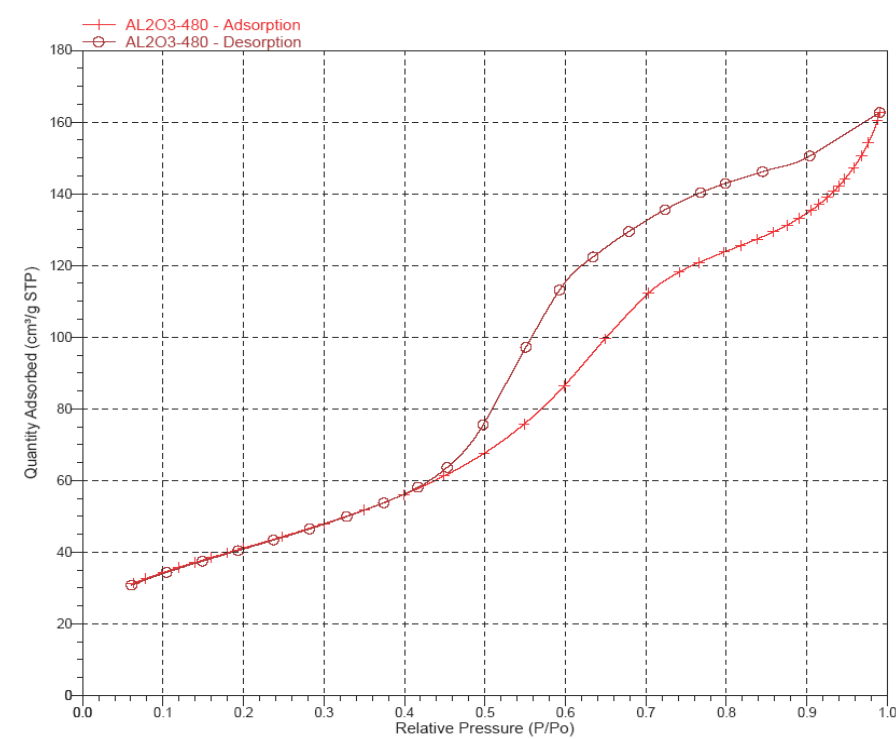

Figura 5-12: Isoterma $\mathrm{N}_{2}$ adsorción/desorción de $\gamma-\mathrm{Al}_{2} \mathrm{O}_{3}(\mathrm{AI})$.

En la Tabla 5-IV se presentan los parámetros de superficie específica y volumen de poros para todas las alúminas.

Tabla 5-IV: Parámetros BET de diferentes alúminas.

\begin{tabular}{ccc}
\hline Soporte & $\begin{array}{c}\mathbf{S}_{\text {BET }} \\
\mathbf{m}^{\mathbf{2}} / \mathbf{g}\end{array}$ & $\begin{array}{c}\text { Vol.Poros } \\
\left(\mathbf{c m}^{\mathbf{3}} / \mathbf{g}\right)\end{array}$ \\
\hline EI & 237 & 0.37 \\
EII & 328 & 0.36 \\
K & 264 & 0.59 \\
A & 159 & 0.23 \\
AI & 150 & 0.24 \\
\hline
\end{tabular}

Se observa que las especies de tipo $\gamma-\mathrm{Al}_{2} \mathrm{O}_{3}$, Esferalite (EI y EII), si bien poseen la misma estructura cristalina presentan diferentes propiedades texturales siendo mayor el área BET para EII. 
Las distribuciones de tamaño de poros para EI y EII se muestran en la Figura 513, en la que se observa que EII es fundamentalmente microporosa con un tamaño de poro efectivo que se encuentra entre los 7 y $9 \AA$.

Tanto EI como A y AI muestran una distribución de tamaño de mesoporos caracterizada por un área muy estrecha, con un máximo centrado entre 18-20 ̊̊ de radio de poro medio para EI y de $50 \AA$ A para A y AI.

$$
\begin{aligned}
& \text { a-EII } \\
& \text { b-EI } \\
& \text { c-A y AI }
\end{aligned}
$$

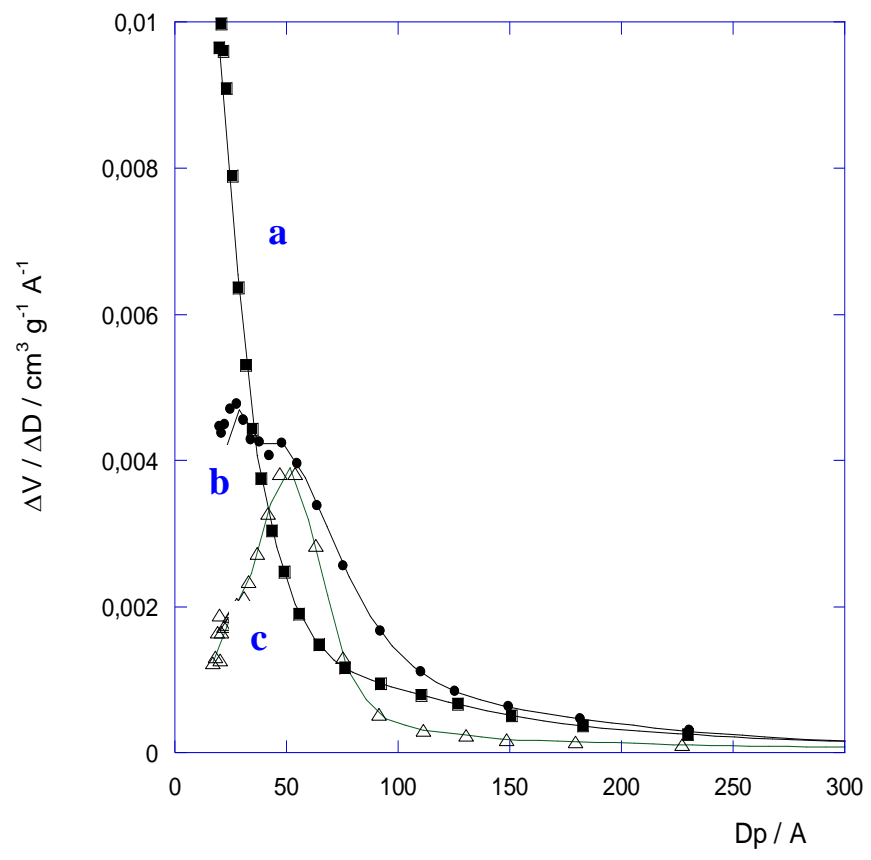

Figura 5-13: Distribución del tamaño de poros comparativa para $\gamma-\mathrm{Al}_{2} \mathrm{O}_{3}(\mathrm{EI}$, EII, A y AI)

\section{2.b. Caracterización por DRX}

La Figura 5-14, muestra el perfil de difracción de rayos X para las especies de fase $\gamma$ : EI o EII coincidentes con la fase de $\gamma-\mathrm{Al}_{2} \mathrm{O}_{3}$ (PDFWIN: 89-7717). La Figura 5-15 muestra el patrón de difracción de polvos por rayos X para (A), (AI) correspondientes al precursor de alúmina luego de ser calcinado a $550^{\circ}$ y $480^{\circ} \mathrm{C}$ respectivamente en atmósfera estática y el correspondiente al sólido K. 
Las señales de difracción de los soportes A, EI, EII y K si bien muestran diferente grado de cristalinidad, resultan coincidentes con la fase cristalográfica de $\gamma$ $\mathrm{Al}_{2} \mathrm{O}_{3}\left(2 \theta: 15^{\circ}, 29.4^{\circ}, 39.0^{\circ}\right.$ y $48.0^{\circ}$, PDFWIN: 89-7717). El diagrama correspondiente a la especie AI revela la presencia de una especie amorfa típica de una alúmina de "transición" que evoluciona desde $\mathrm{Al}(\mathrm{OH})_{3}$ "gibbsite", hacia una fase cristalina, cuyas reflexiones podrían corresponder a una mezcla posiblemente de boehmite $(\gamma$-AlOOH) y la forma $\gamma-\mathrm{Al}_{2} \mathrm{O}_{3}(\gamma-\mathrm{AlOOH}: \mathrm{PDFWIN}-83-2384)$ [8].

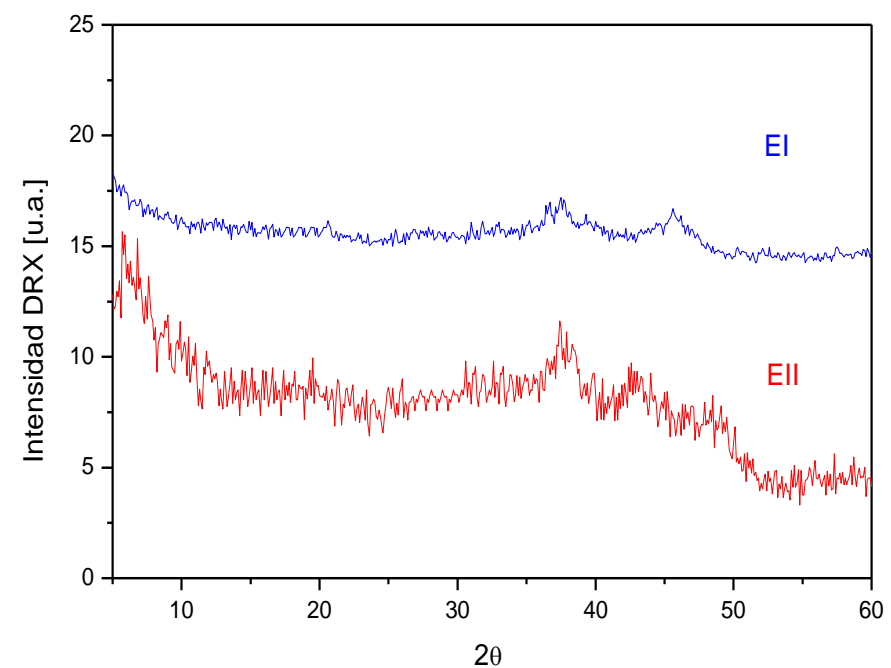

Figura 5-14: Diagramas DRX correspondientes a las alúminas EI y EII.

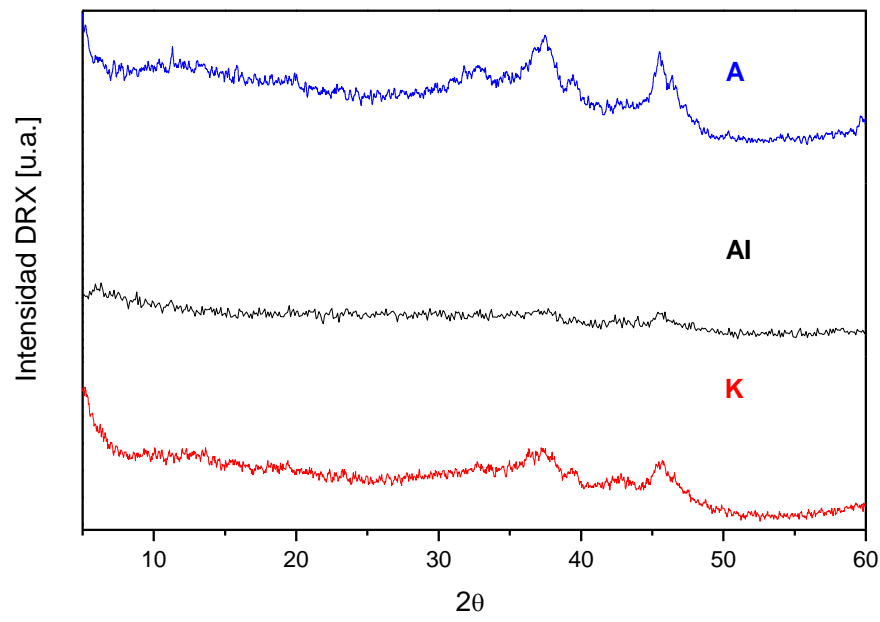

Figura 5-15: DRX para A, AI y el sólido comercial denominado K. 


\section{2.c. Análisis termogravimétrico (TGA)}

Con el objeto de realizar un análisis de hidroadsorción por TGA y Speckle dinámico, al igual que para los soportes a base de sílice, se procedió a estudiar de manera similar las distintas especies de alúmina, humedeciendo las muestras con el mismo procedimiento, antes de cada ensayo.

La Figura 5-16 muestra las curvas TGA de las cinco muestras estudiadas. Se observa en todos los casos una pérdida de masa continua en el intervalo $25-500^{\circ} \mathrm{C}$. La muestra que presenta mayor pérdida de masa es la especie amorfa AI que puede contener una fase tipo hidroxilada, en el intervalo de temperaturas considerado. La deshidratación y/o deshidroxilación de las especies tipo "boehmite" se ha reportado a través de dos mecanismos: eliminación del agua superficial adsorbida en las partículas y eliminación de agua interlaminar de la estructura cristalina [6].

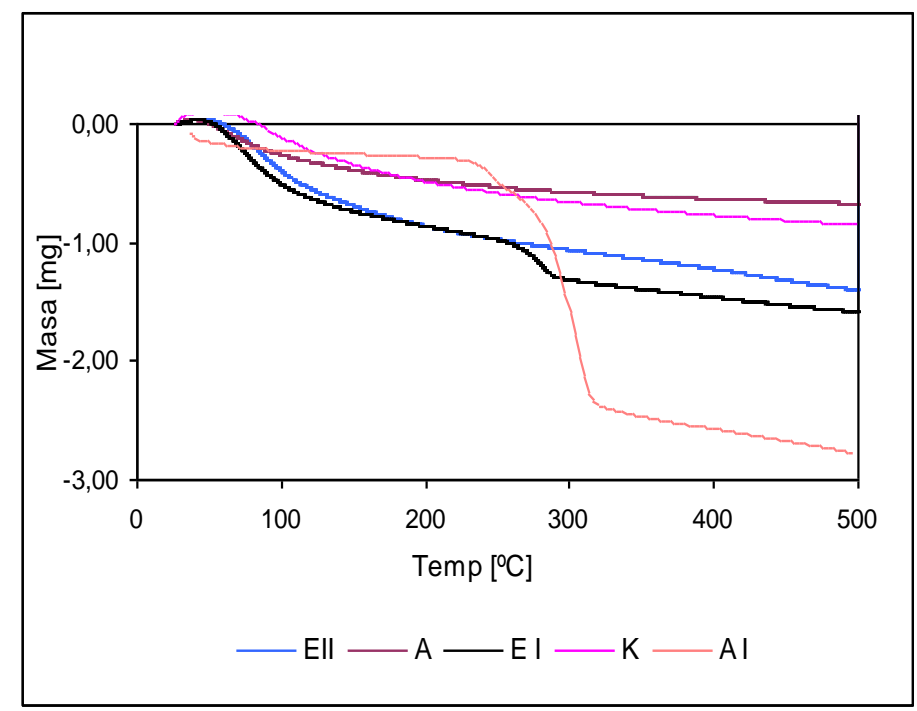

Figura 5-16: Perfiles de TGA para las alúminas estudiadas A, AI, EI, EII y K entre $\mathrm{T}$ ambiente y $500^{\circ} \mathrm{C}$

Al igual que en el análisis por DRX, la fase AI muestra un comportamiento diferente al resto de las especies, mientras $\mathrm{K}$ y $\mathrm{A}$ muestran una pérdida de peso equivalente, EI y EII, si bien presentan un comportamiento inicial similar, EI presenta una pérdida adicional de agua intramolecular, alrededor de $300^{\circ} \mathrm{C}$, efecto que podría asociarse a la diferencia en la distribución de poros respecto a EII. 
Respecto al comportamiento de AI, la presencia de agua y grupos $\mathrm{OH}$ en la estructura cristalina de la "boehmite" y la transición de ésta hacia la fase $\gamma-\mathrm{Al}_{2} \mathrm{O}_{3}$ han sido ampliamente descritos en la literatura [6] y el mecanismo de deshidratación depende del proceso de síntesis utilizado.

En la década de 1960, los estudios clásicos sobre la adsorción de agua sobre alúmina y la naturaleza de los grupos hidroxilo de la superficie de $\gamma$ $\mathrm{Al}_{2} \mathrm{O}_{3}$ fueron publicados por Lippens y col. [9] y Peri y Hannan [10-13].

El primer grupo mostró que las alúminas tienen altas capacidades de adsorción de agua y a continuación Peri y Hannan explicaron que el proceso consiste en una quimisorción no-disociativa de agua a través de enlaces de hidrógeno muy fuertes entre los grupos oxídicos de la superficie y las moléculas del agua, mientras que sólo por calentamiento por encima de $300{ }^{\circ} \mathrm{C}$, se forman grupos de $\mathrm{Al}-\mathrm{OH}$ superficiales [10].

Recientemente, se ha comenzado a observar un gran interés por el estudio de los complejos fenómenos de hidratación en la superficie de alúminas [14-22] y se reportaron varios estudios sobre suspensiones acuosas $\gamma-\mathrm{Al}_{2} \mathrm{O}_{3}[14,17,19,21]$ en los que se muestra que esta alúmina de transición no es estable durante largos períodos de tiempo (de varias semanas a meses), presentando un recubrimiento en la superficie de la especie bayerita, $\beta-\mathrm{Al}(\mathrm{OH})_{3}$ [21]. Posteriormente Rinaldi y col. [6] realizaron un extenso trabajo sobre el efecto de la humedad en las propiedades físico-químicas de varias alúminas de transición analizando los cambios en las propiedades estructurales, morfológicas y de la acidez provocados por la hidratación de las superficies, controlando la humedad atmosférica a temperatura ambiente. Encontraron que además de la adsorción física y química del agua en la superficie, el proceso de hidratación provoca la formación de oxi-hidróxido de aluminio y tri-hidróxido (boehmita y bayerita) y la recalcinación de $\gamma-\mathrm{Al}_{2} \mathrm{O}_{3}$ hidratada no permite recuperar las propiedades ácidas iniciales del material observando que las poblaciones de sitios de débil a moderada acidez, disminuyen fuertemente bajo recalcinación de las alúminas hidratadas. Por otro lado, las poblaciones de sitios ácidos más fuertes no se ven fuertemente afectadas por recalcinación. Este trabajo mostró que la interacción de vapor de agua presente en el aire atmosférico con la superficie de alúmina, es un aspecto muy importante a tener en cuenta desde el punto de vista catalítico [6]. 
En nuestro caso y en base a la metodología propuesta por dicho trabajo, se decidió calcular la cantidad de agua adsorbida de las alúminas en estudio humedecidas previamente, mediante los diagramas de TGA. El cálculo, como ya se expuso en secciones anteriores se realiza en base al agua liberada (W) por las muestras entre $25 \mathrm{y}$ $200^{\circ} \mathrm{C}$, relacionando los datos de TGA y $\mathrm{S}_{\mathrm{BET}}$, mediante la expresión (1):

$$
W=\frac{\Delta m}{M_{H_{2} O}} \frac{1}{S_{\text {BET }} m_{i}} \text { NA }
$$

Los valores de $\mathrm{W}$ de las alúminas liberadas en un intervalo de $25-200^{\circ} \mathrm{C}$, se muestran en la Tabla 5-V.

Tabla 5-V: Datos de moléculas de agua liberadas para soportes de alúmina.

\begin{tabular}{ccc}
\hline Soporte & $\left.\begin{array}{c}\mathbf{W} \\
(\mathbf{m o l e c} \text { agua/nm }\end{array} \mathbf{n}^{2}\right)$ & $\begin{array}{c}\mathbf{S}_{\text {BET }} \\
\mathbf{m}^{2} / \mathbf{g}\end{array}$ \\
\hline EI & 14 & 237 \\
EII & 9 & 328 \\
A & 12 & 150 \\
AI & 6 & 159 \\
K & 11 & 264 \\
\hline
\end{tabular}

La comparación entre las alúminas de tipo $\gamma$, de estructura equivalente antes de ser humedecidas y calcinadas (EI, EII, $\mathrm{K}$ y A), muestra que EI presentó mayor capacidad hidroadsorbente, mientras que la especie de tipo "boehmita" (AI) parece ser la menos hidroadsorbente, a pesar de tener un área superficial comparable a la de la especie A, hecho que corrobora que existe menor concentración de sitios superficiales hidrofílicos.

\section{2.d. Aplicación de la Técnica de Speckle dinámico en el proceso de hidroadsorción.}


Los resultados experimentales se muestran en Figura 5-17 (a). Los materiales de estructura relacionada a $\gamma$ - alumina (EI, EII, A y K) presentaron mayor actividad de Speckle en función del tiempo respecto a la especie de estructura boehmita AI. En la Figura 5.17 (b) se muestra el gráfico ampliado para este grupo de alúminas. Aunque las especies $\mathrm{E}(\mathrm{I}), \mathrm{E}(\mathrm{II}) \mathrm{K}$ y $\mathrm{AI}$ poseen la misma estructura con diferente grado de cristalinidad, muestran diferentes características superficiales respecto a la textura y probablemente respecto a la acidez como se explicó en párrafos anteriores, esta propiedad estaría dada por sitios Brønsted (Al-OH) en la superficie y la población de este tipo de sitios varía con la humedad de la muestra y posterior calcinación. Estas propiedades evidentemente determinan el poder hidroadsorbente. Si comparamos los soportes A y AI, se observa una dinámica Speckle muy diferente posiblemente debido a la diferente acidez superficial ya que entre estas especies no existen diferencias significativas respecto a las propiedades texturales ( $\mathrm{S}_{\mathrm{BET}}$ y porosimetría) si bien existen diferencias en cuanto al tipo estructural y eventualmente de sitios superficiales. Estas alúminas son fases denominadas de "transición" y probablemente AI posee también fase tipo $\gamma$ en formación cuyos picos DRX quedan enmascarados por la presencia de la boehmita. Así, resulta posible relacionar la menor hidroadsorción de AI con una menor acidez en su superficie dado que la estructura y composición de la alúmina depende de la temperatura de calcinación, según Rouquerol, F. [1], a medida que baja la temperatura de calcinación en la etapa de preparación de alúminas, la fuerza ácida es baja, al aumentar la temperatura (como ocurre para las de estructuras tipo $\gamma$ ), la acidez crece debido a la formación de un número creciente de sitios ácidos de Brønsted, ocasionando mayor atracción hacia los dipolos de la molécula de agua, siendo mayor su hidrofilicidad.

Asimismo en la figura 5-18, es posible relacionar el tiempo de estabilización del HTDS de cada especie con el número moléculas de $\mathrm{H}_{2} \mathrm{O} / \mathrm{nm}^{2}$ de alúmina adsorbidas a temperatura ambiente. La tendencia general indica que para menores tiempos de relajación, mayor es el número de moléculas de agua adsorbida. Por otro lado en esta figura también se han representado los valores de área BET. 


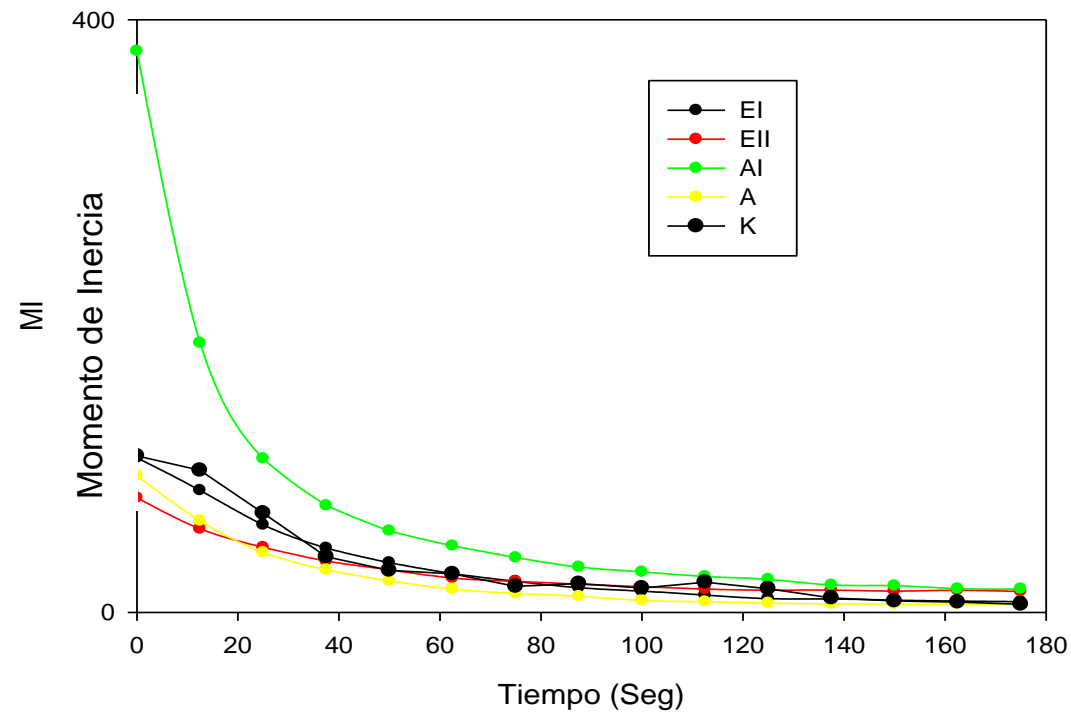

(a)

Figura 5-17 (a): Actividad de Speckle en función del tiempo para todas las alúminas estudiadas.

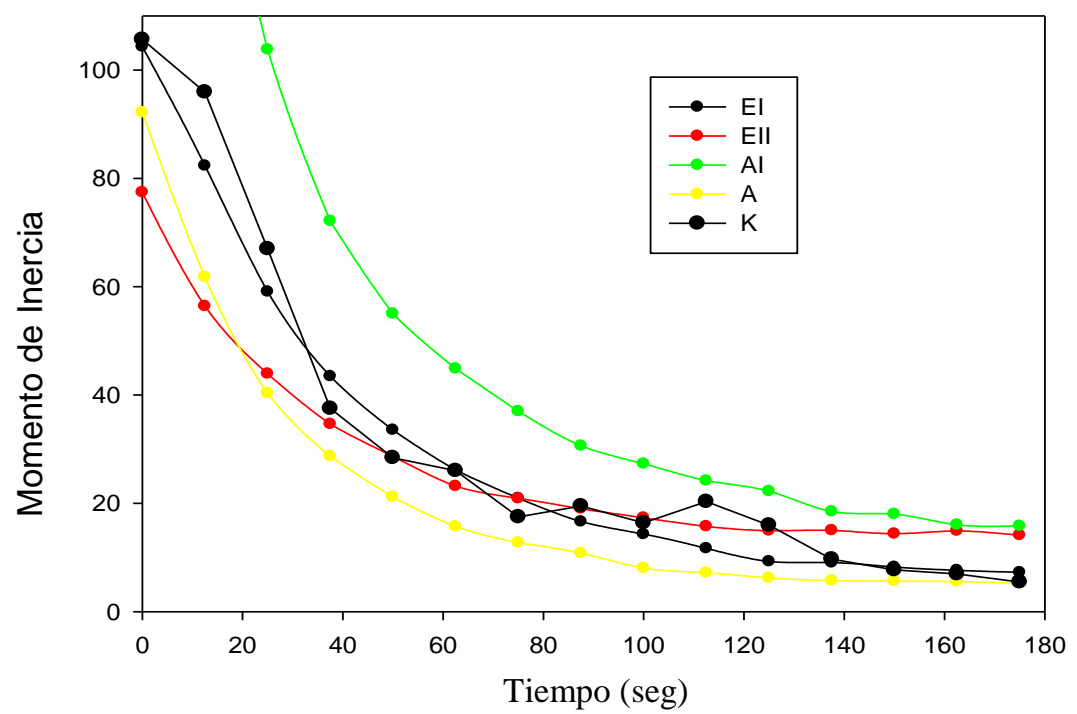

(b)

Figura 5-17 (b): Gráfico ampliado para las alúminas EI, EII, A y K. 


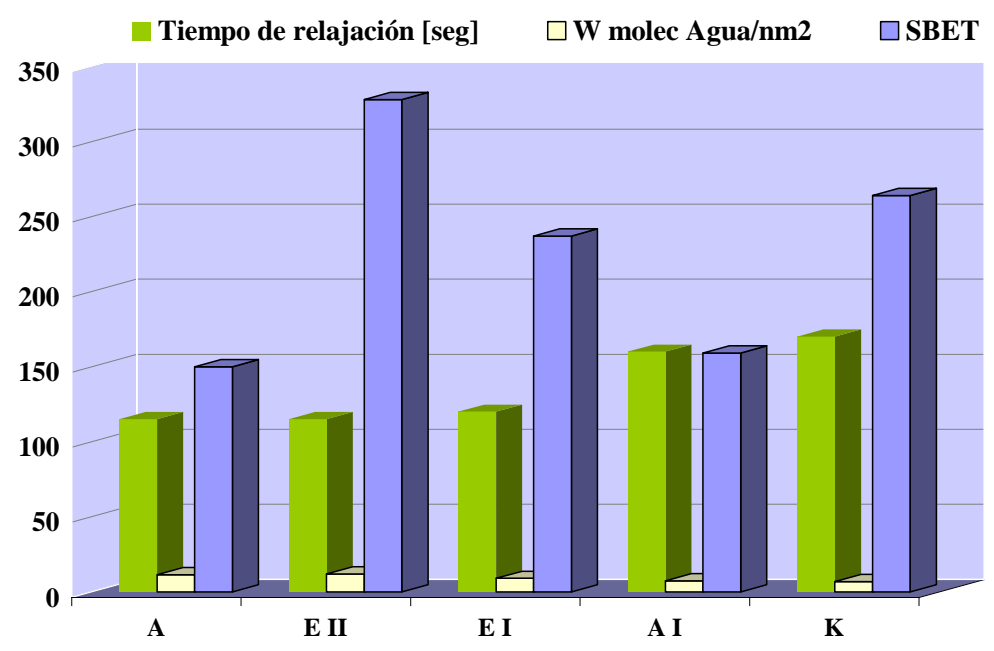

Figura 5-18: Tiempos de estabilización de HTDS en función de W (moléculas de Agua $/ \mathrm{nm}^{2}$ ) y área BET para alúminas.

La relación entre éste parámetro y el tiempo de estabilización, no es directa y no permite observar una tendencia general, posiblemente debido a que las alúminas tienen características de acidez superficial muy disímiles entre si, como ya se mencionó en párrafos anteriores. Solamente entre las alúminas mesoporosas EI y EII, se puede establecer que a menor tiempo de estabilización, mayor área BET, tal como se observó en el análisis de las sílices.

\section{2.e. Conclusiones parciales:}

Se seleccionaron dos alúminas comerciales de tipo estructural $\gamma$, denominadas EI y EII con diferentes propiedades texturales. Por otro lado, en el laboratorio se prepararon otros soportes a partir del precursor de alúmina variando las temperaturas de calcinación, lo que permitió la obtención de "alúminas de transición" de diferentes propiedades texturales y fases cristalinas, de las cuales se seleccionaron dos, las que se denominaron A y AI.

Estos materiales se caracterizaron por técnicas estructurales como DRX y texturales por el método BET. También se estudiaron sus propiedades de hidroadsorción utilizando los diagramas termogravimétricos (TGA) y el método de 
Speckle Dinámico. Los análisis muestran que las alúminas de "transición" resultan especies cuya superficie puede recubrirse de diferentes formas cristalinas de alúmina dependiendo del grado de hidratación al que sean expuestas, adquiriendo de esta manera sitios con diferente fuerza ácida.

Los resultados obtenidos en las medidas de la capacidad hidroadsorbente de alúminas con la técnica de Speckle, muestran que la misma resulta un método novedoso y promisorio para la evaluación de sitios ácidos superficiales en un soporte de alúmina.

\subsection{Preparación y caracterización de soportes a base de alúminosilicatos.}

\section{3.a. Introducción}

Los minerales de arcilla y sus derivados sintéticos o bien obtenidos por modificación química de los mismos, poseen propiedades específicas tales como intercalación, intercambio iónico y posibilidad de expansión. Tales características provienen de varios aspectos relacionados con su especial estructura de configuración laminar [22] tal como ha sido ampliamente explicado en el capítulo 1. En la figura 5-19 se muestra la representación poliédrica de la estructura de la montmorillonita, aluminosilicato laminar 2:1:

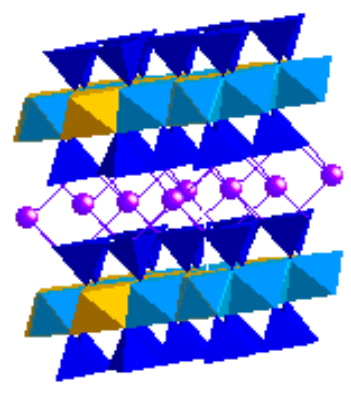

Figura 5-19: Representación estructural de bentonita tipo "montmorillonita".

En particular, el espacio interlaminar presenta efectos estéricos capaces de promover la selectividad catalítica y capacidad de adsorción [23,24]. En sílicoaluminatos naturales, dicho espacio es capaz de albergar diferentes especies ya sea por 
mecanismos de intercambio iónico o por adsorción. Recientemente se han reportado en la literatura varios métodos para la modificación química de arcillas que dan lugar a materiales porosos y de alta superficie específica, denominados corrientemente PILC (Pillared clays) y PCH (Porous clays heterostructured) [25,26]. El primer tipo se obtiene por intercalación de silicatos laminares 2:1 con oligómeros como $\operatorname{Alx}(\mathrm{OH}) \mathrm{n}$; $\mathrm{Zrx}(\mathrm{OH}) \mathrm{n}$, etc. y la posterior conversión térmica del sistema en la que estos polioxocationes se transforman en óxidos metálicos nanoscópicos pasando a constituir los pilares del sistema. El segundo tipo se trata de un método de intercalación utilizando surfactantes iónicos y precursores de grupos silíceo ( $\mathrm{Si}-\mathrm{O})$ como el tetraetoxi ortosilicato (TEOS) cuya hidrólisis y condensación alrededor de los surfactantes, da lugar a la formación de galerías silíciceas nanoestructuradas luego de un calentamiento suave. La carga negativa de las láminas arcillosas es compensada por protones formados durante la descomposición térmica del surfactante y eventualmente los mismos pueden ser intercambiados por cationes metálicos. Asimismo es posible continuar modificando o funcionalizando la superficie de estos sistemas (PILC y PCH) para lograr la adsorción de aniones. Recientemente la superficie de sílices mesoporosas como MCM-41, MCM48 etc., ha sido fácilmente modificada por reacción con organosilanos. Por lo tanto, seleccionando convenientemente el tipo de grupos funcionales terminales del organosilano y el pH de impregnación se puede lograr la inmovilización de las especies metálicas aniónicas (POMs y HPOMS), que proveerán los sitios catalíticos en la superficie del soporte. Dicho proceso conduce a una dispersión adecuada evitando interacciones desfavorables de los sitios metálicos con el soporte [27-30]. En la presente tesis, las especies PILC y PCH fueron adicionalmente funcionalizadas con un surfactante catiónico el 3-aminopropiltrietoxisilano (F) para proveer a la superficie de mayor número de cargas positivas a los fines de lograr la adsorción de los heteropolianiones.

El uso de precursores catalíticos como iso y heteropolimetalatos (POMs y HPOMs) sin soportar está limitado por sus bajas áreas superficiales y bajas temperaturas de descomposición $\left(350^{\circ} \mathrm{C}\right)$, sin embargo soportados en óxidos inertes como alúmina, zirconia, ó sílice, resultan interesantes precursores de estructura ordenada permitiendo la preparación de catalizadores heterogéneos multimetálicos los que recientemente mostraron su eficacia en varios procesos catalíticos [31-33]. 
Tal como se describe en el capítulo 2 (experimental), en la presente tesis se seleccionó un mineral de arcilla tipo bentonita (silicato laminar 2:1 conteniendo estructura de montmorillonita, Figura 5-19), la cual se empleó modificada químicamente (PILC y PCH) y adicionalmente funcionalizada (PILC-F y PCH-F) con el fin de preparar soportes de catalizadores. Todos los materiales poseen diversa relación $\mathrm{Si} / \mathrm{Al}$ y características texturales, tales como área superficial y volumen de poros medidos por el método BET [4].

\section{3.b. Caracterización textural mediante el método BET}

\section{3.b.1. Bentonita purificada por el método de Stokes}

En la Figura 5-20 se muestra la isoterma de adsorción/desorción de $\mathrm{N}_{2}$ para la bentonita purificada, tal como se expuso en la sección experimental, ítem 2.2.c. La isoterma para la bentonita luego del tratamiento de sedimentación, (efectuado para separar la fracción de bentonita pura del cuarzo), muestra un lazo de histéresis abierto debido posiblemente a que la cantidad de muestra utilizada para la medida fue insuficiente, considerando la baja superficie específica que estos materiales presentan normalmente (20 y $60 \mathrm{~m}^{2} / \mathrm{g}$ ). En nuestro caso, luego del tratamiento de purificación se obtuvo una fracción de material inferior a los 2 gr recomendados para el análisis. Sin embargo la forma de la isoterma corresponde al tipo H3 esperable para el presente mineral.

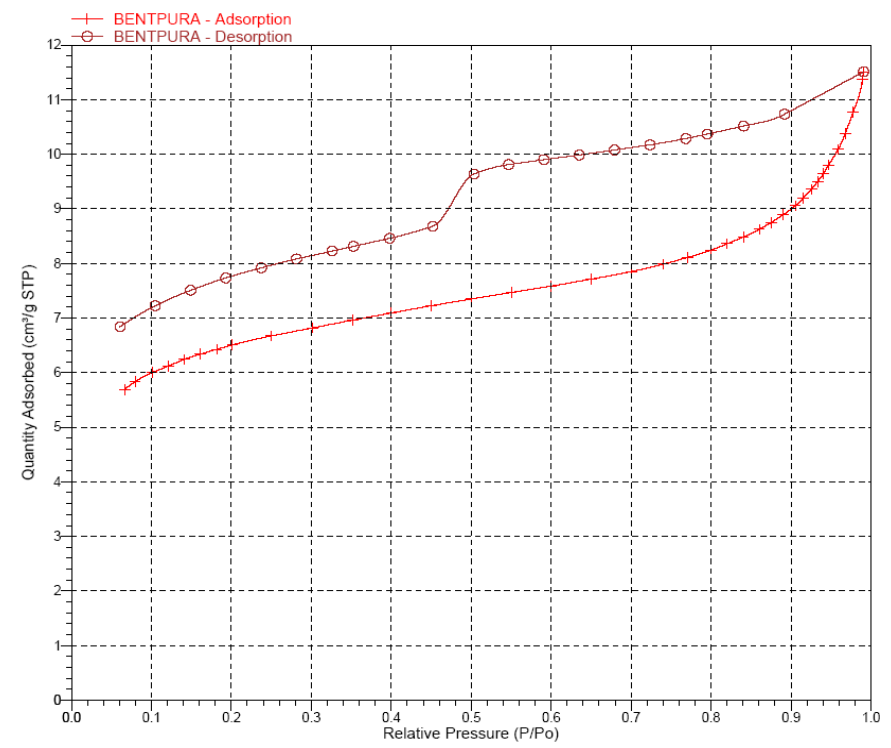

Figura 5-20: Isoterma $\mathrm{N}_{2}$ adsorción/desorción de la Bentonita purificada 
En la Figuras 5-21, 5-22, 5-23 y 5-24 se muestran las isotermas de adsorción/desorción de $\mathrm{N}_{2}$ para las muestras de arcilla modificada por los métodos antes descriptos y denominadas: PILC, PILC-F, PCH y PCH-F. Todos los sistemas presentan el mismo tipo de isotermas. Sin embargo para PILC-F, la isoterma también presenta un lazo abierto, indicando que la cantidad de muestra utilizada para el análisis fue menor a la necesaria ya que la funcionalización adicional condujo a una disminución importante del área específica. Los materiales pilareados (PILC) y heteroestructurados (PCH) antes de la funcionalización mostraron altas áreas específicas por lo que la cantidad de muestra de alrededor de 0.190 gr resultó suficiente dando lugar a un ciclo cerrado. Luego de la funcionalización con el surfactante (F), el área BET de estos materiales, como se observa en la Tabla 5-VI, disminuye notablemente, por lo que en el caso de PILC-F la cantidad usada no fue la óptima. Este hecho, se debe probablemente a la abertura de poros por efecto de la funcionalización, donde los grupos aminos generarían repulsiones electrostáticas. Para las cuatro muestras se observa que, a una presión relativa mayor a 0.4 , se inicia la formación de un lazo de histéresis, y de acuerdo a la clasificación de la IUPAC, estas pueden ser consideradas de tipo H3 [7], asociadas a materiales conteniendo poros en forma de rendijas (slit-shaped).

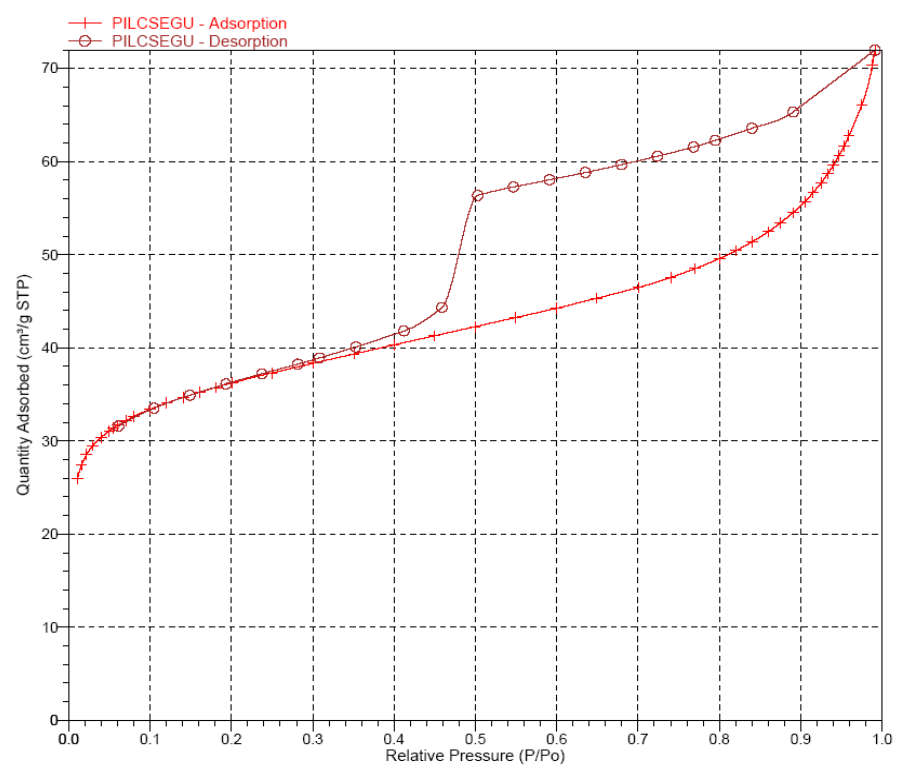

Figura 5-21: Isoterma $\mathrm{N}_{2}$ adsorción/desorción de PILC. 


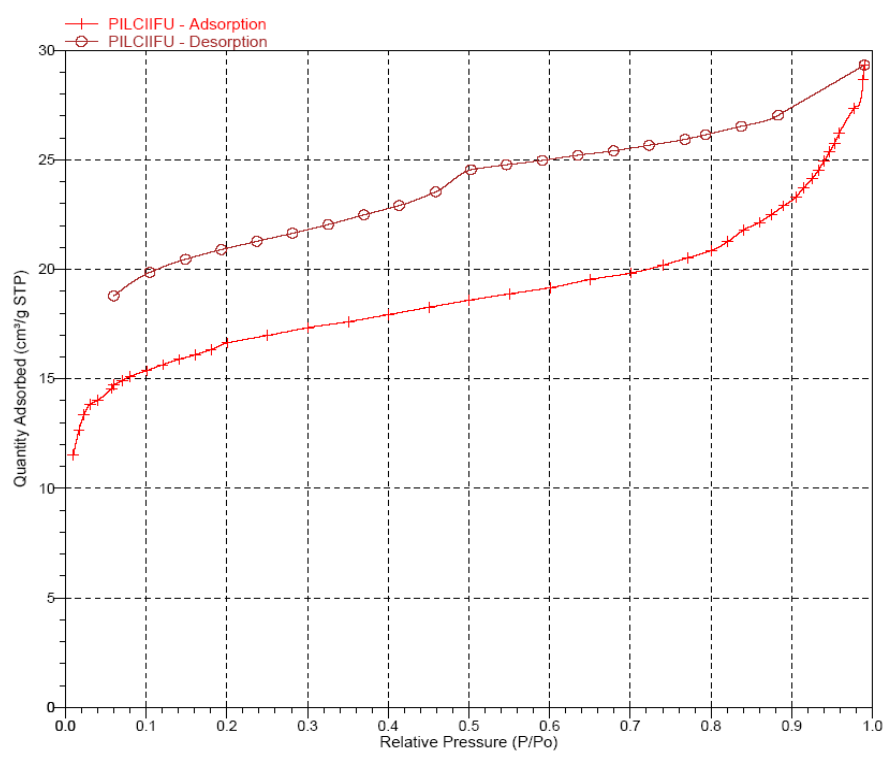

Figura 5-22: Isoterma $\mathrm{N}_{2}$ adsorción/desorción de PILC-F.

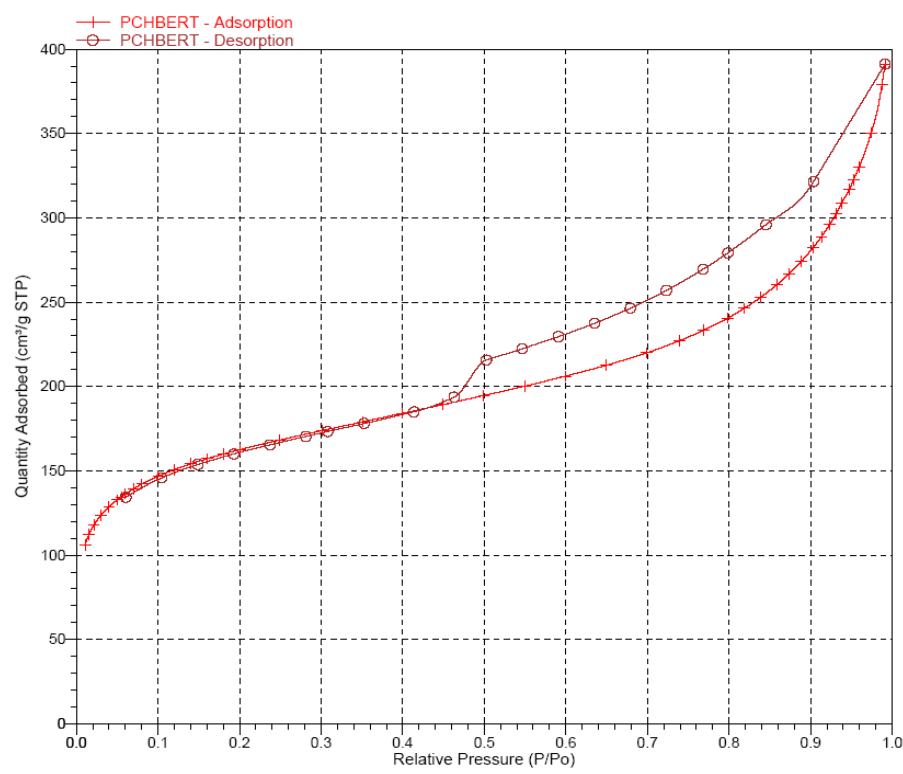

Figura 5-23: Isoterma $\mathrm{N}_{2}$ adsorción/desorción de $\mathrm{PCH}$. 


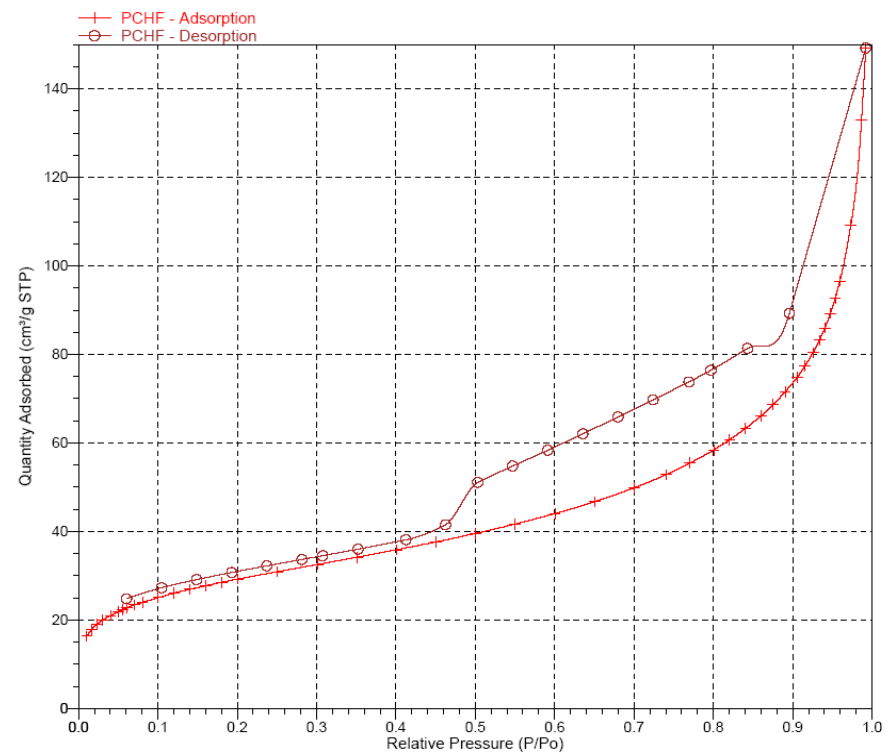

Figura 5-24: Isoterma $\mathrm{N}_{2}$ adsorción/desorción de PCH-F.

El efecto de la funcionalización, obviamente, también conlleva a una disminución en el volumen de poros.

Tabla 5-VI. Propiedades texturales de los soportes a base de bentonita pura, modificada y funcionalizada.

\begin{tabular}{ccccc}
\hline $\begin{array}{c}\text { Tipo de } \\
\text { soporte }\end{array}$ & $\begin{array}{c}\mathbf{S}_{\mathbf{B E T}} \\
\left(\mathbf{m}^{\mathbf{2}} / \mathbf{g}\right)\end{array}$ & $\begin{array}{c}\text { Vol. de Poros } \\
\left(\mathbf{c m}^{\mathbf{3}} / \mathbf{g}\right)\end{array}$ & $\begin{array}{c}\text { Vol. de } \\
\mathbf{m i c r o p o r o s} \\
\left(\mathbf{c m}^{\mathbf{3}} / \mathbf{g}\right)\end{array}$ & $\begin{array}{c}\text { DP-BJH } \\
(\AA)\end{array}$ \\
\hline Bentonita & 22 & 0.02 & 0.005 & 33 \\
PCH & 579 & 0.58 & 0.100 & 56 \\
PILC & 128 & 0.11 & 0.030 & 39 \\
PCH-F & 104 & 0.20 & 0.005 & 82 \\
PILC-F & 59 & 0.04 & 0.014 & 47 \\
\hline
\end{tabular}

Para los materiales heteroestructurados, el diámetro de poro promedio fue de 6 nm para PCH y $11 \mathrm{~nm}$ para la PCH-F, que según la clasificación de Dubinin [34] corresponde a un material mesoporoso. Sin embargo, para $\mathrm{PCH}$, a pesar de poseer 
mesoporos existe la presencia de supermicroporos en alta proporción, esta especie presentó mayor área específica y resultó un sólido microporoso mostrando menos del 10 $\%$ de su área correspondiente a mesoporos (tamaño > $20 \AA$ A).

\section{3.c Caracterización por SEM-EDS.}

El análisis por microscopía SEM-EDS muestra que las superficies de PILC-F y PCH-F están modificadas por el funcionalizante observándose el aumento relativo en la concentración superficial de Si respecto a PILC y PCH, (Tabla 5-VII).

Tabla 5-VII: Análisis semicuantitativo EDS de soportes funcionalizados.

\begin{tabular}{cccccc}
\hline \multirow{2}{*}{ Elemento } & Bentonita pura & PCH & PCH-F & PILC & PILC-F \\
\cline { 2 - 6 } & \% Peso & \% Peso & \% Peso & \% Peso & \% Peso \\
\hline $\mathrm{Al}$ & 19.1 & 3.6 & 2.0 & 30.9 & 32.1 \\
$\mathrm{Si}$ & 80.9 & 31.5 & 36.1 & 57.8 & 68.2 \\
\hline
\end{tabular}

\section{3.d. Caracterización por DRX}

El diagrama de Rayos X del mineral de arcilla utilizado se corresponde con el patrón PDF 291498 (tabla 5-VIII) correspondiente a la montmorillonita. En la figura 525 se presenta el difractograma correspondiente a esta especie, donde el pico de mayor intensidad corresponde a un ángulo $6.7^{\circ}$ de $2 \theta$. El pico observado a $\sim 27^{\circ}$ de $2 \theta$ se debe a la presencia de traza de cuarzo bien cristalino, fase que es eliminada durante el proceso de purificación por la técnica de sedimentación de Stokes. Mediante este proceso de purificación se obtienen las partículas de diámetro menor a $2 \mu \mathrm{m}$, las que corresponden a la fracción de arcilla buscada. 
Tabla 5-VIII: Patrón de Difracción.

\begin{tabular}{ccc}
\hline & $\mathbf{2 \theta}$ & $\mathbf{d}(\AA)$ \\
\cline { 2 - 3 } ASTM PDF 291498 & 6.96 & 12.69 \\
Montmorillonita & 19.71 & 4.5 \\
{$\left[\mathrm{Ca}_{\mathbf{0}, \mathbf{2}}(\mathbf{A l}, \mathbf{M g})_{2} \mathbf{S i}_{\mathbf{4}} \mathbf{O}_{\mathbf{1 0}}(\mathbf{O H})_{\mathbf{2}} \mathbf{4} \mathbf{4 H}_{\mathbf{2}} \mathbf{O}\right]$} & 34.74 & 2.58 \\
& 61.79 & 1.5 \\
\hline
\end{tabular}

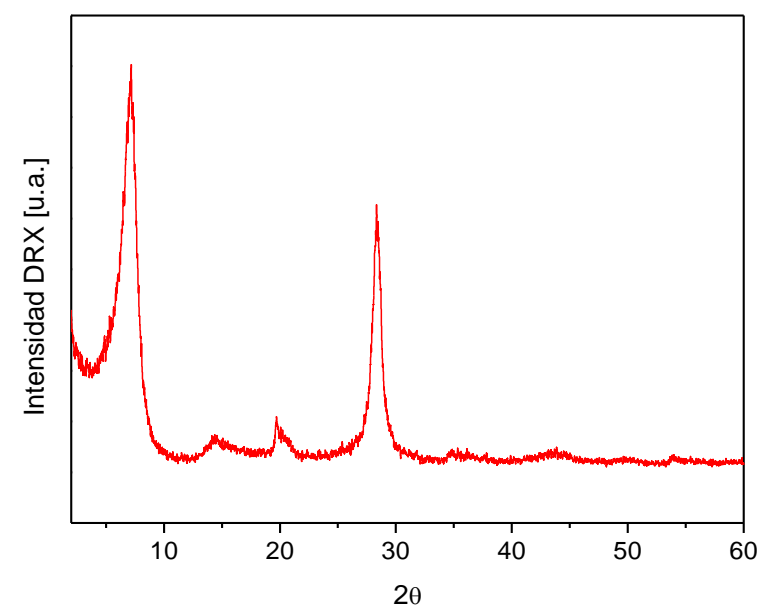

Figura 5-25: Diagrama de difracción de polvos por Rayos X del mineral de arcilla bentonita.

El espaciado interlaminar en la bentonita tipo montmorillonita sin tratar, puede contraerse ó expandirse de acuerdo al grado de hidratación, por lo que un tratamiento térmico conduce a una disminución en las distancias interlaminares. En la figura 5-26 se presentan los diagramas de DRX in-situ para la bentonita tratada a diferentes temperaturas en atmósfera de aire. Se observa el efecto de la temperatura (acercamiento del plano basal (001)) a partir del desplazamiento de la línea de difracción de mayor intensidad $\left(2 \theta=6.7^{\circ}\right)$ hacia mayores ángulos (aprox. $9^{\circ}$ ), como consecuencia de la disminución de la distancia interplanar. Asimismo puede observarse el mantenimiento de la estructura covalente hasta la máxima temperatura de tratamiento $\left(\sim 700^{\circ} \mathrm{C}\right)$. 


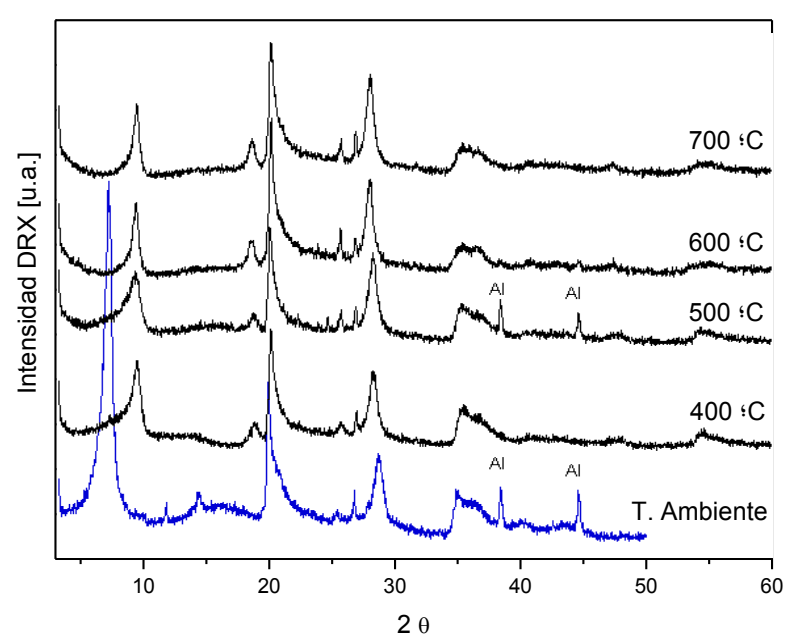

Figura 5-26: Diagramas DRX in situ para la Bentonita tratada hasta $700{ }^{\circ} \mathrm{C}$.

El proceso de "pilareado" se observa por el desplazamiento del pico DRX más intenso de la bentonita hacia menores ángulos ó mayores distancias interplanares d $(\AA)$. En la Figura 5-27 se observa el corrimiento del pico de mayor intensidad correspondiente al plano [001] localizado a $6.7^{\circ}$ de $2 \theta$ (d $12 \AA$ ) hacia ángulos menores, $4.7^{\circ}$ de $2 \theta \quad(d \sim 18 \AA)$ siendo éste efecto una consecuencia de la separación interlaminar de la estructura provocada por la formación de las fases oxídicas nanoscópicas que "pilarean" la bentonita. El diagrama DRX del sistema heteroestructurado $\mathrm{PCH}$ corresponde a una fase aún mas amorfa con una envolvente que no permite observar los picos originales de la arcilla.

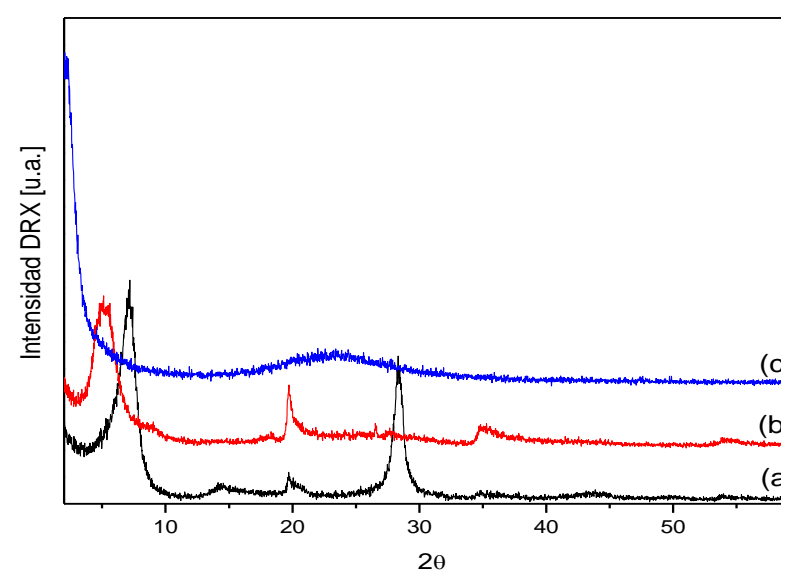

Figura 5-27: Difractogramas DRX para (a) bentonita, (b) PILC y (c) PCH. 
En la figura 5-28 se presentan a modo comparativo los diagramas de DRX para los materiales PILC y PCH antes y después del proceso de funcionalización con F. Se observa que ambos materiales no presentan notables modificaciones estructurales posteriores a la funcionalización.

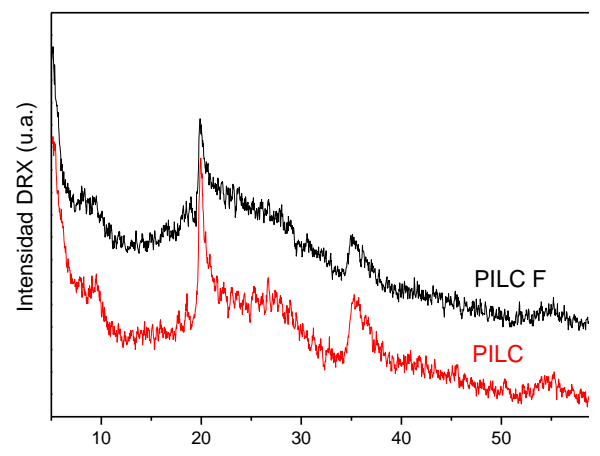

(a)

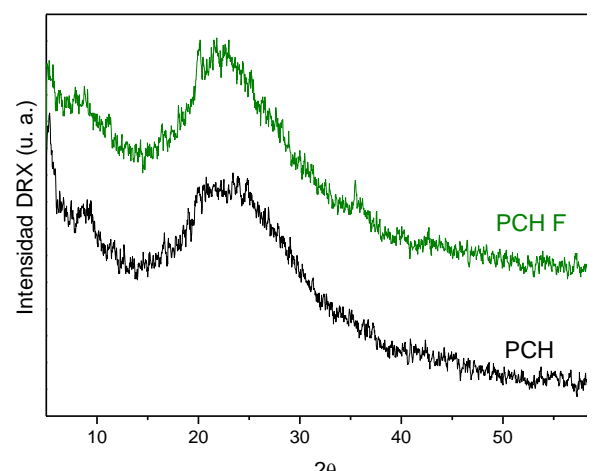

(b)

Figura 5-28: DRX comparativo de (a) PILC sin tratar y funcionalizada y (b) $\mathrm{PCH}$ sin tratar y funcionalizada .

Puede observarse que los diferentes y consecutivos tratamientos sufridos por PILC, PCH y la respectiva funcionalización, generan materiales más amorfos aunque en el caso de PILC, si bien hay variaciones en la intensidad, la posición de la mayoría de los picos es similar a los de la bentonita, excepto el correspondiente al pico de difracción del espacio interplanar $\left(2 \theta=6.7^{\circ}\right)$, de mayor intensidad y que en la especie pilareada se desplaza a menores ángulos de $2 \theta$ (o mayor distancia interplanar) no detectable con el equipo disponible. Para las especies $\mathrm{PCH}$ los diagramas son idénticos, presentan una envolvente en la zona correspondiente a los principales picos (entre $20^{\circ}$ a $40^{\circ}$ de 20). La modificación química no parece producir cambios estructurales importantes en los materiales de partida, si bien provocan una importante disminución de los parámetros texturales como se observa en la tabla 5-VI, probablemente debido a la obstrucción de los poros con la consiguiente disminución del área superficial, evidenciado por el ensanchamiento y desplazamiento de la línea de difracción correspondiente a la distancia entre los planos basales del sistema. 


\section{3.e. Análisis mediante espectroscopía FTIR}

En la figura 5-29, se presentan los espectros comparativos de las especies PILC, $\mathrm{PCH}, \mathrm{PCH}$ (sin calcinar) y la bentonita original, no observándose diferencias significativa entre la posición de las bandas características si bien se pueden observar cambios en el ancho de bandas correspondientes a los modos principales en la región de los estiramientos $\mathrm{T}-\mathrm{OH}(\mathrm{T}=\mathrm{Si}$ o $\mathrm{Al})$, debido a la diferente relación $\mathrm{Si} / \mathrm{Al}$ entre los materiales.

Los espectros FT-IR de alúmino-silicatos laminares, pueden ser divididos en regiones características para la asignación de las vibraciones de los enlaces de los grupos constituyentes, según se indica a continuación:

- $\quad 3700-3200 \mathrm{~cm}^{-1}$ : Estiramiento de los grupos O-H. En particular se encuentran bandas entre 3750 y $3400 \mathrm{~cm}^{-1}$ en aluminosilicatos $2: 1$.

- $1700-1600 \mathrm{~cm}^{-1}$ : Deformación de las moléculas de agua tanto constitutiva como adsorbida entre capas del alúminosilicato.

* $\quad 1200-900 \mathrm{~cm}^{-1}$ : Estiramientos simétricos y antisimétricos $\mathrm{Si}-\mathrm{O}$ en el entorno tetraédrico de la unidad estructural.

- $950-600 \mathrm{~cm}^{-1}$ : Libraciones de los grupos O-H. Además, alrededor de $800 \mathrm{~cm}^{-1}$ se encuentran los estiramientos correspondientes al Al en entorno tetraédrico.

* $800-915 \mathrm{~cm}^{-1}$ : en particular en este rango podemos encontrar vibraciones correspondientes a las deformaciones $\mathrm{M}-\mathrm{OH}$ en entorno octaédrico $(\mathrm{M}=\mathrm{Al}$, $\mathrm{Fe}, \mathrm{Mg})$.

- $600-300 \mathrm{~cm}^{-1}$ : Deformaciones angulares de las unidades tetraédricas T$\mathrm{O}-\mathrm{T}$ ( $\mathrm{Si}-\mathrm{O}-\mathrm{Al}$; $\mathrm{Si}-\mathrm{O}-\mathrm{Fe}, \mathrm{Si}-\mathrm{O}-\mathrm{Mg}$ a $v \sim 525,470$ y $425 \mathrm{~cm}^{-1}$ respectivamente). En esta zona también se encuentran las bandas características de las unidades estructurales octaédricas $\mathrm{M}-\mathrm{O}, \mathrm{M}=\mathrm{Fe}, \mathrm{Mg}, \mathrm{Al}$ (debajo de $550 \mathrm{~cm}^{-1}$, por ej. para el $\mathrm{Mg}$ a $\sim 530$ y 560 $\mathrm{cm}^{-1}$ ) que se solapan con las deformaciones correspondientes a las unidades tetraédricas $\mathrm{Si}-\mathrm{O}$. 


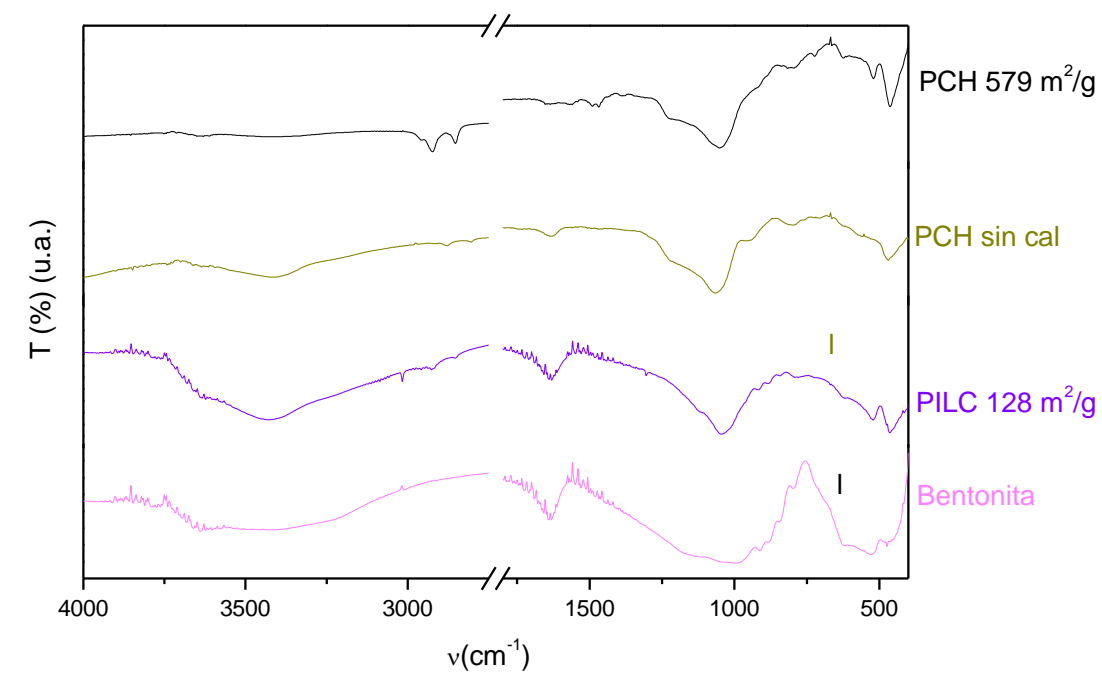

Figura 5-29: Espectros FTIR comparativos entre 4000 y $400 \mathrm{~cm}^{-1}$ [35].

\section{3.f. Análisis termogravimétrico (TGA)}

A efectos comparativos y con la idea de analizar el poder hidroadsorbente de aluminosilicatos de interés en catálisis, se seleccionaron otras dos muestras de aluminosilicatos naturales pero de diferente estructura y composición: caolinita y zeolita tipo "clinoptilolita". El caolín es un alúminosilicato laminar 1:1, es el mineral de arcilla más simple que representa a este grupo conteniendo capas dioctaédricas, donde, desde un punto de vista ideal, el Si queda confinado a los sitios tetraédricos y el $\mathrm{Al}$ a los octaédricos. En cambio la estructura de una zeolita no es laminar, está caracterizada por una estructura tridimensional infinita de tetraedros $\left(\mathrm{SiO}_{4}\right)$ parcialmente sustituidos por Al y enlazados entre si a través de todos los vértices, formando cavidades en forma de canales y cajas que comúnmente están ocupadas por moléculas de agua y cationes. Este tipo de organización estructural le confiere un gran poder de retención de agua (en las naturales) y otras moléculas huésped removibles y reemplazables; de hecho el término zeolita proviene de las palabras griegas "zeo", hervir, y "lithos", piedra, dada su capacidad para perder agua por calentamiento.

La Figura 5-30 muestra los diagramas TG de caolinita, zeolita y bentonita donde se observa claramente el comportamiento de la zeolita acorde a las características 
antes mencionadas presentando una pérdida importante de peso la que continua hasta $\mathrm{T}>300{ }^{\circ} \mathrm{C}$. Para los aluminosilicatos laminares, en el intervalo térmico de 100 a $200^{\circ} \mathrm{C}$, se produce la pérdida de agua interlaminar; mientras que entre $200^{\circ} \mathrm{C}$ y $500^{\circ} \mathrm{C}$, ocurre la pérdida de agua intrareticular; la caolinita, muestra sin embargo una lenta pérdida de masa a menor ritmo que para la bentonita. Esta última especie sufre una pérdida de masa apreciable entre 40 y $150^{\circ} \mathrm{C}$. La variación de la curva TGA relacionada con este proceso, se interpreta como un efecto de rápida pérdida de humedad y deshidratación superficial de la muestra, así como de fases gaseosas intraporosas adsorbidas débilmente en la superficie y microporos. En este rango de temperatura continúa la deshidratación y pérdida de humedad superficial fisisorbida, con una incipiente deshidratación interna de la muestra, sin manifestación de colapso estructural, como se ha podido corroborar con diagramas de Rayos X realizados "in situ” hasta $700^{\circ} \mathrm{C}$, antes mostrados en la figura 531, para la bentonita [36].

Asimismo la clinoptilolita mantiene su estructura cristalina intacta hasta aproximadamente $500^{\circ} \mathrm{C}$, como se observa en la Fig. 5-31.

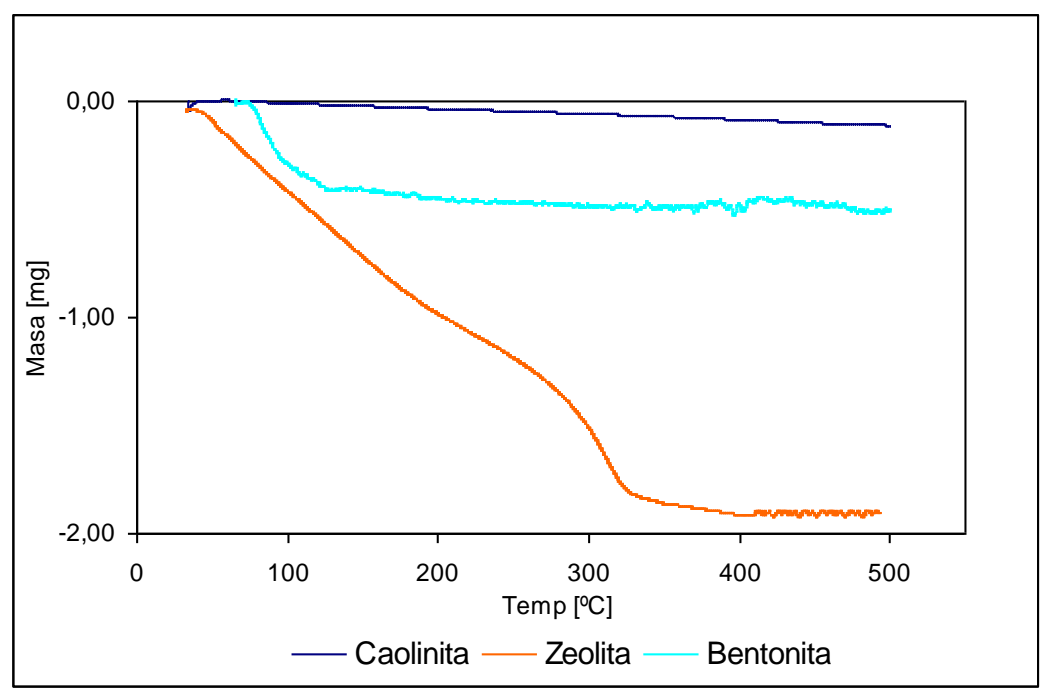

Figura 5-30: Perfiles de TGA para las arcillas Caolinita, Zeolita y Bentonita entre $\mathrm{T}$ ambiente y $500^{\circ} \mathrm{C}$ 


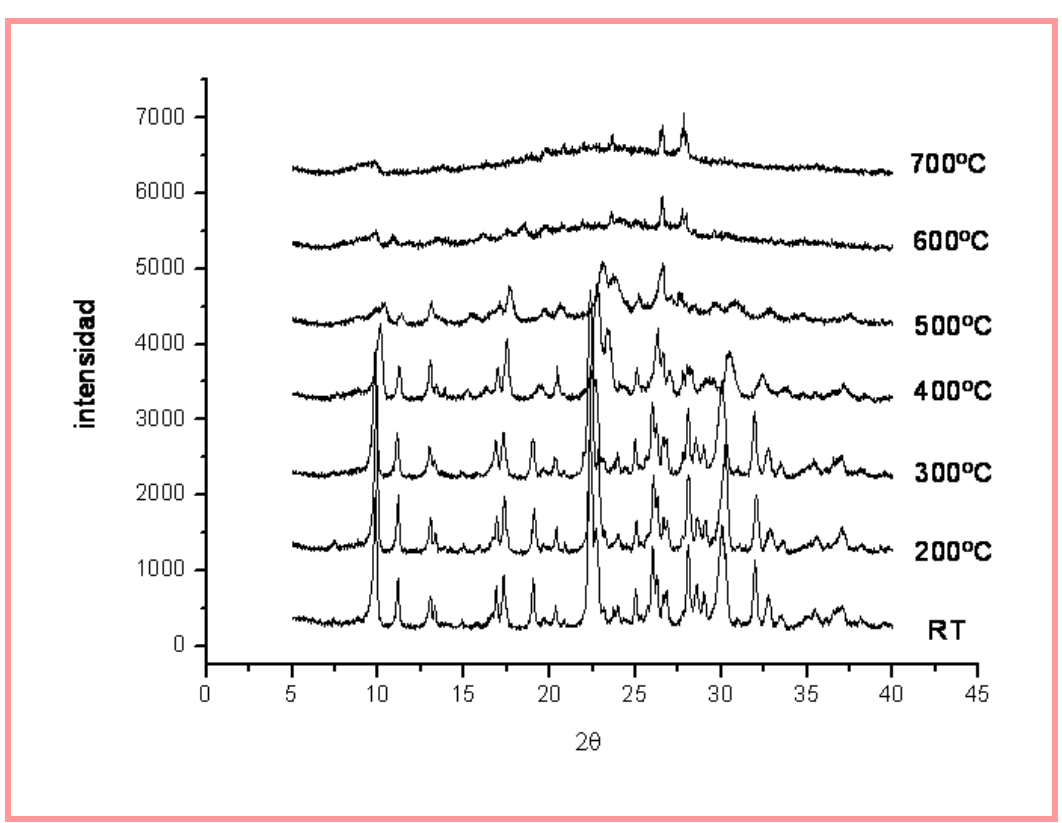

Figura 5-31: Diagramas XRD in situ para la clinoptilolita tratada hasta $700{ }^{\circ} \mathrm{C}$ [36]

La Figura 5-32 (a y b) muestra las curvas TGA de las arcillas PCH, PILC y PCH-F, PILC-F estudiadas. Se observa en ambos casos una pérdida de masa continua en el intervalo $25-500^{\circ} \mathrm{C}$. La muestra que presenta mayor pérdida de masa es la $\mathrm{PCH}-\mathrm{F}$, en el intervalo de temperaturas considerado.

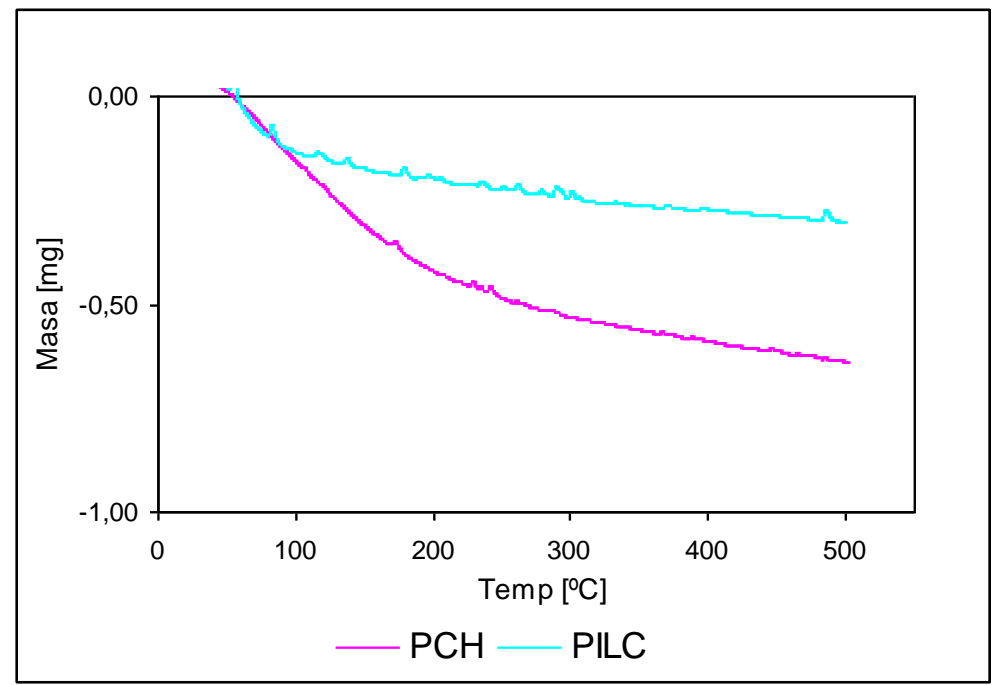

Figura 5-32 (a): Perfiles de TGA para las arcillas estudiadas PCH. 


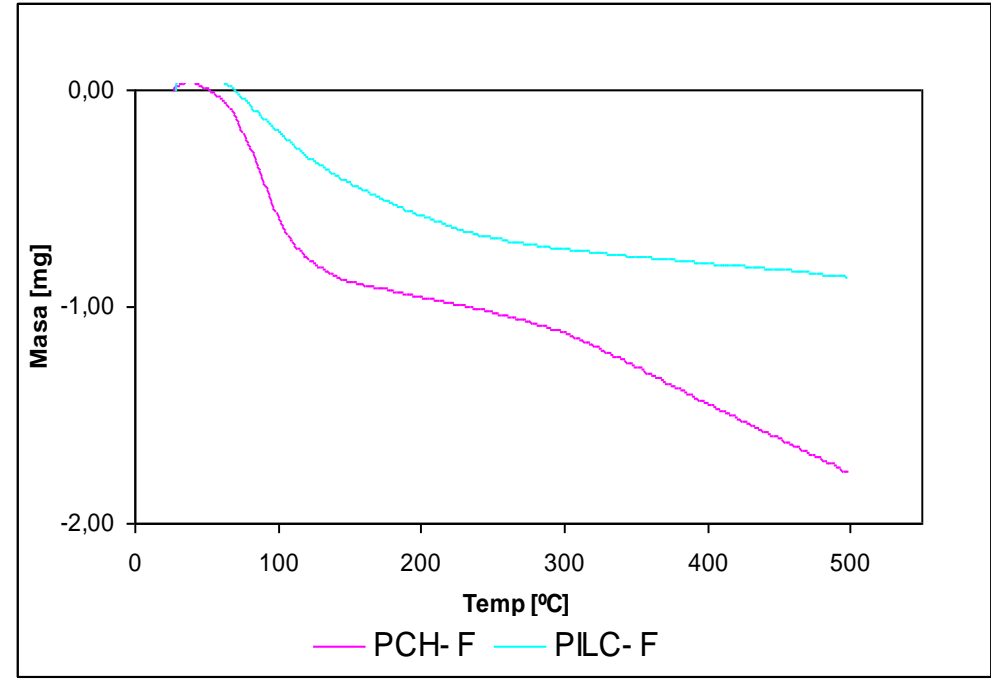

Figura 5-32 (b): Perfiles de las arcillas PCH-F y PILC-F entre T ambiente y $700^{\circ} \mathrm{C}$

\section{3.g. Caracterización del proceso de hidroadsorción de soportes a base de bentonita y otros aluminosilicatos mediante la técnica Laser Speckle dinámico}

En este trabajo de tesis se aplica por primera vez el método del "Speckle Dinámico" al análisis de la hidrofilicidad de los materiales a base de bentonita; PILC, PILC-F, PCH y PCH-F de interés como soportes. Asimismo y a efectos comparativos se analizaron la caolinita y la zeolita tipo Clinoptilolita. La Figura 5-33 (a y b) muestra comparativamente la actividad de Speckle representada como Momento de Inercia en función del tiempo para todos los materiales naturales PILC y PCH.

En la figura 5-33 (b) se muestra la zona a menor escala de MI ampliada. 


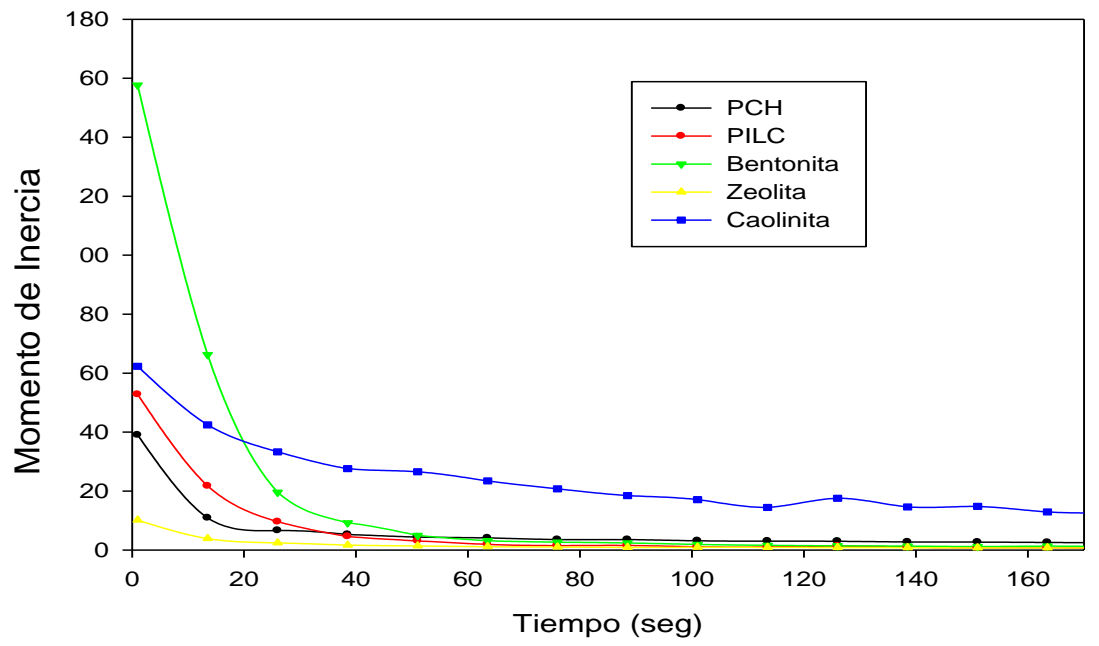

Figura 5-33: (a): Actividad de Speckle en función del tiempo para bentonita, caolinita, zeolita, PCH y PILC.

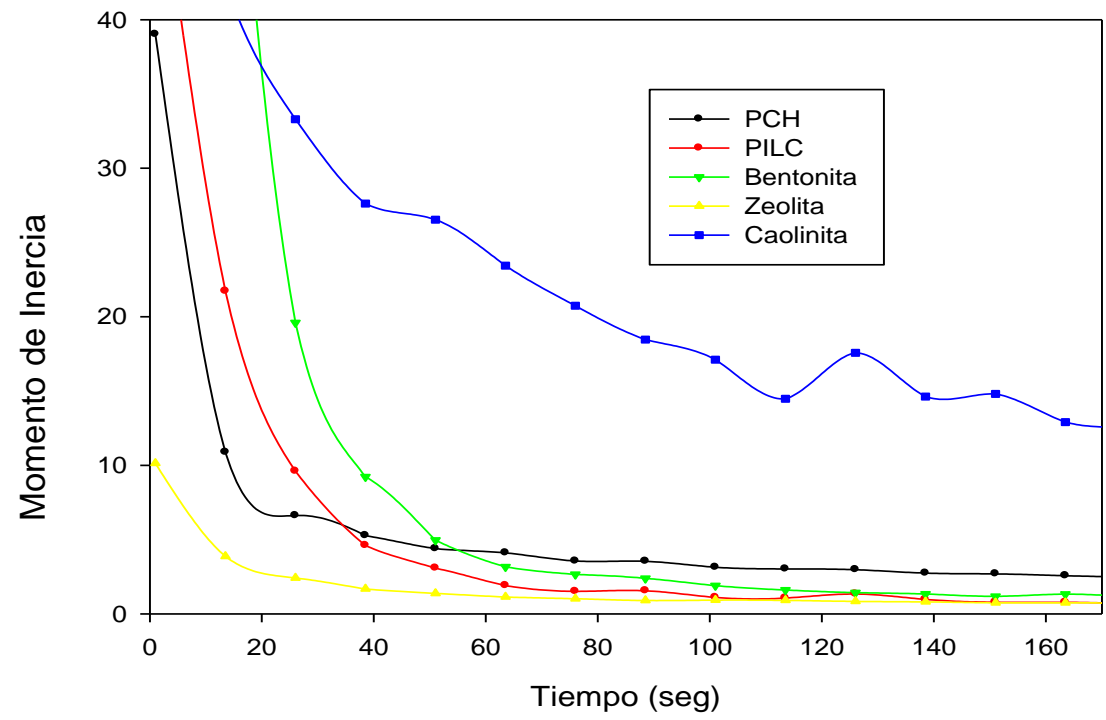

Figura 5-33 (b): Gráfico ampliado para las arcillas PCH, PILC, Zeolita y Caolinita.

En la figura 5-34 se presentan los gráficos de MI en función del tiempo para los sistemas funcionalizados PILC-F y PCH-F. 


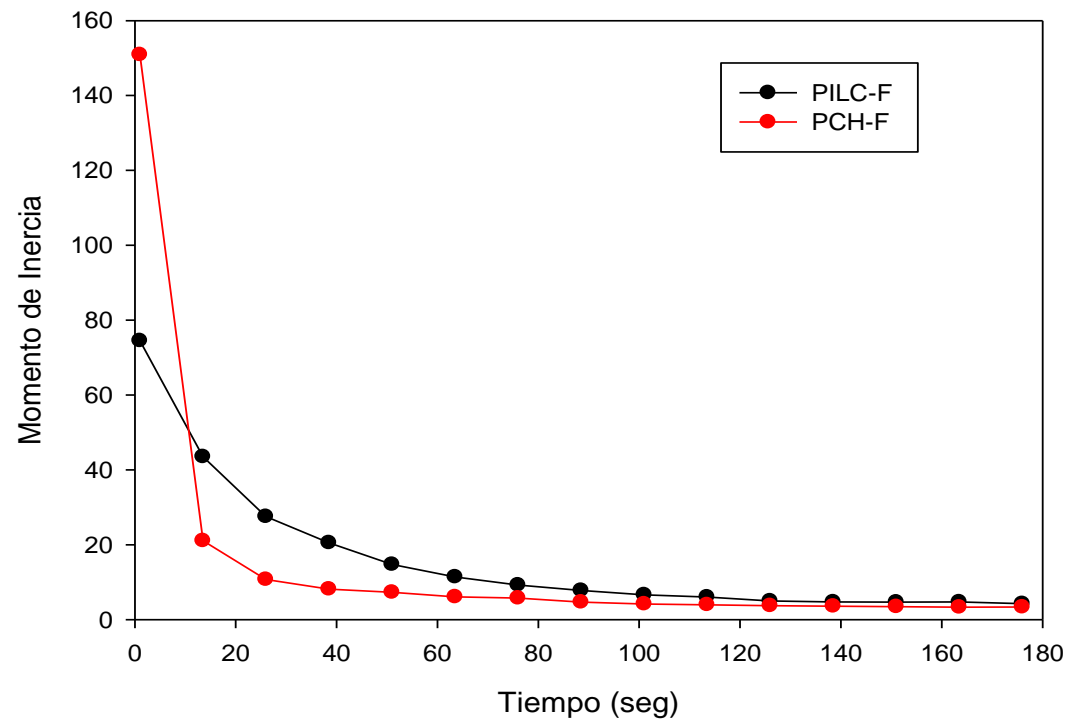

Figura 5-34: Tiempos de estabilización de HTDS en función de la actividad Speckle para las arcillas funcionalizadas.

La Tabla 5-IX muestra los valores del tiempo de estabilización del HTDS, la relación $\mathrm{Si} / \mathrm{Al}$ y el $\mathrm{S}_{\mathrm{BET}}$ obtenido para cada especie.

Tabla 5-IX. Tiempo de estabilización de HTDS; Relación Si/Al y S SET para sílicoaluminatos.

\begin{tabular}{c|c|c|c}
\hline Soporte & $\begin{array}{c}\text { Tiempo de } \\
\text { Estabilización (seg) }\end{array}$ & $\begin{array}{c}\text { Relación } \\
\text { Si/Al }\end{array}$ & $\begin{array}{c}\mathbf{S}_{\text {BET }} \\
\left(\mathbf{m}^{2} / \mathbf{g}\right)\end{array}$ \\
\hline PILC & 100 & 1.87 & 128 \\
Caolinita & 120 & 2.25 & 9 \\
PILC-F & 120 & 2.12 & 58 \\
Bentonita & 110 & 4.22 & 22 \\
Zeolita & 40 & 6.16 & 11 \\
PCH & 40 & 8.65 & 579 \\
PCH-F & 25 & 18.01 & 105 \\
\hline
\end{tabular}

La cantidad de agua adsorbida por la muestra después de la hidratación fue calculada por el método reportado por Rinaldi, et al., [6], utilizando datos de TGA. 
Los valores de $\mathrm{W}$ de los alúminosilicatos a un intervalo de $25-200^{\circ} \mathrm{C}$, se muestran en la Tabla 5-X.

Tabla 5-X: Valores de W de las muestras en estudio

\begin{tabular}{cc}
\hline Soporte & $\begin{array}{c}\text { W } \\
(\mathbf{m o l e c} \text { agua/nm }\end{array}$ \\
\hline Caolinita & 14 \\
Zeolita & 265 \\
Bentonita & 51 \\
PCH & 3 \\
PILC & 4 \\
PCH-F & 31 \\
PILC-F & 28
\end{tabular}

Los tiempos de estabilización del Speckle observados durante el proceso de adsorción de agua, se graficaron en función de la relación Si/Al de cada especie. (Figura 5-35); asimismo se graficaron vs. W (molec. agua $\mathrm{nm}^{2}$ ) (Figura 5-36); y en función del área BET (Figura 5-37). Se observa en forma general que los materiales con mayor relación Si/Al (PCH, PCH-F) son los que muestran el menor tiempo de estabilización o relajación de la actividad de Speckle, lo cual indica una rápida hidroadsorción. Los demás materiales presentan períodos de hidroadsorción más prolongados. Se evidencia un comportamiento contrario a medida que disminuye la relación $\mathrm{Si} / \mathrm{Al}$, siendo posible correlacionar este efecto con la disponibilidad de grupos silanoles ( $\mathrm{Si}-\mathrm{OH})$, responsables de la hidrofilicidad de materiales silíceos [37].

El análisis del tiempo de estabilización en función de la cantidad de agua adsorbida se debe realizar comparando los materiales según su estructura, por ejemplo el comportamiento de los aluminosilicatos laminares bentonita y caolinita difiere notablemente del correspondiente a la zeolita cuya capacidad de absorber gran cantidad de agua en su estructura tridimensional porosa se observa claramente y muestra el menor tiempo de estabilización para un mayor $\mathrm{W}$, entre estos tres sistemas. 


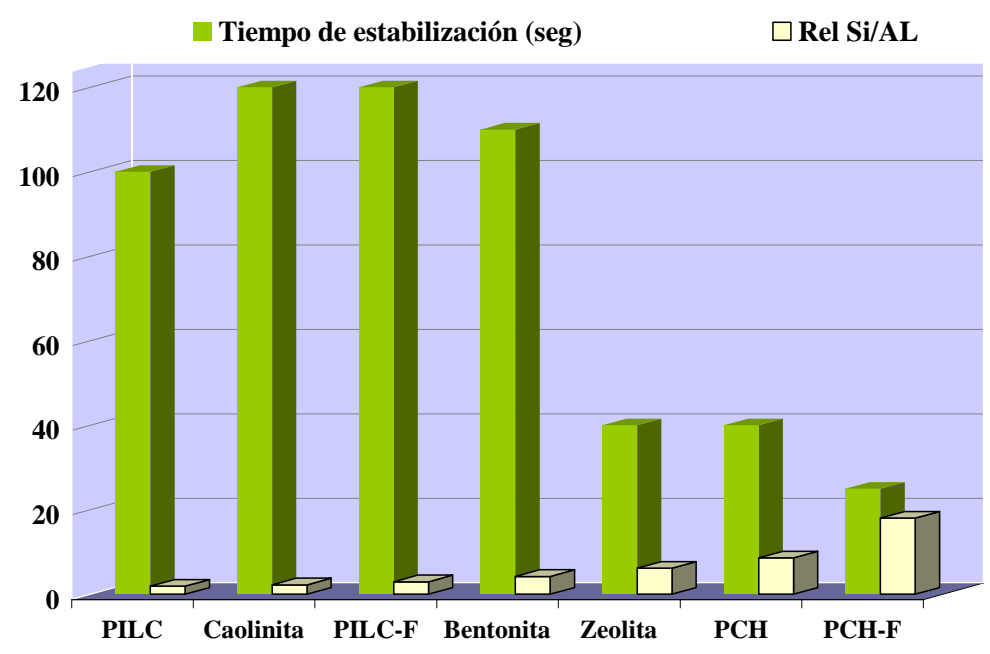

Figura 5-35: Tiempos de estabilización de HTDS en funciónde la Relación Si/Al para sílico-aluminatos.

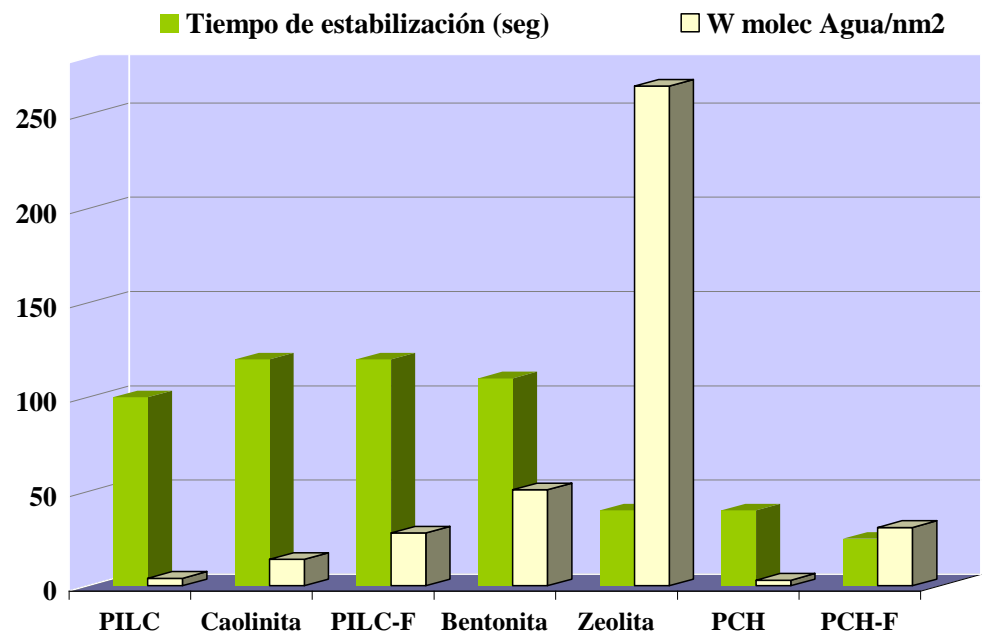

Figura 5-36: Tiempos de estabilización de HTDS en función del $n^{\circ}$ de moléculas de $\mathrm{H}_{2} \mathrm{O}$ adsorbidas.

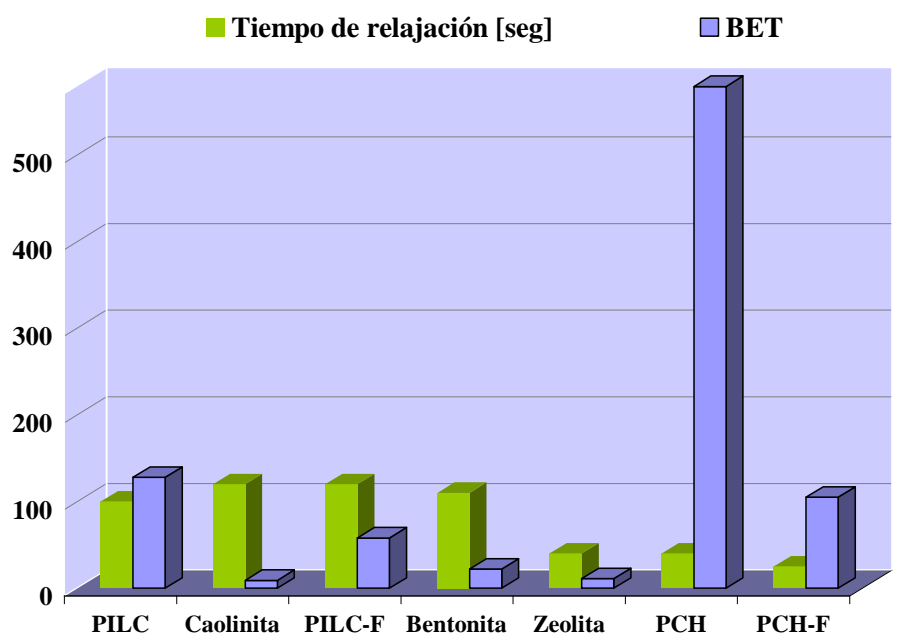

Figura 5-37: Tiempos de estabilización de HTDS y $\mathrm{S}_{\mathrm{BET}}$ para distintas muestras 


\section{3.h. Conclusiones parciales}

Se prepararon soportes a base de mineral de arcilla (bentonita) la que fue modificada químicamente mediante métodos establecidos y necesarios para lograr mejores propiedades texturales (PILC y $\mathrm{PCH}$ ), posteriormente estos materiales se funcionalizaron con un surfactante catiónico con el objetivo de lograr una superficie apta para la adsorción de heteropolianiones. Todos los materiales fueron caracterizados por técnicas físico-químicas de análisis estructural, espectroscópico y térmico. Finalmente la técnica de "speckle dinámico" fue empleada para el estudio de hidrofilicidad de estos soportes y la de otros aluminosilicatos naturales como caolinita y zeolita (clinoptilolita) a efectos comparativos.

Se observó la evolución temporal de los diagramas de speckle, siendo posible correlacionar el tiempo de estabilización del diagrama de cada especie con la relación $\mathrm{Si} / \mathrm{Al}$, la que se asocia directamente con la disponibilidad de grupos $\mathrm{Si}-\mathrm{OH}$ y por ende la hidrofilicidad y acidez Brønsted de la superficie. 
Capítulo 6:

\section{CARACTERIZACIÓN FISICOQUÍMICA DE CATALIZADORES}


En este capítulo se presentan y analizan los principales resultados de la aplicación de diversas técnicas físico-químicas para la caracterización de los catalizadores, logrando así el conocimiento del comportamiento estructural, espectroscópico y térmico de estos sistemas, aspectos que serán de fundamental importancia para interpretar y/o correlacionar el comportamiento catalítico.

Para la preparación de los catalizadores soportados, se emplearon técnicas estudiadas previamente en nuestros laboratorios consistentes en la impregnación en equilibrio del soporte con soluciones acuosas a base del $\mathrm{Rh}(\mathrm{III})$-hexamolibdato tipo Anderson y otras fases a efectos comparativos, tal como se describió en la sección experimental. A continuación se muestran los resultados obtenidos.

\section{1 . Caracterización de Catalizadores a base de heteropolianiones tipo Anderson soportados sobre Sílice.}

\section{1.a. Caracterización por DRX}

Tal como se describe en el capítulo 2, item 2.3.a., se prepararon catalizadores con soportes a base de Sílice con la siguiente denominación, $\mathrm{RhMo}_{6} / \mathrm{D}$ y $\mathrm{RhMo}_{6} / \mathrm{K}$. En este caso se procedió por el método de impregnación en equilibrio utilizando soluciones de la fase $\mathrm{RhMo}_{6}$, intentando lograr un catalizador de $5 \%$ de Mo y $1 \%$ de $\mathrm{Rh}$. La caracterización de la fase soportada en sílice se realizó básicamente por DRX, TPR y XPS. En las Figuras 6-1 (a y b) se muestran los diagramas DRX correspondientes al catalizador $\mathrm{RhMo}_{6} / \mathrm{D}$ antes y luego del tratamiento en condiciones de TPR a $350^{\circ} \mathrm{C}$. Para este ensayo primeramente se realizó un TPR hasta $900^{\circ} \mathrm{C}$ y posteriormente se realizó un tratamiento similar sólo hasta $350^{\circ} \mathrm{C}$ para caracterizar las especies que podrían formarse y actuar como intermediarias durante la reacción catalítica. 


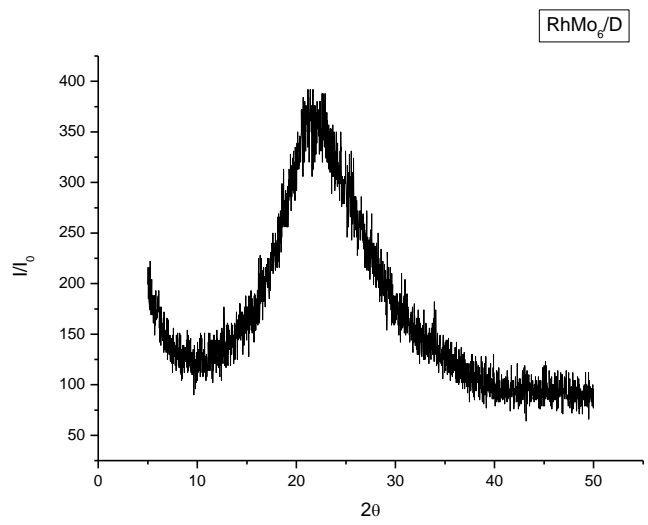

(a)

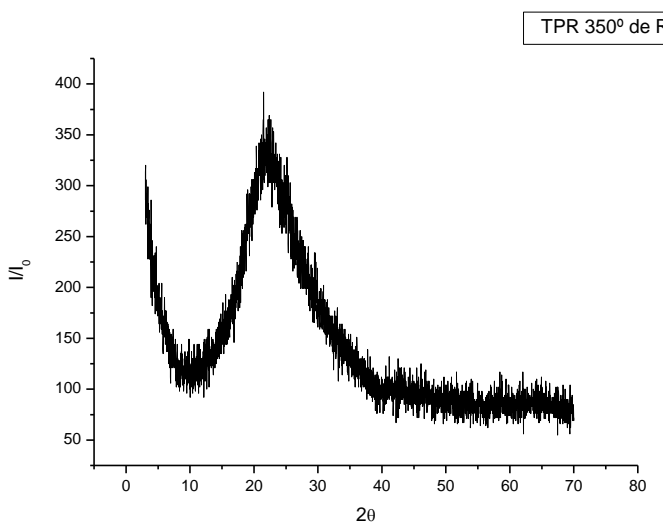

(b)

Figura 6-1: Diagramas de DRX correspondientes al catalizador $\mathrm{RhMo}_{6} / \mathrm{D}$ (tratada) (a) fresco y (b) luego de un tratamiento en atmósfera reducida (TPR) a $350^{\circ} \mathrm{C}$.

Ambos diagramas presentan las señales correspondientes a una sílice hidratada (en la que el pico máximo puede variar entre $17^{\circ}$ y $23^{\circ}$ de $2 \theta$ dependiendo de la estructura resultante del grado de hidratación) ASTM: No 75-1073 [1] o ASTM: No 830675 [2], o ASTM: No 38-0448 [3], estos diagramas coinciden con el del soporte original mostrado en el capítulo 5, ítem 5.1.c. En estos diagramas no se observan picos correspondientes a la fase $\mathrm{RhMo}_{6}$ ni a $\mathrm{Rh}$ o Mo metálico (que podrían generarse a partir del tratamiento reductor) sugiriendo que estas especies se encuentran bien dispersas. Asimismo, igual comportamiento presenta el sistema soportado en la Sílica Kieselgel, Figura 6-2.

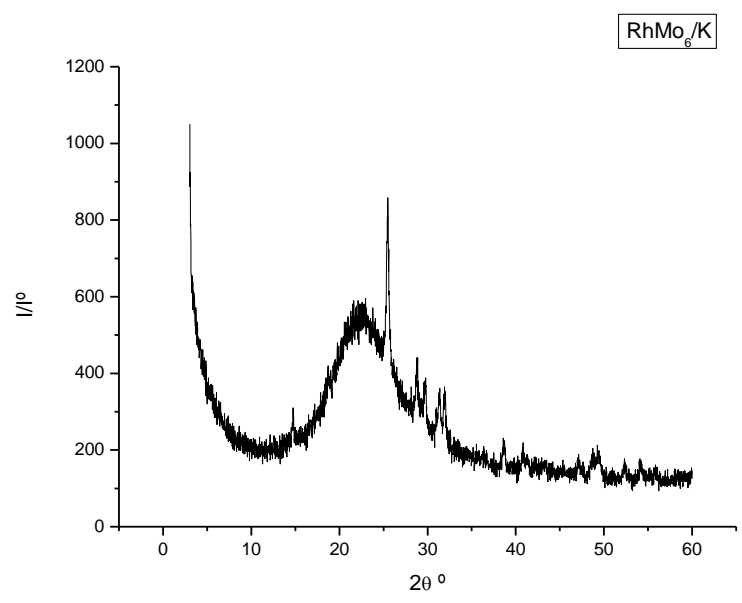

Figura 6-2: Diagrama de DRX correspondiente al catalizador $\mathrm{RhMo}_{6} / \mathrm{K}$ 


\section{1.b. Caracterización mediante Reducción Térmica Programada (TPR).}

En la figura 6-3, se muestran los diagramas de TPR de ambos catalizadores. En ambos perfiles se observa una primera etapa a temperaturas entre 180 y $300{ }^{\circ} \mathrm{C}$. Sin embargo es evidente que la interacción de la fase difiere dependiendo del soporte. En la sílice Degussa se observa una fuerte señal a $287^{\circ} \mathrm{C}$ y luego señales muy débiles que finalizan antes de $600^{\circ} \mathrm{C}$. Este fuerte consumo de hidrógeno inicial implica no sólo la reducción del $\mathrm{Rh}(\mathrm{III}) \mathrm{a} \mathrm{Rh}^{\circ}$, que normalmente ocurre a temperaturas alrededor $200^{\circ} \mathrm{C}$, también sugiere la reducción de la totalidad del $\mathrm{Mo}(\mathrm{VI})$ muy por debajo de $\operatorname{los} 700^{\circ} \mathrm{C}$, la cual corresponde a la temperatura normal de reducción del Mo para una especie como el heptamolibdato de amonio[4]. Este comportamiento implica un efecto promotor del $\mathrm{Rh}$ sobre la reducibilidad del Mo como ha sido recientemente reportado [5].

En la sílice Kiesselgel, se observan tres señales débiles de reducción a 182, 260 y $321^{\circ} \mathrm{C}$ las que implican menor consumo de $\mathrm{H}_{2}$, sugieriendo sólo la reducción del $\mathrm{Rh}(\mathrm{III})$ a $\mathrm{Rh}^{\circ}$, proveniente de especies oxídicas diferentes mientras que el pico a $900{ }^{\circ} \mathrm{C}$ mucho mas intenso indica la reducción del $\mathrm{Mo}(\mathrm{VI})$ a $\mathrm{Mo}^{\circ}$.

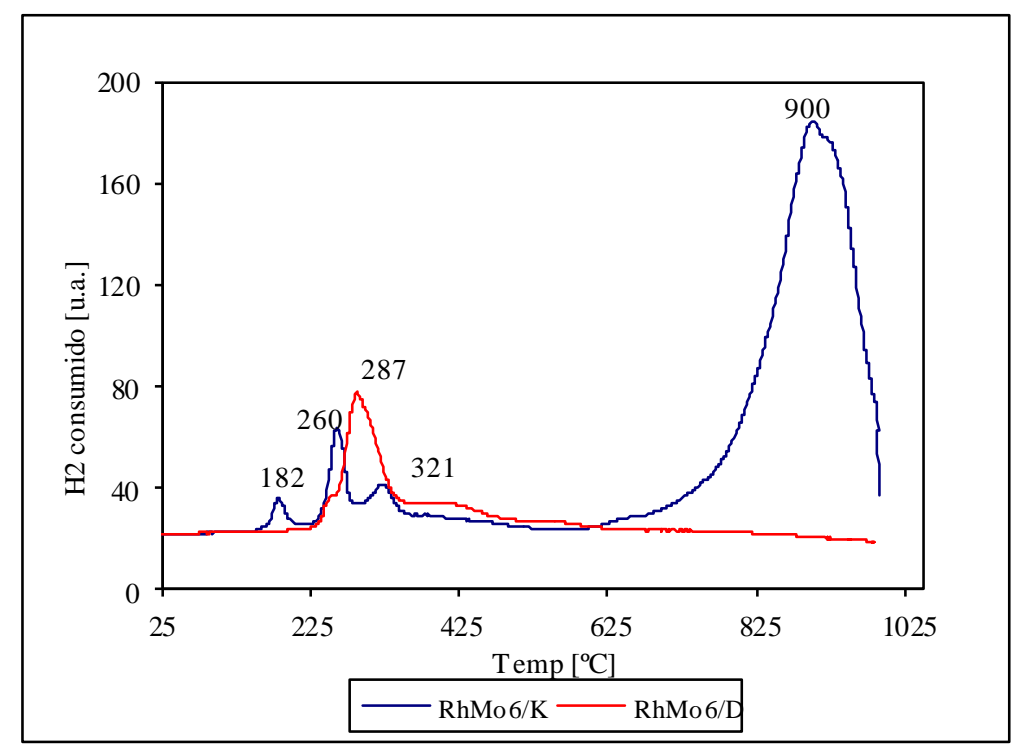

Figura 6-3: Diagramas de reducción térmica programada para los sistemas $\mathrm{RhMo}_{6} / \mathrm{K}$ y $\mathrm{RhMo}_{6} / \mathrm{D}$, entre $\mathrm{T}$ ambiente y $950^{\circ} \mathrm{C}$. 


\section{1.c. Caracterización por espectroscopia fotoelectrónica por rayos X (XPS)}

Para complementar el análisis se realizaron medidas de XPS, mostradas en tabla 6-I. Los datos de la fase pura $\mathrm{RhMo}_{6}$ revelaron una señal $\mathrm{Rh}_{3 / 2}$ a $310,8 \mathrm{eV}$ y una señal de $\mathrm{Mo}_{5} \mathrm{~d}_{5 / 2}$ a 233,0 eV, correspondiente a Rh (III) y Mo (VI), respectivamente. Debido a la superposición de N1s con el componente Mo3 $\mathrm{p}_{3 / 2}$, no se pudo determinar el estado y la cantidad de $\mathrm{N}$.

Para determinar la relación entre las concentraciones de las especies constituyentes de la superficie, se utilizan básicamente las intensidades de las señales XPS empleando la fórmula:

$$
\mathrm{n}_{1} / \mathrm{n}_{2}=\left(\mathrm{I}_{1} / \mathrm{S}_{1}\right) /\left(\mathrm{I}_{2} / \mathrm{S}_{2}\right)
$$

Donde I es la intensidad de la señal, n es el número de átomos del elemento por $\mathrm{cm}^{3}$ de la muestra, $\mathrm{S}$ es un factor atómico de sensibilidad. La detección de los diferentes elementos para cada especie reveló los siguientes resultados:

La composición atómica de la superficie $\mathrm{nRh} / \mathrm{nMo}=0,17$, derivado de la relación de intensidad $\mathrm{Rh} / \mathrm{Mo}$, está en excelente acuerdo con la composición del bulk, $\mathrm{nRh} / \mathrm{nMo}=0,167$. Tanto en las muestras soportadas a base de sílice D como sílice $\mathrm{K}$, se observó la presencia de Mo(VI), sin embargo en el catalizador a base de sílice Degussa no fue posible detectar la presencia de $\mathrm{Rh}(\mathrm{III})$. El catalizador a base de sílica $\mathrm{K}$, tratado por TPR a $350^{\circ} \mathrm{C}$, contiene especies de Mo reducido y otras de Mo (VI) y Mo (IV). Paralelamente se observa una mezcla de las especies $\mathrm{Rh}^{\circ}$ y $\mathrm{Rh}(\mathrm{III})$. Estos resultados corroboran que en el proceso de reducción analizado por TPR, las diferentes señales provienen de $\mathrm{Rh}$ y/o Mo en distintos entornos electrónicos y con diferente capacidad de reducción, indicando que la interacción del HPOM con la sílice es un proceso complejo en ambos soportes. Como se expuso en la sección experimental item 2.2, el punto isoeléctrico de la sílice es 2 . Este valor nos indica la naturaleza ácida del soporte, lo que significa que a $\mathrm{pH}>2$ su superficie presenta mayoritariamente cargas negativas, sin embargo esto llega a ser significativo a $\mathrm{pH} \geq 5$, valor de $\mathrm{pH}$ de la solución acuosa del heteropolianión de interés, en la cual esta especie es estable. Por otro lado, a $\mathrm{pH}=10.6$ (condición que adopta en contacto con $\mathrm{NH}_{4} \mathrm{OH}$ ), ocurre el siguiente fenómeno de polarización:

$$
[\mathrm{Si}-\mathrm{OH}]+\mathrm{NH}_{4}{ }^{+} \leftrightarrow\left[\left(\mathrm{NH}_{4}{ }^{+}\right)(\equiv \mathrm{Si}-\mathrm{O})^{-}\right]+\mathrm{H}^{+}
$$


A partir de $\mathrm{pH}=11$, se produce una disolución significativa de $\mathrm{SiO}_{2}$. De este modo, la sílice es un buen intercambiador catiónico a pH entre 9 y 11 [6,7], por lo que la impregnación de un polianión como $\left[\mathrm{RhMo}_{6} \mathrm{H}_{6} \mathrm{O}_{24}{ }^{3-}\right]$ no produce un intercambio efectivo, como quedó demostrado por los valores obtenidos por el método de AAS, los que arrojaron valores de Mo y Rh adsorbidos del $0.57 \%$ y $0.14 \%$ para sílice D y $0.51 \%$ y $0.10 \%$ para el soporte K, respectivamente. Sin embargo los valores encontrados por el método semicuantitativo de superficie EDS fueron $4.23 \%$ Mo y $1.02 \%$ Rh para la sílice D seleccionada y pretratada como soporte clásico para la reacción elegida. Por estos motivos no se llevaron adelante estudios de isotermas de adsorción de fases $\mathrm{XMo}_{6}$ en sílice, método que se explica en el item 2.4 b.II, en relación a los análisis químicos realizados por Absorción Atómica.

Tabla 6-I: Datos de energías de enlace en $(\mathrm{eV})$ y relaciones atómicas obtenidas por XPS para los catalizadores $\mathrm{RhMo}_{6} / \mathrm{D}, \mathrm{RhMo}_{6} / \mathrm{K}_{\text {y }} \mathrm{RhMo}_{6} / \mathrm{K}$ tratado por TPR a $350^{\circ} \mathrm{C}$.

\begin{tabular}{|c|c|c|c|c|c|c|}
\hline \multirow{4}{*}{$\frac{\text { Catalizador }}{\mathrm{RhMo}_{6} / \mathrm{D}}$} & $\mathrm{Rh} \mathrm{d}_{5 / 2} / \mathrm{eV}$ & $\operatorname{Mo3d}_{5 / 2} / \mathrm{eV}$ & $\mathrm{O} 1 \mathrm{~s} / \mathrm{eV}$ & $\mathrm{Rh} / \mathrm{Si}$ & $\mathrm{Mo} / \mathrm{Si}$ & $\mathrm{Rh} / \mathrm{Mo}$ \\
\hline & \multirow[t]{3}{*}{ n.d. } & 232.2 & \multirow[t]{3}{*}{533.1} & \multirow[t]{3}{*}{ - } & \multirow[t]{3}{*}{0.0033} & \multirow[t]{3}{*}{ - } \\
\hline & & $230.265 \%$ & & & & \\
\hline & & $232.235 \%$ & & & & \\
\hline $\mathrm{RhMo}_{6} / \mathrm{K}$ & 308.4 & 232.1 & 532.9 & 0.0064 & 0.015 & 0.42 \\
\hline $\mathrm{RhMo}_{6} / \mathrm{K}$ & \multirow[t]{3}{*}{307.8} & 232.4 & \multirow[t]{3}{*}{533.0} & \multirow[t]{3}{*}{0.0042} & \multirow[t]{3}{*}{0.018} & \multirow[t]{3}{*}{0.24} \\
\hline Red. $350^{\circ} \mathrm{C}$ & & $231.5 \quad 50 \%$ & & & & \\
\hline & & $233.150 \%$ & & & & \\
\hline
\end{tabular}

Nota: Datos comparados con valores experimentales reportados en la literatura a través de la base de datos: www.lasurface.com/database.

\section{2 . Caracterización de Catalizadores a base de heteropolianiones tipo Anderson soportados sobre $\gamma-\mathrm{Al}_{2} \mathrm{O}_{3}$}

\section{2.a. Caracterización por DRX}

En primer lugar se analizan los resultados para catalizadores a base de $\mathrm{RhMo}_{6}$ soportada sobre $\gamma-\mathrm{Al}_{2} \mathrm{O}_{3}$ tipo (EI). Posteriormente se analiza la fase soportada en alúminas de diferentes propiedades texturales denominadas: (A) y (EII), tal como se 
expuso en el capítulo 2. Asimismo y a los fines de realizar estudios catalíticos comparativos, se caracterizan también en forma comparativa algunos catalizadores a base de otras fases como heptamolibdato de amonio (HMA) y fases como $\mathrm{AlMo}_{6}$, $\mathrm{CoMo}_{6}$ y $\mathrm{Co}_{2} \mathrm{Mo}_{10}$, los que se prepararon siguiendo la misma metodología de impregnación en equilibrio utilizada para la fase de Rh. También se incluye el análisis de un catalizador preparado por impregnación de $\mathrm{RhCl}_{3} \cdot \mathrm{xH}_{2} \mathrm{O}$ y HMA siguiendo la técnica convencional por impregnación sucesiva de ambas fases.

En la Figura 6-4 (a) se muestra el diagrama de polvo por Rayos X correspondiente a los sistemas soportados en $\gamma-\mathrm{Al}_{2} \mathrm{O}_{3}$ (EI y EII) que muestran el perfil típico de la especie de $\gamma$-alúmina de partida. Sin embargo el diagrama correspondiente al soporte denominado A (Figura 6-4 (b), identificado previamente como fase $\gamma-\mathrm{Al}_{2} \mathrm{O}_{3}$, muestra un diagrama bien definido cuyas señales $\left(2 \theta: 15^{\circ}, 29.4^{\circ}, 39.0^{\circ}\right.$ y $\left.48.0^{\circ}\right)$ son características de una forma de alúmina conocida como "bohemita" ( $\gamma$-AlOOH) ICDDNo 83-2384. Según Rinaldi, et al.,[8] la rehidratación de una alúmina de fase gamma puede dar lugar a un cambio de fase hacia una especie hidroxilada por lo que podemos inferir que la impregnación en equilibrio del soporte A con una solución acuosa de $\mathrm{RhMo}_{6}$ dió lugar a la estabilización de la fase de alúmina como "bohemita". Al igual que en el caso de la sílice se observan sólo los perfiles típicos de cada tipo de alúmina, por lo que esta técnica tampoco permitió la identificación de las especies soportadas.

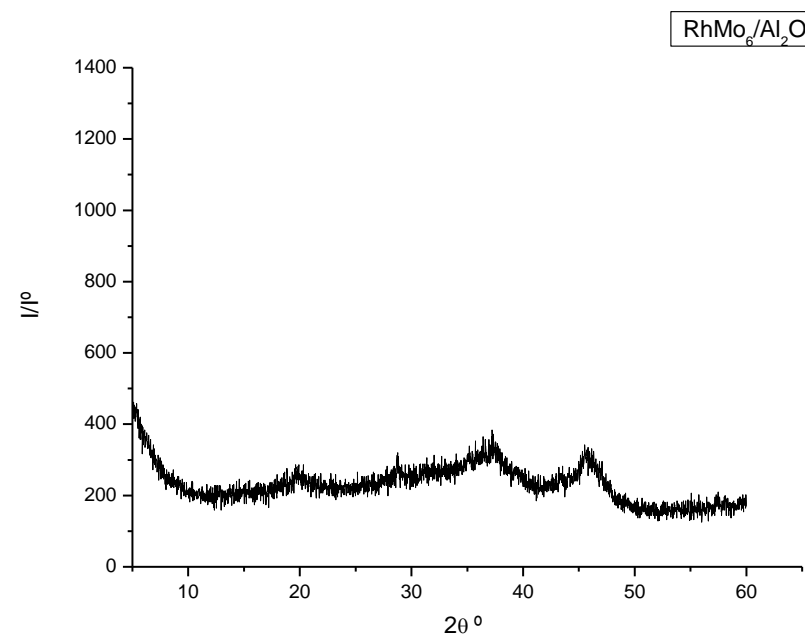

Figura 6-4 (a) Diagramas de DRX correspondiente al catalizador $\mathrm{RhMo}_{6} / \mathrm{EI}-\mathrm{EII}$ 


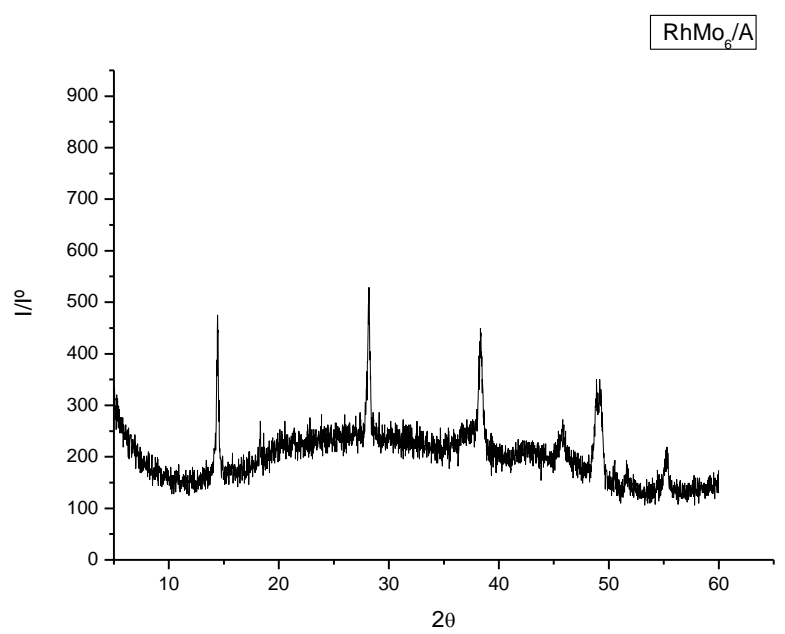

Figura 6-4 (b): Diagramas de DRX correspondiente al catalizador $\mathrm{RhMo}_{6} / \mathrm{A}$

Dado que la caracterización por la técnica de Rayos X no permite la identificación de fases soportadas debido a la fuerte fluorescencia soportes y a la amplia dispersión de los metales en la superficie, se ha recurrido a otras técnicas espectroscópicas y de análisis químico para la determinación de las especies soportadas.

\section{2.b. Estudio de la Isoterma de adsorción de $\mathrm{RhMo}_{6}$ en $\gamma-\mathrm{Al}_{2} \mathrm{O}_{3}(\mathrm{EI})$}

Con el fin de realizar el estudio de la isoterma de adsorción de la fase de $\mathrm{Rh}(\mathrm{III})$ en alúmina, se eligió el soporte de $\gamma-\mathrm{Al}_{2} \mathrm{O}_{3}(\mathrm{EI})$, dado que existía un trabajo previo en nuestros laboratorios empleando este soporte y otras fases de Anderson con diferentes heteroátomos. En la Figura 6-5 se muestra la isoterma obtenida para la fase en estudio.

Al igual que para las otras fases, la forma de la curva responde al modelo de Langmuir, de acuerdo a un incremento de la concentración de Mo adsorbido [g /100 g $(E I)]=$ " $\mathrm{C}_{\mathrm{ad}}$ ", en función del aumento de la concentración final de Mo ( $\mu \mathrm{mol} / \mathrm{ml} \mathrm{de}$ solución al final de la impregnación) $=$ " $\mathrm{C}_{\mathrm{f}}$ ", hasta alcanzar valores constantes de $\mathrm{C}_{\mathrm{ad}}$ [9,10]. El cálculo de $C_{a d}$ para cada catalizador preparado con concentraciones crecientes de Mo, se ha realizado utilizando una ecuación de balance de masas en la que se utilizan los valores de Mo de las soluciones finales e iniciales medidos por el método de 
absorción atómica (AAS): tal como se expuso en la sección experimental, ítem.

\section{4.b.II.}

$$
C_{a d}=\left\{\frac{\left(C_{i}-C_{f}\right) \times V}{m}\right\} \times 100
$$

Donde,

$\mathrm{C}_{\mathrm{ad}}=$ Concentración de Mo adsorbido ( $\mathrm{g}$ Mo/g de soporte).

$\mathrm{C}_{\mathrm{i}}=$ Concentración de Mo inicial $\left(\mathrm{g} \mathrm{Mo}_{\mathrm{cm}}{ }^{3}\right)$.

$\mathrm{C}_{\mathrm{f}}=$ Concentración de Mo final.

$\mathrm{V}=$ volumen inicial de solución impregnante $\left(\mathrm{cm}^{3}\right)$.

$\mathrm{m}=$ masa de soporte $\left(\mathrm{g}\right.$ de $\left.\gamma-\mathrm{Al}_{2} \mathrm{O}_{3}\right)$.

En la Tabla 6-II se presentan los valores obtenidos para la realización de la isoterma de adsorción para la fase $\mathrm{RhMo}_{6}$. Se encontró que la máxima concentración de Mo adsorbida alcanza un valor cercano al $6 \%$.

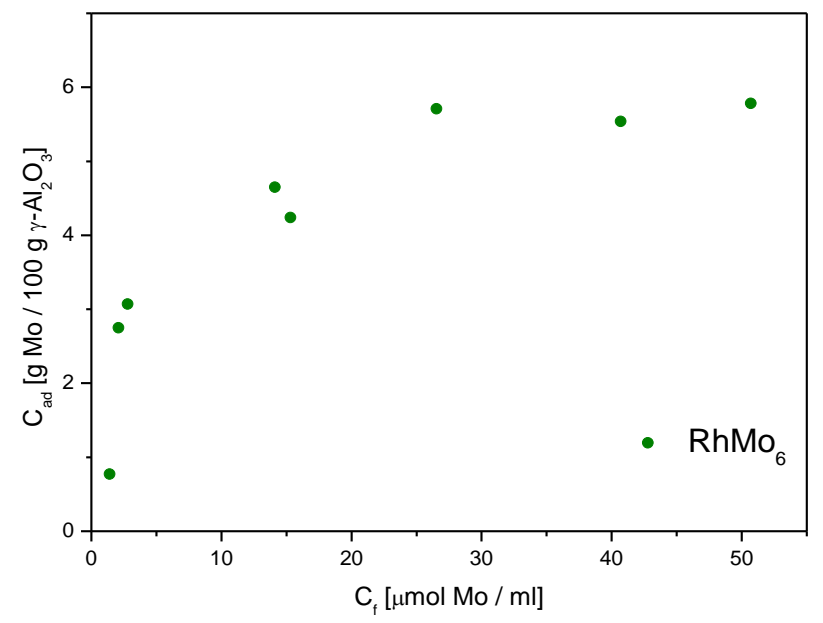

Figura 6-5: Isoterma de Adsorción de $\mathrm{RhMo}_{6}$, expresada en concentración de Mo adsorbido, $\mathrm{C}_{\mathrm{ad}}\left(\mathrm{g} \mathrm{Mo} / 100 \mathrm{~g} \gamma-\mathrm{Al}_{2} \mathrm{O}_{3}\right)$. 
Tabla 6-II: Concentraciones $\mathrm{C}_{\mathrm{i}}$ (inicial) y $\mathrm{C}_{\mathrm{f}}$ (final) de Mo y $\mathrm{Rh}$ en las soluciones impregnantes de seis muestras; contenido de $\mathrm{C}_{\mathrm{ad}}$ (Mo y $\mathrm{Rh}$ adsorbidos) medido por Absorción atómica AAS y posterior cálculo por balance de masas.

\begin{tabular}{|c|c|c|c|c|c|c|c|}
\hline $\mathrm{RhMo}_{6} / \gamma-\mathrm{Al}_{2} \mathrm{O}_{3}$ & $\mathrm{C}_{\mathrm{i}} \mathbf{M o}$ & $\mathrm{C}_{\mathrm{f}} \mathrm{Mo}$ & $\mathrm{C}_{\mathrm{ad}} \mathrm{Mo}$ & $\mathbf{C}_{\mathbf{i}} \mathbf{R h}$ & $\mathrm{C}_{\mathrm{f}} \mathrm{Rh}$ & $\mathbf{C}_{a d} R_{h_{e}}$ & $\mathbf{C}_{\mathrm{ad}} \mathbf{R h _ { \mathrm { c } }}$ \\
\hline 1 & 112.36 & 53.78 & 6.75 & 13.72 & 3.27 & 1.3 & 1.47 \\
\hline 2 & 65.25 & 32.39 & 3.78 & 14.09 & 4.74 & 1.1 & 1.20 \\
\hline 3 & 52.74 & 15.93 & 4.24 & 9.46 & 2.18 & 0.9 & 0.67 \\
\hline 4 & 29.60 & 2.98 & 3.07 & 6.52 & 0.60 & 0.7 & 0.55 \\
\hline 5 & 26.06 & 2.23 & 2.75 & 4.08 & 0.05 & 0.5 & 0.49 \\
\hline 6 & 8.13 & 1.49 & 0.77 & 2.43 & 0.06 & 0.3 & 0.13 \\
\hline
\end{tabular}

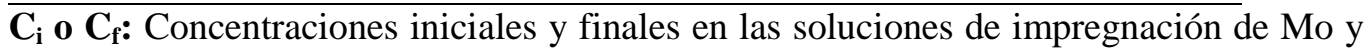
$\mathrm{Rh}$ expresado en $\mu \mathbf{m o l} / \mathbf{m l}$.

$\mathbf{C}_{\mathbf{a d}} \mathbf{M}$ con $\mathbf{M}=\mathbf{M o}$ o $\mathbf{R h}$ : cantidad de metal adsorbido expresado en g M/ $100 \mathrm{~g} \gamma-\mathrm{Al}_{2} \mathrm{O}_{3}$. $\mathbf{C}_{\mathrm{ad}} \mathbf{R} \mathbf{h}_{\mathrm{e}}$ : cantidad de Rh adsorbido calculado y experimental expresado en $\mathrm{g} \mathrm{Rh} / 100 \mathrm{~g} \gamma$ $\mathrm{Al}_{2} \mathrm{O}_{3}$.

\section{2.c. Obtención de los parámetros de adsorción de las Fase de Anderson} soportada en $\gamma-\mathrm{Al}_{2} \mathrm{O}_{3}(\mathrm{EI})$.

Utilizando la correspondiente ecuación linealizada de la ecuación de Langmuir, y mediante el análisis de los datos a partir de la regresión lineal, es posible obtener los parámetros de absorción como el número de sitios activos (S) y la constante de equilibrio de adsorción $\left(\mathbf{K}_{\mathbf{a d}}\right)$ según la siguiente expresión:

$$
C_{\mathrm{f}} / \mathrm{C}_{\mathrm{ad}}=\mathbf{1} /\left(\mathrm{K}_{\mathrm{ad}} * \mathrm{~S}\right)+\mathrm{C}_{\mathrm{f}} / \mathrm{S}
$$

Así, es posible obtener dichos parámetros para la fase a partir de las gráficas mostradas en las Figuras 6-6. 


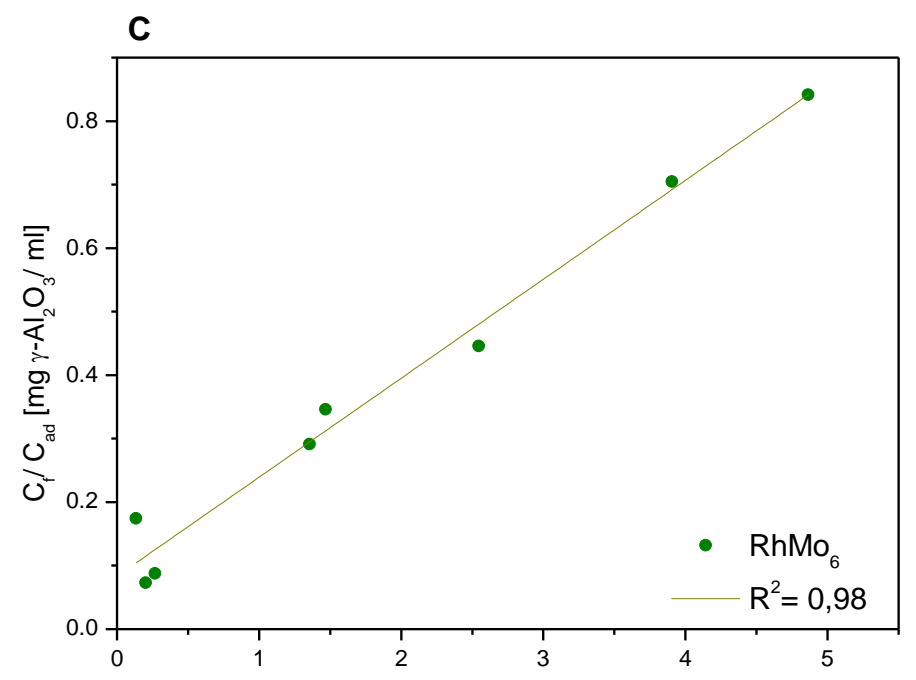

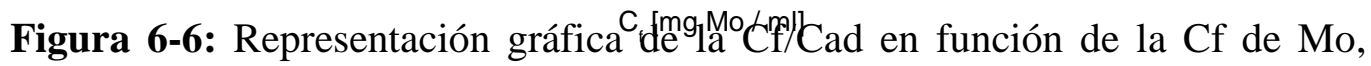
forma linealizada de la Ecuación de Langmuir $\left(\mathrm{Cf} / \mathrm{Cad}=1 /\left(\mathrm{Kad}^{*} \mathrm{~S}\right)+\mathrm{Cf} / \mathrm{S}\right)$ para la fase $\mathrm{RhMo}_{6}$, soportadas sobre $\gamma-\mathrm{Al}_{2} \mathrm{O}_{3}$ (concentración de Mo final (Cf) expresada en $\mathrm{mgMo} / \mathrm{ml}$ y Mo adsorbido, (Cad) en $\mathrm{mgMo} / \mathrm{mg} \gamma-\mathrm{Al}_{2} \mathrm{O}_{3}$ ).

En la Tabla 6-III se presentan los parámetros correspondientes a la isoterma de adsorción obtenidas para los sistemas en estudio, a modo comparativo se incluyen los datos correspondientes al HMA soportados en $\gamma-\mathrm{Al}_{2} \mathrm{O}_{3}$ [11].

Tabla 6-III: Parámetros de Adsorción para los sistemas soportados en $\gamma-\mathrm{Al}_{2} \mathrm{O}_{3}$ a partir de $\mathrm{XMo}_{6}$, con $\mathrm{X}=\mathrm{Rh}$, y HMA.

\begin{tabular}{|c|c|c|c|}
\hline Fase & $\mathbf{K}_{\mathrm{ad}}(\mathbf{m l} / \mathbf{g M o})$ & S (gMo/ gsoporte) & $10^{20} \mathrm{~S}$ (átomos Mo/g sop.) \\
\hline HMA & 290 & 0.10 & 6.30 \\
\hline $\mathrm{RhMo}_{6}$ & 1460 & 0.07 & 4.30 \\
\hline
\end{tabular}
$\gamma-\mathrm{Al}_{2} \mathrm{O}_{3}$.

Es ampliamente conocido que la impregnación de soluciones de iso y heteropolimolibdatos en alúmina involucra una serie de procesos homogéneos y heterogéneos que producen la deposición de la fase aniónica y reacciones secundarias como la disolución del Al del soporte, la contra-difusión y el intercambio de los 
cationes en juego [12,13]. Los procesos que ocurren en la impregnación de fases tipo Anderson pueden describirse como:

1- Deposición:

$$
\mathrm{XMoO}_{6(\mathrm{sc} .)} \Leftrightarrow \mathrm{XMo}_{(\mathrm{ads})}
$$

2- Disolución del soporte:

$$
\mathbf{A l}\left(\text { III) }{ }_{(\text {soporte) }} \Leftrightarrow \quad \mathbf{A l}(\text { III) }\right.
$$

\section{3- Contra-Difusión}

$$
\begin{aligned}
& \mathrm{Al}(\mathrm{III})_{(\text {soporte) }}+\quad \mathrm{XMo}_{6} \text { (ads) } \Leftrightarrow \quad \mathrm{AlMo}_{6} \text { (ads) }+\quad \mathbf{X}_{\text {(soborte) }} \\
& \mathrm{Al}(\mathrm{III})_{(\mathrm{sc})}+\mathrm{XMo}_{(\mathrm{ads})} \Leftrightarrow \mathrm{AlMo}_{(\mathrm{ads})}+\mathrm{X}(\mathrm{III})_{(\mathrm{sc})}
\end{aligned}
$$

proceso de disolución del $\mathrm{Al}(\mathrm{III})$ dependiente de las características del heteroátomo $\mathrm{X}$ presente. Se observó en trabajos anteriores que para la fase de Co(III), las interacciones de intercambio y contra difusión parecen estar minimizadas, mientras que para la fase de Al(III), no están presentes [13]. Se pudo concluir que la presencia de heteroátomos trivalentes de radios iónicos entre $\left(\mathrm{r}_{\mathrm{Al}(\mathrm{III})}=0.50 \AA \mathrm{y} \mathrm{r}_{\mathrm{Rh}(\mathrm{III})}=0.66 \AA\right)$ permite una buena deposición sobre $\gamma-\mathrm{Al}_{2} \mathrm{O}_{3}$ debido al posible intercambio entre $\mathrm{X}(\mathrm{III})$ y el $\mathrm{Al}$ del soporte.

\section{2.d. Caracterización espectroscópica de los catalizadores a base de fases de} Anderson soportadas en $\gamma-\mathrm{Al}_{2} \mathrm{O}_{3}$ tipo EI.

\section{2.d.I. Caracterización espectroscópica por DRS UV-visible}

En la Figura 6-7 se muestra comparativamente el espectro DRS UV-visible para las fases de Anderson de $\mathrm{Co}$ y $\mathrm{Rh}$ puras y soportadas. El espectro correspondiente a CoMo6, presenta en la región UV (200 - 350 nm) las bandas típicas de transferencia de carga (TC) Mo $\rightarrow \mathrm{O}$ centradas en $270 \mathrm{~nm}$ características del Mo(VI) en entorno octaédrico. En la zona del visible (350 - $800 \mathrm{~nm})$, se encuentran dos bandas de transición $d-d$ (spin-permitidas) correspondientes a la configuración del ión $\operatorname{Co}(\mathrm{III})\left(d^{6}\right)$ 
en entorno octaédrico regular, las cuales se conservan también en la especie soportada, Figura 6-7 (a). Estas bandas, ubicadas en 700 - $550 \mathrm{~nm}$ y 500 - $400 \mathrm{~nm}$, respectivamente corresponden a las transiciones $d-d$ desde el estado fundamental ${ }^{1} \mathrm{~A}_{1 \mathrm{~g}}$ a $\operatorname{los}$ estados superiores ${ }^{1} \mathrm{~T}_{\mathrm{g} 1} \mathrm{y}^{1} \mathrm{~T}_{2 \mathrm{~g}}$ respectivamente.

$\mathrm{El}$ espectro de reflectancia difusa correspondiente a la fase soportada en $\gamma-\mathrm{Al}_{2} \mathrm{O}_{3}$ muestra, además de las bandas de TC, un corrimiento de los tránsitos $d-d$ hacia mayor energía, situación que sugiere una interacción con el soporte y un entorno ligeramente diferente para el heteroátomo (banda en $460 \mathrm{~nm}$ ). El espectro revela que el heteropolianión se adsorbe sobre la $\gamma-\mathrm{Al}_{2} \mathrm{O}_{3}$ sin degradarse, debido a que el Co(III) presenta la misma configuración electrónica y el Mo(VI) presenta la banda típica en entorno octaédrico característica de las especies poliméricas, Figura 6-6 (a).

En lo que respecta a la fase de $\mathrm{Rh}(\mathrm{III})$ soportada sobre $\gamma-\mathrm{Al}_{2} \mathrm{O}_{3}$, el espectro DRS, Figura 6-7 (b), presenta bandas menos intensas que las correspondientes a la fase pura. Es posible observar tanto las bandas correspondientes a la transferencia de carga del Mo(VI) en entorno octaédrico $(\sim 300 \mathrm{~nm})$ como la banda a $400 \mathrm{~nm}$ de menor resolución correspondiente al $\mathrm{Rh}(\mathrm{III})$. En este caso también es posible establecer la preservación de la estructura soportada $[14,15]$.

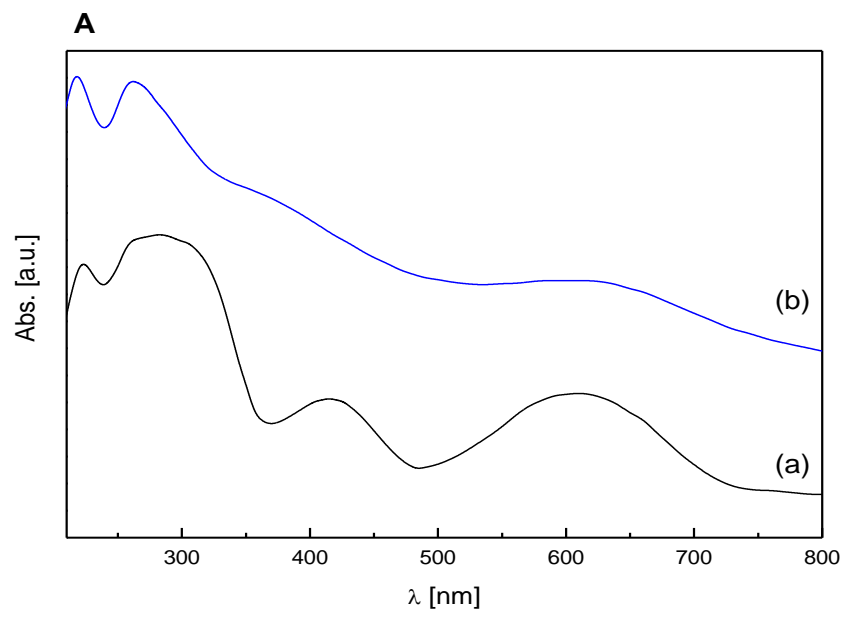




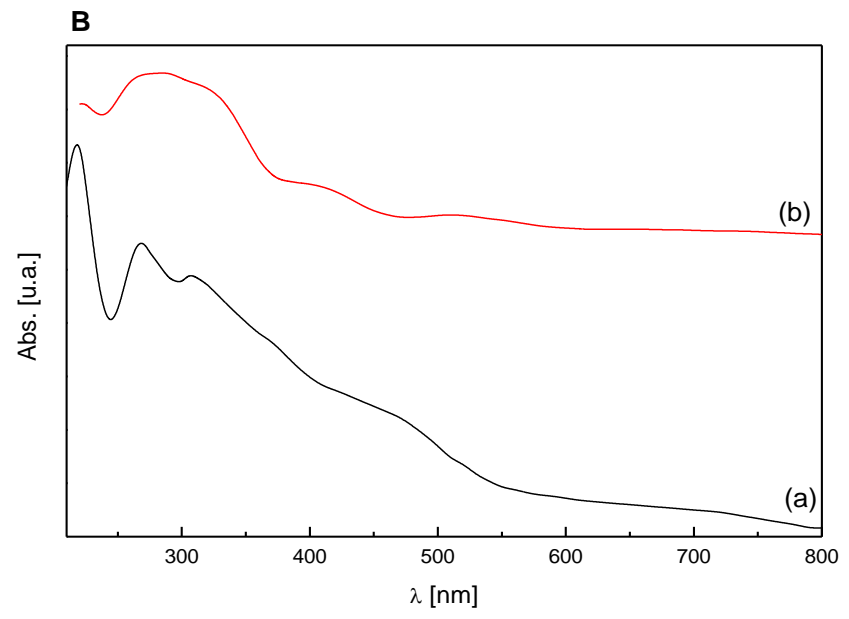

Figura 6-7: Espectros DRS comparativos de las fases Anderson: A) $\mathrm{CoMo}_{6}$ (a) pura y (b) soportada sobre $\gamma-\mathrm{Al}_{2} \mathrm{O}_{3}$; y B) $\mathrm{RhMo}_{6}$ (a) pura y (b) soportada sobre $\gamma$ $\mathrm{Al}_{2} \mathrm{O}_{3}$ (Rango entre 200 y $800 \mathrm{~nm}$ ).

\section{2.d.II. Caracterización mediante Microanálisis Raman}

En la Figura 6-8 se observan los espectros comparativos de las fases $\mathrm{CoMo}_{6}$, $\mathrm{RhMo}_{6}$ puras y soportadas. En base a la asignación realizada en el Capítulo 3 (Tabla 3VI) para las fases puras, se observa que los modos de estiramiento correspondientes a los enlaces $\mathrm{Mo}-\mathrm{O}_{2 \mathrm{t}}$ surgen entre 1000 y $930 \mathrm{~cm}^{-1}$, y los relativos a Mo- $\mathrm{O}_{\mathrm{b}}$ y Mo- $\mathrm{O}_{\mathrm{c}}$ entre 750 y $500 \mathrm{~cm}^{-1}$, respectivamente [2]. De la comparación entre el espectro Raman de las fases puras y soportadas, se observa en general, el ensanchamiento de las líneas correspondiente al estiramiento $\mathrm{Mo}-\mathrm{O}_{2 \mathrm{t}}\left(946 \mathrm{~cm}^{-1}\right.$ para la fase $\mathrm{CoMo}_{6}, \mathrm{y} 947 \mathrm{~cm}^{-1}$ para el $\mathrm{RhMo}_{6}$ ) en las especies soportadas.

Este efecto puede atribuirse a la interacción de la especie Anderson $\mathrm{XMo}_{6}$ con el soporte, la cual puede generar una leve distorsión de la estructura planar simétrica $[13,14,15]$ o a una descomposición parcial de la fase original con la correspondiente 
formación de la estructura Anderson de $\mathrm{Al}(\mathrm{III}), \mathrm{AlMo}_{6}$, a partir de la "disolución" parcial del soporte, sugerido por la presencia de un hombro a $570 \mathrm{~cm}^{-1}$, característica de los modos vibracionales de la especie $\mathrm{AlO}(\mathrm{Mo})$ [14]. De hecho, como se mencionó en el estudio de las isotermas de adsorción, durante el proceso de impregnación pueden ocurrir interacciones heteropolianión-soporte, formación de enlaces coordinativos de los iones con la superficie, disolución del $\mathrm{Al}(\mathrm{III})$ del soporte con formación de $\mathrm{AlMo}_{6}$, difusión del X(III) y reacción de éste en la superficie del soporte, etc. Por lo que no se descarta la posterior reprecipitación de $\mathrm{AlMo}_{6}$ sobre el soporte, así como la difusión del $\mathrm{Rh}(\mathrm{III})$ para una posible formación de la solución sólida [Rh,Al] $\mathrm{Mo}_{6}[13,14,16,17]$. En la Tabla 6-IV se muestran las principales bandas para la fase pura y soportada en $\gamma$ $\mathrm{Al}_{2} \mathrm{O}_{3}$.

Tabla 6-IV: Se presentan las principales bandas de la fase pura y soportada en $\gamma-\mathrm{Al}_{2} \mathrm{O}_{3}$ (EI).

\begin{tabular}{cccc}
\hline Raman/Fase & $\boldsymbol{v}_{\mathbf{s}} \mathbf{M o -} \mathbf{O}_{\mathbf{2 t}}\left(\mathbf{c m}^{-\mathbf{1}}\right)$ & $\boldsymbol{v}_{\mathbf{a s}} \mathbf{M o -} \mathbf{O}_{\mathbf{2 t}}\left(\mathbf{c m}^{-\mathbf{1}}\right)$ & $\boldsymbol{v} \mathbf{M o -} \mathbf{O}_{\mathbf{b}}\left(\mathbf{c m}^{-\mathbf{1}}\right)$ \\
\hline $\mathrm{RhMo}_{6}$ & 949 & 898 & 549 \\
$\mathrm{RhMo}_{6} / \gamma_{-}$ & 943 & 538 & 322 \\
$\mathrm{Al}_{2} \mathrm{O}_{3}(\mathrm{EI})$ & & & \\
\hline
\end{tabular}

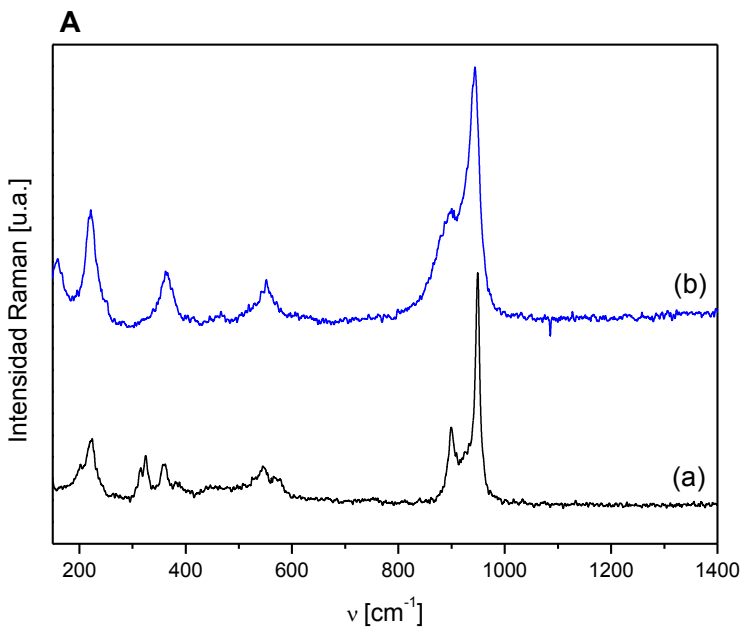




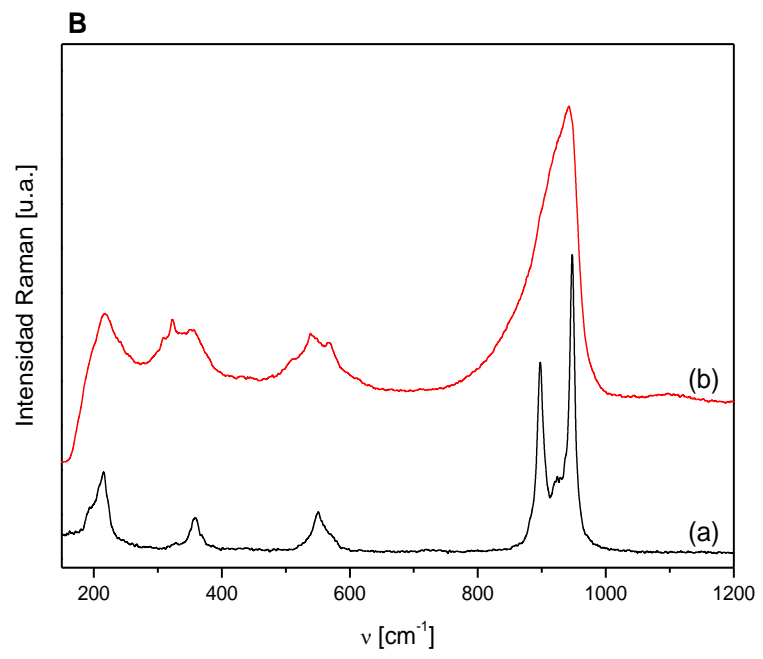

Figura 6-8: Espectros Raman comparativos entre 200 y $1200 \mathrm{~cm}^{-1}$ de las fases Anderson: A) $\mathrm{CoMo}_{6}$ (a) pura y (b) soportada sobre $\gamma-\mathrm{Al}_{2} \mathrm{O}_{3}(\mathrm{EI})$; B) $\mathrm{RhMo}_{6}$ (a) pura y (b) soportada sobre $\gamma-\mathrm{Al}_{2} \mathrm{O}_{3}(\mathrm{EI})$.

Un comportamiento diferente se observó para los catalizadores preparados por impregnación sucesiva del soporte con soluciones acuosas de cloruro de rodio y HMA, de acuerdo a la técnica clásica de preparación de catalizadores $\mathrm{Rh}$ y Mo soportados en alúmina, reportada en la literatura. De la comparación entre el espectro Raman del HMA, Figura 6-9(a) y el catalizador $\mathrm{RhMo} / \gamma-\mathrm{Al}_{2} \mathrm{O}_{3}(\mathrm{~A})$, Figura 6-9(b), se observa en general, el ensanchamiento de las líneas correspondientes al estiramiento simétrico Mo$\mathrm{O}_{2 \mathrm{t}}$ a $934 \mathrm{~cm}^{-1}$ para la especie heptamolibdato hacia frecuencias más altas $\left(947 \mathrm{~cm}^{-1}\right)$, lo cual es indicativo de un cambio en la estructura del isopolianión. Es bien conocido que durante la impregnación del soporte de alúmina con una solución acuosa de HMA, se produce la precipitación del hexamolibdo-aluminato de estructura tipo Anderson $\left(\mathrm{AlMo}_{6}\right)$ debido a la extracción de átomos de aluminio de la superficie [18].

La presencia de una banda ancha alrededor de $540 \mathrm{~cm}^{-1}$, atribuida a los grupos Mo-O-Al, típicas de estructuras Anderson, corresponde a la vibración de los enlaces puentes $\mathrm{Mo}_{\mathrm{b}} \mathrm{O}_{\mathrm{b}}$ (Mo-O-Mo) que se observan en el espectro análogo de la fase pura 
$\mathrm{RhMo}_{6}$, Tabla 6-III, Figura 6-7(a). Además, la presencia de $\alpha-\mathrm{AlO}(\mathrm{OH})$ en el soporte como un componente principal se confirma por la banda centrada alrededor de $333 \mathrm{~cm}^{-1}$, de acuerdo con el patrón Raman reportado para la especie cristalina $\alpha-\mathrm{AlO}(\mathrm{OH})$ [19].

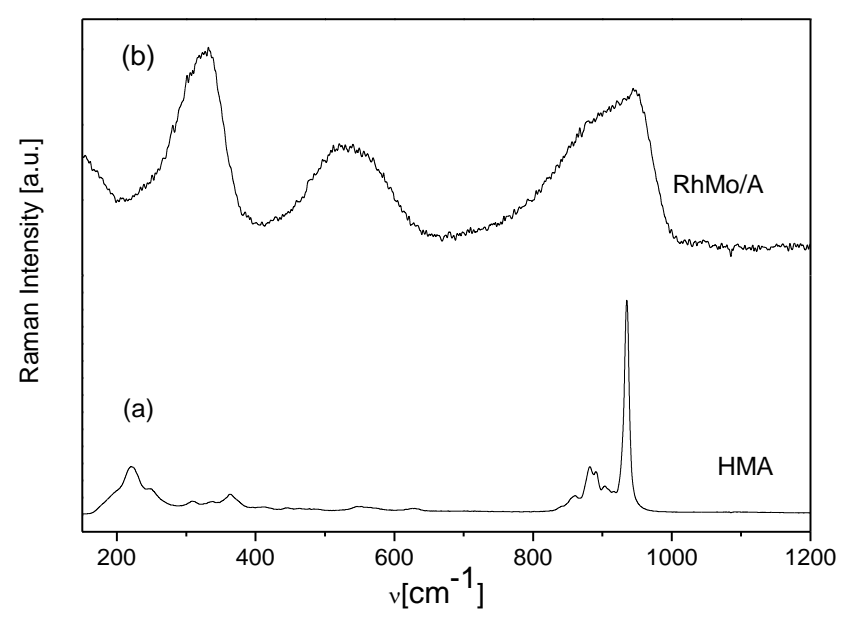

Figura 6-9: Espectros Raman comparativos entre: (a) $\left(\mathrm{NH}_{4}\right)_{6} \mathrm{Mo}_{7} \mathrm{O}_{24} \cdot 4 \mathrm{H}_{2} \mathrm{O}$ (HMA) y (b) RhMo/A

Por otra parte, en el sistema preparado por impregnación sucesiva, $\mathrm{RhMo} / \mathrm{A}$, no se encontraron bandas correspondientes a los modos de estiramiento de $\mathrm{Rh}-\mathrm{O}\left(560 \mathrm{~cm}^{-1}\right)$. También se sugiere que en este sistema, las bandas Rh-O-Al pueden solaparse con la característica $v$ Mo- $\mathrm{O}_{\mathrm{b}}$ asignada al grupo Mo-O-Al $[16,20]$.

\section{2.e. Caracterización mediante Reducción Térmica Programada (TPR).}

La técnica de reducción térmica programada es una de las herramientas más utilizadas en el campo de la catálisis con el fin de caracterizar sistemas oxídicos conteniendo diversos metales fácilmente reducibles en atmósferas conteniendo pequeños porcentajes de $\mathrm{H}_{2}$.

Como ya se mencionó en el capítulo 4, para la fase sin soportar, este tratamiento involucra un efecto sinérgico que genera la superposición de la etapa de reducción del $\mathrm{Rh}(\mathrm{III})$ a $\mathrm{Rh}^{\circ}$ y las dos etapas de reducción del Mo: (Mo(VI) (1) $\rightarrow \mathrm{Mo}$ (IV) (2) $\rightarrow \mathrm{Mo}^{\circ}$ manifestando un intenso pico a menor temperatura $\left(285^{\circ} \mathrm{C}\right)$ si se compara con el heptamolibdato de amonio cuyas etapas ocurren a $430^{\circ} \mathrm{C}$ y $760^{\circ} \mathrm{C}$ respectivamente, siendo la última etapa la de mayor consumo de $\mathrm{H}_{2}$ [21]. Este efecto sinérgico también se 
pudo verificar a través del TPR de las fases soportadas en la sílice D y alúmina. En la Figura 6-10 se muestran comparativamente los diagramas de TPR de la fase pura $\mathrm{RhMo}_{6}$, el HMA y de tres de los catalizadores a base de $\mathrm{RhMo}_{6}$ en diferentes soportes: $\mathrm{RhMo}_{6} /(\mathrm{EI}), \mathrm{RhMo}_{6} /(\mathrm{EII}), \mathrm{RhMo}_{6} / \mathrm{A}$ y un catalizador preparado de manera convencional, por impregnación sucesiva de $\mathrm{RhCl}_{3} \cdot \mathrm{xH}_{2} \mathrm{O}$ y $\mathrm{HMA}$,: $\mathrm{RhMo/(A)}$.

El perfil de TPR de HMA (Figura 6-10, curva a) consiste en un pico de baja intensidad aproximadamente a $430^{\circ} \mathrm{C}$, otro intenso aproximadamente a $760^{\circ} \mathrm{C}$, correspondientes respectivamente a dos etapas de reducción: (Mo(VI) (1) $\rightarrow \mathrm{Mo}(\mathrm{IV})$ $\left.(2) \rightarrow \mathrm{Mo}^{\circ}\right)$. El perfil de la fase $\mathrm{RhMo}_{6}$ muestra un pico intenso a $277^{\circ} \mathrm{C}$ y otros picos de baja intensidad a $370^{\circ} \mathrm{C}$ y $707^{\circ} \mathrm{C}$ (Figura 6-10, curva b). El primer pico puede estar

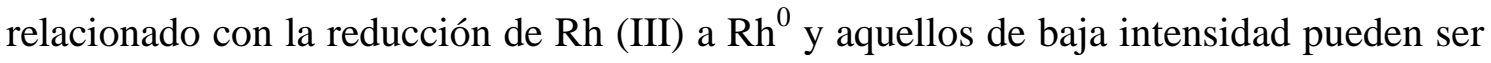
asignados a las etapas de reducción de molibdeno.

El catalizador $\mathrm{RhMo}_{6} / \mathrm{E}(\mathrm{I})$ exhibió picos de consumo de $\mathrm{H}_{2}$ a $211^{\circ} \mathrm{C}$ y $307^{\circ} \mathrm{C}$ y una señal amplia aproximadamente a $727^{\circ} \mathrm{C}$ (Figura 6-10, curva c), mientras que, tanto los catalizadores $\mathrm{RhMo} / \mathrm{A}$ y $\mathrm{RhMo}_{6} / \mathrm{A}$ mostraron perfiles de TPR en el rango de $327^{\circ} \mathrm{C}$ $627^{\circ} \mathrm{C}$ (Figura 6-10, las curvas e y f).

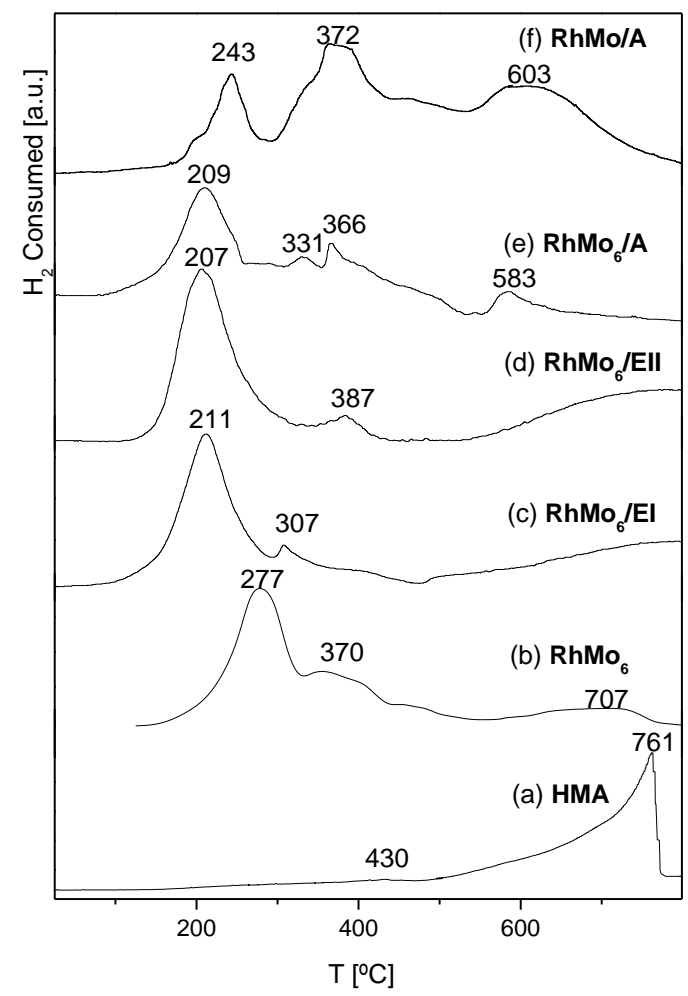


Figura 6-10: Diagrama TPR comparativo para las fases puras y soportadas: (a) HMA y (b) $\mathrm{RhMo}_{6}$; (c) $\mathrm{RhMo}_{6} / \mathrm{EI}$; (d) $\mathrm{RhMo}_{6} / \mathrm{EII}$; (e) $\mathrm{RhMo}_{6} / \mathrm{A}$ y (f) RhMo/A.

En este estudio se pudo establecer que la alta reducibilidad de $\mathrm{RhMo}_{6}$ se puede asociar al potencial de reducción del heteroátomo $\left(\mathrm{E}^{\circ} \mathrm{Rh}(\mathrm{III})-\mathrm{Rh}^{\circ}=0.44 \mathrm{~V}\right)$ el cual promueve la activación del $\mathrm{H}_{2}$, el que a su vez, afecta la estabilidad del Mo(VI), cuya reducción comienza a menor temperatura. Esto se manifiesta con un alto consumo de $\mathrm{H}_{2}$ mostrado por las curvas centradas a $285^{\circ} \mathrm{C}$ en la fase pura y alrededor de $210^{\circ} \mathrm{C}$ en las soportadas. Este comportamiento de las fases bimetálicas, es análogo al encontrado en otros sistemas convencionales RhMo soportados [17]. Caracterizaciones previas por Difracción de polvos por RX y microscopía SEM-EDS de muestras puras tratadas a la temperatura del pico principal, hicieron evidente la presencia simultánea de $\mathrm{Rh}^{\circ}$ y fases de Mo reducido como $\mathrm{Mo}^{\circ}$ y $\mathrm{MoO}_{2}$ [22]. A efectos comparativos, en la Tabla 6-V se presentan los datos de TPR y productos mayoritarios observados, para distintas fases de Anderson puras (según trabajos anteriores), mostrando el efecto del heteroátomo en la reducibilidad del Mo.

Tabla 6-V: Comparación de los resultados obtenidos por TPR de diferentes fases de amonio tipo Anderson y del heptamolibdato de amonio mostrando el efecto del heteroátomo en la reducibilidad del Mo.

\begin{tabular}{ccccc}
\hline Fase & $\begin{array}{c}\text { Señal T } \\
\text { Soportada }\end{array}$ & $\begin{array}{c}\text { Productos } \\
\text { Intermedios* }\end{array}$ & $\begin{array}{c}\text { Señal T } \\
\text { Sin Soportar }\end{array}$ & $\begin{array}{c}\text { Productos } \\
\text { Intermedios* }\end{array}$ \\
\hline $\mathrm{RhMo}_{6}$ & 307,211 & $\mathrm{MoRh}_{2} \mathrm{O}_{6}$ & 285 & $\mathrm{Rh}, \mathrm{MoO}_{2}, \mathrm{Mo}$ \\
$\mathrm{CrMo}_{6}$ & 510,915 & $\mathrm{MoO}_{2}, \alpha-(\mathrm{CrAl})_{2} \mathrm{O}_{3}$ & $337,468,516,574$, & $\mathrm{MoO}_{2}$, \\
$\mathrm{CoMo}_{6}$ & 467,845 & $\mathrm{MoO}_{2}, \mathrm{CoAl}_{2} \mathrm{O}_{4}$ & $430,500,610,848$ & $\mathrm{MoO}_{2}, \mathrm{CoMoO}_{4}$ \\
& & $\mathrm{MoO}_{2}, \mathrm{Al}_{2}\left(\mathrm{MoO}_{4}\right)_{3}$, & $400,586,842,990$ & $\mathrm{Al}_{2}\left(\mathrm{MoO}_{4}\right)_{3}$, \\
$\mathrm{AlMo}_{6}$ & $485,801,862$ & $\mathrm{Mo}_{4} \mathrm{O}_{11}$ & & $\mathrm{MoO}_{2}$ \\
\hline
\end{tabular}




\begin{tabular}{ccccc}
\hline $\mathrm{Ni} \mathrm{Mo}_{6}$ & 415,818 & $\mathrm{MoO}_{2}, \mathrm{NiAl}_{2} \mathrm{O}_{4}$ & $427,455,521,769$ & $\mathrm{MoO}_{2}, \mathrm{Ni}$ \\
$\mathrm{MoO}_{4}$ \\
$\mathrm{HMA}$ & 490,872 & $\mathrm{MoO}_{2}$ & $500,730,850$ & $\mathrm{MoO}_{2}$ \\
\hline
\end{tabular}

*Observados por DRX y SEM-EDS

La distribución de especies en la superficie del soporte es compleja y dependiente de factores estructurales y químicos, los que afectan la fuerza de la interacción soporte-monocapa [23]. En relación a los factores estructurales se puede observar que la diferencia de temperatura entre los picos para la primera etapa de reducción de la fase no soportada y los de la fase soportada alcanza los $100^{\circ} \mathrm{C}$ (siendo la simetría planar de estas especies $\mathrm{D}_{3 \mathrm{~d}}$ ), mientras que la diferencia entre los picos correspondientes al HMA soportado y no soportado alcanza los $240^{\circ} \mathrm{C}$ (siendo esta especie no planar de simetría $\mathrm{C}_{2 \mathrm{v}}$ ). En una primera aproximación, esta diferencia puede ser atribuida a la carga y al radio iónico del heteroátomo si bien deben tenerse en cuenta sus propiedades ácidas y capacidad redox. Tales características tienen influencia en la interacción entre el heteroátomo y el soporte en adición a las interacciones que ocurren con los grupos $\mathrm{OH}$ en la superficie de la $\gamma-\mathrm{Al}_{2} \mathrm{O}_{3}$ las que han sido objeto de varios estudios [24]. Estas últimas interacciones que se manifiestan de acuerdo a la propiedad ácido-base de la superficie del soporte (de naturaleza Brønsted), también juegan un rol importante en la interacción adsortiva del heteroátomo.

Finalmente, la tabla mostrada permite analizar la similitud entre la temperatura de la primera señal TPR para el HMA y la correspondiente a la fase $\mathrm{AlMo}_{6}$ soportados, mostrando la evidencia concreta de la disolución del soporte $\gamma-\mathrm{Al}_{2} \mathrm{O}_{3}$ como consecuencia del contacto de la superficie con una solución conteniendo molibdatos octaédricos condensados, de manera que, en la superficie del sistema $\mathrm{HMA} / \gamma-\mathrm{Al}_{2} \mathrm{O}_{3}$ es posible la formación de entidades $\mathrm{AlMo}_{6}$. 


\section{2.f. Caracterización Espectroscopia Fotoelectrónica por rayos X (XPS)}

El análisis de XPS nos proporciona información sobre el estado químico y el grado de dispersión de las especies de la superficie en la fase pura y para los catalizadores soportados (Tabla 6-VI).

Los datos de la fase pura $\mathrm{RhMo}_{6}$ revelaron una señal $\mathrm{Rh} 3 \mathrm{~d}_{5 / 2}$ a $310,8 \mathrm{eV}$ y una señal de $\mathrm{Mo}_{5} \mathrm{~d}_{5} / 2$ a 233,0 eV, correspondiente a Rh (III) y Mo (VI), respectivamente. Debido a la superposición de la señal de nitrógeno, N1s con el componente Mo3 $\mathrm{p}_{3 / 2}$, no se pudo determinar el estado y la cantidad de $\mathrm{N}$.

Aplicando la relación: $\mathrm{n}_{1} / \mathrm{n}_{2}=\left(\mathrm{I}_{1} / \mathrm{S}_{1}\right) /\left(\mathrm{I}_{2} / \mathrm{S}_{2}\right)$, se calculó, la composición atómica de la superficie $\mathrm{nRh} / \mathrm{nMo}=0,17$, derivado de la relación de intensidad $\mathrm{Rh} / \mathrm{Mo}$, está en excelente acuerdo con la composición del bulk, $\mathrm{nRh} / \mathrm{nMo}=0,167$.

Tabla 6-VI. Energías de enlaces (eV) y composición de la fase $\mathrm{RhMo}_{6}$ pura y soportada

\begin{tabular}{|c|c|c|c|c|}
\hline \multirow{2}{*}{ Catalizador } & \multirow{2}{*}{$\mathbf{R h} 3 \mathbf{d}_{5 / 2} / \mathbf{e V}$} & \multirow{2}{*}{$\operatorname{Mo3d}_{5 / 2} / \mathbf{e V}$} & \multicolumn{2}{|c|}{ Composición* } \\
\hline & & & $(\mathrm{nRh} / \mathrm{nMo})^{\mathrm{S}}$ & $(\mathrm{nRh} / \mathrm{nMo})^{\mathrm{A}}$ \\
\hline $\mathrm{RhMo}_{6}$ & 310.8 & 233.0 & 0.17 & 0.167 \\
\hline $\mathrm{RhMo}_{6} / \mathrm{EI}$ & 309.4 & 232.7 & 0.23 & 0.223 \\
\hline $\mathrm{RhMo} / \mathrm{A}$ & 309.3 & 232.6 & 1.22 & 0.229 \\
\hline
\end{tabular}

* ${ }^{\mathrm{S}}$, XPS valores derivados; ${ }^{\mathrm{A}}$, datos analíticos por AAS.

\subsection{Catalizadores a base de fase de Anderson de $\mathrm{Rh}$ soportados sobre bentonita modificada químicamente: PILC, PCH, PILC-F y PCH-F}

Tal como se detalla en el capítulo 2, item 2.3.c.1.2, se prepararon catalizadores con soportes a base de bentonita modificada químicamente y luego funcionalizada según la siguiente denominación: PILC (Bentonita pilareada); PCH (Bentonita heteroestructurada); PILC-F y PCH-F sistemas funcionalizados, cuya caracterización ha sido analizada en la sección experimental, ítem 5.3.b. 
El estudio preliminar para la preparación de catalizadores a base de PILC-F y PCH-F, se llevó a cabo mediante la adsorción de Mo de estos sistemas utilizando soluciones de $\mathrm{HMA}\left(\left[\mathrm{Mo}_{7} \mathrm{O}_{24}\right]^{6-}\right)$ y $\mathrm{AlMo}_{6}\left(\left[\mathrm{AlMo}_{6} \mathrm{O}_{24} \mathrm{H}_{6}\right]^{3}\right)$ y realizando la cuantificación del Mo por AAS en las soluciones antes y después del proceso de impregnación en equilibrio, utilizando el balance de masas de la misma manera que para el resto de los catalizadores. En la Tabla 6-VII se muestran los resultados obtenidos. Se observa un incremento del $10 \%$ de Mo adsorbido en aquellos sistemas funcionalizados.

Tabla 6-VII: Concentración de Mo adsorbido evaluado por AAS (p/p \%)

\begin{tabular}{rc||cc}
\hline Catalizador & $\begin{array}{c}\text { Mo Adsorbido } \\
(\boldsymbol{\%})^{*}\end{array}$ & Catalizador & $\begin{array}{c}\text { Mo Adsorbido } \\
(\boldsymbol{\%})^{*}\end{array}$ \\
\hline PILC/ HMA & 1.6 & PILC/AlMo $_{6}$ & 1.8 \\
PILC-F/ HMA & 13.0 & PILC-F/AlMo $_{6}$ & 14.4 \\
\hline PCH/ HMA & 1.0 & PCH/AlMo & 1.1 \\
PCH-F/ HMA & 13.0 & PCH-F/AlMo $_{6}$ & 13.6 \\
\hline
\end{tabular}

*\% (mg metal/100 g soporte).

En base a los resultados antes expuestos, se prepararon catalizadores con $\mathrm{RhMo}_{6}$. Los mismos se denominan: $\mathrm{RhMo}_{6} / \mathrm{PILC}$ y $\mathrm{RhMo}_{6} / \mathrm{PILC}-\mathrm{F} ; \quad \mathrm{RhMo}_{6} / \mathrm{PCH}$ y $\mathrm{RhMo}_{6} / \mathrm{PCH}-\mathrm{F}$ respectivamente. Los análisis por AAS arrojaron valores cercanos al $1 \%$ de Mo en los sistemas a base de PILC y PCH sin funcionalizar. Sin embargo en los catalizadores soportados en material funcionalizado, estos porcentajes alcanzaron el $7 \%$ para $\mathrm{RhMo}_{6} / \mathrm{PCH}-\mathrm{F}$ y $2 \%$ para $\mathrm{RhMo}_{6} / \mathrm{PILC}-\mathrm{F}$. El valor de $7 \%$ es coincidente con el obtenido en trabajos previos al soportar la fase en $\gamma-\mathrm{Al}_{2} \mathrm{O}_{3}\left(\mathrm{~S}_{\mathrm{BET}}=\mathrm{de} 200-300 \mathrm{~m}^{2} / \mathrm{g}\right)$ [20]. En la Figura 6-11, se muestra el espectro registrado por la técnica ESEM-EDS para la muestra con mayor concentración de fase adsorbida. Se observa la presencia de $\mathrm{O}, \mathrm{Al}$, Si y Fe como elementos mayoritarios del soporte de alúmino-silicato original. En menor proporción se observan Mo y Rh correspondientes a la fase soportada. El análisis semicuantitativo EDS para la relación de masas $\mathrm{Rh} / \mathrm{Mo}$ resultó algo mayor al esperado 
para la fase original $(0,18 \%)$ debido a la falta de precisión del método para medir el Rh dado que sus líneas principales son coincidentes con las líneas del Mo, como se observa en el espectro. Los datos del análisis químico por AAS y semicuantitativo por EDS para $\mathrm{RhMo}_{6} / \mathrm{PILC}-\mathrm{F}$ y PCH-F se muestran en la Tabla 6-VIII.

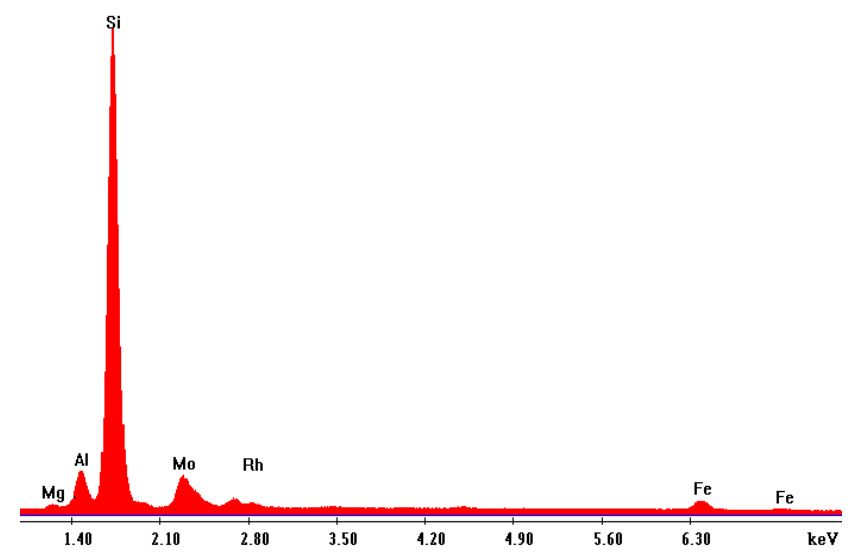

Figura 6-11: Espectro EDS del catalizador $\mathrm{RhMo}_{6} / \mathrm{PCH}-\mathrm{F}$.

Tabla 6-VIII: Datos del análisis químico por AAS de Mo y por EDS* de los elementos mayoritarios contenidos en los sistemas $\mathrm{RhMo}_{6} / \mathrm{PILC}-\mathrm{F} / \mathrm{PCH}-\mathrm{F}$

\begin{tabular}{|c|c|c|c|c|c|c|}
\hline Catalizador & $\begin{array}{l}\text { \% Mo } \\
\text { (AAS) }\end{array}$ & $\begin{array}{l}\text { \% Mo } \\
\text { (EDS) }\end{array}$ & $\begin{array}{l}\% \text { Rh } \\
\text { (EDS) }\end{array}$ & $\begin{array}{l}\% \mathrm{Si} \\
\text { (EDS) }\end{array}$ & $\begin{array}{l}\% \text { Al } \\
\text { (EDS) }\end{array}$ & $\begin{array}{l}\% \mathrm{Fe} \\
(\mathrm{EDS})\end{array}$ \\
\hline $\mathrm{RhMo}_{6} / \mathrm{PCH}-\mathrm{F}$ & 7 & 17.20 & 5.00 & 70.00 & 5.70 & 2.00 \\
\hline $\mathrm{RhMo}_{6} / \mathrm{PILC}-\mathrm{F}$ & 2 & 1.10 & 0.25 & 61.50 & 26.00 & 9.00 \\
\hline
\end{tabular}

*Datos calculados tomando como base un material compuesto solo por los elementos mayoritarios sin cuantificar el oxígeno, cuyo valor en ambas muestras fue del $40 \%$.

Los valores encontrados para los elementos $\mathrm{Si}$ y Al están de acuerdo con las cantidades esperadas para los materiales finales considerando el agregado adicional 
tanto de Al como de Si durante las respectivas modificaciones químicas sufridas por la arcilla original.

\section{3.a. Caracterización de la fase soportada por Espectroscopía de Reflectancia}

\section{Difusa, DRS}

En la Figura 6-12 se muestran los espectros DRS comparativos de los sistemas HMA/PILC y $\mathrm{RhMo}_{6} / \mathrm{PILC}$, ambos espectros presentan una banda intensa centrada a $247 \mathrm{~nm}$, la que puede ser asignada a la transferencia de carga $\mathrm{Mo}(\mathrm{VI}) \leftarrow \mathrm{O}$ para el Mo en coordinación octaédrica. Es bien conocido que los catalizadores a base de Mo soportado en alúmina obtenidos por impregnación con soluciones de HMA, pueden presentar especies de Mo(VI) octaédrico y/o tetraédrico dependiendo de las condiciones de preparación, como la concentración de Mo de la solución de partida, el pH, el tiempo de contacto, la temperatura de secado y/o calcinación. Ambas especies presentan sólo pequeñas diferencias en la forma de la curva de absorción [25]. En este caso se observa que la banda correspondiente a la fase $\mathrm{RhMo}_{6} / \mathrm{PILC}$ presenta mejor definición que aquella perteneciente al sistema interaccionando con el isopolianión HMA, la cual resulta más ancha.

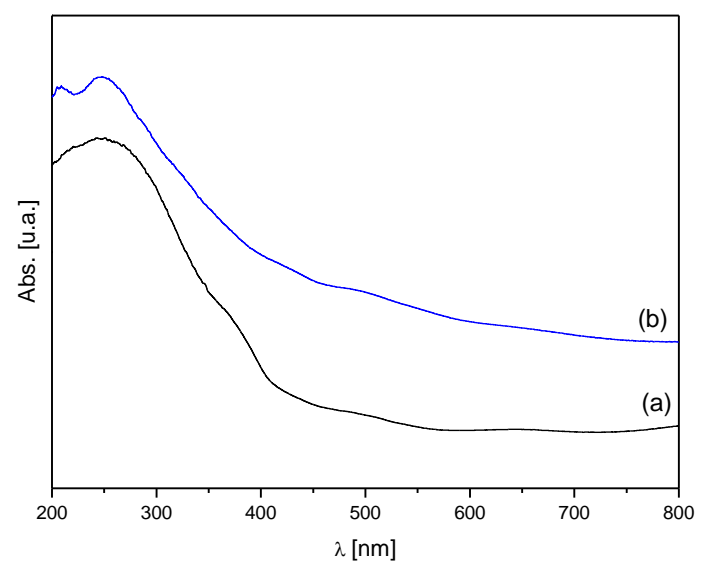

Figura 6-12: Espectros DRS comparativos de los sistemas: a) HMA y (b) $\mathrm{RhMo}_{6}$ soportados sobre PILC (Rango entre 200 y $800 \mathrm{~nm}$ ). 


\section{3.b. Análisis de acidez superficial de soportes y catalizadores por TPSR}

La reacción de descomposición catalítica de isopropanol es extremadamente sensible a la distribución y fuerza de los sitios ácidos y básicos presentes en los sistemas catalíticos, lo que la hace adecuada como reacción de caracterización. Cuando se produce la descomposición de isopropanol en contacto con la superficie de un sólido, puede ocurrir una reacción de deshidrogenación, obteniéndose acetona e hidrógeno como productos o reacciones de deshidratación que originan propileno y agua o diisopropil éter y agua.

Como lo han demostrado Ai y colab. [26], la deshidratación de isopropanol es catalizada por sitios ácidos mientras que la deshidrogenación, en ausencia de metales, es catalizada por sitios ácidos y básicos a través de un mecanismo determinado.

En el análisis TPSR del soporte PILC-F no se observó la desorción de moléculas indicando la falta de sitios activos. En el catalizador $\mathrm{RhMo}_{6} / \mathrm{PILC}-\mathrm{F}$ hubo desorción solamente de propileno Figura 6-13(a), indicando que el agregado de la fase al soporte añade sitios ácidos de Lewis a la superficie y no hay presentes sitios del tipo base fuerte-ácido Lewis débil (mecanismo $\mathrm{E}_{1 \mathrm{CB}}$, ver en la sección experimental, ítem 2.11.a.).
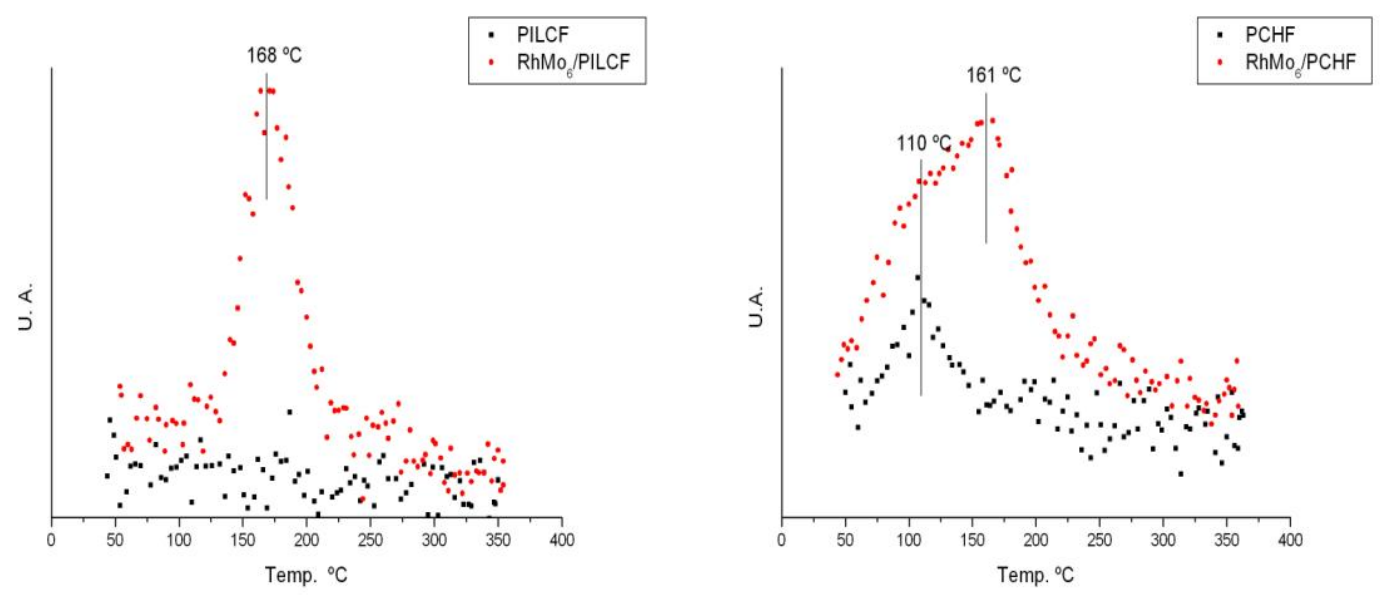

Figuras 6-13 (a y b): (a) Desorción de propileno en función de la temperatura (TPSR), para el soporte PILC-F y catalizador RhMo 6 /PILC-F; (b) Ídem para el soporte $\mathrm{PCH}-\mathrm{F}$ y catalizador $\mathrm{RhMo}_{6} / \mathrm{PCH}-\mathrm{F}$. 
Respecto al soporte PCH-F, por TPSR se detectaron sitios ácidos propios del soporte de manera que al agregarse el heteropolianión, este adicionó nuevos sitios, ligeramente más fuertes y de tipo Lewis, por lo que el propileno, se desorbió a mayor temperatura. Figura 6-13 (b). La presencia de $\mathrm{RhMo}_{6}$ sobre ambos soportes, produjo la desorción de propileno a temperaturas muy similares, indicando sitios de acidez comparables.

También se observó sobre el catalizador a base de PCH-F, la desorción de $\mathrm{CO}_{2}$ a $100^{\circ} \mathrm{C}$ (Figura 6-14) implicando la presencia de sitios básicos débiles no observados en el soporte original. No se observó la desorción de acetona, indicando la no existencia de sitios básicos fuertes, ni de di-isopropil éter, que mostrarían sitios ácidos fuertes.

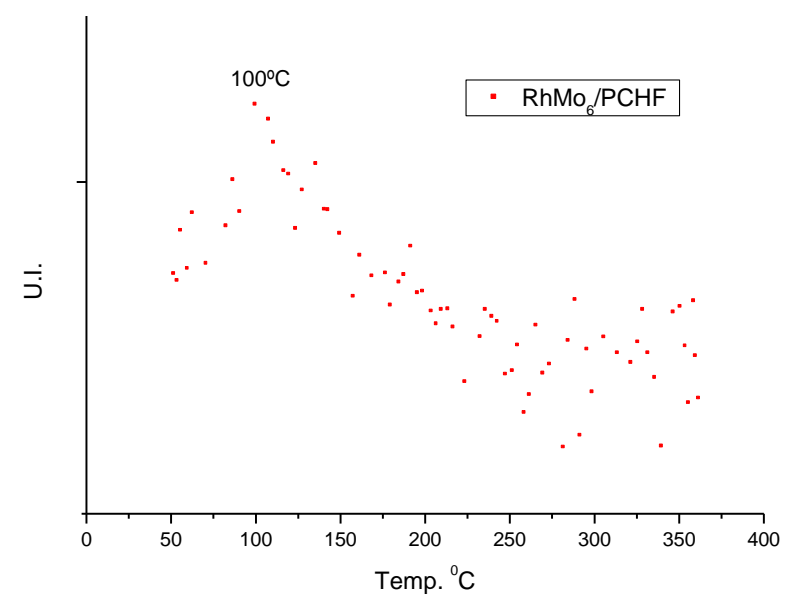

Figuras 6-14: Desorción de $\mathrm{CO}_{2}$ del catalizador $\mathrm{RhMo}_{6} / \mathrm{PCH}-\mathrm{F}$

\section{3.c. Análisis por TPR de los soportes y catalizadores soportados.}

El comportamiento en atmósfera reductora de esta fase así como otras fases isomorfas conteniendo otros heteroátomos ( $\mathrm{Co}, \mathrm{Ni}, \mathrm{Cu}, \mathrm{Cr}$, etc.) ha sido ampliamente estudiado en trabajos anteriores en nuestro laboratorio. Estos resultados han sido expuestos en la tabla 6.V a efectos comparativos [12]. En la Figura 6-15 se muestran comparativamente los diagramas TPR correspondientes a la fase $\mathrm{RhMo}_{6}$ original y soportada en los materiales modificados. El perfil de la fase pura exhibe un pico intenso 
cercano a $280^{\circ} \mathrm{C}$, y dos señales de menor intensidad alrededor de 370 y $707{ }^{\circ} \mathrm{C}$. El primer pico se atribuye a la reducción de $\mathrm{Rh}(\mathrm{III}) \mathrm{a} \mathrm{Rh}^{\circ}$, mientras que los picos menos intensos se asignan a las etapas de reducción del Mo (Mo(VI) a Mo(IV) a Mo ${ }^{0}$ ) [27]. En comparación con fases conteniendo otros heteroátomos, se observó que la presencia de $\mathrm{Rh}$ metálico induce la reducción completa del Mo a bajas temperaturas ( $\left.250^{\circ} \mathrm{C}\right)$. La alta reducibilidad de $\mathrm{RhMo}_{6}$ puede asociarse al carácter oxidante del metal noble como ya se discutió en parágrafos anteriores para los sistemas a base de sílice y alúmina. Asimismo, en el sistema soportado en PCH-F, se observa una fuerte señal alrededor de $235^{\circ} \mathrm{C}$ correspondiente al $\mathrm{Rh}$, mientras que las señales a $350^{\circ} \mathrm{C}$ y a $620^{\circ} \mathrm{C}$ corresponden al Mo. Una señal de baja intensidad a $540^{\circ} \mathrm{C}$ puede ser asignada a la reducción del Fe perteneciente a la arcilla original. Los valores encontrados ligeramente menores en este caso se deben al efecto de la interacción con el soporte [12]. En el caso de $\mathrm{RhMo}_{6} / \mathrm{PILC}-\mathrm{F}$, debido a la baja concentración de la fase soportada, se observa sólo una señal débil cercana a $300{ }^{\circ} \mathrm{C}$ asignable al $\mathrm{Rh}$ y otra débil señal entre 600 y $700^{\circ} \mathrm{C}$ que correspondería al Mo. Dicho comportamiento muestra que la fase $\mathrm{RhMo}_{6}$ presenta diferente grado de adsorción dependiendo del soporte y sugiere que en el soporte PCHF la interacción parece menor debido a la mayor reducibilidad de la fase, si bien existe mayor concentración adsorbida mientras que en el caso de PILC, se da el efecto inverso.

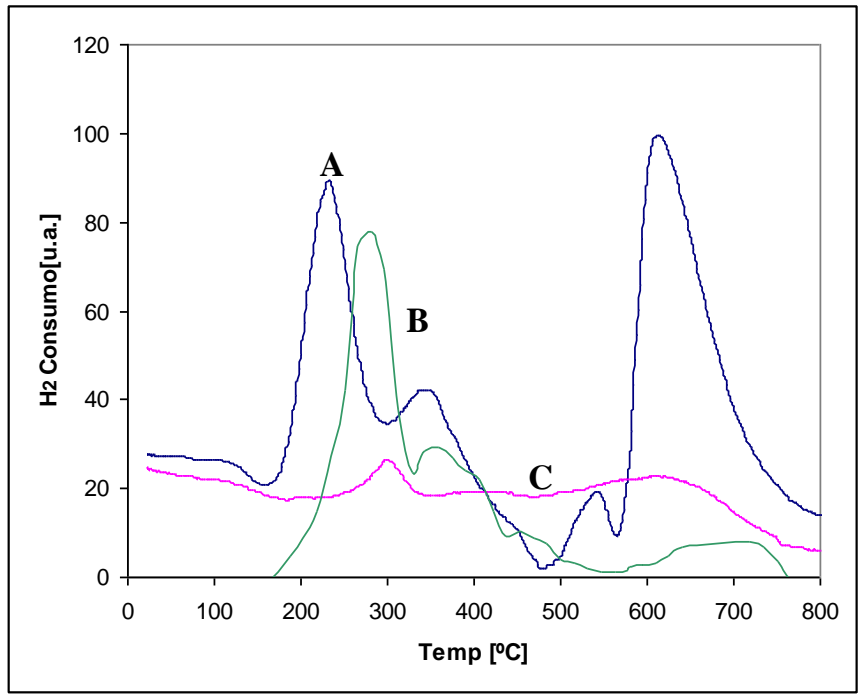
A) $\mathrm{RhMo}_{6} / \mathrm{PCH}-\mathrm{F}$
B) $\mathrm{RhMo}_{6}$ fase pura
C) $\mathrm{RhMo}_{6} / \mathrm{PILC}-\mathrm{F}$ 
Figura 6-15: Diagramas de TPR correspondientes a la fase $\mathrm{RhMo}_{6}$ original y soportada en los materiales modificados PILC-F y PCH-F.

\section{3.d. Análisis termogravimétrico (TGA)}

La Figura 6-16 muestra las curvas TG de dos catalizadores. Se observa en ambos casos una pérdida de masa continua en el intervalo $25-500^{\circ} \mathrm{C}$. En este intervalo, la muestra que presenta mayor pérdida de masa es $\mathrm{RhMo}_{6} / \mathrm{PCH}-\mathrm{F}$. A $100^{\circ}$, la deshidratación es mayor en este último sistema corroborando así las características ácidas antes observadas y la mayor cantidad de fase adsorbida.

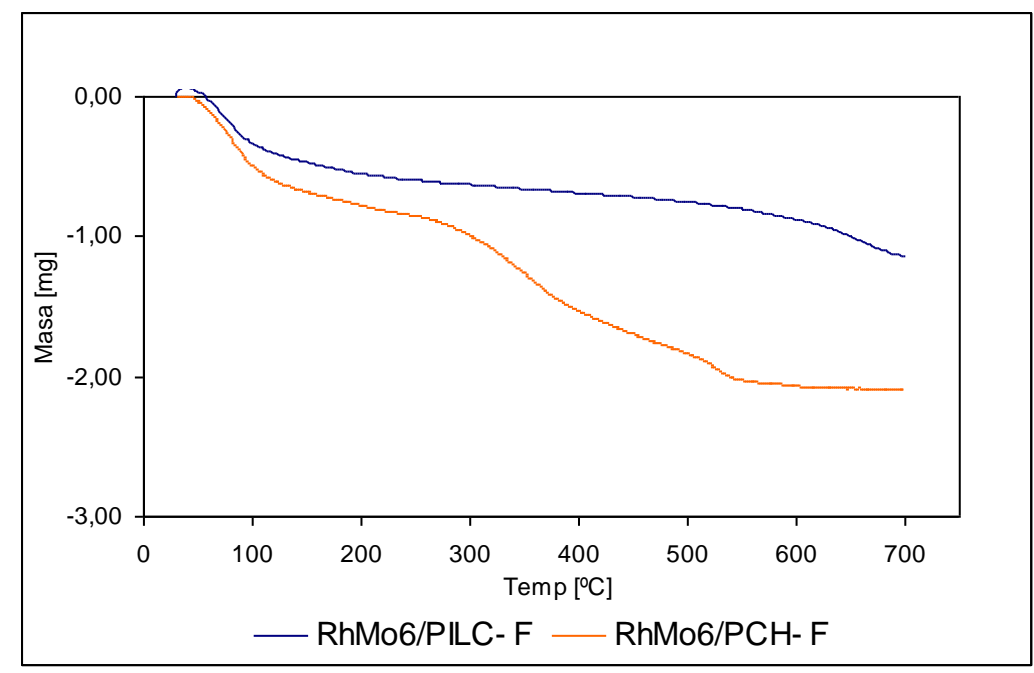

Figura 6-16: Diagramas de TGA correspondientes a los catalizadores $\mathrm{RhMo}_{6} / \mathrm{PILC}-\mathrm{F}$ y $\mathrm{RhMo}_{6} / \mathrm{PCH}-\mathrm{F}$

\section{3.e. Caracterización estructural y espectroscópica comparativa de} catalizadores a base de $\mathrm{CoMo}_{6}, \mathrm{RhMo}_{6}$ y $\mathrm{Co}_{2} \mathrm{Mo}_{10}$ soportados en bentonita modificada químicamente.

Considerando la combinación de propiedades ácidas y redox mostradas por los catalizadores estudiados, resultó interesante explorar su actividad en una reacción test de oxidación selectiva de sulfuros aromáticos, realizada a baja temperatura y en presencia de peróxido de hidrógeno. Para ello se prepararon catalizadores a base de Co 
y Mo usando la fase de $\mathrm{CoMo}_{6}$ y otra fase derivada estructuralmente de fórmula: $\left(\mathrm{NH}_{4}\right)_{6}\left[\mathrm{Co}_{2} \mathrm{Mo}_{10} \mathrm{H}_{4} \mathrm{O}\right] \cdot \mathrm{H}_{2} \mathrm{O}$, denominada $\mathrm{Co}_{2} \mathrm{Mo}_{10}$. En este caso se partió de soluciones con concentraciones de $10 \mathrm{mg}$ de $\mathrm{Mo} / \mathrm{ml}$, con las que se realizó una impregnación en equilibrio del soporte PCH-F. En la tabla 6-IX se presentan los valores de concentración de $\mathrm{Co}$, Rh y Mo adsorbidos para los tres sistemas elegidos para su comparación, medidos por AAS y EDS.

Tabla 6-IX: Composición de elementos mayoritarios \% en masas a partir del análisis químico por EDS y concentración de Mo adsorbido por AAS, para las PCH-F soportadas con $\mathrm{CoMo}_{6}, \mathrm{Co}_{2} \mathrm{Mo}_{10}$ y $\mathrm{RhMo}_{6}$.

\begin{tabular}{cccc}
\hline Elemento & $\begin{array}{c}\text { \% masa } \\
\mathbf{R h M o}_{\mathbf{6}} / \mathbf{P C H}-\mathbf{F}\end{array}$ & $\begin{array}{c}\text { \% masa } \\
\mathbf{C o M o}_{\mathbf{6}} / \mathbf{P C H}-\mathbf{F}\end{array}$ & $\begin{array}{c}\text { \% masa } \\
\mathbf{C o}_{2} \mathbf{M o}_{\mathbf{1 0}} / \mathbf{P C H}-\mathbf{F}\end{array}$ \\
\hline $\mathbf{A l}$ & 5.69 & 9.59 & 6.75 \\
$\mathbf{S i}$ & 70.03 & 64.49 & 67.99 \\
$\mathbf{M o}$ & 17.26 & 19.92 & 20.9 \\
$\mathbf{X}^{\mathbf{1}}$ & 5.01 & 2.59 & 1.86 \\
$\mathbf{F e}$ & 2.01 & 3.42 & 2.5 \\
\hline $\mathbf{X} / \mathbf{M o}{ }^{\mathbf{1}}$ & 0.29 & 0.13 & 0.09 \\
$\mathbf{X} / \mathbf{M o ~ T e o ́ r i c a ~}$ & 0.18 & 0.10 & 0.12 \\
\hline $\mathbf{C}_{\mathbf{A d}} \mathbf{M o ~ \% ~}^{2}$ & 14.70 & 8.00 & 10.50 \\
\hline
\end{tabular}

${ }^{1} \mathrm{X}=\mathrm{Rh}, \mathrm{Co} ;{ }^{2} \mathrm{C}_{\mathrm{Ad}}$ Mo expresado en mg Mo/100 mg PCH-F

En la figura 6-17 se presentan comparativamente los diagramas DRX de los sistemas $\mathrm{PCH}, \mathrm{PCH}-\mathrm{F}$, la fase pura $\mathrm{CoMo}_{6}$ y a modo demostrativo solo se presenta el sistema soportado con la fase $\mathrm{CoMo}_{6}$. Es posible observar que el diagrama DRX del catalizador resultó menos amorfo respecto que los soportes ( $\mathrm{PCH}$ y $\mathrm{PCH}-\mathrm{F})$ y presenta líneas de intensidad media que se podrían corresponder a las del heteropolianión aunque con un ligero desplazamiento debido a la interacción con el soporte. 
Por espectroscopía vibracional Raman Microprobe, figura 6-18, es posible observar para los sistemas soportados líneas características de los heteropolimolibdatos tipo Anderson. En el caso del sistema $\mathrm{CoMo}_{6}$ soportado sobre $\mathrm{PCH}$, figura 6-17, el espectro, presenta dos líneas características alrededor de 947 y 968 cm$^{-1}$ correspondientes a los estiramientos Mo-Ot antisimétrico y simétrico respectivamente. Las mismas se observan con baja intensidad y ligeramente desplazadas con respecto a la fase Anderson pura debido a la interacción con el soporte, la que genera un cambio en las energías de enlace del heteropolioxomolibdato. Asimismo el tipo de aluminosilicato presente en el soporte PCH produce efectos de fluorescencia en espectroscopía Raman, mostrando una línea de base distorsionada que no permite visualizar claramente las bandas del polianión [28].

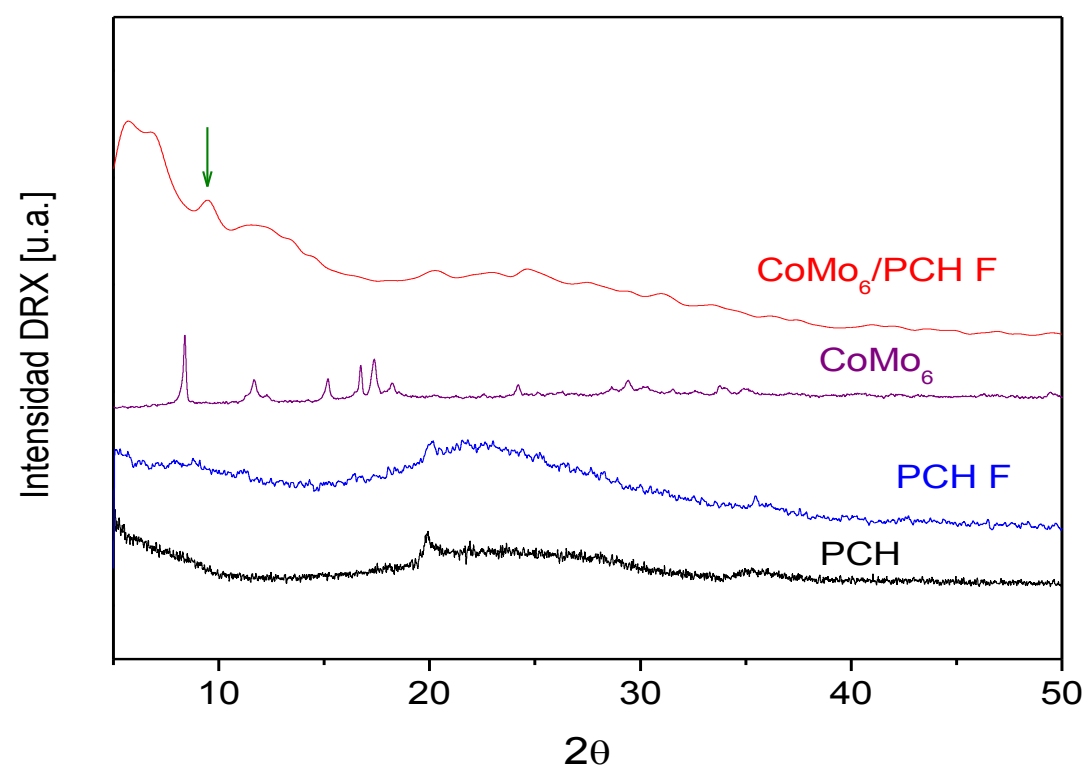

Figura 6-17: DRX comparativo de $\mathrm{PCH}$ pura, funcionalizada (PCH-F), funcionalizada soportada con las fases $\mathrm{CoMo}_{6} \mathrm{y} \mathrm{CoMo}_{6}$ puro. 


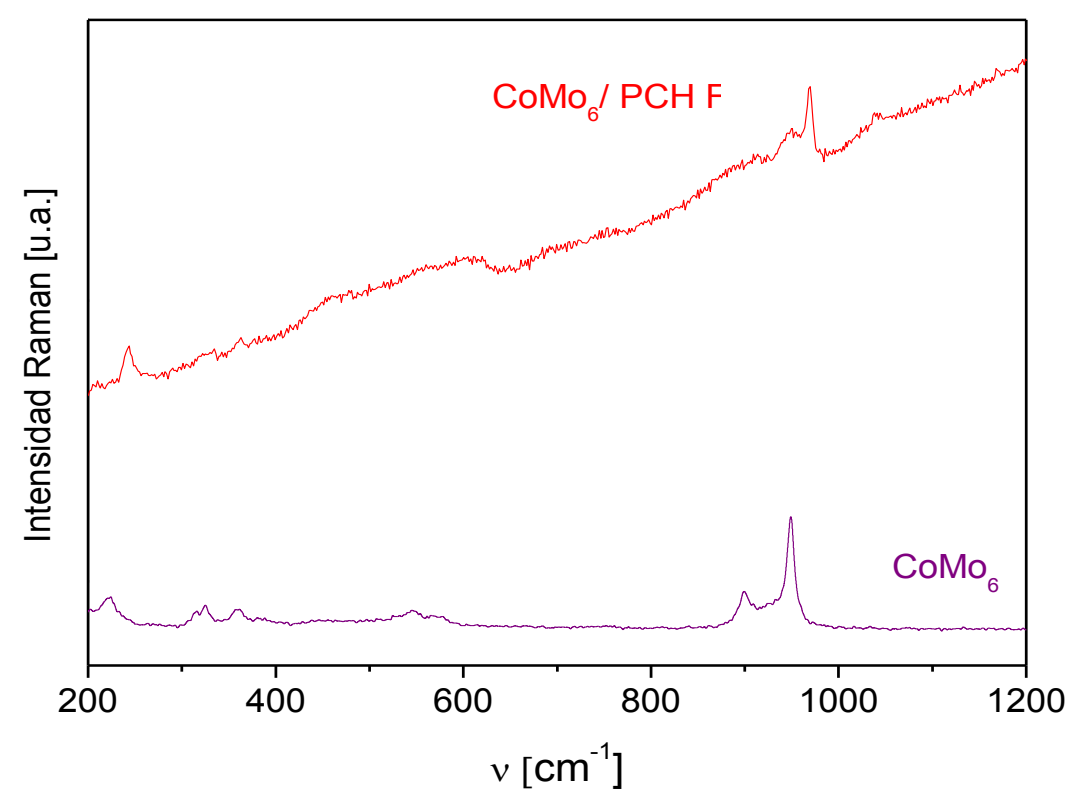

Figura 6-18: Espectros Raman comparativos entre 200 y $1500 \mathrm{~cm}^{-1}$ para la fase $\mathrm{CoMo}_{6}$ pura y para el sistema soportado $\mathrm{CoMo}_{6} / \mathrm{PCH}-\mathrm{F}$.

\section{3.f. Conclusiones parciales}

La preparación de catalizadores a base de fase $\mathrm{RhMo}_{6}$ soportada en dos muestras de sílice de diferente textura y manufactura, dio lugar a sistemas de concentración de Rh y Mo por debajo de los valores esperados, de acuerdo al método de análisis químico por absorción atómica empleado. Sin embargo los análisis realizados por técnicas de superficie como XPS y el método semicuantitativo SEM-EDS, muestran mayores concentraciones de Rh y Mo, sugiriendo que la adsorción de la fase en este soporte es heterogénea, no existiendo buena dispersión, posiblemente debido a que el punto isoeléctrico del soporte no permite una interacción efectiva al valor de $\mathrm{pH}$ de estabilidad del HPOM, el que podría descomponerse en contacto con la superficie.

En lo que respecta a los catalizadores preparados por el método de impregnación en equilibrio de heteropolimolibdatos del tipo Anderson sobre $\gamma-\mathrm{Al}_{2} \mathrm{O}_{3}$ la estructura planar de la especie $\mathrm{XMo}_{6}$, con $\mathrm{X}=\mathrm{Co}(\mathrm{III}), \mathrm{Al}(\mathrm{III}), \mathrm{Rh}(\mathrm{III})$ interacciona con el soporte, preservando su estructura y formando una monocapa conteniendo entre 6 y $8 \%$ de Mo adsorbido. Se pudo establecer la siguiente secuencia para la fuerza de la interacción de acuerdo a la constante de adsorción $\left(\mathrm{K}_{\mathrm{ad}}\right)$ encontrada: 


\section{$\mathrm{RhMo}_{6}>\mathrm{CoMo}_{6}>\mathrm{AlMo}_{6}$}

Para la serie estudiada, este parámetro resultó mayor que para el HMA.

La similitud de la geometría de coordinación octaédrica del heteroátomo de la fase $[\mathrm{Rh}(\mathrm{III})$ o $\mathrm{Co}(\mathrm{III})]$ y la del $\mathrm{Al}(\mathrm{III})$ de la alúmina, permite sugerir que la efectiva interacción de estas fases con dicho soporte, se debe a una mayor afinidad o posibilidad de intercambio del heteroátomo con el $\mathrm{Al}(\mathrm{III})$, mientras que, en el caso de la sílice, el silicio posee un entorno tetraédrico, que no favorece este tipo de intercambio lo que influye negativamente en el proceso de adsorción.

Los estudios por microanálisis Raman y TPR permiten corroborar lo antes expuesto y postular la disolución de la $\gamma-\mathrm{Al}_{2} \mathrm{O}_{3}$ como consecuencia del contacto de este soporte con una solución conteniendo molibdatos octaédricos condensados, de manera que, en la superficie de los catalizadores HMA o $\mathrm{XMo}_{6} / \gamma-\mathrm{Al}_{2} \mathrm{O}_{3}$, es posible la formación de entidades $\mathrm{AlMo}_{6}$.

El estudio por TPR se reveló, para todos los catalizadores, como un interesante método para estudiar el tipo de interacción heteropolianión $\mathrm{RhMo}_{6}$-soporte y la influencia que ejerce el heteroátomo Rh en la reducibilidad del Mo.

En lo que respecta al empleo de especies minerales puras o modificadas, se prepararon catalizadores a base de $\mathrm{RhMo}_{6}$ soportado en PILC-F y PCH-F. A efectos comparativos, se prepararon catalizadores a base de $\mathrm{CoMo}_{6}$ y $\mathrm{Co}_{2} \mathrm{Mo}_{10}$ soportados en PCH-F, utilizando el método de impregnación en equilibrio, los que se caracterizaron por DRX y Raman Microprobe.

Se observó que para las bentonitas puras, para PILC y PCHs la adsorción de Mo solo alcanza valores entre 1 y $4 \%$.

En PILCs y PCHs funcionalizadas, se observó un incremento del $10 \%$ en el contenido de Mo adsorbido respecto a los sistemas no funcionalizados. Esto es atribuido a la interacción preferencial de los polioxoaniones sobre la superficie funcionalizada (presencia de grupos amino) sugiriendo un mecanismo ácido-base de transferencia de electrones. 
El método de análisis de sitios ácido-base por TPSR, permitió corroborar la presencia de sitios ácidos de diferente fuerza en los materiales a base de arcilla modificada, mostrando sitios de tipo Brønsted en los soportes (PCH-F) y de tipo Lewis en los sistemas soportados $\mathrm{RhMo}_{6} / \mathrm{PCH}-\mathrm{F}$ debidos a la fase bimetálica. 


\section{PARTE IV:}

\section{EVALUACIÓN CATALÍTICA}


Capítulo 7:

HIDROGENACIÓN SELECTIVA DE CINAMALDEHIDO Y OXIDACIÓN SELECTIVA DE DIFENILSULFURO 
En este capítulo se presentan y discuten los resultados obtenidos en los ensayos catalíticos de la hidrogenación selectiva de cinamaldehído (CAL) empleando como catalizadores los siguientes sistemas:

A base de sílice: $\mathrm{RhMo}_{6} / \mathrm{D}$ y $\mathrm{RhMo}_{6} / \mathrm{K}$.

A base de alúmina: $\mathrm{RhMo}_{6} / \mathrm{EI}, \mathrm{RhMo}_{6} / \mathrm{EII}, \mathrm{RhMo}_{6} / \mathrm{A}, \mathrm{RhMo} / \mathrm{EI} \mathrm{RhMo} / \mathrm{EII}$ y RhMo/A.

$>$ A base de bentonita modificada: $\mathrm{RhMo}_{6} / \mathrm{PCH}, \mathrm{RhMo}_{6} / \mathrm{PCH}-\mathrm{F}, \mathrm{RhMo}_{6} / \mathrm{PILC}$ y $\mathrm{RhMo}_{6} / \mathrm{PILC}-\mathrm{F}$.

\subsection{Hidrogenación selectiva de cinamaldehído. Introducción}

En el Capítulo I se mencionó la importancia que reviste la hidrogenación de aldehídos insaturados a sus respectivos alcoholes, para la obtención de productos e intermediarios en química fina. Por ejemplo, en el caso del aldehído cinámico que se estudia en este capítulo, su hidrogenación es de interés como intermediario en la síntesis de fármacos para el tratamiento del HIV [1-3].

Además es una reacción "test" para la evaluación de propiedades quimioselectivas de los catalizadores analizados, tal como surge del esquema de reacción que se presenta a continuación.

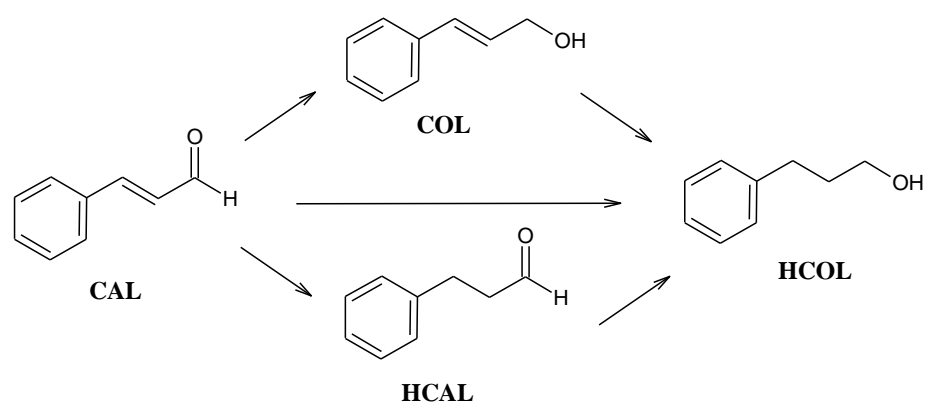

Figura 7-1: Esquema de reacción para la hidrogenación de cinamaldehido. Donde CAL es: Cinamaldehído; HCAL: hidrocinamaldehído; COL: Alcohol cinámico; HCOL: Alcohol hidrocinámico. 
De la observación de la Figura 7-1 resulta claro que la hidrogenación puede llevarse a cabo en la doble ligadura $\mathrm{C}=\mathrm{C}$ y en el grupo carbonilo $\mathrm{C}=\mathrm{O}$, además el anillo bencénico es susceptible de ser hidrogenado, así como también pueden ocurrir reacciones de hidrogenólisis dando productos de craqueo y reacciones de isomerización del alcohol insaturado para dar aldehído saturado.

\subsection{Evaluación Catalítica}

Se realizaron ensayos preliminares con el fin de determinar la existencia de reacciones entre los productos de hidrogenación con el solvente utilizado. El aldehído cinámico es soluble en tolueno y dado que este solvente es un hidrocarburo que no posee grupos $\mathrm{OH}$ reactivos, no participa en ninguna reacción lateral. Para ninguno de los sistemas, en las condiciones estudiadas en este trabajo, se observaron productos de craqueo o de hidrogenación del grupo aromático.

El pretratamiento de los catalizadores y la reacción de hidrogenación en fase líquida se llevaron a cabo tal como se detalla en el capítulo experimental, item 2.13.a.

La conversión (\%) de CAL se calculó en base a la diferencia entre moles iniciales de CAL y moles de CAL no consumidos en un tiempo t/moles iniciales de CAL.

La selectividad (\%) se calculó en base a la relación de mol de producto deseado/moles totales de productos obtenidos.

\section{2.a. Actividad del sistema $\mathrm{Rh}(\mathrm{III})$-hexamolibdato/SiO $\mathrm{S}_{2}$ en la hidrogenación selectiva de cinamaldehido.}

Se exploró el comportamiento catalítico de los siguientes sistemas soportados en diferentes Sílices y condiciones descriptas en la sección experimental, item 2.3.a. y 2.13.a: 
$\boldsymbol{R h M \boldsymbol { o } _ { 6 }} / \boldsymbol{D}$ (en $\mathrm{SiO}_{2}$ preparada según Dalmon y Martín [4]).

$\boldsymbol{R} \boldsymbol{h} \boldsymbol{M} \boldsymbol{o}_{6} / \boldsymbol{K}\left(\right.$ en $\mathrm{SiO}_{2}$ comercial Kieselgel-Merck (K)).

En la Figura 7-2 tanto se presenta la actividad expresada como conversión en función del tiempo de reacción.

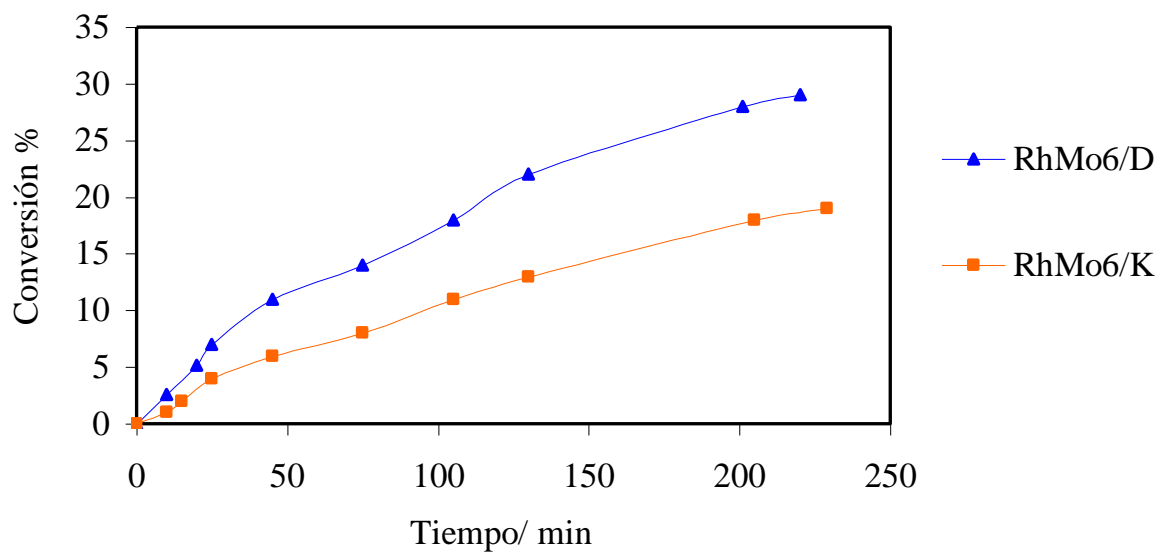

Figura 7-2: Conversión vs. Tiempo de reacción para los catalizadores $\mathrm{RhMo}_{6} / \mathrm{D}$ y $\mathrm{RhMo}_{6} / \mathrm{K}$ en la reacción de hidrogenación selectiva de CAL.

En la Figura 7-2, se presenta la conversión alcanzada para cada uno de los sistemas estudiados luego de 250 minutos de reacción. Si bien las actividades no alcanzaron el 30\%, como puede observarse, el sistema $\mathrm{RhMo}_{6} / \mathrm{D}$ resultó ser más activo que el sistema $\mathrm{RhMo}_{6} / \mathrm{K}$ cuyo soporte sin embargo presentó mejores propiedades texturales para la adsorción del heteropolianión.

Ambos sistemas mostraron a igual conversión la misma distribución de productos hacia HCAL y COL. En la tabla 7-I, se muestran los valores de conversión y selectividad. 
Tabla 7-I: Concentración de Mo y Rh adsorbidos (g/100g soporte), Conversión (\%) y Selectividad (\%) para los catalizadores $\mathrm{RhMo}_{6} /(\mathrm{D})$ y $\mathrm{RhMo}_{6} /(\mathrm{K})$.

\begin{tabular}{ccccccc}
\hline Catalizador & $\begin{array}{c}\mathbf{C a}^{\mathrm{Mo}} \\
(\boldsymbol{\%})\end{array}$ & \multirow{2}{*}{$\begin{array}{c}\mathbf{C a}^{\mathrm{Rh}} \\
(\boldsymbol{\%})\end{array}$} & $\begin{array}{c}\text { Conversión } \\
(\boldsymbol{\%})\end{array}$ & \multicolumn{3}{c}{ Selectividad (\%) } \\
\cline { 6 - 8 } & 0.57 & 0.14 & 30.0 & 92.7 & 0.0 & 7.3 \\
$\mathrm{RhMo}_{6} / \mathrm{D}$ & $0.5 \mathrm{H}$ & & & COL & HCOL \\
$\mathrm{RhMo}_{6} / \mathrm{K}$ & 0.51 & 0.10 & 15.0 & 91.0 & 0.0 & 9.0 \\
\hline
\end{tabular}

Los datos de adsorción obtenidos y por consiguiente la baja conversión lograda se pueden asociar a las características ácidas del soporte. Los grupos superficiales silanoles cargados, son los sitios de adsorción del ión activo en el intercambio y su concentración determina la cantidad de especies positivas o negativas que pueden ser adsorbidas sobre la superficie del sólido. En este caso y tal como se analizó en el capítulo 6, ítem 6.1.c. la impregnación de sílice con un HPOM como $\left[\mathrm{RhMo}_{6} \mathrm{H}_{6} \mathrm{O}_{24}\right]^{3-}$ no produce un intercambio efectivo, teniendo en cuenta la incompatibilidad entre el punto isoeléctrico de este soporte y el $\mathrm{pH}=5$ de la solución de impregnación en la que el heteropolianión es estable.

\section{2.b. Actividad del sitema $\mathrm{Rh}(\mathrm{III})$-hexamolibdato/ $\gamma-\mathrm{Al}_{2} \mathrm{O}_{3}$ en la} hidrogenación selectiva de cinamaldehído

Se exploró el comportamiento catalítico de los siguientes sistemas soportados en diferentes alúminas y condiciones descriptas en la sección experimental, item 2.3.b.y 2.13.a:

$\boldsymbol{R h} \boldsymbol{M} \boldsymbol{o}_{6} / \boldsymbol{A}\left(\mathrm{en} \gamma-\mathrm{Al}_{2} \mathrm{O}_{3}\right.$ preparada por calc. a $\left.500^{\circ} \mathrm{C}\right)$.

$\boldsymbol{R h M o}_{6} / \boldsymbol{E I}\left(\right.$ en $\gamma-\mathrm{Al}_{2} \mathrm{O}_{3}$ comercial esferalite (I)).

$\boldsymbol{R h M \boldsymbol { o } _ { 6 }} / \boldsymbol{E I I}\left(\right.$ en $\gamma-\mathrm{Al}_{2} \mathrm{O}_{3}$ comercial esferalite (II)).

Con fines comparativos se prepararon los siguientes catalizadores convencionales a base de heptamolibdato de amonio y cloruro de Rh(III) soportados por impregnación sucesiva en diferentes alúminas y en condiciones descriptas en la sección experimental, item 2.3.b.I. 
$\boldsymbol{R h M o} / \boldsymbol{A}\left(\right.$ en $\gamma-\mathrm{Al}_{2} \mathrm{O}_{3}$ preparada por calc. a $\left.500^{\circ} \mathrm{C}\right)$

$\boldsymbol{R} \boldsymbol{h M o} / \boldsymbol{E I}$ (en $\boldsymbol{\gamma}-\mathrm{Al}_{2} \mathrm{O}_{3}$ comercial esferalite (I)).

$\boldsymbol{R h M o / E I I ~ ( e n ~} \gamma-\mathrm{Al}_{2} \mathrm{O}_{3}$ comercial esferalite (II)).

En la Figura 7-3 se presenta la actividad expresada como conversión en función del tiempo de reacción.

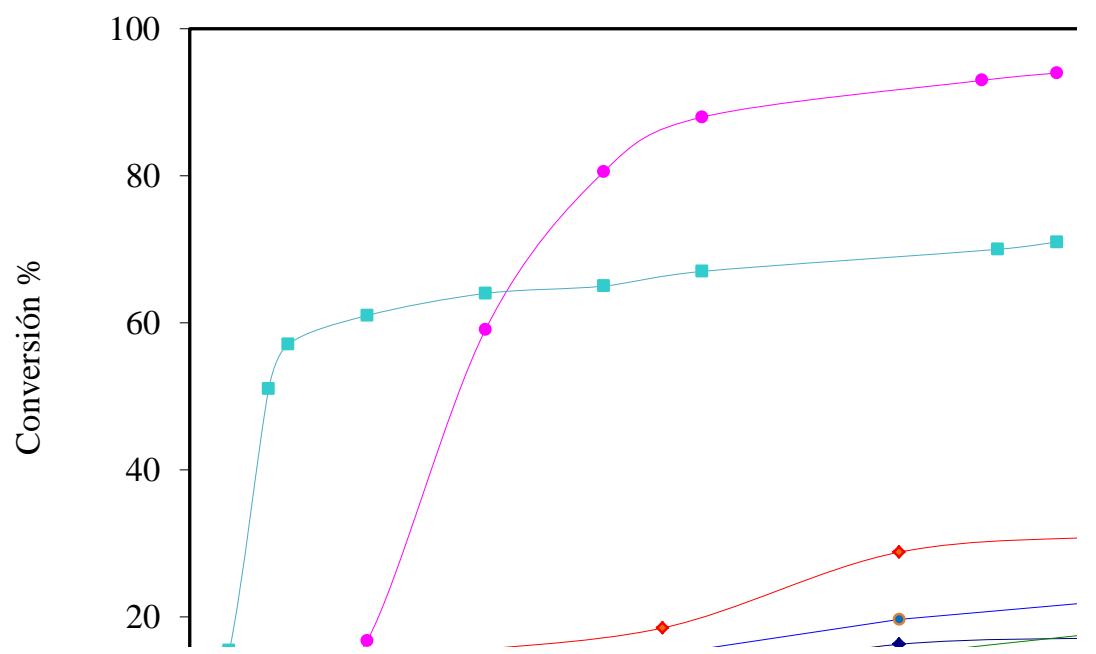

Figura 7-3: Conversión vs. Tiempo de reacción para los catalizadores $\mathrm{RhMo}_{6} / \mathrm{EII}$, $\mathrm{RhMo}_{6} / \mathrm{EI}, \mathrm{RhMo}_{6} / \mathrm{A}, \mathrm{RhMo} / \mathrm{EII}, \mathrm{RhMo} / \mathrm{EI}$ y $\mathrm{RhMo} / \mathrm{A}$, en la reacción de hidrogenación selectiva de CAL.

En primer lugar se observó que todos los catalizadores fueron selectivos a HCAL. La conversión de CAL a HCAL (60 \%) a 75 min de reacción, alcanzada con $\mathrm{RhMo}_{6} / \mathrm{EI}$ y $\mathrm{RhMo}_{6} / \mathrm{EII}$ fue mayor que para los sistemas soportados en (A) los que mostraron tendencia a la desactivación, Figura 7-3. Asimismo se observa en general que los catalizadores a base del precursor $\mathrm{RhMo}_{6}$ mostraron mayor actividad que aquellos convencionales RhMo, sin embargo entre estos, el soportado en (EI) fue el mas activo. Asimismo se observa que el sistema RhMo/A fue el único que mostró casi un $20 \%$ de selectividad a COL. 
Para realizar una evaluación comparativa del comportamiento catalítico del heteropolianión soportado frente a un sistema convencional, se seleccionaron los siguientes sistemas:

$\boldsymbol{R h M o}_{6} / \boldsymbol{E I}, \boldsymbol{R h M o} \boldsymbol{o}_{6} / \boldsymbol{E I I}, \boldsymbol{R h M o} \boldsymbol{o}_{6} / \boldsymbol{A}$ y $\boldsymbol{R h M o / A}$. Este último sistema se eligió como ejemplo de catalizador preparado de manera convencional utilizando alúmina pretratada en el laboratorio e impregnada con los reactivos en forma sucesiva de acuerdo a la literatura y que además presentó cierta selectividad a COL por lo que resultó interesante su estudio.

En la Figura 7-4, se muestra la selectividad a $55 \%$ conversión en la reacción de hidrogenación selectiva de CAL a HCAL para sistemas, $\mathrm{RhMo}_{6} /(\mathrm{EI}$, EII y A) y $\mathrm{RhMo/(A)} \mathrm{y} \mathrm{en} \mathrm{la} \mathrm{tabla} \mathrm{7-II} \mathrm{se} \mathrm{muestran} \mathrm{los} \mathrm{valores} \mathrm{de} \mathrm{composición} \mathrm{(Rh} \mathrm{y} \mathrm{Mo} \mathrm{\%}$ adsorbido), conversión (\%) y de selectividad (\%).

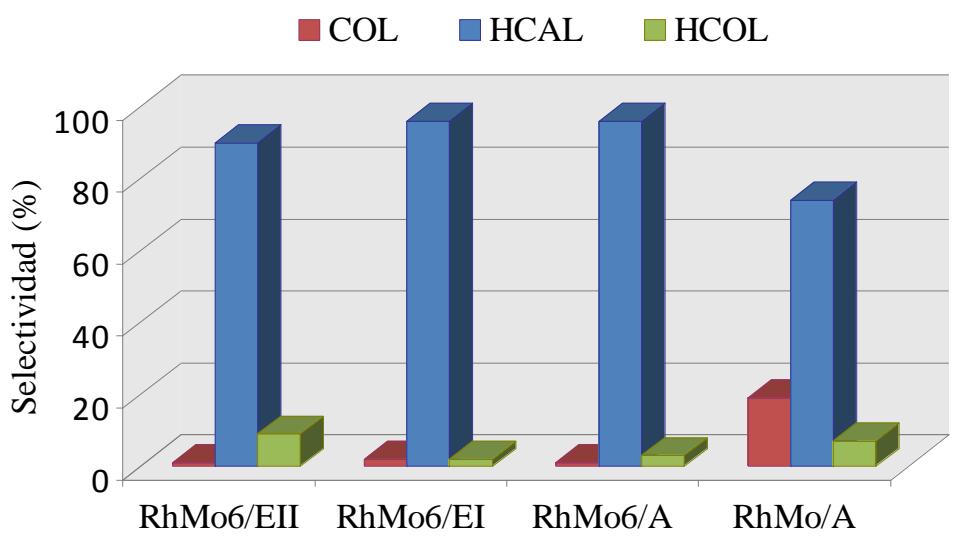

Figura 7-4: Selectividad a 55\% conversión en la reacción de hidrogenación selectiva de CAL a HCAL. 
Tabla 7-II: Datos de concentración adsorbida de Mo y Rh (por AAS), $[\mathrm{Ca}(\%)=\mathrm{gM} / 100$ g alumina], conversión (\%) y selectividad (\%) para sistemas $\mathrm{RhMo}_{6}$ y $\mathrm{RhMo} / \gamma-\mathrm{Al}_{2} \mathrm{O}_{3}$ en la reacción de hidrogenación selectiva de CAL a HCAL.

\begin{tabular}{|c|c|c|c|c|c|c|}
\hline \multirow{2}{*}{ Catalizador } & \multirow{2}{*}{$\begin{array}{l}\mathrm{Ca}^{\mathrm{Mo}} \\
(\%)\end{array}$} & \multirow{2}{*}{$\begin{array}{l}\mathrm{Ca}^{\mathrm{Rh}} \\
(\%) \\
\end{array}$} & \multirow{2}{*}{$\begin{array}{c}\text { Conversión } \\
(\%)^{\mathrm{a}}\end{array}$} & \multicolumn{3}{|c|}{ Selectividad $(\%)^{b}$} \\
\hline & & & & HCAL & COL & HCOL \\
\hline $\mathrm{RhMo}_{6} / \mathrm{EI}$ & 6.0 & 1.5 & 79.0 & 100.0 & 0.0 & 0.0 \\
\hline $\mathrm{RhMo}_{6} / \mathrm{EII}$ & 6.7 & 1.5 & 59.0 & 100.0 & 0.0 & 0.0 \\
\hline $\mathrm{RhMo}_{6} / \mathrm{A}$ & 5.7 & 1.4 & 16.0 & 94.0 & 0.0 & 6.0 \\
\hline $\mathrm{RhMo} / \mathrm{A}$ & 6.0 & 1.0 & 11.0 & 90.0 & 10.0 & 0.0 \\
\hline
\end{tabular}

En la Tabla 7-II se muestra la selectividad a 15\% de conversión de CAL (excepto para $\mathrm{RhMo} / \mathrm{A}$ medida a $10 \%$ de conversión). El producto principal de reacción para los cuatro catalizadores fue HCAL (como se ve en la figura 7-4), lo que indica que la reacción predominante es la hidrogenación selectiva del enlace $\mathrm{C}=\mathrm{C}$.

Para explicar el comportamiento relacionado con la selectividad, existen varios aspectos a considerar, uno de ellos es el efecto producido por la relativa proximidad entre Rh y Mo, la que depende de la estequiometría y estructura del heteropolianión, y que podría conducir a la estabilización oxidativa de pequeños agregados de Rh. Como resultado, la interacción de $\mathrm{Rh}$ con el grupo carbonilo del cinamaldehído, podría favorecer la formación de HCAL. Estos resultados están de acuerdo con los reportados por el trabajo de Lowenthal et al. acerca de quimisorción de $\mathrm{C}=\mathrm{O}$ e $\mathrm{H}$ para diferentes sistemas de Rh y Mo soportado sobre sílice y alúmina [10]. Dichos estudios han demostrado que una gran proximidad entre Mo y $\mathrm{Rh}$, conduce tanto, a la estabilización oxidativa y cinética de pequeños agregados de $\mathrm{Rh}$, como a la coexistencia de especies $\mathrm{Rh}^{\delta+}$ y $\mathrm{MoO}_{\mathrm{x}}$.

Otro aspecto a considerar se pone de manifiesto al tener en cuenta el análisis por $\mathrm{DRX}$, el que no mostró la presencia de estructuras que contengan $\mathrm{Rh}$ y/o Mo en los catalizadores soportados, por este motivo es posible sugerir que existen especies de Rh también como partículas metálicas pequeñas que no pueden ser observadas por DRX (Figura 4 (a y b), capítulo 6). Además, los resultados de TPR para sistemas $\mathrm{RhMo}_{6}$ 
mostraron la reducción de Rh a baja temperatura (Figura 10, capítulo 6). Este efecto puede indicar que la especie reducida se dispersa en forma de pequeñas partículas que interactúan débilmente con el soporte y por tanto, los resultados de selectividad también se pueden explicar en términos de un efecto de tamaño de partícula.

De acuerdo con Richard et al. [11], las partículas grandes conducen al alcohol insaturado preferentemente, mientras que las partículas pequeñas conducen al aldehído saturado. Además, factores estéricos relacionados con la molécula que va a reducirse no pueden ser descartados, por lo que se debe tener en cuenta que la rigidez de la molécula de cinamaldehído (donde el anillo fenilo está conjugado con enlaces $\mathrm{C}=\mathrm{C}$ y $\mathrm{C}=\mathrm{O}$ ) favorece la adsorción de pequeñas partículas a través del enlace $\mathrm{C}=\mathrm{C}$, mientras que partículas grandes reaccionan con el enlace $\mathrm{C}=\mathrm{O}[12]$.

De esta manera la selectividad para COL obtenido con el catalizador RhMo/A se puede explicar como una consecuencia del hecho que el Mo (VI) y el Rh (III), se encuentran con diferente dispersión y menor proximidad u ordenamiento que en el caso del heteropolianión. De hecho, el diagrama de TPR para el sistema RhMo/A demostró que los picos de reducción aparecen a temperatura más alta que para el resto de los catalizadores y por lo tanto la cantidad de Rh no reducido a la temperatura empleada en la reducción de nuestros catalizadores $\left(350^{\circ} \mathrm{C}\right)$ podría ser mayor que para los otros catalizadores. Paralelamente, los datos de XPS revelaron un enriquecimiento de la superficie en especies $\mathrm{Rh}^{\delta+}$ (Tabla V, Capítulo 6), efecto que podría ser responsable de la polarización del enlace $\mathrm{C}=\mathrm{O}$. Se debe considerar, además, el efecto del Mo (VI) el que promueve la activación del enlace $\mathrm{C}=\mathrm{O}$, facilitando la transferencia de hidrógeno a partir de sitios adyacentes de Rh.

\section{2.b.I. Cálculo de actividad por centro activo: TOF (o factor de "turn-over")}

Con el fin de profundizar el análisis y teniendo en cuenta los resultados antes mostrados, se procedió a estudiar la actividad por centro activo de los catalizadores, calculando la dispersión del Rh y los valores TOF (factor de turn-over, expresado en nuestro caso como moles del producto mayoritario (hidrocinamaldehido), obtenido por mol de Rh por minuto, de acuerdo con los valores de dispersión de Rh calculados mediante la valoración $\mathrm{H}_{2} / \mathrm{O}_{2}$ por el método Boudart [13]. Tal como se expuso en la sección experimental, ítem 2.13.b.I. Estos valores se presentan en la tabla 7-III. 
Los valores de $\mathrm{r}^{\mathrm{o}}$ y TOF para $\mathrm{RhMo}_{6} / \mathrm{EI}$ resultaron significativamente mayores que para el resto de los catalizadores. Se observa además una apreciable diferencia en los valores de dispersión del $\mathrm{Rh}$ en los catalizadores a base de $\mathrm{RhMo}_{6}$ según el soporte. Asimismo se observa menor dispersión en el catalizador convencional denominado A.

Tabla 7-III: Datos de composición $\left(\mathrm{C}_{\mathrm{a}}{ }^{\mathrm{M}}=\mathrm{g} \mathrm{M} / \mathrm{g}\right.$ alumina), actividad ( $\mathrm{r}^{\mathrm{o}}$ [CAL] $\mu$ moles $\mathrm{s}^{-1}$ ), Dispersión y TOF de $\mathrm{Rh}$, para sistemas $\mathrm{RhMo}_{6}$ y $\mathrm{RhMo} / \gamma-\mathrm{Al}_{2} \mathrm{O}_{3}$ en la reacción de hidrogenación selectiva de CAL a HCAL.

\begin{tabular}{|c|c|c|c|c|c|c|c|}
\hline Catalizador & $\begin{array}{c}\text { CaMo } \\
(\%)\end{array}$ & $\begin{array}{c}\text { CaRh } \\
(\%)\end{array}$ & $\begin{array}{l}\mathbf{r}^{0}[\text { CAL }] \\
\mu \text { moles } ~^{-1}\end{array}$ & $\operatorname{Rh} \times 10^{19}$ & $\mathrm{TOF}_{\mathrm{Rh}} \times 10^{-3}$ & $\begin{array}{l}\mathrm{S}_{\mathrm{BET}} \\
\mathrm{m}^{2} / \mathrm{g}\end{array}$ & $\begin{array}{l}\text { Dispersión } \\
\text { de Rh }\end{array}$ \\
\hline $\mathrm{RhMo}_{6} / \mathrm{EI}$ & 6.0 & 1.5 & 2.45 & 1.75 & 168 & 237 & 0.5 \\
\hline $\mathrm{RhMo}_{6} / \mathrm{EII}$ & 6.7 & 1.5 & 0.502 & 1.75 & 49 & 328 & 0.35 \\
\hline $\mathrm{RhMo}_{6} / \mathrm{A}$ & 5.7 & 1.4 & 0.370 & 1.64 & 40 & 150 & 0.34 \\
\hline $\mathrm{RhMo} / \mathrm{A}$ & 6.0 & 1.0 & 0.256 & 1.17 & 44 & 328 & 0.30 \\
\hline
\end{tabular}

\section{2.b.II. Análisis de la influencia de las características texturales del soporte}

Considerando los resultados antes expuestos, se procedió a realizar un análisis del comportamiento catalítico en función de las propiedades texturales de los soportes. La menor actividad catalítica del sistema soportado en (EII) respecto al sistema soportado en (EI) se puede explicar teniendo en cuenta que una fracción de aproximadamente del $50 \%$ del $\mathrm{S}_{\mathrm{BET}}$ de (EII) está cubierta por mesoporos estrechos (dp. $<30 \AA$ ) dificultando el acceso de la fase $\mathrm{RhMo}_{6}$ durante la impregnación y luego del reactivo CAL durante la reacción, mientras que (EI) exhibe una distribución de tamaño de poros más favorable con sólo el $20 \%$ del $\mathrm{S}_{\mathrm{BET}}$ total de mesoporos estrechos, ver Figura 5.13, Capítulo 5. Las diferencias observadas tanto en la dispersión de la fase metálica y los valores TOF pueden ser asignados a las diferentes características texturales entre (EI) y (EII). Los sistemas a base de $\mathrm{RhMo}_{6}$, mostraron en general una mejor performance catalítica en la hidrogenación de CAL a HCAL respecto al sistema convencional, el cual tiende a desactivarse con el tiempo. Este hecho confirma que la interacción heteropolianión/soporte produce una superficie activa con una distribución 
ordenada y deposición uniforme de los elementos Rh y Mo en el soporte, produciendo un efecto sinérgico que favorece la actividad catalítica.

Aunque $\mathrm{RhMo}_{6} /$ EII mostró la actividad más alta en 75 minutos, sus valores de TOF y dispersión de Rh son comparables a los de sistemas soportados sobre alúmina (A). Por otro lado $\mathrm{RhMo}_{6} / \mathrm{A}$ presentó mayor selectividad hacia HCAL, pero una menor conversión a igual tiempo de reacción. Asimismo se observó que el catalizador convencional $\mathrm{RhMo} / \mathrm{A}$ resultó menos activo y selectivo comparado con los catalizadores a base del heteropolianión.

En este punto resulta interesante correlacionar los resultados obtenidos en el estudio de la capacidad de hidroadsorción de los mencionados soportes mediante la técnica Laser de Speckle Dinámico. Como se establece en el capítulo 5 el soporte que presentó mayor adsorción de moléculas de agua fue EI, mostrando menor tiempo de estabilización de la actividad de speckle, lo que indicó una rápida hidroadsorción. Los demás materiales presentaron mayores tiempos de estabilización del Speckle debido a que el período de hidroadsorción es más prolongado tal como se discutió en el ítem 5.2.d. Asimismo mediante este método se puede sugerir que el comportamiento de hidroadsorción del soporte (A) respecto al soporte (AI) se debe a su mayor acidez.

7.2.c. Hidrogenación selectiva de cinamaldehido sobre catalizadores de Rh(III)-hexamolibdato soportados en aluminosilicatos naturales funcionalizados.

Se exploró el comportamiento catalítico de los siguientes sistemas soportados en aluminosilicatos y condiciones descriptas en la sección experimental, item 2.3.c.1.2. y 2.13.a:

$\mathrm{RhMo}_{6} / \mathrm{PCH}$

$\boldsymbol{R h M o}_{6} / \boldsymbol{P C H}-\boldsymbol{F}$ (en PCH funcionalizada).

$\mathrm{RhMo}_{6} / \mathrm{PILC}$

$\boldsymbol{R h M o _ { 6 }} / \boldsymbol{P I L C} \boldsymbol{C} \boldsymbol{F}$ (en PILC funcionalizada). 
El objetivo es utilizar este material como soporte de catalizadores (el cual presenta un $\mathrm{pI} \sim 3.1$ ), dado que el $\mathrm{pH}$ de impregnación de HPOMs es mayor al pI se dificulta la adsorción del heteropolioxoanión. Por tal motivo se realizó la funcionalización de las arcillas para lograr la adsorción efectiva de HPOMs en la superficie de la PILC y PCH.

Se utilizó como funcionalizante un órgano-silano, el (3-aminopropil)trimetoxisilano $(\mathrm{F})$. La funcionalización de los silanoles $(\mathrm{Si}-\mathrm{OH})$ superficiales, se produce según la ecuación mostrada en la sección 2.2.c.III. [14,15]. El mecanismo de funcionalización implica la interacción de los grupos metoxi con tres grupos silanoles de la superficie de la arcilla modificada, generándose un grupo amino terminal en dicha superficie, el que actúa uniéndose al heteropolianión, luego del proceso de impregnación en equilibrio. En la Figura 7-5 se presenta la actividad expresada como conversión de CAL en función del tiempo de reacción controlada hasta 360 min.

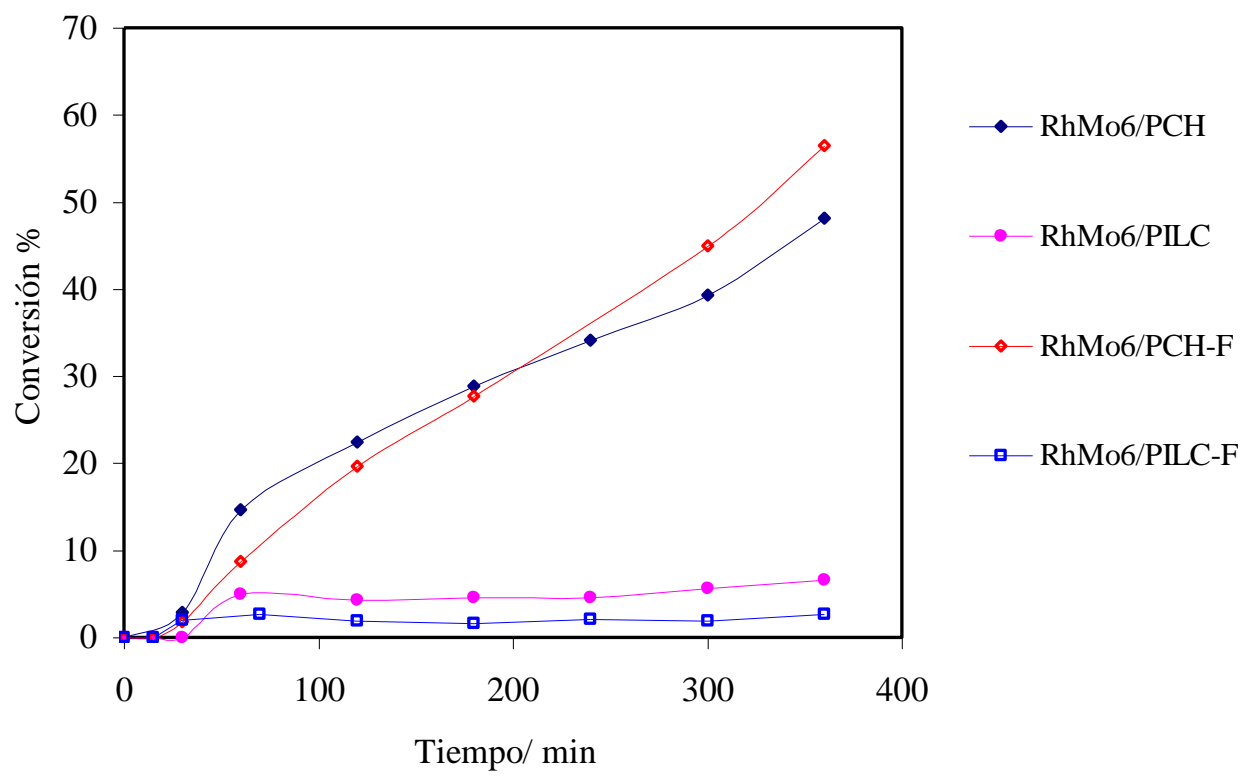

Figura 7-5: Conversión (\%) en función de tiempo, para los sistemas $\mathrm{RhMo}_{6} / \mathrm{PILC} / \mathrm{PILC}-\mathrm{F} / \mathrm{PCH} / \mathrm{PCH}-\mathrm{F}$, en la reacción de CAL a HCAL, $\mathrm{T}=85^{\circ} \mathrm{C}$ y presión $=15$ bar.

Como puede observarse, los sistemas soportados sobre PCH resultaron ser más activos que los soportados sobre PILC. Las características de las arcillas heteroestructuradas y funcionalizadas permiten preparar sistemas con una mayor 
cantidad del metal con capacidad hidrogenante ( $\mathrm{Rh}$ ), obteniendo de este modo catalizadores significativamente más eficiente en la reacción estudiada. Además, como puede verse en la Figura 7-5, la funcionalización de este soporte conduce a un aumento de actividad respecto al sistema sin funcionalizar.

Todos los catalizadores estudiados presentaron una alta selectividad a hidrocinamaldehído.

En la Figura 7-6, se reporta la selectividad a los distintos productos a igual conversión (3\%); $\mathrm{RhMo}_{6} / \mathrm{PILC}$ y $\mathrm{RhMo}_{6} / \mathrm{PILC}-\mathrm{F}$ presentaron la misma distribución de productos (HCAL y COL), sin embargo $\mathrm{RhMo}_{6} / \mathrm{PCH}-\mathrm{F}$ muestra similar selectividad a los productos minoritarios (HCOL y COL) comparado con el mismo sistema sin funcionalizar. Este comportamiento se puede asociar a las características ácidas Lewis (mostradas en el estudio por TPSR), responsables de la hidrogenación del grupo $\mathrm{C}=\mathrm{O}$. La distribución de los productos minoritarios, COL y HCOL mostrada por los dos sistemas a base de materiales modificados (PILC-F y PCH-F) pueden explicarse a partir de dichas características ácidas proporcionadas por el heteropolianión, las que en PCHF se incrementan debido a la acidez mostrada por el soporte. Estos valores se presentan en la tabla 7-IV.

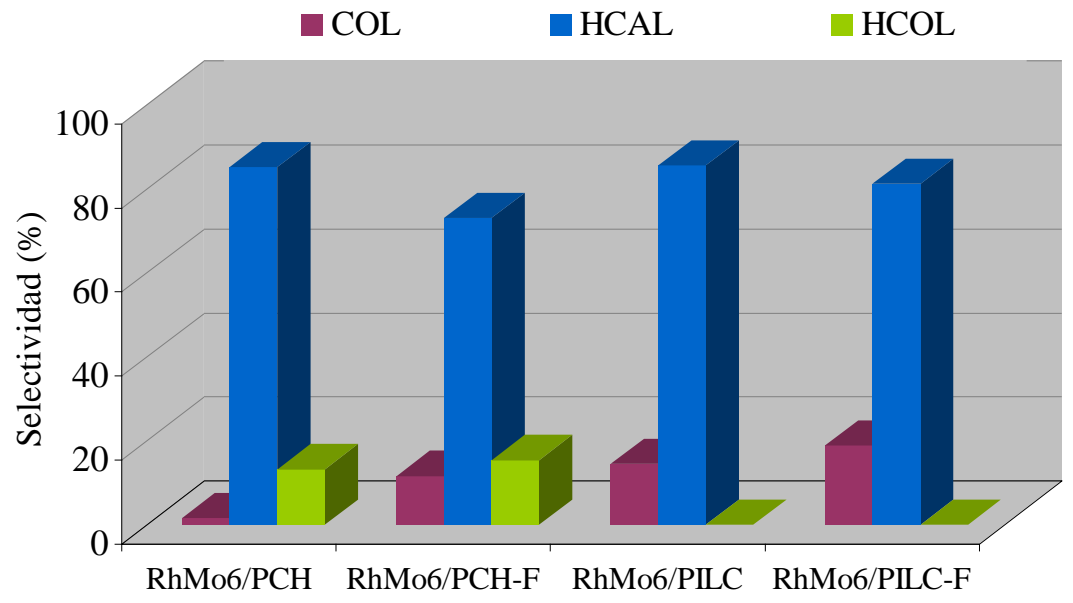

Figuras 7-6: Selectividad a productos a $3(\%)$ de conversión para los sistemas $\mathrm{RhMo}_{6} / \mathrm{PILC} / \mathrm{PILC}-\mathrm{F} / \mathrm{PCH} / \mathrm{PCH}-\mathrm{F}$, en la reacción de $\mathrm{CAL}$ a HCAL, $\mathrm{T}=85^{\circ} \mathrm{C}$ y $\mathrm{P}=15$ bar. 
Tabla 7-IV: Conversión (\%) y selectividad (\%) a 360 min, para sistemas $\mathrm{RhMo}_{6}$ soportados sobre aluminosilicatos naturales en la reacción de hidrogenación selectiva de CAL a HCAL.

\begin{tabular}{lcccc}
\hline \multirow{2}{*}{ Catalizador } & \multirow{2}{*}{ Conversión $(\%)$} & \multicolumn{4}{c}{ Selectividad (\%) } \\
\cline { 3 - 5 } $\mathrm{RhMo}_{6} / \mathrm{PCH}$ & 48.0 & 85 & 2 & 13 \\
$\mathrm{RhMo}_{6} / \mathrm{PCH}-\mathrm{F}$ & 56.0 & 73 & 12 & 15 \\
$\mathrm{RhMo}_{6} / \mathrm{PILC}$ & 7.0 & 85 & 15 & 0 \\
$\mathrm{RhMo}_{6} / \mathrm{PILC}-\mathrm{F}$ & 3.0 & 81 & 19 & 0 \\
\hline
\end{tabular}

Resulta interesante correlacionar los resultados obtenidos en el estudio de la capacidad de hidroadsorción de los mencionados soportes mediante la técnica Laser de Speckle Dinámico. Como se establece en el capítulo 5 los soportes que presentaron mayor adsorción de moléculas de agua fueron los materiales con mayor relación $\mathrm{Si} / \mathrm{Al}$ (PCH, PCH-F), mostrando menor tiempo de estabilización de la actividad de speckle, lo que indicó una rápida hidroadsorción. Los demás materiales presentaron mayores tiempos de estabilización del speckle debido a que el período de hidroadsorción es más prolongado tal como se discutió en el ítem 5.3.g.

\subsection{Oxidación selectiva de difenilsulfuro. Introducción}

7.3.a. Evaluación de fases anderson $\left[\mathrm{MMo}_{6} \mathrm{O}_{24} \mathrm{H}_{6}\right]^{3-}$ con $\mathrm{M}=\mathrm{Rh}(\mathrm{III}) \mathrm{y}$ $\mathrm{Co}(\mathrm{III})$ y un derivado estructural, $\left[\mathrm{Co}_{2} \mathrm{Mo}_{10} \mathrm{H}_{4} \mathrm{O}_{38}\right]^{6-}$ soportadas en arcillas porosas heteroestructuradas para la oxidación selectiva de difenilsulfuro.

En el capítulo I se mencionó la importancia que reviste la oxidación selectiva de sulfuros aromáticos como el difenilsulfuro. Esta evaluación, no sólo resulta interesante como primera aproximación a la oxidación desulfurativa (ODS) utilizado actualmente como método "amigable con el ambiente" alternativo a la hidrodesulfurización de cortes del petróleo, también es de interés en la producción de sulfóxidos y sulfonas, como intemediarios de síntesis de productos farmacológicos. En general, la oxidación de sulfuro a sulfóxido presenta menor conversión que la obtenida 
en el proceso sulfóxido a sulfona, por lo que este aspecto dificulta la síntesis de medicinales que requieren menos del $0.5 \%$ de sulfonas en su formulación (como rabeprazole, lansoprazole, omeprazole, etc.). En este sentido, el método de separación de sulfóxidos y sulfonas para obtener los reactivos aislados debe ser optimizado y por ello resulta de gran interés estudiar nuevos catalizadores y reacciones de oxidación selectiva de sulfuros aromáticos.

En este trabajo de tesis los sistemas elegidos para dicho test, fueron aquellos a base de fases de Anderson soportadas en arcillas modificadas PCH-F considerando los escasos reportes en la literatura de este tipo de catalizadores frente a los sistemas convencionales de polimolibdatos o tungstatos soportados en alúmina. El test elegido fue el de tipo batch para oxidación selectiva de difenisulfuro (DFS), utilizando $\mathrm{H}_{2} \mathrm{O}_{2}$ como oxidante y acetonitrilo como solvente. Los catalizadores evaluados fueron aquellos que mostraron mayor concentración de Mo adsorbido: $\mathrm{CoMo}_{6}, \mathrm{Co}_{2} \mathrm{Mo}_{10} \mathrm{y}$ $\mathrm{RhMo}_{6} / \mathrm{PCH}-\mathrm{F},[16,17]$.

\section{3.b. Evaluación Catalítica}

En el esquema I se presenta la reacción de oxidación estudiada, la que se llevó a cabo en un reactor batch, a $80^{\circ} \mathrm{C}$, durante períodos determinados a partir de resultados preliminares obtenidos por cromatografía en capa delgada (CCD). Se disolvió $1 \mathrm{mmol}$ de difenilsulfuro (DFS) en $5 \mathrm{ml}$ de $\mathrm{CH}_{3} \mathrm{CN}$. Se agregaron $50 \mathrm{mg}$ de catalizador y $1 \mathrm{ml}$ de $\mathrm{H}_{2} \mathrm{O}_{2} 35 \% \mathrm{p} / \mathrm{V}$. En relación a la cantidad de polioxomolibdatos adsorbidos sobre las PCH-F, el estudio fue realizado mediante cuantificación del Mo por absorción atómica (AAS) de las soluciones de $\mathrm{Rh}$ o $\mathrm{CoMo}_{6} \mathrm{y} \mathrm{Co}_{2} \mathrm{Mo}_{10}$ antes y después del proceso de impregnación en equilibrio de la fase activa sobre el soporte, asimismo se realizaron medidas semicuantitativas por EDS.

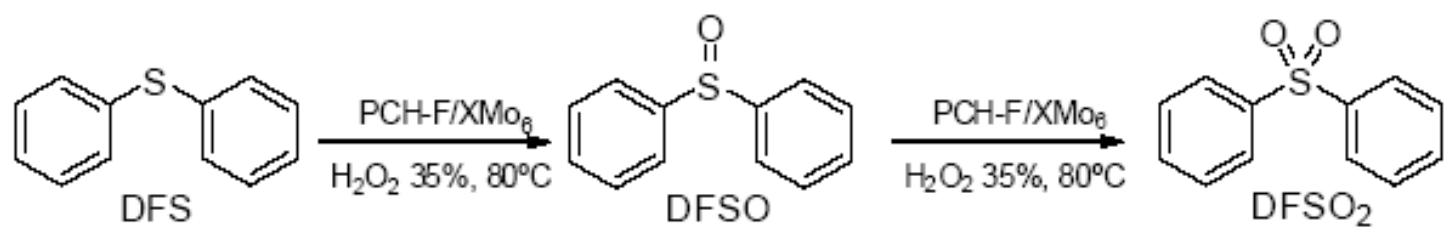

Esquema I: Representación de la reacción de oxidación de DFS. 
En la Tabla 7-V se muestran los resultados correspondientes a estos análisis y los valores obtenidos de Mo adsorbido calculados por balance de masas. Cabe mencionar que por este último método, aquellos sistemas funcionalizados arrojaron un valor entre 14 y $10 \%$ de Mo adsorbido mientras que los sistemas soportados en PCH sin funcionalizar arrojaron un valor del 1\% de Mo. Los valores obtenidos por EDS, llegaron a valores relativos hasta el $20 \%$ de Mo en la superficie de los sistemas funcionalizados. Este resultado mostró una interacción efectiva entre los grupos amino, existentes en la superficie de la PCH-F durante la impregnación ( $\mathrm{pH}$ ligeramente ácido), y los heteropolioxoaniones bimetálicos. Sin embargo se observa que los valores de Mo y del resto de los elementos sufren variaciones apreciables entre los sistemas, indicando que las fases tienen diferente grado de afinidad de acuerdo no sólo a sus características estructurales espaciales si no al tipo de heteroátomo presente (Co ó Rh) como se ha visto anteriormente en estudios de isotermas de adsorción de polioxoaniones sobre $\gamma$ alúmina [18].

Tabla 7-V: Composición de elementos mayoritarios \% en masas a partir del análisis químico por EDS y concentración de Mo adsorbido por AAS, para las PCH-F soportadas con $\mathrm{CoMo}_{6}, \mathrm{Co}_{2} \mathrm{Mo}_{10}$ y $\mathrm{RhMo}_{6}$.

\begin{tabular}{|c|c|c|c|}
\hline Elemento & $\begin{array}{c}\mathrm{RhMo}_{6} / \mathrm{PCH}-\mathrm{F} \\
\% \text { masa }\end{array}$ & $\begin{array}{c}\mathrm{CoMo}_{6} / \mathrm{PCH}-\mathrm{F} \\
\% \text { masa }\end{array}$ & $\begin{array}{c}\mathrm{Co}_{2} \mathrm{Mo}_{10} / \mathrm{PCH}-\mathrm{F} \\
\% \text { masa }\end{array}$ \\
\hline$\overline{\mathrm{Al}}$ & 5.69 & 9.59 & 6.75 \\
\hline Si & 70.03 & 64.49 & 67.99 \\
\hline Mo & 17.26 & 19.92 & 20.9 \\
\hline $\mathbf{X}^{1}(\operatorname{Co~o~Rh})$ & 5.01 & 2.59 & 1.86 \\
\hline Fe & 2.01 & 3.42 & 2.5 \\
\hline $\mathbf{X} / \mathbf{M o}^{1}$ & 0.29 & 0.13 & 0.09 \\
\hline X/Mo Teórica & 0.18 & 0.10 & 0.12 \\
\hline $\mathrm{C}_{\text {Ad }} \mathrm{Mo} \%^{2}$ & 14.70 & 8.00 & 10.50 \\
\hline
\end{tabular}


La Figura 7-7 muestra gráficamente los resultados de conversión en estado estacionario de DFS en función del tiempo. Se encuentra que para los sistemas $\mathrm{CoMo}_{6}$, $\mathrm{Co}_{2} \mathrm{Mo}_{10}$ y $\mathrm{RhMo}_{6} / \mathrm{PCH}-\mathrm{F}$, resulta similar ( $\left.100 \%\right)$. Sin embargo, en los primeros minutos de reacción la conversión de DFS fue mayor para el sistema $\mathrm{RhMo}_{6} / \mathrm{PCH}-\mathrm{F}$ (90\%) seguido de $\mathrm{Co}_{2} \mathrm{Mo}_{10}(80 \%)$ y $\mathrm{CoMo}_{6}(50 \%)$.

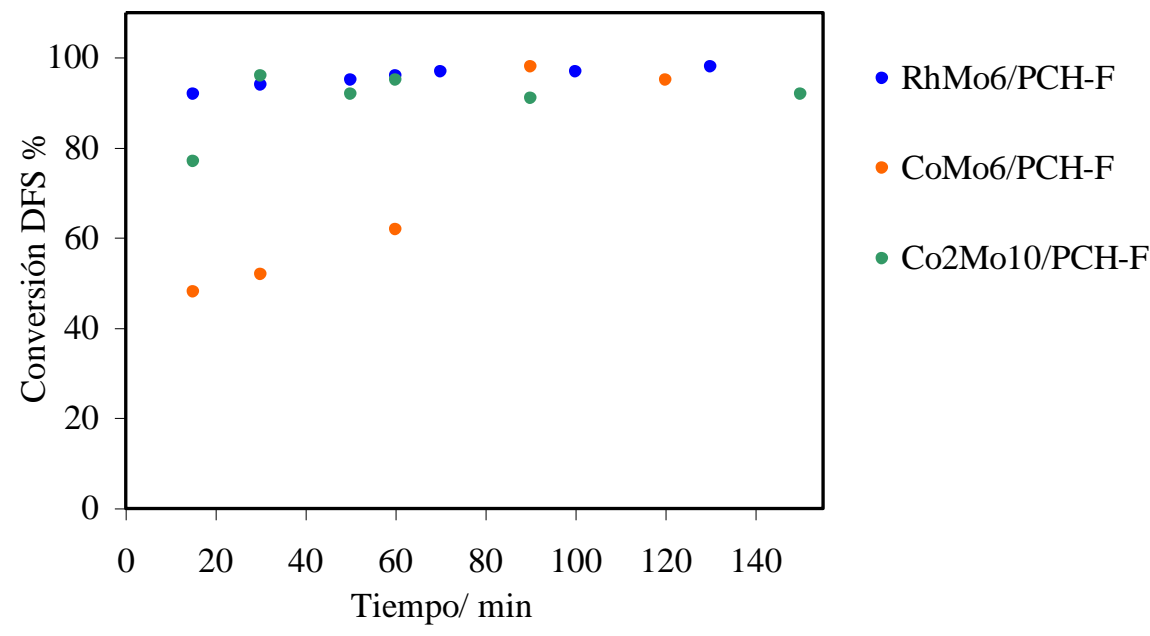

Figura 7-7: Conversión de DFS (\%) en la oxidación con $\mathrm{H}_{2} \mathrm{O}_{2}$ en función del tiempo para los sistemas $\mathrm{CoMo}_{6}, \mathrm{Co}_{2} \mathrm{Mo}_{10}$ y $\mathrm{RhMo}_{6} / \mathrm{PCH}-\mathrm{F}$.

Para las especies de Co, la diferencia posiblemente esté relacionada con la mayor disponibilidad de los sitios activos en el $\mathrm{Co}_{2} \mathrm{Mo}_{10}$ al ser una estructura no planar y más distorsionada que la correspondiente de fase de Anderson convencional plana [19], Figura.7-8 Por último, la Tabla 7-VI presenta las selectividades hacia los productos posibles, se observa sin embargo, que el sistema que presentó menor conversión, $\mathrm{CoMo}_{6} / \mathrm{PCH}-\mathrm{F}$ fue el más selectivo a DFSO en cortos periodos de reacción. 
Tabla 7-VI: Selectividad (\%) obtenida a 1 y a 3 hs de la reacción de oxidación de DFS en presencia de $\mathrm{H}_{2} \mathrm{O}_{2}$ con los sistemas $\mathrm{CoMo}_{6}, \mathrm{Co}_{2} \mathrm{Mo}_{10}$ y $\mathrm{RhMo}_{6} / \mathrm{PCH}-\mathrm{F}$ como catalizadores.

\begin{tabular}{l|cc|cc}
\hline \multirow{2}{*}{\multicolumn{1}{c}{ Catalizador }} & \multicolumn{2}{c}{ Select. (\%) 1h } & \multicolumn{2}{c}{ Select. (\%) 3h } \\
\cline { 2 - 5 } & DFSO & DFSO $_{2}$ & DFSO & DFSO $_{2}$ \\
\hline $\mathrm{RhMo}_{6} / \mathrm{PCH}-\mathrm{F}$ & 8 & 92 & 0 & 100 \\
$\mathrm{CoMo}_{6} / \mathrm{PCH}-\mathrm{F}$ & $83^{*}$ & $17^{*}$ & 2 & 98 \\
$\mathrm{Co}_{2} \mathrm{Mo}_{10} / \mathrm{PCH}-\mathrm{F}$ & 54 & 35 & 1 & 99 \\
\hline
\end{tabular}

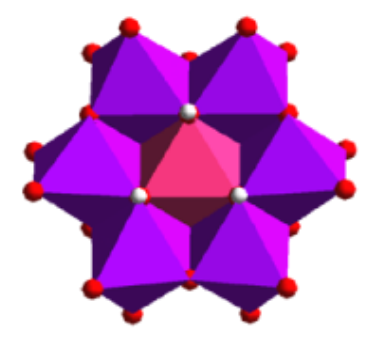

(a)

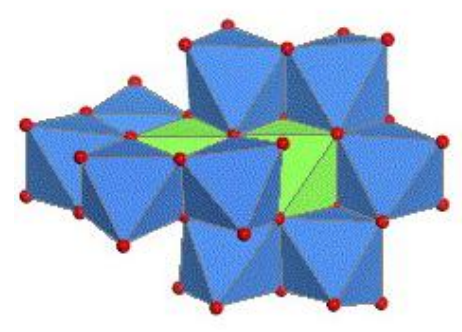

(b)

Figuras 7-8: (a) Estructura del heteropolianión tipo Anderson y (b) estructura del heteropolianión $\mathrm{CoMo}_{10}$

\section{3.c. Conclusiones parciales}

Los catalizadores preparados a base de $\mathrm{RhMo}_{6} /$ Sílice presentaron muy baja conversión en la hidrogenación selectiva de cinamaldehído debido a que no fue posible la adsorción efectiva del heteropolianión en este tipo de soporte.

Los sistemas a base de $\mathrm{RhMo}_{6}$ soportados en diferentes tipos de alúmina mostraron actividad catalítica de hasta $80 \%$ de conversión en la hidrogenación de cinamaldehido a hidrocinamaldehido mientras el sistema convencional RhMo/alúmina mostró el 20\% de conversión a igual carga metálica, el cual tiende a desactivarse con el tiempo. Este hecho confirma que la interacción heteropolianión/alúmina produce una superficie activa con una distribución ordenada y deposición uniforme de los elementos $\mathrm{Rh}$ y Mo en el soporte, produciendo un efecto sinérgico que favorece la actividad 
catalítica.

El estudio realizado utilizando alúminas de diferentes propiedades texturales y acidez superficial, mostró que estas propiedades influyen notablemente en la adsorción de la fase activa y por ende en la performance catalítica.

Asimismo, se obtuvieron catalizadores a base de $\mathrm{RhMo}_{6}$ soportados en un aluminosilicato natural modificado químicamente $(\mathrm{PCH})$ y posteriormente funcionalizado (PCH-F). Estos sistemas resultaron ser activos en la hidrogenación de cinamaldehído mostrando una selectividad a HCAL de $77 \%$ a $25 \%$ de conversión.

Catalizadores a base de $\mathrm{RhMo}_{6}, \mathrm{CoMo}_{6} \mathrm{y} \mathrm{Co}_{2} \mathrm{Mo}_{10} / \mathrm{PCH}-\mathrm{F}$ conteniendo hasta $14 \%$ de Mo adsorbido, se emplearon en la reacción de oxidación selectiva de difenilsulfuro con peróxido de hidrógeno como oxidante, a $80^{\circ} \mathrm{C}$, obteniendo valores por arriba de $90 \%$ de conversión y hasta el $100 \%$ de selectividad a sulfona. El catalizador más activo fue el sistema de Rh. Entre las especies de Co, la diferencia en la performance puede deberse no solo a la diferencia en la cantidad de Mo adsorbido sino también a un efecto estérico asociado a la mayor disponibilidad de los sitios activos en el $\mathrm{Co}_{2} \mathrm{Mo}_{10}$ al poseer este una estructura no planar y más distorsionada que la correspondiente a la fase plana de tipo Anderson. 
Capítulo 8:

\section{CONCLUSIONES Y PERSPECTIVAS}




\section{Conclusiones y perspectivas}

A los fines de obtener un heteropolianión bimetálico catalíticamente activo, se sintetizó y caracterizó una fase de estructura Anderson de fórmula: $\left(\mathrm{NH}_{4}\right)_{3}\left[\mathrm{RhMo}_{6} \mathrm{H}_{6} \mathrm{O}_{24}\right] \cdot 7 \mathrm{H}_{2} \mathrm{O}$, $\left(\mathrm{RhMo}_{6}\right)$. Los análisis estructurales por DRX, de microestructura por SEM-EDS y espectroscópicos por FTIR y Raman Microprobe realizados en forma comparativa con otras fases similares conteniendo $\mathrm{Co}$ (III) y $\mathrm{Al}$ (III) en lugar de $\mathrm{Rh}$, confirmaron que las mismas son isomorfas. Sin embargo el estudio de la descomposición térmica tanto en atmósfera oxidante (TG-DTA) como atmósfera reductora (TPR), mostró que el comportamiento de la fase de $\mathrm{Rh}$ difiere respecto a las otras fases debido a la formación de un intermediario, el óxido mixto de tipo tri-rutilo $\mathrm{RhMo}_{2} \mathrm{O}_{6}$, estable entre 700 y $900^{\circ} \mathrm{C}$, donde el $\mathrm{Rh}$ en condiciones reductoras actúa como promotor de la reducción de Mo.

En lo que respecta al pre-tratamiento o modificación química y posterior caracterización de los materiales para soporte del heteropolimolibdato de $\mathrm{Rh}$, en primer lugar se seleccionaron dos tipos de sílices, uno de los cuales, el aerosil fue tratado con $\mathrm{NH}_{4}(\mathrm{OH})$ con el fin de elevar sus propiedades texturales. Luego de realizar la caracterización estructural (DRX) y textural (BET) se realizó el análisis térmico convencional y se abordó el estudio de la capacidad hidroadsorbente por el método Laser DSL. Esta técnica permitió diferenciar el comportamiento hidrofílico entre el aerosil original y tratado y una sílice comercial de mayor área BET, con mayor eficacia que el método de análisis térmico-gravimétrico, permitiendo correlacionar la actividad de "Speckle" con el valor de área específica. Por otro lado y teniendo en cuenta que la superficie de las sílices pirogénicas utilizadas generalmente como soportes, contienen grupos silanoles $\mathrm{Si}-\mathrm{OH}$ cuyo número y densidad determina la mayor o menor afinidad por el agua, el método desarrollado se considera una potencial herramienta para predecir también, las propiedades ácidas Brønsted del soporte.

En relación a las alúminas, se seleccionaron algunos óxidos comerciales de características texturales conocidas y un precursor de alúmina el que fue tratado a temperaturas entre $480{ }^{\circ} \mathrm{C}$ y $550{ }^{\circ} \mathrm{C}$ en atmósfera oxidante y distintos tiempos de calentamiento con el objetivo de obtener $\gamma-\mathrm{Al}_{2} \mathrm{O}_{3}$. El resultado de este procedimiento dió lugar a la obtención de varias "alúminas de transición" presentando muestras con 
ligeras variaciones en sus propiedades ácidas, texturales y otras fases cristalinas como boehmita de acuerdo a las técnicas estructurales y texturales de BET. Los resultados obtenidos en las medidas de la capacidad hidroadsorbente mediante la técnica de Speckle, mostraron también que este método es promisorio para caracterizar alúminas mediante la evaluación de sitios ácidos superficiales.

Con el propósito de preparar soportes utilizando un alúminosilicato natural de bajo costo, se caracterizó un mineral de arcilla tipo bentonita procedente de depósitos argentinos. Este material fue modificado químicamente para su potencial aplicación como soporte del heteropolimolibdato de $\mathrm{Rh}(\mathrm{III})$. La modificación química comprendió el uso del oligómero $\mathrm{Al}_{13}$ como agente pilareante (PILC); el empleo de surfactantes catiónicos, neutros y un precursor silíceo TEOS para dar lugar al sistema heteroestructurado $(\mathrm{PCHs})$. Estos tratamientos dieron lugar al incremento del área superficial y la generación de materiales micro y mesoporosos. La funcionalización adicional de estos compuestos con una especie amino-organosilano, condujo a la obtención de superficies aptas para la adsorción de heteropolianiones. La aplicación del método Laser para el estudio de la hidrofilicidad mostró en forma general que los materiales con mayor relación $\mathrm{Si} / \mathrm{Al}$ ( $\mathrm{PCH}, \mathrm{PCH}-\mathrm{F})$ presentaron el menor tiempo de estabilización o relajación para la actividad de Speckle, lo cual indicó una rápida hidroadsorción, siendo posible correlacionar este efecto con la disponibilidad de grupos silanoles $(\mathrm{Si}-\mathrm{OH})$, responsables de la hidrofilicidad y acidez de materiales silíceos.

En lo que respecta a los catalizadores preparados por el método de impregnación en equilibrio de $\gamma-\mathrm{Al}_{2} \mathrm{O}_{3}$ con soluciones acuosas de heteropolimolibdatos del tipo Anderson, la estructura planar de la especie $\mathrm{RhMo}_{6}$, interacciona con el soporte, preservando su estructura y formando una monocapa conteniendo entre 6 y $8 \%$ de Mo adsorbido. Los estudios por microanálisis Raman y TPR permiten sugerir la disolución de la $\gamma-\mathrm{Al}_{2} \mathrm{O}_{3}$ como consecuencia del contacto de este soporte con una solución conteniendo molibdatos octaédricos condensados, de manera que, en la superficie del sistema $\mathrm{HMA} / \gamma-\mathrm{Al}_{2} \mathrm{O}_{3}$ es posible la formación de entidades $\mathrm{AlMo}_{6}$. Este fenómeno permite que el heteroátomo perteneciente a una fase tipo Anderson como $\mathrm{CoMo}_{6} \mathrm{O}$ $\mathrm{RhMo}_{6}$ interaccione con mayor efectividad con un soporte de alúmina, dada la posibilidad de intercambio entre el heteroátomo $\mathrm{X}$ (III) y el $\mathrm{Al}(\mathrm{III})$, ambos cationes en coordinación octaédrica. 
Asimismo el análisis por TPR permitió observar el efecto promotor del Rh en la reducibilidad del Mo.

La interacción del heteropolianión con la sílice sin embargo, condujo a una menor adsorción dando lugar a catalizadores de menor contenido metálico, este efecto se asocia al valor del punto isoeléctrico de la sílice que la convierte en un buen intercambiador catiónico no favorable para un intercambio efectivo con el heteropolianión.

Los catalizadores a base de $\mathrm{RhMo}_{6}$ soportados en alúmina obtenidos mediante la estrategia de síntesis propuesta en este trabajo, resultaron catalizadores activos en la hidrogenación selectiva de cinamaldehido a hidrocinamaldehído, una especie de alto valor agregado como intermediario en la síntesis de fármacos para el tratamiento del HIV. Pueden citarse como aspectos relevantes del estudio:

-Diferenciar y establecer las características necesarias del soporte para obtener una buena interacción heteropolianión/soporte dando lugar a una superficie activa con una distribución ordenada y deposición uniforme de los elementos $\mathrm{Rh}$ y Mo, produciendo un efecto sinérgico que favorece la actividad catalítica y una selectividad del $100 \%$ a HCAL.

En relación a la actividad de catalizadores a base de mineral de arcilla modificada, los resultados logrados son promisorios e inducen a continuar el estudio desde el punto de vista preparativo, con el objetivo de reemplazar material de soporte de origen importado. En relación al proceso de oxidación selectiva de difenilsulfuro, el empleo de peróxido de hidrógeno como oxidante limpio, resultó operativamente simple; trabajando a reflujo en un medio de acetonitrilo. Pueden citarse como ventajas del procedimiento: a) uso de materiales catalíticos no corrosivos y potencialmente reutilizables, b) condiciones de reacción no agresivas al ambiente y tiempos de procesamiento cortos, c) se obtuvieron rendimientos del orden del $90 \%$ con buena selectividad a sulfona, trabajando a temperaturas entre 75 y $80{ }^{\circ} \mathrm{C}$. Es importante destacar que la utilización de catalizadores heterogéneos permite reemplazar los ácidos inorgánicos, contribuyendo de esta manera a la reducción en la generación de residuos tóxicos. 
Cabe señalar que el estudio realizado induce a continuar la investigación con el fin de diseñar y caracterizar racionalmente sistemas catalíticos heterogéneos basados en arcillas modificadas con metales de transición, de potencial utilización en diferentes procesos no agresivos al ambiente.

Finalmente, en el presente trabajo, la técnica Laser de Speckle Dinámico se ha revelado como potencial herramienta, simple, no destructiva y eficiente para determinar propiedades higroscópicas y ácidas de superficies adsorbentes, presentando interesantes perspectivas de aplicación en la caracterización de sitios ácidos de catalizadores heterogéneos. En este sentido se planea aplicar la técnica Laser durante el proceso de impregnación o adsorción de un soporte, reemplazando el agua por soluciones acuosas de las diferentes especies conteniendo los iones metálicos necesarios para la formación de sitios activos. 


\section{BIBLIOGRAFÍA}




\section{Capítulo 1}

[1] M. T. Pope, "Heteropoly and Isopoly Oxometalates", (Springer-Verlag), Berlin, New York, (1983) Cap. 1.

[2] M. T. Pope, A. Müller, Angew. Chem. Int. Ed. Engl. 30 (1991) 34-48.

[3] W. Porterfield "Inorganic Chemistry" 2nd Edition, Academic Press, Inc. (1993) Cap 6.

[4] J-P. Jolivet, M. Henry, J. Livage, “De la solution à l'oxyde”, InterÉditions et CNRS Éditions, Paris (1994) cap 1.

[5] T. J. R. Weakley, Structure and Bonding, Eds, 18 (1974) 131.

[6] J. M. Maestre Horcajo, Tesis, URV, España (2003); versión online: www.tdx.cesca.estesis_URV/.

[7] J.S. Anderson, Nature, 140 (1937) 850.

[8] M. T. Pope, A. Müller, "Polyoxometalate Chemistry from topology via Selfassembly to Application”, Kluwer Academic Publishers, London (2001).

[9] C.I. Cabello, I.L. Botto, H.J. Thomas; Appl. Catal. A 197 (2000) 79-86.

[10] C. I. Cabello, F. M. Cabrerizo, A. Alvarez and H. J. Thomas. J. of Mol. Catal. A. Chem. 186 (2002) 89.

[11] B. Liu, L. Lu, B. Wang, T. Cai, I. Katsuyoshi, Appl. Catal. A: Gen. 171 (1998) 117.

[12] B. Liu, L. Lu, T. Cai, K. Iwatani, Appl. Catal. A: Gen. 180 (1999) 105.

[13] Boudart, M., Adv. Catal., 20, 153 (1969).

[14] M. Consonni, R. Touroude, D. Yu. Murzin; Chem. Eng. Tech., 21 (1998) 7.

[15] Masel, R.I. Principles of adsorption and reaction on solid surfaces. WileyIntersciencie, New York 1996.

[16] P. Gallezot, D. Richard; Catal. Rev. Sci. Eng. (1998) Vol.: 40: 81-90.

[17] J. Kijenski, P. Winiarek; Appl. Catal. A: Gen. 193 (2000) L1-L4.

[18] L1. F. Delbecq, P. Sautet; J. Catal. 152 (1995) 217-236.

[19] I. Kroschwitz (Ed.), Kirk-Othmer; En. of Chem.Tech. 6, 4th ed., Wiley, N. Y., 1992, 349.

[20] S. Narayanan, Bull; Cat. Soc. India 2 (2003) 107-116.

[21] A.M.C.F. Castelijns, J.M. Hogeweg, S.P.J.M. van Nispen, PCT Int. Appl., WO 96/11898 Al (April 25, 1996) 14 pp. 
[22] A.M.C.F. Castelijns, J.M. Hogeweg, S.P.J.M. van Nispen, PCT Int. Appl., US Patent 5, 811, 588 (September 22, 1998) 6 pp.

[23] A. Muller, J. Bowers, WO Patent WO 99/08989 (February 25, 1999) to First Chemical Corporation.

[24] G.F. Santori, M.L. Casella, O.A. Ferretti; J. Mol. Catal. A: Chem. 186 (2002) 223.

[25] M. Lashdaf, A.O.I. Krause, M. Lindblad, M. Tiitta, T. Venäläinen; Appl.Catal. A: Gen. 241 (2003) 65-75.

[26] J.Breen, Burch, Gomez-Lopez, K. Griffin, M. Hayes; Appl. Cat. A: Gen. 268 (2004) 267-274.

[27] P. Reyes, C. Rodriguez, G. Pechi, J.L. Fierro, Catal. Letters 69 (2000) 27.

[28] Françoise Rouquerol, Jean Rouquerol y Kenneth Sing, en "Adsorption by Powders and Porous Solids", Elsevier (1999).

[29] U. B. Mioc, S. K. Milonjic, D. Malovic, V. Stamenkovic, Ph. Colomban, M. M. Mitrovic, R. Dimitrijevic, Solid State Ionics, 97 (1997) 239.

[30] E. García Romero, Universidad Complutense (Madrid), M. Suárez Barrios, Universidad de Salamanca. http://www.uclm.es/users/higueras/yymm/Arcillas.htm

[31] J . T. Kloprogge, W. J . J: Welter, E. Booy, V. H. J. De Beer, R. A. van Santen, J. W. Geus, J . B. H. Jansen. Appl. Catal. A: General, 97 (1993) 77

[32] Clark C. Williams, John G. Eckerdt, Jih-Mirn Jehng, Franklin D. Hardcastle, Israel E. Wachs, J. Phys. Chem., 95 (1991) 8791

[33] A. Gil, L. M. Gandía, M. A. Vicente, Catal. Rev. Sci. Eng., 42 (1) (2000) 145.

[34] H. Khalaf, O. Bouras, V. Perrichon, Microporous Mater., 8 (1997) 141.

[35] J. S. Dailey, T. J. Pinnavaia, Chemi. Mat., 4 (1992) 855.

[36] M. Polverejan, Y. Liu, T. J. Pinnavaia, Chem. Mater., 14 (2002) 2283-2288.

[37] V. Chandra Srivastava, RSC Advances, 2 (2012) 759-783.

[38] K. Sato, M. Hyodo, M. Aoki, X-Qi Zheng and R. Noyorip, Tetrahedron 57 (2001) 2469-2476.

[39] B. Zapata, F. Pedraza, M.A. Valenzuela, Catal. Today 106 (2005) 219-221.

[40] A. Chica, A. Corma, M. E. Domine, J. Catal. 242 (2006) 299-308.

[41] Z. Ismagilov, S. Yashnik, M. Kerzhentsev, V. Parmon, A. Bourane, F. M. AlShahrani, A. A. Hajja, O. R. Koseoglu, Catal. Rev. 53 (2011) 199-255.

[42] J. M. Campos-Martin, M. C. Capel-Sanchez, P. Perez-Presas, J.L.G. Fierro, J. Chem. Technol. Biotechnol. 85 (2010) 879-890. 
[43] J. L. García-Gutiérrez, G. A. Fuentes, M. E. Hernández-Terán, P. García, F. Murrieta-Guevara, F. Jiménez-Cruz, Appl. Catal. A: General 334 (2008) 366-373.

[44] A. Akbari, M. Omidkhah, J. Toufighi Darian, World Academy of Science, Engineering and Technology 67 (2012) 328-331.

[45] D. H. Wang, E. W. H. Qian, H. Amano, K. Okata, A. Ishihara, T. Kabe. Appl. Catal. A 253 (2003) 91-99.

[46] K. J. Stanger, R. J. Angelici, Energy \& Fuels, 20 (2006) 1757-1760.

\section{Capítulo 2}

[1] I. L. Botto, A. C. Garcia, H. J. Thomas, J. Phys. Chem. Solids, 53 (8), (1992) 1075.

[2] C. Martin, C. Lamonier, M. Fournier, O. Mentré, V. Harlé, D. Guillaume, E. Payen, Inorg. Chem., 43, (2004) 4636.

[3] C. I. Cabello, I. L. Botto, H. J. Thomas, Thermochim. Acta, 232, (1994) 183.

[4] C. I. Cabello, M. Muñoz, E. Payen, H. J. Thomas, Catal. Lett., 92, (2004) 69 - 73.

[5] C. I. Cabello, I. L. Botto, F. Cabrerizo, M. G. González, H. J. Thomas, Adsorpt. Sci. Technol., 18 (7), (2000) 591 - 608.

[6] C. I. Cabello, F. M. Cabrerizo, A. Alvarez, H. J. Thomas, J. Mol. Catal. A Chem., 186, (2002) 89.

[7] R.D. Gonzalez, H. Miura, Catal. Rev. 36 (1994) 145.

[8] J.F. Le Page, Catalyse de contact, cap. V, Ed. Technip (1978).

[9] J. A. Dalmon, G. A. Martin, J. Catal 66 (1981) 214

[10] O. Bouras, Tesis doctoral, Université de Limoges, Faculté de Sciences et Techniques, Francia (2003) cap. 2.

[11] M. E. Gyftopoulou, M. Millan, A. V. Bridgwater, D. Dugwell, R. Kandiyoti, J. A. Hrilja, Applied Catalysis A: General, 282, (2005) 205-214.

[12] A. Gil, L. M. Gandia, M. A. Vicente, Catal. Rev. Sci. Eng., 42, (2000) 145-212.

[13] J. Ho Son, Y. Uk Kwon, O. Hee Han, Inorg. Chem., 42, (2003) 4153.

[14] A. Aouad, T. Mandalia, F. Bergaya, Applied Clay Science, 28, (2005) 175-182.

[15] O. Bouras, Tesis doctoral, Université de Limoges, Faculté de Sciences et Techniques, Francia (2003) cap. 2. 
[16] J. T. Kloprogge, L. V. Duong, R. L. Frost: "A review of the synthesis and characterization of pillared clays and related porous materials for cracking of vegetable oils to produce biofuels", Springer-Verlag 2005 Environ Geol, 47, (2005) 967-981.

[17] K. Bahranowski, J. Janas, T. Machej, E. M. Serwicka, L. Vartikian, Clay Miner., 32, (1997) 665.

[18] G. Fetter, G. Heredia, L. A. Velázquez, A. M. Maubert, P. Bosch, Appl. Cat. A Gral., 162, (1997) 41.

[19] M. Benjelloum, P. Cool, P. Van Der Voort y E. F. Vansant, Phys. Chem. Chem. Phys., 4, (2002) 2818.

[20] L. Chmielarz, P. Kustrowski, M. Drozdek, R. Dziembaj, P. Cool, E. F. Vansant, Catalysis Today, 114, (2006) 319-325.

[21] J. Ho Son, H. Choi, Y. Uk Kwon, O. H. Han, J. Non-Cryst. Solids, 318 (2003)

[22] G. Sathicq, L. Musante, G. Romanelli, G. Pasquale, J. Autino, H. Thomas, P. Vázquez, Studies in Surface Science and Catalysis, 162, (2006) 227 - 234.

[23] P.Reyes, C. Rodriguez, G. Pechi, J.L. Fierro; Catal. Letters 69 (2000) 27-32.

[24] T. J. Manning, W. R. Grow, "The chemical Educator" 1 / vol. 2, Nro. 1 (http://journals.springer-ny.com/chedr), Springer-Verlag, New York (1997).

[25] B. Welz, M. Sperling, “Atomic Absorption Spectrometry”, Ed.Wiley-UCH, (1999) $3^{\circ}$ ed.

[26] C. D. Wagner, L.E. Davis, M.V. Zeller, J.A. Taylor, R. H. Raymond, L. H. Gale, Surf. Interf. Anal. 3 (1981) 211.

[27] K. Nakamoto, "Infrared and Raman Spectra of Inorganic and Coordination Compounds", John Wiley \& Sons (1986).

[28] Van der Marel y H. Beutelspacher, "Atlas of Infrared Spectroscopy of Clay Minerals and their admixtures", Elsevier Pub. (1976).

[29] R. Martins, “Espectroscopía IR”, (NUCAT).

[30] I. E. Wachs, "Curso Heterogenous Cat. \& Surface Charact.”, (2005).

[31] O. Ferretti, M. Casella, G. Siri, G. Santori, Curso Catalizadores Heterogéneos, (2004).

[32] S. J. Gregg, K. S. W. Sing, "Adsorption, Surface Area and Porosity, A. P.”, London, (1982).

[33] G. Leofanti, M. Padovan, G. Tozzola, B. Venturelli, Catalysis Today, 41, (1998) 207. 
[34] Hoffmann, E., Stroobant, V. Mass Spectrometry. Principles and Applications. Paris : Jonh Wiley \& Sons LTD, 2nd Ed. (1999).

[35] C. I. Cabello, G. Bertolini, S. Amaya, R. Arizaga, M. Trivi, XV Cong. Arg. de Catálisis y IV Cong. de Catálisis del Mercosur, Actas.

[36] G. Cárdenas, R. Oliva, P. Reyes, B. L. Rivas; J. Mol. Catal. A: Chem., 191(2003) 75.

[37] J.C. Menezo, M.F.Denaot, S. S. Peyrovi, J. Barbier; Appl. Catal., 15 (1985) 353.

[38] J.E.Benson, M. Boudart, J. of Catal. 4, 704, (1965).

[39] J. Herrero, C. Blanco, C. Prieto, H. Dexpert, F.J. Lahoz, J. García; Jpn. J. Appl. Phys. 32 Suppl., 32 (1993) 484.

[40] A. Akbari, M. Omidkhah, J. Toufighi Darian, World Academy of Science, Engineering and Technology 67 (2012) 328-331.

[41] D. H. Wang, E. W. H. Qian, H. Amano, K. Okata, A. Ishihara, T. Kabe. Appl. Catal. A 253 (2003) 91-99.

[42] K. J. Stanger, R. J. Angelici, Energy \& Fuels, 20 (2006) 1757-1760.

\section{Capítulo 3}

[1] Dainty, J. C., Laser Speckle and Related Phenomena, Dainty, J. C., Ed., Springer Verlag (1975),

[2] I. Newton. Optics (Reimpreso por Dover Press, New York, 1952). Libro I. Parte I Prop. VIII, Prob. II (1730).

[3] Rayleigh, Lord, Note on the explanation of coronas, as given in Verdet's Lecons d'Optique Physique and other works, Proc. Lond. Math. Soc., 3, 267, 1871.

[4] Sirohi, R. S. (Ed), Speckle Metrology, Marcel Dekker, New York, 1993.

[5] Goodman, J. W., Speckle Phenomena in Optics: Theory and Applications, Roberts and Co., Englewood, Colorado, 2007.

[6] Goodman, J. W., Statistical properties of laser speckle patterns, in Laser Speckle and Related Phenomena, chap. 2. Dainty, J. C., Ed., Springer Verlag, Berlin, 1975.

[7] E. N. Leith, J. Upatnieks, Journal Optical Society of America, 52,1123 (1962).

[8] TS Mc Kechnie Laser Speckle and Related Phenomena, Cap. 4, Dainty, J. C., Ed., Springer Verlag (1975), 
[9] H. J. Rabal, R. Braga Eds Dynamic Laser Speckle and Applications,. CRC Press Taylor and Francis, Boca Raton FL. (2009)

[10] R.K. Erf (Ed). “ Speckle Metrology Academia Press, New York (1978).

[11] Eliasson, B. and Mottier, F., Determination of the granular radiance distribution of a diffuser and its use for vibration analysis, J. Opt. Soc. Am., 61, 559, 1971.

[12] Burch, J. M. and Tokarsky, J. M. J., Production of multiple beam fringes from photographic scatters, Optica Acta, 15, 101, 1968.

[13] Asakura, T. and Takai, N., Dynamic laser speckles and their application to velocity measurements of the diffuse object, Appl. Opt., 25, 179, 1981.

[14] Francon, M., Laser Speckle and Applications in Optics, Academic Press, New York, (1979).

[15] Creath, K., Phase shift speckle interferometry, Appl. Opt., 24, 3053, 1985.

[16] J. Pomarico, N. Gaggioli en Dynamic Laser Speckle and Applications Cap 1. H.J. Rabal, R. Braga, Eds.CRC Press Taylor and Francis, Boca Raton FL. (2009)

[17] Aizu, Y. and Asakura, T., Biospeckles, in Trends in Optics, A. Consortini, Ed., Academic Press, San Diego, 1996, chap. 2.

[18] Arizaga, R., Trivi, M., and Rabal, H., Speckle time evolution characterization by the co-occurrence matrix analysis, Opt. Laser Tech., 31(2), 163, 1999.

[19] M. Trivi en Dynamic Laser Speckle and Applications Cap 2. H.J. Rabal, R. Braga, Eds.CRC Press Taylor and Francis, Boca Raton FL. (2009)

[20] Oulamara, A., Tribillon, G., and Duvernoy, J., Biological activity measurement on botanical specimen surfaces using a temporal decorrelation effect of laser speckle, Journal of Modern Optics, 36, 165, 1989.

[21] R. Arizaga, en Dynamic Laser Speckle and Applications Cap 4. H.J. Rabal, R. Braga, Eds.CRC Press Taylor and Francis, Boca Raton FL. (2009).

\section{Capítulo 4}

[1] H. T. Evans, Jr., J. Am. Chem. Soc., 70, (1948) 1291.

[2] M. T. Pope, "Heteropoly and Isopoly Oxometalates", Springer, Berlin (1983).

[3] J. Loub, Collect. Czech. Chem. Commun., 42 (1977) 960.

[4] M. H. Alizadeh , J. S. Emampoura, A. R. Salimi, H. Razavi, Spectrochimica Acta Part A, 66 (2007) 1126-1132. 
[5] I. L. Botto, J. Less Common Metals, 128 (1986) 47.

[6] C. Rocchiccioli Deltcheff, M. Fournier, R. Franck, R. Thouvenot, Inorg. Chem., 22 (1983) 207.

[7] I. L. Botto, A. C. Garcia, H. J. Thomas, J. Phys. Chem. Solids., 53(1992) 1075.

[8] I. L. Botto, C. I. Cabello, G. Minelli, M. Occhiuzzi, Mater. Chem.Phys., 39 (1994) 21.

[9] C. Martin, C. Lamonier, M. Fournier, O. Mentré, V. Harlé, D. Guillaume, E.Payen, Inorg. Chem., 43 (2004) 4636.

[10] L. Le Bihan, P. Blanchard, M. Fournier, J. Grimblot, E. Payen, J. Chem. Soc., Faraday Trans., 94 (7) (1998) 937.

[11] K. Nomiya, T. Takahashi, T. Shirai, M. Miwa, Polyedron, 6 (1987) 213.

[12] C. I. Cabello, I. L. Botto, H. J. Thomas, Thermochim. Acta, 232 (1994), 183.

[13] C. I. Cabello, I. L. Botto, H. J. Thomas, Appl. Catal. A, 197 (2000) 79.

[14] I. L. Botto, C. I. Cabello, H. Thomas, Mater. Chem. Phys., 47 (1997) 37.

[15] A. Jones, B. Mc Nicol, “Temperature Programmed Reduction for Solid

Materials Characterization”, Marcel Dekker, New York (1986) 109.

[16] I. L. Botto, J. Less Common Metals, 128 (1986) 47.

[17] C. I. Cabello, I. L. Botto, H. J. Thomas, Thermochim. Acta, 232 (1994), 183.

\section{Capítulo 5}

[1] Françoise Rouquerol, Jean Rouquerol y Kenneth Sing, en "Adsorption by Powders and Porous Solids", Elsevier (1999).

[2] U. B. Mioc, S. K. Milonjic, D. Malovic, V. Stamenkovic, Ph. Colomban, M. M. Mitrovic, R. Dimitrijevic, Solid State Ionics, 97 (1997) 239-246.

[3] J. A. Dalmon, G. A. Martin, J. Catal 66 (1981) 214

[4] Emmett and Teller Brunauer, (BET) method in "Introduction to characterization and testing of catalysts", J.R.Anderson y K.C.Pratt Ed. Academic Press Australia (1985).

[5] E. P. Barrett, L. G. Joyner, P.P. Halenda, J. Amer.Chem. Soc. 73 (1951), 373.

[6] Rinaldi, R.; Fred, and Fujiwara, y. Schuchardt, U.. "Structural, morphological and acidic changes of nanocristalline aluminas caused by a controlled humidity atmosphere". Appl. Catal. A: v. 315, p. 44-51. 2006. 
[7] Sing K. S. W., Everett D. H., Haul R. A.W., Moscou L., Pierotti R. A., Rouquerol J., Siemieniewska T. Pure Appl. Chem. 57(2), 603 (1985).

[8] C.J. Doss, Phys. Rev. B 48 (1993) 15626.

[9] Lippens B. C., and Steggerda J.J. (1970) In: Phisical and Chemical Aspects of adsorbents and Catalysts. (B.G. Linsen ed.) Academic Press London, p.171.

[10] J.B. Peri, R.B. Hannan, J. Phys. Chem. 64 (1960) 1526.

[11] J.B. Peri, J. Phys. Chem. 69 (1965) 211.

[12] J.B. Peri, J. Phys. Chem. 69 (1965) 220.

[13] J.B. Peri, J. Phys. Chem. 69 (1965) 231.

[14] C. Dyer, P.J. Hendra,W. Forsling, M. Ranheimer, Spectrochim. Acta 49A (1993) 691.

[15] J.M. McHale, A. Navrotsky, A.J. Perrotta, J. Phys. Chem. B 101 (1997) 603.

[16] J.M. McHale, A. Auroux, A.J. Perrotta, A.J. Navrotsky, Science 277 (1997) 788.

[17] E. Laiti, P. Persson, L.-O. O “ hman, Langmuir 14 (1998) 825.

[18] K.C. Hass, W.F. Schneider, A. Curioni, W. Andreoni, Science 282 (1998) 265.

[19] H. Wijnja, C.P. Schulthess, Spectrochim. Acta Part A 55 (1999) 861.

[20] P.J. Eng, T.P. Trainor, G.E. Brown, G.A. Waychunas, M. Newville, S.R. Sutton, M.L. Rivers, Science 288 (2000) 1029.

[21] G. Lefevre, M. Duc, P. Lepeut, R. Caplain, M. Fedoroff, Langmuir 18 (2002) 7530.

[22] F. Bergaya, G. Lagaly "General introduction: clays, clay minerals, and clay science. In: Bergaya F, Theng, BKG, Lagaly G (Eds.), Handbook of Clay Science: Developments in Clay Science, Elsevier, Amsterdam, vol. 1 (2006).

[23] Ch. Zhou; Applied Clay Science 48 (1-2) (2010) 1-4.

[24] Ch. Zhou, Xn. Li, Zh. Ge, Qw. Li, Ds. Tong; Catalysis Today 93 (5) (2004) 607613.

[25] A. Gil, L. M. Gandia, M. A. Vicente; Catal. Rev. Sci. Eng. 42 (2000) 145-212.

[26] M. Benjelloum, P. Cool, P. Van Der Voort, E. F. Vansant; Phys. Chem. Chem. Phys., 4 (2002) 2818-2823.

[27] J. F. Diaz, K. J. Balkus Jr., F. Bedioui, V. Kurshev, L. Kevan; Chem. Mater., 9 (1997) 61-67.

[28] K. Yu, C. W. Jones; Organometallics 22 (2003) 2571-2580.

[29] G. Sathicq, L. Musante, G. Romanelli, G. Pasquale, J. Autino, H. Thomas, P. Vázquez; Studies in Surface Science and Catalysis 162 (2006) 227-234. 
[30] G. Sathicq, L. Musante, G. Romanelli, G. Pasquale, J. Autino, H. Thomas, P. Vázquez; Catalysis Today 455 (2008) 133-135.

[31] M. Akimoto, Y. Tsuchida, K. Sato, E. Echigoya; J. Catal. 72 (1981) 83-94.

[32] R. Neumann, M. Levin; J. Org. Chem. 56 (1991) 5707-5710.

[33] (a) R. D. Gall, M. Faraj, C. L. Hill; Inorg. Chem. 33 (1994) 5015-5021. (b) R. D.

Gall, C. L. Hill, J. E. Walker; Chem. Mater. 8 (1996) 2523-2527.

[34] Dubinin, M.M.Chem. Rev. 1960, 60, 235-238.

[35] Tesis doctoral Mercedes Muñoz: "Diseño, síntesis y aplicación de catalizadores a base de polioxometalatos y de soportes oxídicos de origen natural y sintético". Fac. de Ciencias Exactas, UNLP, 2010.

[36] Tesis doctoral María Florencia Agosto, "Estudio Tecnológico de zeolitas de depósitos argentinos: su aplicación en agroindustria y protección ambiental”. Fac. de Ciencias Exactas, UNLP, 2012.

[37] C. I. Cabello, G. Bertolini, S. Amaya, R. Arizaga, M. Trivi, XV Cong. Arg. de Catálisis y IV Cong. de Catálisis del Mercosur, Actas.

\section{Capítulo 6}

[1] M. J. Barrow, E. A. V. Ebsworth, M. M. Harding, Acta Crystallog. Sec. B, 35, (1979) 2093.

[2] K. W. Toenroos y col. Acta crystallog., Sec. B: Structural Science, 51, (1995) 155.

[3] P. Bayliss, P. Males, Mineral Mag. 35, (1965) 429.

[4] A. Jones, B. Mc Nicol, "Temperature Programmed Reduction for Solid Materials Characterization”, Marcel Dekker, New York (1986) 109.

[5] C. I. Cabello, M. Muñoz, I.L. Botto, E. Payen; Thermochimica. (2006) Acta 447: 22-29.

[6] R.D. Gonzalez, H. Miura, Catal. Rev. 36 (1994) 145.

[7] J.F. Le Page, Catalyse de contact, cap. V, Ed. Technip (1978).

[8] Rinaldi, R.; Fred, and Fujiwara, y. Schuchardt, U Appl. Catal. A: v. 315, p. 44-51. 2006.

[9] C. H. Giles, D. Smith, A. J. Huitson, J. Colloid Interfase Sci., 47 (1974) 755.

[10] C. H. Giles, A. P. D’Silva, I. A. Easton, J. Colloid Interfase Sci., 47 (1974) 766. 
[11] C. V. Cáceres, J. L. G. Fierro, A. Lopez Agudo, M. N. Blanco, H. J. Thomas, J. Catal., 95 (1985) 501.

[12] X. Carrier, J. B. D’Espinose de la Caillerie, J. F. Lambert, M. Che, J. Am. Chem. Soc., 121 (1999) 1641.

[13] C.Cabello, I. Botto, F. Cabrerizo, M. González, H.Thomas; Ads. Sci. Tech. 18 (7) (2000) 591-608.

[14] H. T. Evans, J. S. Showell, J. Am. Chem. Soc., 91 (1969) 3275.

[15] A. B. P. Lever, "Inorganic Electronic Spectroscopy", Elsevier, Amsterdam, (1984).

[16] L. Le Bihan, P. Blanchard, M. Fournier, J. Grimblot, E. Payen, J. Chem. Soc., Faraday Trans., 94 (7) (1998) 937.

[17] J. B. d'Espinose de la Caillerie, O. Clause, Stud. Surf. Sci. Catal., 101 (1996) 1321.

[18] X. Carrier, J. F. Lambert, M. Che, J. Am. Chem. Soc., 119 (1997) 10137.

[19] X. Carrier, J. B. D’Espinose de la Caillerie, J. F. Lambert, M. Che, J. Am. Chem. Soc., 121 (1999) 3377. 45

[20] C. J. Doss, Phys. Rev. B 48 (1993) 15626.

[21] F. Corá, C. Richard, A. Catlow, J. Mol. Catal. A, 119 (1997) 57.

[22] Z. Vit, M. Zdrazil, J. Catal., 171 (1997) 305.

[23] S. Musi' c, A. `Sari’ c, S. Popovi’ c, M. Ivanda, J. Mol. Struct. 221 (2009) 924926.

[24] C.T. Williams, E.K.-Y. Chen, C.G. Takoudis, M.J. Weaver, Phys. Chem. J. B102 (1998) 4785.

[25] M. Fournier, C. Louis, M. Che, P. Chaquin, D. Masure, J. Catal., 119 (1989) 400.

[26] Ai, M. Suzuki, S. Journal of Catalysis (1973) 30, 362.

[27] C. I. Cabello, M. Muñoz, I.L. Botto, E. Payen; Thermochimica. (2006) Acta 447: 22-29.

[28] C. Cabello, M. Muñoz, E. Payen, H. Thomas; Catal. Lett. 92 (2004) 69-73.

\section{Capítulo 7}

[1] A.M.C.F. Castelijns, J.M. Hogeweg, S.P.J.M. van Nispen, PCT Int. Appl., WO 96/11898 Al (April 25, 1996) 14 pp

[2] A.M.C.F. Castelijns, J.M. Hogeweg, S.P.J.M. van Nispen, PCT Int. Appl., US Patent 5,811,588 (September 22, 1998) 6 pp. 
[3] A. Muller, J. Bowers, WO Patent WO 99/08989 (February 25, 1999) to First Chemical Corporation.

[4] J. A. Dalmon, G. A. Martin, J. Catal 66 (1981) 214

[5] R.D. Gonzalez, H. Miura, Catal. Rev. 36 (1994) 145.

[6] J.F. Le Page, Catalyse de contact, cap. V, Ed. Technip (1978).

[7] M. J. Barrow, E. A. V. Ebsworth, M. M. harding, Acta Crystallogr. Sec. B, 35 (1979) 2093.

[8] K. W. Toernroos et all., Acta Crystallogr. Sec. B: Structural Science, 51 (1995) 155.

[9] P. Bayliss, P. Males, Mineral Mag. 35:429 (1965) 21764.

[10] C. I. Cabello, F. M. Cabrerizo, A. Alvarez, H. J. Thomas, J. of Molec. Catalysis A: Chemical 186 (2002) 89-100.

[11] A. Giroir-Fendler, D. Richard, P. Gallezot, Catal. Lett. 5 (1990) 175.

[12] M. Lashdaf, A.O.I. Krause, M. Lindblad, M. Tiitta, T. Venäläinen, Appl. Catal. A: Gen. 241 (2003) 65.

[13] J.E.Benson, M. Boudart, J. of Catal. 4, 704, (1965).

[14] J. Ho Son, H. Choi, Y. Uk Kwon, O. H. Han, J. Non-Cryst. Solids, 318 (2003)

[15] G. Sathicq, L. Musante, G. Romanelli, G. Pasquale, J. Autino, H. Thomas, P. Vázquez; Studies in Surface Science and Catalysis 162 (2006) 227-234.

[16] C. Cabello, M. Muñoz, E. Payen, H. Thomas; Catal. Lett. 92 (2004) 69-73.

[17] M. Muñoz, G. Romanelli, I. L. Botto, C. I. Cabello, C. Lamonier, M. Capron, P. Baranek, P. Blanchard, E. Payen; Appl. Catal B: Environmental 100 (2011) 254-263.

[18] C. I. Cabello, M. Muñoz, E. Payen, H. Thomas; Catal. Lett. 92 (2004) 69-73.

[19] C. I. Cabello, F. M. Cabrerizo, A. Alvarez, H. J. Thomas, J. of Molec. Catalysis A: Chemical 186 (2002) 89-100.a 


\section{PUBLICACIONES}




\section{Publicaciones generadas en el marco de realización de la presente Tesis}

\section{En revistas internacionales periódicas con arbitraje.}

$>$ "Catalysts based on $\mathrm{Rh}(\mathrm{III})$-hexamolybdate $/ \gamma-\mathrm{Al}_{2} \mathrm{O}_{3}$ and their application in the selective hydrogenation of cinnamaldehyde to Hydrocinnamaldehyde". Guillermo R. Bertolini, Carmen I. Cabello, Mercedes Muñoz, Mónica Casella, Delia Gazzoli, Ida Pettiti, and Giovanni Ferraris. Journal of Molecular Catalysis A: Chemical 366 (2013) $109-115$.

"Materials Adsorption Characterization by Random Coherent Electromagnetic Waves”. Carmen Ines Cabello, G. Bertolini, M. J. González, I. L. Botto, R. Arizaga, and Marcelo Trivi. PIERS 2011: Progress in Electromagnetics Research Symposium (PIERS), Proceedings of The Electromagnetics Academy, E.E.U.U. (2011) 490-501.

$>$ "Hydrophilic character study of Silica-gel by a laser dynamic speckle method". C. I. Cabello, G. Bertolini, S. Amaya, R. Arizaga, M. Trivi. Revista Cubana de Física, Vol. 25 N0 2 (2008) p.67-69.

\section{En congresos internacionales con arbitraje.}

"Influencia del soporte en la actividad del sitema $\mathrm{Rh}(\mathrm{III})$-hexamolibdato $/ \gamma-\mathrm{Al}_{2} \mathrm{O}_{3}$ en la hidrogenacion selectiva de cinamaldehido". Guillermo R. Bertolini, Carmen I. Cabello, Mercedes Muñoz, Mónica Casella, Delia Gazzoli, Ida Pettiti and Giovanni Ferraris. XXIII Congreso Iberoamericano de Catálisis, Santa Fe, 2-7 de setiembre de 2012.

$>$ "Dynamic Speckle technique to analysis of hydro-adsorption processes in clay surfaces” M. J. González, G. Bertolini, I. L. Botto, C. I. Cabello, R. Arizaga and M. Trivi. Latin America Optics and Photonics Technical Digest COSA 2012, Sao Sebastiao, Brasil, Nov. 2012.

> "Analisis de la hidroadsorción de alúminas mediante Laser Speckle Dinamico". Guillermo R. Bertolini, Carmen I. Cabello, Ricardo Arizaga y Marcelo R. Trivi. XXIII Congreso Iberoamericano de Catálisis, Santa Fe, 2-7 de setiembre de 2012. 
> “Aplicación del método "Laser Speckle Dinámico" en la Hidroadsorción de Alúminas". Guillermo R. Bertolini, C. I. Cabello, R. Arizaga y M. R. Trivi. Encuentro Brasilero y Simposio Iberoamericano sobre Adsorción, Recife-PE-Brasil. 6-10 MAY 2012, Actas Electrónicas.

> "Mineral Species to Removal Contaminants: Characterization Trough Dynamic Speckle Techniques”. María J. González, Guillermo Bertolini, Irma L. Botto, Carmen I. Cabello, R. Arizaga and Marcelo Trivi. ICO-22 22nd General Congress of the International Commission for Optics (ICO), Puebla, México Agosto 15-19, 2011.Actas Electrónicas. № 2284762.

"Hidrogenación selectiva de Cinamaldehído sobre catalizadores de Rh(III)hexamolibdato soportados en aluminosilicatos naturales funcionarizados". Guillermo R. Bertolini, Virgina Vetere, Mónica L. Casella, Luís Gambaro y Carmen I. Cabello. XVII Congreso Arg. De Catálisis y VI Congreso de Catálisis del Mercosur, 17-20 octubre de 2011, Salta, Argentina. Actas. Ed. Univ. de Salta, ISBN: 978-987-633-075-6.

$>$ "Preparación y evaluación de fases de Anderson $\mathrm{Rh} / \mathrm{CoMo}_{6}$ soportadas en arcillas porosas heteroestructuradas para la oxidación selectiva de difenilsulfuro". Esneyder Puello Polo, Lucrecia Lapuente, Guillermo Bertolini, Mercedes Muñoz, Gustavo Romanelli y Carmen I. Cabello. XVII Congreso Arg. De Catálisis y VI Congreso de Catálisis del Mercosur, 17-20 octubre de 2011, Salta, Argentina. Actas. Ed. Univ. de Salta, ISBN: 978-987-633-075-6.

$>$ "Original and Fe-activated clay minerals to remove arsenic in groundwater: surface characterization by Laser techniques". María J. González, Guillermo Bertolini, Delia Gazzoli, Irma L. Botto, Carmen I. Cabello, Ricardo Arizaga and Marcelo Trivi. ECASIA'11 European Conference on applications of surface and interfaces Analysis, 49 septiembre 2011, Cardiff City Hall, Cardiff, Wales, UK.

"Análisis de hidroadsorción por técnicas de Speckle" C. I. Cabello, G. Bertolini, S. Amaya, R. Arizaga, M. Trivi, en: Tecnolaser 2007, La Habana, Cuba, abril de 2007.

$>$ "Silica-gel Adsorption characterization by a laser speckle technique". C. I. Cabello, G. Bertolini, S. Amaya, R. Arizaga, M. Trivi. III International Sol-Gel Science and Technology Congress y VI Congreso Nacional de Materiales Sol-Gel Guanajuato, Mexico, Set 3 de 2006. 


\section{Congresos, encuentros y jornadas de divulgación nacionales}

"Estudio de catalizadores soportados a base de arcillas modificadas y heteropolimolibdatos de Rh(III) en la hidrogenación de cinamaldehído". Guillermo R. Bertolini, Virgina Vetere, Mónica L. Casella y Carmen I. Cabello. XVIII Congreso Argentino de Catálisis. San Luis. 30 de Octubre al 1 de Noviembre de 2013.

> "Estimación de la propiedad higroscópica de porcelanas electrotécnicas mediante “Laser Speckle Dinámico”. Guillermo Bertolini, Carmen I. Cabello, Ricardo Arizaga, Marcelo Trivi, y Gustavo Barbera. "SAASA-2 ${ }^{\circ}$ Simposio sobre adsorción, adsorbentes y sus aplicaciones”, San Luís, febrero 2013.

$>$ “Evaluación mediante "Laser Speckle Dinámico" de la capacidad hidroadsorbente de sílices mesoporosas SBA-15 funcionalizadas". María S. Legnoverde Rey, Elena Basaldella, Guillermo Bertolini, Carmen I. Cabello, Ricardo Arizaga y Marcelo Trivi. "SAASA-2 Simposio sobre adsorción, adsorbentes y sus aplicaciones", San Luís, febrero 2013.

$>$ "Minerales de arcilla activados con Fe para la remoción de As en aguas subterráneas: Caracterización superficial mediante técnicas Laser”. Guillermo Bertolini, María J. González, Delia Gazzoli, Irma L. Botto, Carmen I. Cabello, Ricardo Arizaga y Marcelo Trivi. I Jornada "Cuidando al medio ambiente desde diferentes enfoques" realizadas por la Red de Estudios Ambientales La Plata del Conicet La Plata, 8 de Junio de 2012.

$>$ "Análisis de la hidroadsorción de materiales silíceos y sílico-aluminatos naturales mediante "speckle laser". Guillermo Bertolini, Carmen I. Cabello, Irma L. Botto, Ricardo Arizaga y Marcelo Trivi. Primeras Jornadas de Ciencia Aplicada 2010, organizadas por el CINDECA, La Plata, Buenos Aires, Argentina, Noviembre de 2010.

> “Análisis de la hidroadsorción de materiales silíceos y sílico-aluminatos naturales mediante "speckle laser". Guillermo Bertolini, Carmen I. Cabello, Irma L. Botto, Ricardo Arizaga y Marcelo Trivi. Exposición oral en la II Reunión Interdisciplinaria de Tecnología y Procesos Químicos. Huerta Grande, Córdoba, Argentina, Octubre de 2010.

$>$ "Catalizadores a base de $\mathrm{Rh}(\mathrm{III})$-Hexamolibdato $/ \gamma-\mathrm{Al}_{2} \mathrm{O}_{3}$ y su aplicación en la hidrogenación selectiva de cinamaldehido a hidrocinamaldehido". Guillermo R. Bertolini, Carmen I. Cabello, Mercedes Muñoz, M. Caselle Delia Gazzoli e Ida Pettiti. 
XVI Congreso Argentino de Catálisis. Buenos Aires, Argentina, Agosto de 2009.

" $\mathrm{Rh}(\mathrm{III})-\mathrm{Hexamolibdato}$ como precursor catalítico en hidrogenación selectiva de cinamaldehido". Guillermo R. Bertolini, Carmen I. Cabello, Mercedes Muñoz, Delia Gazzoli e Ida Pettiti. XXVI Congreso Argentino de Química. Tucumán, Argentina, Septiembre de 2008.

"Estudio de hidroadsorcion de sílica-gel utilizando una técnica "laser". C. I.Cabello, G. Bertolini, S. Amaya, R. Arizaga, M. Trivi, en: XV Congreso Argentino de catálisis, La Plata, Argentina, noviembre de 2007.

“Análisis de hidrofilicidad de silica-gel utilizando la técnica de speckle laser". Guillermo Bertolini, S. Amaya, C. I. Cabello, R. Arizaga, M. Trivi,XV Congreso de Físico-Qca. e Inorgánica Abril 2007.

Semana de Divulgación del Conocimiento de la Facultad de Ciencias Exactas, UNLP. Estudio de hidroadsorción de sílica-gel utilizando una técnica "laser". La Plata, Argentina, Diciembre de 2007. 